Programa de Doctorado en Europa y el Mundo Atlántico: Poder, cultura y sociedad.

Instituto Universitario de Historia Simancas

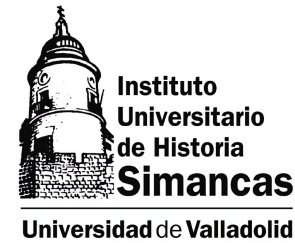

TESIS DOCTORAL

\title{
La conformación del Estado nacional chileno durante el siglo XIX: educación, nación y ciudadanía
}

Presentada por Ricardo Iglesias Segura para optar al grado de

Doctor por la Universidad de Valladolid

Dirigida por:

Dr. Guillermo Á. Pérez Sánchez

Dr. Adolfo Carrasco Martínez 
A mi familia de antes y de ahora:

A mis padres y hermanos

A Paola, Gonzalo y Amparo 
«Sí, señor, no hay bien que no pueda alcanzarse; no hay mal que no se pueda evitar y destruir por medio de la instrucción que es el efecto y el fin de la educación; ella es por quien las naciones prosperan; y sólo por su falta decaen y se arruinan. Con ella, la agricultura, la industria, el comercio, la navegación, todas las fuentes del poder y la riqueza pública y privada, se perfeccionan, mientras que, sin ella, todas se desalientan, y atrasan, y decaen. Por ella, se propagan los buenos principios, así en el orden moral, como en el civil; se mejoran las costumbres, se difunden las virtudes sociales y se destierran aquellos groseros y funestos vicios que son efecto necesario de la ignorancia y origen cierto e inevitable de la decadencia y ruina de los pueblos.»

Gaspar Jovellanos, Apuntamientos para el plan de estudios o discurso al rey, 1798 


\section{AGRADECIMIENTOS}

La investigación histórica sobre los procesos que conforman el pasado constituyen un trabajo individual en que las herramientas conceptuales, los libros, los archivos y las fuentes documentales se ponen al servicio para conocer y comprender las acciones y concepciones de hombres y mujeres en el pasado.

A pesar que la labor de investigación histórica muchas veces se realiza en forma solitaria, en nuestras vidas nos encontramos con muchas personas con las cuales compartimos afectos e intereses y que uno no puede dejar de agradecerles pues nos han ayudado a alcanzar la meta. A estas personas quiero recordarlas para manifestarles mi más entrañable gratitud por acompañarme, aconsejarme, motivarme y presionar para que el camino andado tuviese un final adecuado.

A Paola, por su infinita generosidad y compañía que llenarían miles de páginas por todo lo que me ha ayudado y soportado.

A mis amigos y compañeros de la Pontificia Universidad Católica de Valparaíso, Nelson Vásquez por su infinita gratitud y ayuda, a Mauricio Molina porque siempre se va alegrar por los logros de los demás, a David Aceituno por su ayuda y consejos.

A María Sánchez Agustí e Isidoro González Gallego, por su generosidad de haberme ayudado y cobijado en esta tarea.

Mi agradecimiento especial al Dr. Guillermo Á. Pérez Sánchez por su disponibilidad de dirigir esta tesis doctoral, por sus sugerencias, consejos, rigor histórico y lingüístico que fueron de vital importancia para dar forma a los resultados finales, y también al Dr. Adolfo Carrasco Martínez por acompañarme en tales afanes. 


\section{ÍNDICE}

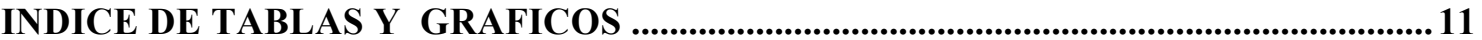

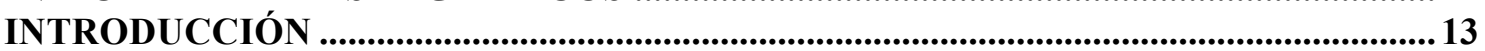

La educación como experiencia histórica: nación, nacionales y ciudadanos ............................15

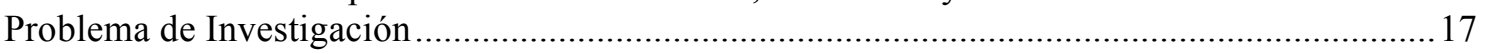

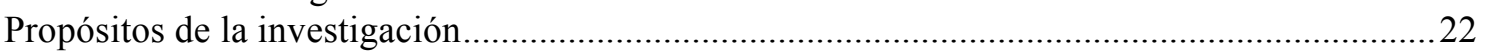

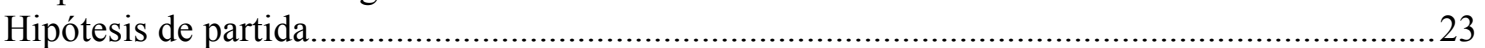

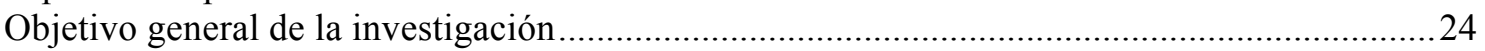

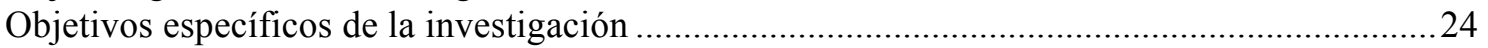

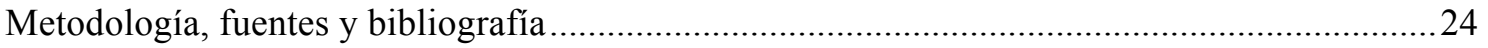

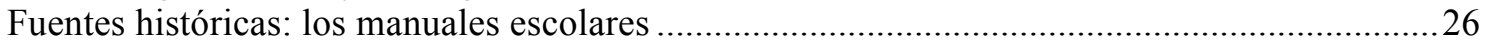

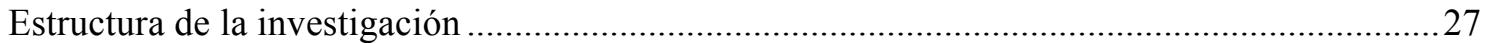

Capítulo 1. Visiones conceptuales e historiográficas acerca de la

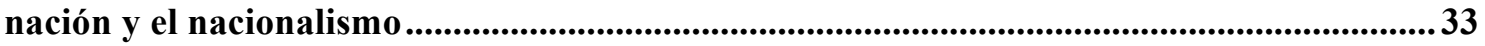

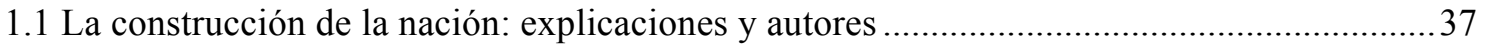

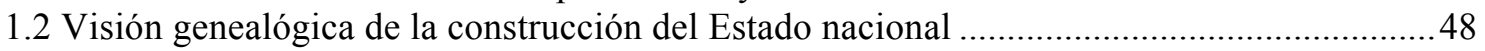

1.3 Visión histórica-modernista y la construcción del Estado nacional ......................................51

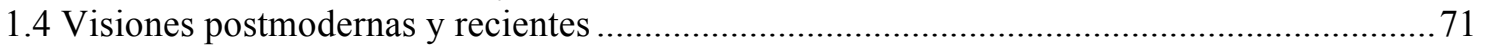

1.5 Visión de la construcción del Estado nacional chileno en el sigo XIX ….............................. 75

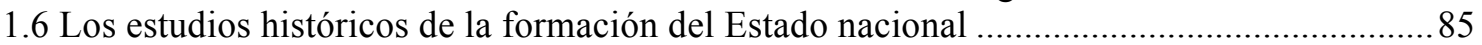

Capítulo 2. El rol de la educación en la construcción del estado

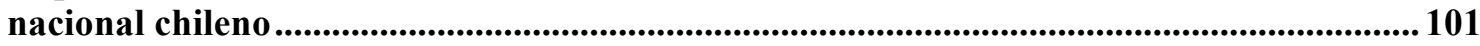

2.1 Educación y Estado nacional: reciprocidad en la construcción de lo nacional......................105

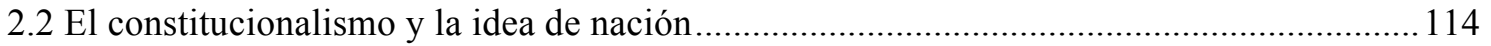

2.3 La educación artífice del proyecto nacional: inclusión y homogeneización. .........................119

$2.4 \mathrm{La}$ acción del Estado en el proyecto educativo decimonónico ...............................................126

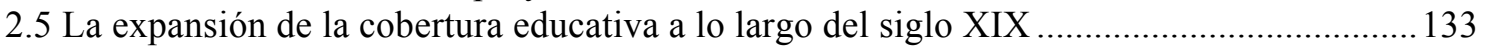

2.6 Ley de Instrucción: hacia la consolidación del sistema educativo chileno.............................136

2.7 La pedagogía cívica en la construcción de lo nacional: fiestas y funerales.......................... 142

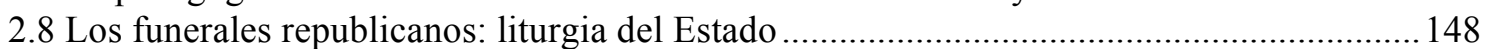

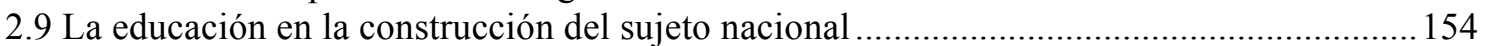

2.10 La educación nacional: liberalismo, progreso y civilización................................................ 167

2.11 Los recursos en educación: presupuesto, escuela y demás aspectos

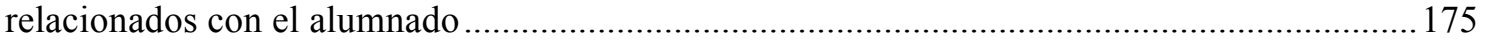

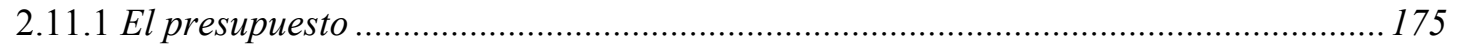

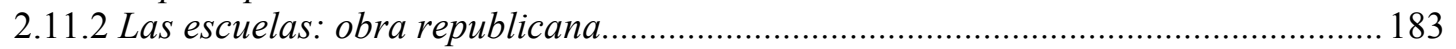

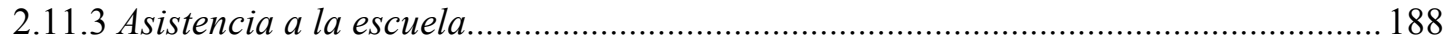

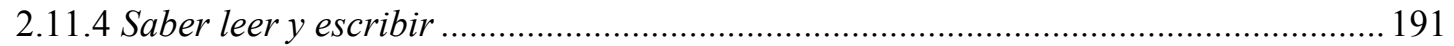

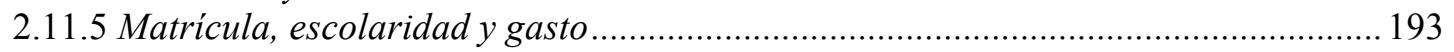

Capítulo 3. La enseñanza de la Historia, la Geografía, la Urbanidad

y la Formación de la Ciudadanía chilena en la construcción del Estado

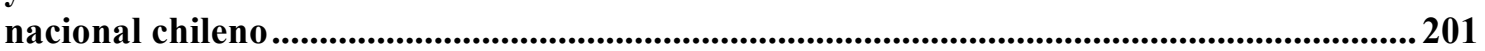

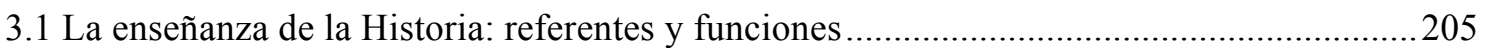

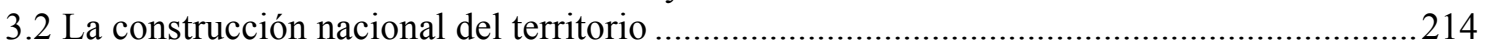

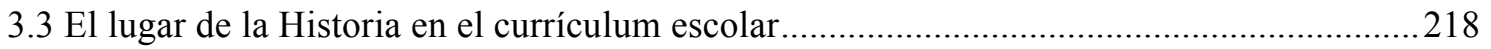

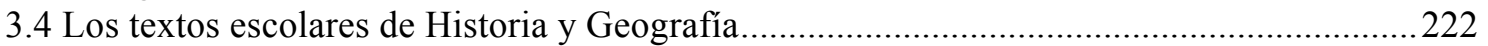

3.5 Los contenidos de los textos escolares: pasado y nación......................................................228 
3.6 La representación de la Geografía en los textos escolares del siglo XIX

3.7 Urbanidad y formación de la ciudadanía chilena en los manuales

generales y escolares

3.7.1 Los manuales de Urbanidad en la formación del ciudadano chileno...........................2275

3.7.2 Los manuales de Urbanidad y la construcción del sujeto ideal...................................228

3.7.3 Los manuales de Urbanidad en cuestiones de género y espacios de sociabilidad .......290

3.7.4 La formación Cívica: el último eslabón de la construcción de la nación......................296

3.7.5 Los manuales de Formación Cívica en Chile a fines del siglo XIX ............................. 304

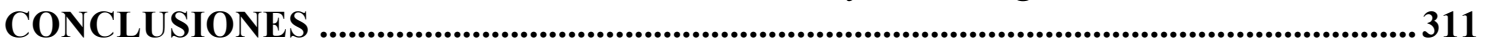

Sobre la conformación del Estado nacional chileno en el siglo XIX: conceptos e historia........313

Papel de la educación en el proyecto de construcción de la nación, los nacionales y la ciudadanía

Representaciones e imaginarios republicanos presentes en la elite chilena y en los manuales de

Historia, Geografía, Urbanidad y Formación cívica durante el siglo XIX …….........................317

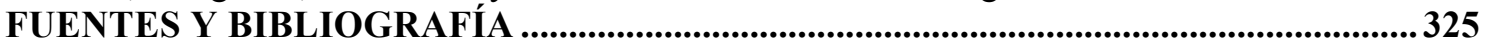




\section{ÍNDICE DE TABLAS Y GRÁFICOS}

CUADRO N.ำ. NÚMERO DE ESCUELAS Y ALUMNOS DEL SISTEMA DE INSTRUCCIÓN PRIMARIA, 1848-1906 135

CUADRO N ${ }^{\circ}$ 2. PRESUPUESTO DE INSTRUCCIÓN PÚBLICA DE LA NACIÓN, 1840-1890. (VALOR MONEDA 1890) 180

GRÁFICO No 1 . PORCENTAJE DEL PRESUPUESTO DE INSTRUCCIÓN PÚBLICA

EN EL PRESUPUESTO TOTAL DE CHILE. 1845.1890. 182

GRÁFICO N ${ }^{\circ} 2$. NÚMERO DE ESCUELAS PÚBLICAS Y PARTICULARES EN CHILE, 1848-1906. 184

CUADRO No3. NÚMERO DE ESCUELAS Y ALUMNOS EN CORRESPONDENCIA

A LA POBLACIÓN ESCOLAR (5 A 15 AÑOS). CHILE 1854-1907. 186

CUADRO N4. POBLACIÓN URBANA Y RURAL EN CHILE SEGÚN CENSOS: 1865-1907. 188

CUADRO No 5 . ASISTENCIA MEDIA DE ESCUELAS PÚBLICAS (1862-1895)

CUADRO N $^{\circ}$ 6. PORCENTAJE DE ALFABETOS Y ANALFABETOS EN CHILE. 1854-1895 192

CUADRO N ${ }^{\circ} 7$. TOTAL DE ALUMNOS MATRICULADOS EN ESCUELAS PRIMARIAS Y SECUNDARIAS, 1854-1895.

CUADRO N ${ }^{\circ}$. TASA DE ESCOLARIDAD TOTAL Y POR NIVEL. 1852-1900. 195

CUADRO N ${ }^{\circ}$ 9. ALUMNOS MATRICULADOS POR NIVEL EDUCACIONAL Y GASTO ANUAL PÚBLICO POR ALUMNO EN CADA NIVEL.1852-1900. 196 
INTRODUCCIÓN 
En las sociedades modernas, la escuela y la enseñanza de la Historia han tenido un papel muy importante. A través de ellas se entregan conocimientos que suelen utilizarse para justificar el pasado y el presente, en este sentido, los estados desde el siglo XIX «optaron por convertirse en inspiradores y vigilantes del relato histórico y se han dedicado a elaborar e imponer el que conviene a sus pretensiones e intereses» ${ }^{1}$. Los estados y gobiernos se han ocupado de fiscalizar la producción histórica y decidieron vigilar celosamente la escuela y lo que se enseñaba en ella. Los relatos históricos que se enseñaron en las escuelas chilenas eran parte de la narrativa política de los constructores del Estado nacional. Estos cumplieron la función de legitimar y consolidar los valores que la clase dirigente necesitaba, pero no tan sólo la escuela ha sido el lugar predilecto, sino que también la pedagogía cívica por medio de monumentos, celebraciones, nombres de calles y ciudades que tienden a la exaltación de la nación han sido mecanismos de nacionalización.

\section{La educación como experiencia histórica: nación, nacionales y ciudadanos}

El surgimiento y consolidación del Estado nacional en el siglo XIX involucró el desarrollo de tres aspectos claves para sus propios fines: la creación de la nación, la formación de nacionales y de ciudadanos. Estos aspectos proporcionaron los soportes de la nueva legitimidad del naciente orden político republicano que se sostuvo en la soberanía nacional y la representación política. Para el ejercicio de la soberanía nacional se requirió de la formación de los atributos republicanos en la población chilena por medio de varios mecanismos que el Estado consideró apropiados. El siglo XIX fue un siglo especialmente interesado en la formación de nacionales. Para el caso chileno y para el resto de los países americanos, la elite consideró que el espacio apto para dicha formación se encontraba en la educación y, por lo tanto, era necesario promover y estimular su implementación.

El tema de la educación ha sido permanentemente revisado e interpretado como uno de los tópicos fundamentales para comprender como emergieron los estados nacionales en

\footnotetext{
${ }^{1}$ FONTANA, Josep, «¿Qué historia para el siglo XXI?», Analecta, Revista de Humanidades, Nº1 (2006), p. 4.
} 
el siglo XIX, y como aquellos lograron imponer una ideología a la mayor parte de la población. El proceso histórico de configuración y consolidación del Estado nacional y la consiguiente identidad nacional estatal fue una forma dominante de construcción de identidades colectivas en América. Al mismo tiempo, toda la configuración estatal se basaba en una pertenencia de los individuos a la comunidad nacional coincidente con una unidad política necesaria para asegurar la homogeneidad de todos sus miembros. La aspiración de la homogeneidad por parte de las elites tuvo en la escuela el instrumento ideal para asumir la misión de extender el imaginario nacional con la idea de crear una identidad nacional fundamentado en una cultura compartida que fuera capaz de convencer a los escolares por medio de la enseñanza las virtudes republicanas y el amor a la patria.

El Estado chileno otorgó a la educación un papel de la mayor relevancia en el siglo XIX convirtiéndola en servicio público con la tarea promover la homogeneidad de la población. Los dirigentes y fundadores del Estado nacional tomaron la decisión que la educación debía enlazarse en un sistema público para toda la población, organizado y controlado por el Estado. Como en la mayor parte de los estados nacionales en el siglo XIX, la educación, si bien consagra un sistema de enseñanza pública, fue estructurada mediante dos vías destinadas a poblaciones distintas. Una enseñanza primaria para toda la población y una secundaria y superior destinada preferentemente a las elites procedentes de los sectores acomodados, ya fuesen de procedencia urbana o agraria. Se constituyó un sistema educativo que se correspondía con los intereses de las clases sociales que condujeron los destinos del Estado nacional chileno. El desarrollo de lo sistemas públicos de educación fue consecuencia de un consenso al interior de la clase dirigente chilena y respondieron a un triple objetivo: formar la identidad nacional, transmitir los valores de la sociedad liberal e inculcar una disciplina moral a la población.

La conformación de los nacionales tuvo varias dimensiones que la estructuraron, entre ellas encontramos: la psicológica, determinada como un sentimiento compartido por un grupo de personas que enaltece la idea de nación y las instituciones se encargan a lo 
largo de la historia de premiar a aquellos que defienden y promueven la nación; la cultural, determinada por el legado de valores, creencias, tradiciones, lengua y prácticas sociales que se transmiten de generación en generación; la territorial, concebida como el espacio donde se encarnan las tradiciones y la cultura de la nación que les conecta con el pasado y asegura el porvenir; una dimensión relacionada a la historia, que contribuye a la memoria colectiva como forjadora de la nación, $y$, por último, una dimensión cívica y política en concomitancia con el Estado que proporcionó racionalidad jurídica, orden y poder actuando en la construcción de una sociedad cohesionada. Sostenemos que desde la dimensión política, la educación desempeñó un papel importante, puesto que promovió la cultura nacional, una lengua oficial y, de ese modo, el Estado nacional chileno inició y favoreció la formación de los chilenos.

Todas estas dimensiones fueron utilizadas por el Estado nacional chileno permitiendo la creación y empleo de una imagen de nación, delimitar las fronteras, compartir una historia y cultura común, utilizar signos y símbolos, desarrollar lealtades hacia la nueva realidad política, y, obviamente, la educación contribuyó a la propagación de la imagen de la nación imaginada por medio de valores, símbolos, signos, ritos y modos de vida en consonancia con el deber ser del tipo de chileno que idealizó la elite. El sistema educativo se estableció como uno de los principales factores que aspiraba a la integración social, política, de identidad y cohesión nacional, que transmitiera valores cuyo ideal fue lograr la constitución de la nación, de allí la necesidad de formar al chileno más allá de la igualdad política y económica.

\section{Problema de Investigación}

La educación no fue la única vía que el Estado utilizó para nacionalizar a su población. Nosotros la resaltamos, pues ésta nos permite reflexionar sobre cómo el Estado con sus acciones logró construir una nación en el tiempo. La educación como acción estatal nos permite medir las intenciones que tuvieron los que han ostentado poder a lo largo de los más de doscientos años de vida republicana: en el siglo XIX la educación tuvo por finalidad la conformación de nacionales, en el siglo XX fueron los ciudadanos y en la 
actualidad una sumatoria de demandas que la escuela segura no está en condiciones de cumplir: nacionales, ciudadanos, ecologistas, consumidores, entre otras.

La educación fue uno de los cimientos donde se pensó que debía descansar la nueva realidad política y como mecanismo para alcanzar el pleno desarrollo como sociedad moderna y civilizada. Para la elite chilena, la educación era un medio para adherir a los preceptos del liberalismo burgués como la nación y la ciudadanía. La condición esencial para la construcción de la nación era la educación, ya que por medio de ella se buscó homogeneizar a la población con un sistema que se fue ampliando en cobertura a lo largo del siglo. Para el caso chileno desde los primeros tiempos de la independencia se comprendió el valor de la instrucción pública con hitos muy importantes en ese derrotero como fueron el movimiento cultural de 1842 manifestado como símbolo máximo en la creación de la Universidad de Chile y, en 1861, con la promulgación de la Ley de Instrucción Pública. El arco temporal hasta fines del siglo XIX estuvo impregnado en acciones tendientes a mejorar la cobertura y los planes de estudio. La incorporación progresiva de las asignaturas de Historia, Geografía y Formación Cívica tuvo su colofón en el siglo XX cuando en 1920 se dictó la Ley de Instrucción Primaria Obligatoria. Procuramos adentrarnos en las formas en que el Estado chileno aplicó por medio de la enseñanza de la Historia, la Geografía y la Formación Ciudadana la conformación de la nación y la ciudadanía.

Siendo el tema de investigación la relación entre la educación y la construcción del Estado nacional chileno en el siglo XIX, nos importa plantear las preguntas y problemas que siguen a continuación:

¿Cómo podemos explicar y comprender la conformación de la nación chilena a la luz de los conceptos y debates históricos e historiográficos? ¿Cómo fue el papel de la educación en el proyecto de la construcción de la nación chilena y los mecanismos educativos que utilizó para la construcción de nacionales y ciudadanos? ¿Cómo se fue implementado institucionalmente el sistema educativo chileno durante el siglo XIX? ¿Cuáles fueron las representaciones e imaginarios republicanos presentes en la elite 
chilena y en los manuales de historia, geografía, urbanidad y formación ciudadana durante el siglo XIX?

Estudiando la educación, la nación y la conformación de los ciudadanos podemos conocer las condiciones y las formas en que se desarrolló una nueva cultura política tributaria del proyecto de la construcción de la república. El supuesto central de la investigación es que la educación es un producto cultural que es necesario conocer, comprender y analizar.

La formación de las naciones modernas se explica siempre con referencia al Estado. Las naciones modernas son naciones políticas que emergieron y se desarrollaron en un marco de tiempo que no se puede explicar su construcción de manera independiente del Estado. Las naciones existen y, desde el siglo XIX, constituyen la plataforma material y simbólica de mayor magnitud entre las comunidades humanas, de ellas se desprende una identidad de carácter superior a la de género, región, clase e incluso de religión.

El marco temporal en el que se desarrolla nuestra investigación está circunscrito al siglo XIX. Todo el siglo XIX americano aparece cruzado por el problema de definir la nación: se inicia con la emancipación de las colonias americanas de España y termina con la construcción hegemónica de la identidad nacional. Es el siglo de los historiadores, del capitalismo industrial, de la escritura y de la escuela. Todos estos factores son tributarios del coloso contemporáneo: el Estado nacional. La lengua, la historia, el territorio, las costumbres y las tradiciones se nacionalizaron en dicho siglo logrando una fidelidad y lealtad que no se había obtenido en el pasado.

Cronológicamente fijamos el punto de partida en la sociedad posterior a la independencia, en tanto que el punto de llegada se marca alrededor del 1900; el primer momento resulta particularmente significativo, ya que hacia esa época Chile dio curso a una serie de medidas que permitieron la consolidación y estabilidad del Estado nacional, en tanto que la segunda marca la consolidación de los planteamientos de lo que fue la educación. Hemos fijado como límite temporal último en torno a 1900 cuando el Estado 
chileno se dio a la tarea de incorporar e implementar la formación ciudadana formalmente en las escuelas chilenas. La invasión napoleónica y la debilitada Corona se constituyeron en elementos claves para desencadenar en América en general y en Chile en particular los procesos de independencia que instalaron Juntas de Gobierno en América y España. En Chile se instaló la Primera Junta de Gobierno en 1810 declarando adhesión a Fernando VII y rechazando a los usurpadores del trono español. La idea separatista tomó fuerza luego de las acciones realizadas a partir del retorno del rey Fernando al trono. Chile proclamó la Independencia el 12 de febrero de 1818.

Terminada la etapa de las guerras de independencia, el sector dirigente asumió el desafío de estructurar un tipo de Estado que respondiera a los ideales republicanos que les permitiese la inserción en el tablero internacional. Tuvo que construir un sistema administrativo estatal que modernizara el país e instituir una fuerza militar obediente al poder civil y buscar un sistema de régimen político. Chile tenía una población de carácter rural de un $80 \%$, la mayor parte del territorio no estaba habitado y esta se concentraba en la parte central del país. Dicha población se encontraba al interior de las haciendas y hasta mediados del siglo XIX Chile mantenía su fisonomía colonial en las ciudades.

La elite que se afianzó en el poder requería darle forma a la naciente república. El orden se afianzó con la proclamación de la Constitución Política de 1833 que permitió establecer el orden público, regular las relaciones entre los poderes, afianzar la soberanía nacional y, por último, impulsar una organización estatal en lo relativo a economía, administración y educación. Chile y su Estado lograron dar origen a discursos y acciones coherentes y homogeneizadoras de forjar la nación cuyos planteamientos se mantuvieron durante todo el siglo XIX no ajeno a fricciones, pero que no pusieron en debate el proyecto republicano. A lo largo de la presente investigación podremos advertir rasgos y características que propiciaron la concreción del plan. 
La instalación de un sistema de educación estatal fue una inquietud prioritaria en el siglo decimonónico. Al impulso otorgado al Instituto Nacional en 1813, le siguió la formación de escuelas y liceos en las principales ciudades del país. Posteriormente, la creación de escuelas de Profesores y Profesoras, indicaron la voluntad que hubo por fomentar la educación entre los chilenos. A lo anterior podemos agregar la fundación de la Universidad de Chile, una institución clave del sistema educacional chileno al establecer las bases de la educación moderna y liberal.

Desde el período posterior a la independencia hasta 1900 transitamos desde los proyectos y discusiones hasta la consolidación de un sistema educativo que caracterizaría a Chile. Este estudio es de carácter histórico reflexivo más que un estudio pormenorizado de acontecimientos, hechos y fechas que pudieron haber marcado los temas y problemas que nos preocupan. Intentamos dar respuesta a una diversidad de cuestiones que aún se plantean en la historiografía nacional en un período fundamental para el posterior desarrollo de la nación. Esperamos que esta investigación resulte valiosa para comprender el proceso de conformación de la nación y de la cultura política durante el siglo XIX influida fuertemente por el discurso liberal que advirtió que el sistema educativo se convirtió en una estrategia pedagógica y política de características modernas. Para una mejor comprensión de lo ocurrido en Chile en dicha centuria nos hemos planteado sobre las bases de presupuestos teóricos vinculados a nación y el Estado que coadyuvaron a un estudio más profundo sobre la forma histórica en que se conformó Chile. Otro aspecto que justifica nuestra investigación tiene que ver con la incorporación de los manuales con fines educativos que se utilizaron en las escuelas chilenas entrelazados con los planteamientos teóricos y conceptuales acerca de la configuración de los estados nacionales.

Hemos abordado un período y temática histórica que permite aumentar y mejorar el panorama sobre la educación chilena. Igualmente, contribuye a la conformación de investigaciones que permitan construir la historia del sistema educativo nacional y aportar en la relación existente entre educación, enseñanza de Historia, Geografía y Ciudadanía con la conformación del Estado nación en Chile en el siglo XIX. 


\section{Propósitos de la investigación}

El interés por los estudios históricos acerca de la educación ha sido importante en los últimos años con una cantidad significativa de publicaciones. Estos estudios han abordado el número de escuelas, profesores, estudiantes, nivel de infraestructura y los currículums que se han utilizado en el sistema educativo chileno. Nuestro interés ha sido entrelazar la educación con los proyectos políticos de la elite y las representaciones de los individuos, de la historia, del territorio y el tipo de sujeto que deseaba modelar el Estado nacional chileno durante el siglo XIX. Esto permite apreciar el valor y significado en configuración del Estado y nación chilena. Por lo anterior, resulta oportuno historiográficamente estudiar la educación y el papel que desempeñó en la formación de la nación, de los nacionales y de la ciudadanía. En un país como Chile, que se consolidó tempranamente en forma unitaria, el problema educativo fue planteado de manera homogénea para todo el territorio lo que permite comprender mejor la conformación de la nación chilena y la ciudadanía. Por lo anterior creemos importante estudiar y analizar históricamente la educación y el rol que desempeñó la pedagogía de la nación usada como defensora del nuevo Estado en la obtención de sujetos dispuestos a proteger el orden institucional republicano.

Esta investigación en rigor no es una historia de la educación, sino que es un estudio histórico de la acción de la elite y del Estado para conformar una nación, unos nacionales y unos ciudadanos por medio de la educación. En tal sentido, desde la perspectiva histórica analizamos la estrecha relación entre el proyecto de construcción del Estado-nación con el sistema de educación desarrollado en Chile en el siglo XIX. En este sentido, las categorías y conceptos de nación, nacionalidad y Estado están estrechamente relacionadas con república, patria, representación y soberanía. Los conceptos serán cuidadosamente utilizados en el análisis e interpretación histórica con la finalidad de aproximarnos de mejor modo a lo ocurrido. Se trata fundamentalmente de descubrir y comprender los discursos políticos, culturales y sociales del que fueron actores y portadores los que construyeron el Estado nacional chileno y el sistema educativo respectivamente. 


\section{Hipótesis de partida}

En Chile, la situación del Estado nacional unitario y homogéneo que se configuró en el siglo XIX se encuentra actualmente en los debates políticos e historiográficos en entredicho. Ante esta situación, la historiografía ha buscado las causas que expliquen tales posiciones y para poder entender y comprender el problema se hace necesario recurrir al siglo XIX, ya que en dicho siglo se inició la conformación del Estado nacional chileno posterior al proceso de independencia. El proyecto decimonónico buscaba emular a las sociedades europeas modernas y civilizadas y la elite chilena entendió que para la constitución de la nación y de nacionales debían estar conformado por personas vinculadas políticamente y que compartiesen lengua, religión, cultura, territorio e historia común.

Para la creación de estos nuevos individuos se debía reñir con las antiguas estructuras coloniales y utilizar la educación como un mecanismo para construir el nuevo escenario político: la república. La construcción de la nación demandó relatos e historias compartidas por la población, especialmente sobre el origen de la nación, los héroes y las gestas que permitieron alcanzar la libertad y la independencia. Al mismo tiempo se requería constituir un entramado constitucional y legal que proporcionara legitimidad y permitiera el vínculo entre sus habitantes y por ello fue necesario comunicar por medio de la escuela los símbolos, la civilidad, la urbanidad, la historia, la geografía y los conocimientos básicos requeridos para construir la nación, los nacionales y la ciudadanía.

La hipótesis de partida sostiene que el Estado nacional chileno convencido de la importancia de la educación para unificar la nación, instruir al pueblo y lograr el progreso material se abocó a diseñar e implementar un proyecto educativo dirigido a modelar la nacionalidad y la ciudadanía chilena con valores republicanos y hábitos modernos que le permitiesen reconocer y practicar las libertades individuales, cumplir con los deberes constitucionales y convertirse en personas modernas. 


\section{Objetivo general de la investigación}

El objetivo principal es estudiar el rol y alcance de la educación en la construcción del Estado nacional chileno durante el siglo XIX, ya que este permite advertir la profundidad del debate acerca de la sociedad que se deseaba construir en el pasado decimonónico. La educación representa una gran posibilidad para el estudio de las ideas, de las sociedades, de las mentalidades y de la cultura entre otros. Esta investigación analizará discursos, proyectos y acciones en torno a la cual la educación contribuyó a la construcción de lo nacional en Chile.

\section{Objetivos específicos de la investigación}

Para alcanzar el objetivo general de la investigación se han establecido tres objetivos específicos. Así, el primer objetivo es analizar desde los referentes teóricos y conceptuales la conformación del Estado nacional chileno durante el siglo XIX. El segundo objetivo específico es contribuir al conocimiento y comprensión de los procesos histórico en materia educativa que se desarrolló en Chile durante el siglo XIX. Fundamentalmente los relacionados con el papel de la educación en la conformación de nación, nacionales y ciudadanos. El tercer objetivo específico es analizar desde la perspectiva histórica, educativa, heurística y bibliográfica los manuales escolares de Historia, Geografía, Urbanidad y Formación Cívica utilizados en Chile en el siglo XIX. Con la finalidad de apreciar las principales características político-ideológica para identificar las representaciones sobre la nación, república, historia, territorio, urbanidad e instituciones.

\section{Metodología, fuentes y bibliografía}

El estudio histórico de cómo el Estado nacional chileno implementó la educación debe cumplir con la forma en que se desarrolla nuestra disciplina. La metodología usada estuvo enfocada a tres puntos de vista: a) Teórico y conceptual: se refiere a la revisión de material bibliográfico concerniente a las diversas interpretaciones acerca de la conformación de los estados nacionales; b) Legal-institucional: se abordará la forma en 
que el Estado nacional chileno desarrolló legislaciones y normas asociadas a los temas educativos y como esto se fue vinculando con el proyecto de nación y ciudanía, y c) Educativo: de este modo se realizara un análisis histórico de la implementación de la educación y cómo ésta asumió el imaginario de la nación y la formación ciudadana promovida por el Estado y la elite.

Adicionalmente, es necesario tener presente que en esta investigación contemplamos la revisión de fuentes, documentos y bibliografía acerca de la formación de las nacionalidades, la educación y la enseñanza de la Historia y Geografía. Dicha metodología realizó una revisión de las visiones y enfoques acerca del origen de los estados nacionales, de las posturas y debates propios de la historiografía chilena, en función de la bibliografía existente acerca del papel desempeñado por la educación, la escuela y la enseñanza de la Historia en la conformación del estado nacional. La revisión bibliográfica permitió iluminar, contrastar y vincular su marcos conceptuales, teóricos e históricos con evidencias documentales disponibles y consultadas. Para el análisis y la reflexión histórica frente a estas cuestiones se utilizarán documentos oficiales, informes parlamentarios, leyes, decretos y estadísticas custodiadas en el Archivo Nacional y Biblioteca Nacional de Chile. La bibliografía sobre el tema de educación y Estado nacional ha sido fundamental en su información y análisis para orientamos y satisfacer vacíos; y compone un cuerpo epistemológico, que ya constituye un objeto de discusión de envergadura. La bibliografía ha sido iluminadora para ubicar la Educación y el Estado nacional en un contexto más amplio y comprender sus particularidades y problemas.

Para demostrar el alcance que tuvieron las políticas nacionalizadoras del Estado chileno realizamos un examen sintético de los enfoques y visiones acerca de la formación de la nación que nos permitió poner en sintonía las acciones estatales con referentes conceptuales y teóricos de mayor alcance para valorar la creación de un sistema educativo que acompañó a la configuración del Estado-nación chileno. 


\section{Fuentes históricas: los manuales escolares}

El apoyo documental para este trabajo -además de las fuentes primarias de archivos y otras secundarias como prensa, legislación, informes, memorias, crónicas- lo encontramos en los manuales escolares de Historia, Geografía, Urbanidad y Formación Ciudadana que se dispusieron para el uso de las escuelas chilena. Esta investigación se propuso además realizar un análisis heurístico, bibliográfico y documental de los manuales escolares con el objetivo de estudiar su relación con los procesos históricos, políticos, educativos y culturales desarrollados en Chile en el siglo XIX.

Por las características de esta investigación, el uso de los manuales escolares resultó clave al momento de abordar asuntos relacionados con la formación de la nacionalidad, las representaciones republicanas sobre el pasado, los antiguos habitantes, el territorio, el tipo de ciudadano que se aspiró a construir y las formas que demandaba la nueva vida en ciudad. Estos textos, en tanto que documentos históricos, nos proporcionaron no tan sólo información, sino que además nos mostró los imaginarios y representaciones que la sociedad chilena tuvo sobre el tiempo y el espacio en que se produjeron. Estos textos exponen las características y atributos de la República de Chile, las razones de su existencia, la trascendencia de la nación y de los habitantes convertidos en chilenos y futuros ciudadanos que debía cumplir los consejos morales, políticos y aprehender los hechos y personajes de la historia patria con el fin de reconocer y valorar su importancia en pro de la constitución de una nación políticamente moderna y civilizada.

Los manuales de Historia, Geografía, de Urbanidad y de Formación Cívica fueron utilizados en su doble condición de fuente y objeto de estudio. Su uso permitió a esta investigación aproximarse a los objetivos, discursos y representaciones sobre la historia, el territorio y tipo de hombre que se pretendía modelar, también nos ayudó a comprender los aspectos fundamentales de los intereses educativos que el Estado chileno se formuló para la construcción de la república. Desde una óptica histórica los textos escolares están ligados estrechamente al desarrollo y expansión de los sistemas educativos, especialmente en la implementación de los sistemas de instrucción primaria donde leer, escribir y contar fueron tareas prioritarias. En los sistemas educativos 
originados en el siglo XIX el texto se estableció como un elemento regulador del diseño y desarrollo del currículum escolar. Los manuales fueron percibidos por la elite chilena de características liberales y burguesas como una herramienta apropiada para comunicar a los niños y jóvenes los valores de lo nacional y de la ciudadanía y, por lo mismo, estos libros han sido productos culturales controlados por el poder político. Desde el siglo XIX los textos escolares se han transformado en un material permanente como material pedagógico y probablemente de más larga duración y utilización en la historia de la educación. Los textos escolares seleccionan y representan el universo ideológico que se enseña a los estudiantes reflejando los valores y estereotipos de la sociedad en que se formulan.

Nuestra propuesta metodológica -como se ha dicho- explicita el papel de los manuales como mecanismo utilizado para transmitir a la población las pretensiones y discursos asociados al tipo de sociedad deseable. La interpretación histórica se pudo llevar a cabo mediante un estudio de los signos y representaciones que los manuales proporcionaban en aras de aproximarnos a una realidad más oculta y asumirlos como textos históricos y no como simples evidencias del contexto en que se generaron, acaso como artefactos basados en la palabra escrita que reflejaron las concepciones sociales, culturales, políticas y educativas. Todo lo anterior nos permitió la comprensión de los manuales en tanto documentos y productos culturales utilizados en la escuela.

\section{Estructura de la investigación}

En el Capítulo I titulado «Visiones conceptuales e historiográficas acerca de la nación y el nacionalismo» referido a los enfoques y visiones sobre la configuración de la nación concerniente a una revisión de las interpretaciones que a nuestro juicio son las más distintivas que se han elaborado para el estudio de la nación y del nacionalismo. Hemos decidido agrupar estas interpretaciones en tres categorías: genealogistas, modernistas y postmodernas. La necesidad de incorporar estos referentes responde a la ausencia explicita en gran parte de la historiografía chilena que se ha ocupado del Estado nacional de referentes historiográficos y teóricos. La revisión de estos autores a 
los que nos referiremos a continuación, ayuda a comprender el fenómeno chileno en un espectro más amplio y menos autorreferencial sustentado en la pretendida excepcionalidad chilena. De las posturas examinadas, las que mejor ayudaron a la comprensión de la historia desarrollada en el siglo XIX chileno fueron los estudios de autores modernistas como Hobsbawm, Gellner, Anderson y Smith por mencionar los más destacados. Esta revisión de los referentes teóricos y conceptuales ha permitido vincular las acciones del Estado nacional chileno a concepciones más amplias y más profundas que permitan comprender de mejor manera la forma en que configuró la nación y los chilenos como realidad y sujeto político respectivamente en dicho siglo. El planteamiento modernista es que la construcción de los Estados nacionales fue obra de las elites, de los intelectuales y por cierto del propio Estado chileno caracterizado por la centralización del poder y sus instituciones, y por caracterizar y concebir al Estado como una comunidad política que se configura en un espacio y tiempo determinado.

En el Capítulo II, «EI rol de la educación en la construcción del Estado nacional chileno», hemos revisado las acciones y propósitos diseñados por el Estado nacional chileno para generar un sistema educativo, el tipo de sujeto y las lealtades que se requerían para la nueva comunidad política también los discursos acerca de la nación imaginada y proyectada que se transmitió a los estudiantes, el pretendido y logrado discurso unitario y homogéneo de la incipiente república y el examen de cifras y estadísticas sobre el estado de la educación en el Chile durante el siglo XIX y los primeros años del siglo XX. La bibliografía ha sido clave y de gran ayuda para la comprensión de la relación entre nación, nacionalismo y educación. En los análisis es recurrente fijar la atención en los debates entre liberales y conservadores, siendo esto interesante, nos hemos fijado más bien en elementos que consensuaron un tipo de relato nacional.

El Capítulo III «La enseñanza de la Historia, la Geografía, la Urbanidad y la Formación Cívica en la construcción del Estado nacional chileno», se adentra en el examen y análisis de los relatos e imperativos acerca de la nación, la sociedad, el tipo humano y la ciudadanía que perseguía el sistema educativo; al mismo tiempo hemos 
estudiado el lugar e importancia de los contenidos curriculares a partir de los manuales de Historia, Geografía, Urbanidad y Formación Cívica que dispuso el Estado nacional chileno utilizados en los establecimientos educacionales.

En este apartado, esperamos describir y comprender los relatos que se construyeron y transmitieron acerca del pasado colonial, la independencia, los indígenas, las características del paisaje nacional como sustento territorial del Estado nacional, el comportamiento individual y social prescrito para la población chilena y el tipo de ciudadanía que se pretendía configurar para el período estudiado. Abordamos cómo la enseñanza de todos estos contenidos fue concebida por la elite y el Estado, los alcances y cobertura que alcanzaron, pero especialmente estudiados como testimonio de los relatos ofrecidos por la nueva república. El análisis de los manuales escolares nos permitirá conocer los principios sobre los cuales se sustentaba el relato nacional. Los manuales, compendios y catecismos fueron géneros textuales convertidos en piezas fundamentales de modelación de los niños y jóvenes chilenos en el siglo XIX. Si bien fueron instrumentos utilizados a lo largo de los tiempos para otro tipo de adoctrinamiento, con el nuevo régimen político después de la independencia fueron consignados para impartir una educación que creara nuevos sujetos políticos que demandó el proyecto de nación chilena. Constituyó una enseñanza por medio de contenidos históricos, geográficos, institucionales y consejos morales para que valoraran la importancia de las reglas de comportamiento como los principios de una sociedad moderna y civilizada.

Los discursos presentes en estos textos son manifestaciones de los valores que la elite chilena consideró pertinentes y reflejo del entorno cultural en el cual se constituyeron. En estos manuales encontraremos estereotipos, ideologías y representaciones del carácter republicano como testimonios del espíritu de un tiempo histórico, pero también de las continuidades y cambios, porque, como afirma Roger Chartier, «los textos escolares, son pues, al igual que todos los textos, una representación del mundo que se los apropia, es decir de las cogniciones de sus autores y usuarios. Estas representaciones, en sus estructuras formales, en sus metáforas y en sus simulacros, y 
no sólo en sus contenidos, comportan además un sentido, que es percibido como un acuerdo semántico por todos los sujetos del grupo en que circulan los textos» ${ }^{2}$.

En efecto, los manuales que analizaremos se comprenden como representaciones de las ideas republicanas que se concibieron en el Chile del siglo XIX. En los manuales de Historia se difundió la gesta del origen de la república enalteciendo la patria, los héroes y el hito fundacional de la independencia como génesis de la construcción del Estado nacional chileno. Los manuales de Geografía nacionalizaron la república definiendo sus límites y fronteras como parte irrenunciable del nuevo Estado, pues el territorio debía operar en la mente de los habitantes como una comunidad imaginada que permitiera conocerlo y ensalzarlo en su consideración de nacional. Los manuales de Urbanidad prescribieron los comportamientos para los niños y jóvenes con la finalidad de reglamentar la vida pública y privada en función de un ser humano modelo capaz de cumplir el discurso normativo. Los manuales de Formación de la Ciudadanía chilena reflejaron el interés por establecer los principios que permitiesen concretar el proyecto político liberal, es por ello que se consideró que la educación era un mecanismo clave para modelar a los niños y jóvenes en los nuevos códigos morales y cumplir los preceptos del ciudadano moderno y civilizado.

La presente investigación es un análisis histórico sobre el proceso de formación republicana en función del sistema educacional pensado e implementado durante el siglo decimonónico. Desde esta perspectiva, es preciso comprender que la educación fue uno de los mecanismos por los cuales se llevó a cabo la construcción del Estado nacional. En el siglo XIX, la elite chilena se orientó a dicha tarea, asunto que involucraba, por una parte, la constitución del Estado como organización política en un territorio definido, y, por otra parte, la conformación de una nación que proporcionara sentido de pertenencia y de sustentabilidad de la unidad política. La educación formó parte del proceso de construcción del Estado nacional que buscó racionalizar y homogeneizar desde el concepto de nación. Esperamos poder demostrar cómo el Estado

\footnotetext{
${ }^{2}$ El mundo como representación. Historia cultural entre política y representación, Barcelona, Editorial GEDISA, 1996, p. 51.
} 
nacional chileno por medio de una consolidación temprana de su institucionalidad, una elite mínima y cohesionada se dio a la tarea de la construcción de una sociedad política y para lo cual implementó varios mecanismos y uno de ellos fue la educación.

Durante el siglo XIX el quehacer fundamental del Estado en materia educativa fue ampliar el número de estudiantes en las escuelas con objetivos muy claros: alfabetizar, construir el vínculo con la historia y la geografía nacional y disciplinar a la población. A lo largo de la centuria decimonónica el proceso de escolarización fue el de la progresiva alfabetización en los saberes elementales: leer y escribir. El camino hacia la alfabetización pasaba por la escolarización de la población por el impulso estatal a la misma. La mejor forma de asentar la nación y la ciudadanía fue promoviendo la alfabetización, ya que, de este modo, el Estado chileno pudo promover el ideario liberal. 


\section{Capítulo 1}

Visiones conceptuales e historiográficas acerca de la nación y el nacionalismo 
«El problema que tenemos delante se deriva del hecho de que la nación moderna, ya sea como Estado o como conjunto de personas que aspiran a formar tal Estado, difiere en tamaño, escala y naturaleza de las comunidades reales con las cuales se han identificado los seres humanos a lo largo de la mayor parte de la historia, y les exige cosas muy diferentes.»

Eric Hobsbawm, Naciones y nacionalismo desde 1870 


\subsection{La construcción de la nación: explicaciones y autores}

La discusión teórica sobre Nación, nacionalismo y Estado nacional ha sido muy intensa y larga, y que aún no genera acuerdos y consensos entre los historiadores. La cuestión del surgimiento de los estados nacionales reviste una cantidad considerable de puntos de discusión. La cantidad de pareceres adopta matices innumerables, no sólo por las características propias de cada región, sino porque las posturas políticas e historiográficas que aparecen en escena. El ejercicio histórico consiste en acercar tanto las acciones y posiciones de los propios actores del proceso como de los posteriores estudios del tema y tratar de situarlas en un plano discursivo susceptible de incontables análisis. Una revisión rápida de las evidencias históricas y de las primeras obras historiográficas nos demostrará la inconexión entre los proyectos políticos de formación y consolidación de los estados nacionales en América Latina del siglo XIX y las posteriores representaciones históricas que se han hecho a lo largo del tiempo.

Esto conlleva a señalar el inevitable problema de definir la nación y el estado. Podemos afirmar que los modelos instalados y proyectados en América fueron adquiridos de las ideas y realidades europeas. La pregunta entonces, es ¿cómo se usó la idea de nación y la idea de Estado en América Latina para sostener los proyectos políticos de construcción del Estado nacional?

Las ideas modernas de construcción de los estados nacionales en América Latina - como queda dicho- tenían su origen en Europa. El primero esbozo de realizar proyectos políticos provenía de hombres formados en el viejo continente. A comienzos del siglo XIX las delineaciones del pensamiento nacionalista habían sido expuestos por J. G. Fichte y J. G. Herder ${ }^{3}$. Estos autores habían puesto énfasis en la idea de nación como elemento articulador de los pueblos junto al paisaje natural: la tierra. Este se oponía al pensamiento rousseniano que defendía la idea del contrato social y voluntario entre los ciudadanos libres. La novedad en el siglo XIX dada por el pensamiento alemán estaba constituida por la necesidad del sustentar la relación «nación-tierra», y ese

\footnotetext{
${ }^{3}$ Vid. FICHTE, Discursos a la nación alemana, Buenos Aires, ORBIS, 1984, y también HERDER, J.G, Ideas para una filosofía de la Historia de la Humanidad, Buenos Aires, Ed. Losada, 1959.
} 
sustento debía proporcionarlo el estado. Este principio adquirió mayor fuerza con la Revolución Francesa de 1789 que propició la idea que los pueblos son soberanos y tienen derroteros históricos que se deben plasmar por medio de la presencia de elementos fundamentales como: la tierra y un Estado que provean y garanticen poder alcanzar los objetivos propuestos. Ahora bien, el factor determinante para lograr los objetivos era la idea de nación: la idea de una pertenencia común, un mismo origen, una misma lengua y unas mismas prácticas culturales.

Los estados latinoamericanos en el siglo XIX fueron «estados-nación» en virtud de la idea predominante que toda nación requería de un Estado y que todo Estado estaba basado en una nación. El concepto de una única nación y un solo estado ha sido prácticamente inexistente a lo largo de la historia, ninguna nación europea está sustentada en tales principios y «los países latinoamericanos también fueron étnicamente diversos, de tal manera que varios historiadores han dudado si alguna vez constituyeron naciones» ${ }^{4}$.

Lo que sí es correcto en América Latina es que existieron estados que realizaron lo que lo que éstos suelen hacer: cobrar impuestos, hacer leyes, hacer guerras, demandar soberanía sobre territorios en virtud de lo nacional. Los grupos asociados en la elite encontraron en la nación y la república nuevas bases de legitimación, y el discurso disponible es el republicano liberal. Se trata de un proyecto político de carácter utilitarista e igualitario, que postula la separación de poderes, elección de autoridades por la vía electoral-representativa, instituciones públicas, educación e ilustración impulsadas desde el estado, libertades y derechos individuales de inspiración iusracionalista.

Los estados en América Latina asimilaron «forjar nación» con «forjar estado». Es un debate abierto con cuestiones pendientes. En general, el debate está centrado en dos interpretaciones. En primer lugar, el planteamiento modernista, de considerar que los

\footnotetext{
${ }^{4}$ KNIGHT, Alain, «El Estado en América Latina desde la Independencia», Revista Economía y Política, $\mathrm{N}^{\circ} 1$ (2013), p. 7.
} 
estados emergieron del agonizante imperio español para luego constituir las naciones desde «arriba hacia abajo»; y segundo, la tesis que existieron protonaciones por debajo del envoltorio imperial y que con la independencia se habrían consolidado como estados nacionales y que estos sentimientos proto-patrióticos explicarían en parte, el fin del imperio y la configuración de los nuevos estados nacionales en Hispanoamérica. Estos debates centrales, dejan con claridad que Estado y nación estaban imbricados en la práctica, pero que son conceptual y analíticamente distintos.

La concepción de Estado-nación de raíz alemana y también influida por las ideas de la Ilustración francesa permitieron dejar atrás sus realidades coloniales en pro de una serie de proyectos políticos que tenían como norte ineludible: la independencia. El concepto de nación estaba ampliamente confundido con el de Estado, justamente, «hacia 1810, el utillaje conceptual de las élites iberoamericanas ignoraba la cuestión de la nacionalidad, y más aún, utilizaba sinonímicamente los vocablos de Nación y Estado» ${ }^{5}$. En los primeros años de vida independiente, la preocupación más inmediata y coyuntural era la de definir grados de autonomía y soberanía respecto a otros poderes y estados que habían emergido con la independencia. El conflicto primordial era centralizacióndescentralización, tendencias que explicaban parte importante de las luchas por organizar los nuevos estados. Estamos seguros que la nación y la nacionalidad fueron productos y no elementos fundantes de la organización sociopolítica que se produce a lo largo del siglo XIX latinoamericano. Fue el Estado el que creó la nación en cada uno de los países.

Los factores que permitieron que el Estado nación se conforme en América Latina están dadas por la presencia de oligarquías pequeñas y consolidadas y un orden neocolonial emergido de una fuerte centralización del poder que impuso el control sobre el espacio territorial y la sociedad. La centralización del poder se hizo posible gracias a la formación de una fuerza militar organizada que dominó toda la escena política latinoamericana en el siglo decimonónico.

\footnotetext{
${ }^{5}$ CHIARAMONTE, José Carlos, «La Formación de los Estados Nacionales en Iberoamérica», Boletín del Instituto de Historia Argentina y Americana Dr. Emilio Ravignani, vol. 15 (1997), p. 145.
} 
El Estado en construcción invocó soberanía sobre un territorio nacional donde estableció su poder. Este tiene facultades para poder funcionar dada por las fuerzas coercitivas, burocracia, capital, moneda, Constitución y leyes. La legitimidad siempre constituye un rasgo esencial del Estado, y en el siglo XIX la nación y del nacionalismo fueron usados con esos fines. La legitimad al amparo de la nación exige obediencia de sus ciudadanos, aunque en varios estados latinoamericanos tuvieron que enfrentar a otros actores como caudillos y movimientos revolucionarios con sus discursos, materiales, intereses, identidades, agravios, promesas sobre el futuro, trabajo y movilidad social. También el Estado debió enfrentar a otra fuerza poderosa y un contendiente serio: la Iglesia que ha sido el rival más antiguo y fuerte.

Los estados en su relación con la sociedad desarrollaron varias funciones. La promoción de la estabilidad política y económica con la finalidad de legitimarse a sí mismos y al sistema socio-político promoviendo educación, cultura nacional y consenso son aspectos capitales. No es menos cierto, que la acción más importante del Estado en América haya sido la de educador, benefactor y árbitro. El Estado también asumió un rol autónomo en lo económico promoviendo la inversión o desarrollando abiertamente actividades económicas, precisamente el Estado construyó o asistió los ferrocarriles, fundó bancos, desarrolló obras públicas, etc.

El concepto de nación ha sido ampliamente utilizado, tanto en la historiografía como en las ciencias sociales, y quizás es uno de los más difíciles de explicar o definir; y confundido con el de Estado. El vocablo nación usado desde Roma en referencia a lo lejano y extranjero asociado a los conceptos de clan, raza y hasta con el de gens. En el mundo medieval seguía siendo asociado a lo extranjero y también empezó a ser usado para describir pueblos homogéneos en lengua y costumbres. Si nos situamos desde el siglo XVIII, en Inglaterra y Francia, «la nación vino a ocupar el lugar del término latino populus que antiguamente describía el "pueblo del estado", el segmento político de un Estado (...) aquellos con derecho a la representación parlamentaria» ${ }^{6}$. En cambio, en

\footnotetext{
${ }^{6}$ SANDERS, Karen, Nación y Tradición. Cinco discursos en torno a la nación peruana, 1885-1930, Lima, Fondo de Cultura Económica, 1997, p. 38.
} 
Alemania, nación fue asociado a la idea de los habitantes nativos de un país, unidos por su origen común, lengua y costumbres. De esta forma la raíz del problema significó una imprecisión de un término que tuvo una connotación cultural y social al principio para acabar en una de corte político. El contenido político del vocablo nación fue reforzado en el siglo XIX con el discurso del nacionalismo. En este sentido desear entender y explicar para la época contemporánea el término nación revela cierta complejidad, aún así es importante algunas indicaciones.

La primera indicación es entre la nación y el Estado. Siendo evidente la distinción entre ambos conceptos, no podemos desconocer que están impregnados ambos de un discurso nacionalista. Está claro que los términos refieren a realidades distintas, contrariamente a que en el lenguaje vulgar, políticos y comunicacional se usan para mencionar la misma realidad. El historiador británico Seton-Watson señala que «la creencia de que todo estado es nación o que todos los estados soberanos son estados nacionales, ha contribuido mucho a oscurecer el entendimiento humano de las realidades políticas» ${ }^{7}$. Para una mayor comprensión de la nación revisaremos los principales modelos explicativos que lo nacional ha originado.

Un primer grupo explicativo la constituyen aquellos planteamientos que consideran a la nación como una comunidad cultural. La afirmación central es que existen grupos humanos que se pueden definir por rastros comunes como afinidad racial, lenguaje, territorio o historia común. Uno de los clásicos de este paradigma es Herder según el cual la unidad natural de la sociedad es la nación, donde la base cultural está dada por la lengua y con el agregado, que, si era más pura, podía reflejar el espíritu original de ese pueblo o nación. De este modo sostiene que «cada nación es un pueblo, teniendo su propia forma, y también su propia lengua» ${ }^{8}$. Lo anterior se convirtió en un elemento ahistórico y definitorio de la nacionalidad de carácter absolutamente inmutable. Los planteamientos de Herder fueron el punto de partida de las naciones étnicas y culturales. Fueron el arquetipo de la tradición esencialista de la nación. La idea central es que todas

\footnotetext{
${ }^{7}$ Nations and States, Londres, Methuen, 1982, p. 1.

${ }^{8}$ HERDER, Johann Gottfried, Ideas para una filosofía de la historia de la humanidad, Buenos Aires, Editorial Losada, 1959, p. 266.
} 
las personas por naturaleza pertenecen a una nación por gozar de unas señas inmutables de identificación nacional.

Independientemente de las grandes críticas que ha recibido este planteamiento sobre todo por su inmutabilidad, etnicidad y lo ahistórico del mismo, no podemos negar que la mayor parte de las naciones se han conformado en torno a un núcleo común manifestado y expresado de distinta forma como mitos, tradiciones, etc. Es Anthony Smith quien se revela en contra de que la nación es sólo productos culturales de la modernidad y sostiene que en todas las naciones existe un tronco común de etnicidad, «las naciones están muy relacionadas con las comunidades étnicas, muchas veces creciendo de ellas, o siendo construidas de materia étnica» ${ }^{9}$.

Una segunda explicación sobre la nación es la que pone de manifiesto la voluntariedad de la agrupación que se reconoce en un pasado y expresa el deseo de continuar un proyecto en común. El más representativo de esta tendencia es Renan quien decía que la nación «supone un pasado, se resume, no obstante, en el presente por un hecho tangible: el consentimiento, el deseo claramente de continuar la vida en común» ${ }^{10}$. Los autores que han adscrito a la dimensión voluntarista de la nación señalan la importancia de los factores históricos en la constitución de las mismas. Uno de los intelectuales más referidos en los temas de nación y nacionalismo, Benedict Anderson la definía como una comunidad imaginada: Anderson no desconoce las peculiaridades históricas que han dado lugar a la nación, pero no indica ningún elemento definitorio para el concepto, y que en algún sentido se parece mucho a conceptos asociados al parentesco y religión ${ }^{11}$.

Anderson reconoce el aspecto artificial de la nación, pero no cree que sea un producto ideológico y manipulador como puede ser comprendido en Hobsbawm. Este último intenta demostrar la falsedad de las explicaciones naturalistas poniendo énfasis en su

\footnotetext{
${ }^{9}$ The ethnic revival, Cambridge, Cambridge University Press, 1981, p. 85.

${ }^{10}$ ¿Qué es una nación?, Buenos Aires, Editorial Elevación, 1947, p. 42.

${ }^{11} \mathrm{Cfr}$. ANDERSON, Benedict, Comunidades imaginadas. Reflexiones sobre el origen y la difusión del nacionalismo, Buenos Aires, Fondo de Cultura Económica, 1993, p. 23.
} 
carácter de invento. Relega a la nación a la condición de ficción como fruto de razones socioeconómicas, y desconectadas de los pueblos. No es más que una explicación de tradición marxista al considerar al nacionalismo como una etapa del desarrollo económico del capitalismo, en consecuencia, éste sería el triunfo de las fuerzas burguesas por sobre los intereses de las clases populares y proletarias.

La aportación de Hobsbawm es innegable al proporcionar un valor correctivo a las explicaciones ingenuamente naturalistas que no son capaces de develar el dinamismo histórico de la acción de los hombres en el tiempo y el espacio. El dinamismo histórico como constitutivo de la naturaleza humana, las comunidades humanas se configuran en el tiempo y por tanto tienen historia, que involucra un proceso de selección por el cual se selecciona del pasado lo que se quiere recordar; y convertirlo en tradición nación. El historiador británico sostenía que «(...) no considero la "nación" como una entidad social primaria ni invariable. Pertenece exclusivamente a un período concreto y reciente desde el punto de vista histórico» ${ }^{12}$. La explicación de Hobsbawm, por su carácter histórico proporciona sentido a los estudios sobre la nación y el nacionalismo, configurando un análisis a partir de las evidencias y productos de los hombres en el espacio y el tiempo.

Una tercera explicación acerca del concepto de nación es la que ofrece la tendencia funcionalista y modernista. Desde esta perspectiva se explica la nación como fruto de las desintegraciones de las estructuras tradicionales. La nación se convierte en agente modernizador e integrador de la comunidad favorecida por procesos sociales, económicos, culturales de innovación.

El papel modernizador del Estado recalca que en la creación de las naciones la política moderna ha tenido un rol fundamental y tanto los historiadores como los sociólogos han destacado que las ideas y las estructuras estatales han sido claves en el fortalecimiento de las naciones. Acton en un artículo de 1862 señalaba en alusión al Estado como constructor de la nación y que ésta «(...) no es la creación de la unidad fisiológica o

\footnotetext{
${ }^{12}$ Naciones y Nacionalismo desde 1780, Barcelona, Editorial Crítica, 1998, p. 17-18.
} 
geográfica, sino que se desarrolla en el curso de la historia a través de la acción del Estado. Se deriva del Estado y no está por encima de él» ${ }^{13}$. En este camino de la construcción de la nación, existen al menos dos vías: una primera tipificación que señala que las transformaciones económicas, políticas y culturales reemplazaron la manera de concebir y constituir el Estado.

La novedad histórica estuvo en concebir el Estado como un trozo de tierra habitada donde espacio, pueblo y gobierno son sucesivos para su existencia y en donde no se admite que muchos pueblos sean gobernados por un Estado como en los Imperios, ni tampoco de situaciones extraordinariamente atomizadas como el feudalismo. La erosión del sistema feudal, la eclosión del poder de la Iglesia y de todos los estamentos contribuyó al afianzamiento del poder centralizado de carácter secular y laico en el siglo XVI se reforzó por los requisitos del mercantilismo y la amenaza constante de la guerra. Tilly es uno de los máximos exponentes de asignarle a la guerra un papel fundamental en la construcción de la nación. Según este autor, la disputa por los medios para hacer la guerra generó grandes estructuras y que «a largo plazo, el carácter cambiante de la guerra dio superioridad militar a los Estados que pudieron formar unas fuerzas militares grandes y permanentes con su propia población, y éstos fueron, en medida creciente, los Estados nacionales»» ${ }^{14}$. De este modo, la guerra contribuye como fuerza congregadora del Estado nacional. Lo favorece por la sacralización del territorio, una política unificadora, movilización de población y la consiguiente centralización del poder. El Estado nacional constituye una formula eficaz para afianzar y ganar la guerra.

En este ámbito se destaca también el papel desempeñado por la doctrina de la soberanía popular como factor decisivo para comprender la razón de porque los estados europeos se configuraron como estados nacionales, indudablemente el referente obligado es la ilustración y Revolución Francesa. La soberanía popular dependía de la legitimidad política y la nación fue el concepto que sirvió para el cometido. La unidad homogénea y compacta se constituyó en una tarea nueva de la nueva realidad política. Desde el siglo

\footnotetext{
${ }^{13}$ «Nationality» en Essays in the History of Liberty. Selected Writings, tomo 1, Liberty Classics, Indianapolis, 1986, p. 425.

${ }^{14}$ Coercion, Capital and European States 990-1990, Oxford, Blackwell, 1990, p. 63.
} 
XVIII, pero con mayor fuerza en el XIX es que el Estado buscó la integración de los sistemas económicos, judiciales, administrativos, educativos, etc. de una forma absolutamente nueva.

La estrecha relación entre el Estado y la nación se configura en torno a la acción política del Estado, «(...) la cuestión fundamental de que, por encima de todo, el nacionalismo tiene que ver con la política y la política tiene que ver con el poder. El poder en el mundo moderno principalmente tiene que ver con el control del estado» ${ }^{15}$. Así, bajo la premisa del papel fundamental del Estado, la existencia de la nación poco o nada importa, lo esencial es saber la fórmula política para controlar el poder, donde la nación puede ser uno de los elementos.

La nación como resultado de los procesos de industrialización es una variante de las explicaciones modernistas que los elementos de la industrialización, en especial, la comunicación y cultura que le otorgan a la sociedad movilidad y crecimiento cognitivo, y por ende dinámica. Esto en clara referencia a las sociedades agrarias que son estáticas, estamentales, desiguales con monopolio y control cultural de la elite. Las sociedades agrarias son altamente opositoras a unidades políticas y culturales. En las sociedades industrializadas y en las que tienen a esas sociedades como referentes plantean la necesidad de una movilidad social que conlleve una cultura homogénea que tenga al menos como meta la participación y la igualdad. Así lo sostiene Ernest Gellner:

«En las comunidades autosuficientes (...) la cultura suele hacerse invisible, pero cuando la movilidad y la comunicación se convierten en núcleo de la vida social, la cultura en que se nos ha enseñado a comunicarnos se convierte en la esencia de la propia identidad» ${ }^{16}$.

Para esta variante del modernismo que explica la nación, la cultura que se desarrolla en el Estado industrial se va imponer en forma hegemónica, que generará desigualdad, pero que no se sustenta en ninguna doctrina como en las antiguas sociedades. Luego, la nación se convierte entre muchos otros, en un elemento de convergencia de poder,

\footnotetext{
${ }^{15}$ BREUILLY, John, Nationalism and the State, Manchester, Manchester University Press, 1982, pp. 2-3.

${ }^{16}$ Naciones y nacionalismo, Madrid, Alianza Editorial, 1988, p. 87.
} 
cultura en derredor del Estado. La explicación amparada en la acción política y cultural del Estado no implica que todas las culturas tengan como destino y derrotero final: el Estado nacional, la mayoría de las culturas convive con otros grupos en unidades políticas que se pueden fundir, extinguir o mezclarse. Es un rechazo a las explicaciones voluntaristas como formación de la nación, no las ignora, pero no son suficientes para el nacimiento de una comunidad nacional, es necesaria una coyuntura histórica y social que se produce en el siglo XIX como efecto de la industrialización.

La cultura y el poder emanado del Estado del siglo XIX favorece y permite la existencia de una sociedad uniforme, con un tipo de ciudadano que requiere la modernidad. Por lo tanto, la convergencia es clara entre unidad política y unidad cultural en la sociedad moderna. Un planteamiento descriptivo y analítico que esclarece cómo los procesos de la modernidad favorecieron la constitución de comunidades nacionales, pero que es una definición reduccionista que oscurece la heterogeneidad cultural e histórica de las naciones.

En la óptica funcionalista e histórica la religión es otro elemento que aparece en los análisis acerca de la formación de la nación. El argumento básico es que el hombre tiene sentimientos religiosos que debe expresar y que en las circunstancias de declive del cristianismo a fines del siglo XVIII por la influencia del pensamiento ilustrado generaron un vacío religioso. Esta coyuntura histórica habría permitido la transformación de la nación en una categoría religiosa posterior a la Revolución Francesa de 1789. Uno de los principales exponentes de esta categoría es Hayes quien, al referirse al Estado nacional, sostiene que «se ha atribuido, como la Iglesia universal, una misión de salvación y un ideal de inmortalidad. La nación es una concepción es eterna $(\ldots))^{17}$.

La nación como toda religión tiene su liturgia, sus lugares sagrados, santos, héroes, banderas, fiestas e himnos en un espectáculo cultural de viejo, pero renovado cuño. La nueva fe en el progreso, tan propio del siglo decimonónico fue testigo de una nueva

${ }^{17}$ El nacionalismo: una religión, México, U.T.E.H.A., 1986, p. 7. 
conciencia histórica afirmada en la razón y la ciencia y también por un nuevo sacerdocio, el de los intelectuales y burócratas seculares, todos símbolos del progreso y la modernización. Hubo todo un despliegue a lo largo del siglo XIX en Europa y América de la nueva religiosidad nacional por el derrumbe de las viejas certidumbres y se inventaron nuevas tradiciones.

El ocaso de la religión como elemento clave en el origen de las naciones también fue advertido por Anderson, en el sentido que la nación moderna es una comunidad imaginada $^{18}$. El argumento se ubica en un marco temporal, muy anterior al siglo XIX, precisamente en la época de la Reforma como génesis, época en que la cosmovisión religiosa comenzó a perder fuerza: la idea que una lengua única daba acceso a la salvación, que la sociedad jerarquizada correspondía a un orden natural y que la temporalidad humana estaba fuertemente imbricada con el tiempo divino. Estas bases se mermaron a lo largo de la época moderna. Uno de los factores que el autor pone en gran relieve es la invención y masificación de la imprenta ya que contribuyó a la formación de una gran cantidad de lectores posicionándose como el principio de la comunidad imaginada de manera nacional. La comunidad y la nación imaginada desde la Reforma son el punto de partida de la conquista de la nación como una forma de organizar la nueva comunidad política en el siglo XIX.

Podemos asegurar a hojas vistas que el concepto de nación ha evolucionado históricamente. Evidentemente es un concepto dinámico que ha sido definido y caracterizado de diversas formas desde el siglo XVIII. Nuestra línea argumentativa y, por ende, nuestra Tesis sostiene que las explicaciones históricas de la nación son de creación reciente y que su desarrollo está asociado a procesos políticos típicamente modernos como la burocracia, la secularización o la homogenización generados desde el Estado.

\footnotetext{
${ }^{18}$ Cfr. Comunidades imaginadas. Reflexiones ..., op. cit., pp. 30-31.
} 
En nuestra revisión por las diferentes interpretaciones de lo que es una nación, inexcusablemente hemos tenido que hacer referencia a la relación entre nación y Estado, a continuación, examinaremos con mayor detalle las diferentes interpretaciones acerca de dicha relación.

Los demiurgos de la historia construyeron relatos nacionales buscando en pasados remotos y míticos formas preliminares de estados nacionales. Iniciaban sus narrativas describiendo una serie de agrupaciones, -tribus, ciudades-estados, etnias, etc.,- como someras formas preliminares e incompletas de modernas naciones-estados. En el curso del último siglo los historiadores denunciaron sistemáticamente el anacronismo implícito en este punto de vista.

Se podría sintetizar la evolución y las formas de estudio de este problema estableciendo diversas perspectivas, las cuales no son sucesivas ni se encuentran en orden temporal correlativo, sino que han logrado coexistir hasta nuestros días en diversos ambientes intelectuales, aunque algunas son de mayor data que otras y poseen mayor o menor reconocimiento académico.

\subsection{Visión genealógica de la construcción del Estado nacional}

La perspectiva genealógica fue la imperante desde fines del siglo XVIII hasta mediados del XX. Esta concepción tiene por premisa que la nación es un fenómeno objetivo y naturalmente concebido. El supuesto es que las naciones existen, constituyen el ordenamiento natural para las distintas colectividades humanas, y convirtiéndose en la esencia de la organización estatal. De esta forma, la tarea radica en descubrir los elementos constitutivos e inalienables de ella, su raíz histórica, su evolución y cómo se han transmitido estos elementos a lo largo del tiempo.

Entre los primeros y más influyentes intelectuales de esta visión se encuentran -los ya citados- J.G. Herder y J.G. Fichte, entre ambos definieron los elementos característicos 
e indispensables de la nación. En primer lugar, el suelo, entendido como el «espacio físico» donde se ha desarrollado la historia de la nación, o como lo denominaba Herder, la «dimensión poética de la geografía» ${ }^{19}$, entendida como un terreno delimitado, en el cual se sitúan todas las posibilidades de experiencias e influencias que pudiera tener la colectividad que la habita. El espacio se presenta como un factor condicionante del carácter nacional, proporcionándole posibilidades ilimitadas de vivencias, influyendo así en la conformación de éste desde un plano cognitivo y espiritual.

En segundo lugar, se encuentra el concepto de lengua, entendida como el medio de expresión del espíritu nacional, porque «en cada uno de los idiomas están expresados el carácter y el intelecto de un pueblo (...) el genio de un pueblo no se revela en ningún lugar mejor que en la fisonomía de su lenguaje» ${ }^{20}$. Cada lengua cumple con la función de conectarnos con nuestros antepasados, dándonos el sentido de trascendencia y pertenencia a una comunidad, haciéndonos parte de este proyecto histórico que constituye la nación. Por otra parte, al igual que el factor suelo, la lengua, condiciona el carácter nacional al dotarlo de un modo de pensamiento y comprensión de la realidad particular.

La composición étnica constituye un tercer elemento de la nación. La raza se concibe como la adhesión natural e inalienable, genética si se quiere, a una comunidad específica, es la sangre como expresión de un conjunto de individuos que posee parentesco entre sí, y, por ende, una constitución única de su carácter que se expresa en determinadas formas filiales y afectivas de relacionarse. Esta vinculación natural fundamenta el nombre otorgado a esta perspectiva de la nación como orgánica, al concebir la comunidad como un cuerpo vivo, una entidad biológica, única e irremplazable. Esta perspectiva llevó irremediablemente a una concepción particularista de la historia, en el cual se exige que los modelos sociales, políticos y económicos sean nativos, o adaptados a los valores y características innatas de la comunidad para que sean coherentes al «carácter» de la nación.

\footnotetext{
${ }^{19}$ Ideas para una filosofía de la historia ..., op. cit., p. 225.

${ }^{20}$ Ibidem, p. 273.
} 
Las etnias tienen un papel significativo en la construcción de los estados nacionales y para ello había que indagar en el pasado para conocer la estirpe que «no es sólo tener un sentido de la procedencia sino, lo que es quizá más importante, un sentido de continuidad en la cual, hasta cierto punto, uno encuentra el significado personal y social de la existencia humana.» ${ }^{21}$ Esta perspectiva, a pesar, del carácter fáctico del Estado nacional, insisten en que el elemento constituyente, la etnia y la herencia cultural de lengua, religión, espacio y tiempo convierten a la nación en algo más que un producto cultural y político.

Uno de los principales exponentes de esta interpretación es A.D. Smith, quien ha planteado que existe un vínculo entre la permanencia de los grupos étnicos y la formación de los estados nacionales. Él mismo define la etnia como «poblaciones humanas con un nombre propio que tienen mitos ancestrales, historias y culturas, una asociación con un territorio específico y un sentido de solidaridad» ${ }^{22}$. Para este autor, la etnia es una condición esencial, ya que la etnia precede a la nación y ésta al Estado nacional. De igual manera, distingue que para la creación de los estados nacionales existen cuatro vías y todas requieren la presencia de lo étnico. La vía occidental es una primera vía en la cual se construye el Estado territorial en torno a un grupo étnico, y de esta forma surge la nación, es el caso del Reino Unido y Francia. Una segunda vía es por medio de emigrantes, en la cual un grupo étnico adquiere un Estado y mediante acciones colonizadoras va incorporando sucesivamente olas de emigrantes. Australia, Estados Unidos y Argentina son ejemplo de esta vía. La tercera vía es la que materializó en Europa Oriental, donde la existencia de grupos étnicos sin una consciente manifestación territorial y política y por influencia del nacionalismo se convirtieron en ejemplo de modelo étnico de nación. Estos estados nacionales pusieron énfasis en los mitos genealógicos, el tronco común, el fortalecimiento de lo rural y la lengua. Bajo esta premisa en «la concepción étnica de la nación, la historia viene a ser el equivalente de cultura para las concepciones territoriales de la nación» ${ }^{23}$. La cuarta vía es la que han

\footnotetext{
${ }^{21}$ DE VOS, G. Y ROMANUCCI-ROSS, L., Ethnicity: Vessel of Meaning and Emblem of Contrast, Chicago, The University of Chicago Press, 1982, p. 364.

${ }^{22}$ The Ethnic Origins of Nations, Oxford, Blacwell, 1986, p. 66.

${ }^{23}$ Ibidem, p. 138.
} 
seguido los países en África y Asia que les proporciona sentido de comunidad y de arraigo histórico con el pasado.

El valor de lo étnico en la conformación de los estados nacionales según este planteamiento ha tenido un papel significativo, aunque es difícil distinguir la diferencia entre etnia y nación. Anthony Smith advierte que no hay que confundir estos postulados con una actitud xenófoba o hermética frente a las influencias extranjeras, la base de este pensamiento no es renunciar al mundo sino adaptar estas influencias a la propia realidad y a las características de la nación. Es lo que este autor denomina un «horizonte de expectativas». La paradoja es que al mismo tiempo que toda nación busca el contacto con los demás para enriquecerse en términos materiales, «busca purificar a la propia cultura de todo elemento considerado extranjero y producto de ese intercambio» ${ }^{24}$. Este planteamiento sostiene que la conjugación de estos tres elementos: tierra, lengua y etnia proporcionan un determinado espíritu colectivo que culmina siendo la explicación de todas las diferencias reconocidas entre las distintas naciones y el fundamento principal para el ordenamiento internacional basado en el Estado-nación.

\subsection{Visión histórica-modernista y la construcción del Estado nacional}

Las visiones modernistas de la construcción del Estado nacional plantean que ésta es producto de los cambios asociados a procesos propios de la modernidad como el capitalismo, la alfabetización y la industrialización. En este grupo se encuentra un número importante de teóricos que interpretan que la conformación del Estado nacional es obra de las élites, intelectuales y del propio Estado como arquitectos de la transición del mundo campesino, tribal, feudal, aun mundo urbano y capitalista, determinados por la concentración del poder a manos del Estado.

El enfoque modernista se inaugura en la segunda mitad del siglo XIX a partir de los postulados de Renan, quien reconocía la existencia de las naciones, y que cada una de

\footnotetext{
${ }^{24}$ SMITH, Anthony, «Culture, Community and Territory. The Politics of Ethnicity and Nationalty», International Affairs, vol. 72, № 3 (Julio 1996), p. 458.
} 
ellas poseía un espíritu único de pertenencia declarando que ningún hombre es «esclavo de su raza, ni de su lengua, ni de su religión (...) Una gran agregación de hombres, sana de espíritu y cálida de corazón, crea una conciencia moral que se llama una nación $(\ldots) »^{25}$. Indicaba, además, que el único aspecto en la configuración del Estado nacional era la voluntad de los miembros de vivir en una determinada comunidad y que ese espíritu está formado por un rico legado de recuerdos, otorgado por la historia y la memoria que ha experimentado la sociedad. Por esto, la nación sería un fenómeno creado en función a una elección racional e individual de aspirar a ser miembro de una comunidad de derechos y deberes. Esta elección fue refrendada por Renan que apuntaba que «una nación es una gran solidaridad, constituida por el sentimiento de los sacrificios que se ha hecho y de aquellos que todavía se está dispuesto a hacer» ${ }^{26}$. Con el pasado como referente, se requiere, además, para la constitución de lo nacional, un consentimiento permanente de desear vivir juntos y en comunidad. De allí, que la voluntad expresada persistentemente es el único criterio genuino para organizar estados nacionales.

El Estado y la nación, son fenómenos subjetivos, creaciones humanas y no son hechos biológicos ni naturales, requieren del asentimiento de la población; $\mathrm{y}$, por ende, un derecho renunciable al momento de no desear renovar tal plebiscito en búsqueda de una comunidad más afín al carácter o intereses personales.

Tras la Segunda Guerra Mundial el enfoque voluntarista predominó en Europa, promovido especialmente por los excesos de la Alemania nazi y la aplicación de políticas racistas de supremacía. Como correlato surge una segunda generación de especialistas que profundizaron las ideas de Renan, denominados a posteriori los antigenealógicos o modernistas.

El enfoque de la construcción de la nación desde el Estado, no acepta que haya continuidad entre las identidades pre-modernas y las modernas y plantea que las

\footnotetext{
${ }^{25}$ ¿Qué es una nación? ..., op. cit., p. 42.

${ }^{26}$ Ibidem, p. 44.
} 
naciones son construcciones históricas acotadas temporalmente. En esta dimensión desempeñaron un papel fundamental los gobernantes y las élites estatales, que, por medio de la educación, la estandarización de la lengua y los medios de comunicación, construyen la identidad nacional como una cultura política en la que se apoya la comunidad, los civiles, los sectores populares y el territorio.

El autor más destacado de esta visión renovada es Karl Deutsch que con su obra Nationbuilding se convierte en autor de referencia de esta postura, quien definió la trayectoria a la construcción de la nación como la unión de diversidad de elementos de la población en un todo congruente, mediante la construcción de nuevas lealtades e identidades en un nivel nacional para que finalmente el Estado nacional se constituyera en una amalgama de «(...) integración política con la asimilación de todos los grupos en un lenguaje y cultura común» ${ }^{27}$. Para el alemán, el Estado Nacional es una necesidad del mundo moderno, en el que la división internacional del trabajo, los movimientos del capitalismo y los mercados requieren de formas de comunicación con grupos más grandes de gentes; y para ello el Estado requiere a su vez de una comunidad homogénea en cual establecerse. En este sentido, el Estado promueve e impulsa la construcción de la nación utilizando como estrategia ineludible la asimilación de todos en una cultura común, proceso que se logra por los medios que el estado produce y divulga. En general, tanto en Deutsch como en otros autores adscritos a esta idea advierten etapas en ese proceso de nacionalización de las poblaciones de un territorio que van desde la resistencia declarada a la política estatal de asimilación hasta la fusión en la cultura nacional.

Las sociedades del mundo pre-moderno poseían formas y caracteres muy diversos desde ciudades-estados, principados feudales, comunidades étnicas e imperios. En el mundo moderno y contemporáneo esas formas son casi siempre naciones y estados-nación. Uno de los aspectos centrales de la modernidad es la revolución en la administración y las comunicaciones, cambio que generó nuevas formas de asociación por medio de las

\footnotetext{
${ }^{27}$ JAFFRELOT, Cristopher «Los modelos explicativos del origen de las naciones y del nacionalismo. Revisión Crítica» en DELANNOI, G. y TAGUIEFF, Pierre (comps.), Teoría del Nacionalismo, Barcelona, Paidos, 1993, p. 207.
} 
cuales se incide en el entorno. En ello encontramos uno de los planteamientos basales del Estado como creador de las naciones con la premisa que el Estado moderno requiere para el éxito de su empresa una comunidad e identidad política a su imagen y semejanza. Uno de los grandes precursores de esta idea es Giddens, quien en Nations, States and Violence sostiene que el Estado Nacional es la «expresión de las dislocaciones de la historia moderna» ${ }^{28}$ donde las funciones administrativas $\mathrm{y}$ territoriales permiten «mantener el monopolio administrativo sobre un territorio expresamente delimitado, cuyo gobierno es sancionado por una ley y por el control directo de la violencia interna y externa ${ }^{29}$. Esto significa que a diferencia de otras formas de comunidades políticas anteriores al siglo XIX estas poseen una administración que ejerce poder y autoridad desde una ciudad sobre espacios territoriales bien definidos. En la era moderna, los estados nacionales surgieron como producto de la centralización administrativa del Estado y la fijación de fronteras. Para Giddens la nación y el nacionalismo están fuertemente vinculados a lo moderno. El Estado construye la nación sujeta a la administración del Estado, no sólo por medio de la ordenación de las personas que viven en ese territorio y la administración pública, sino que fundamentalmente por la afiliación simbólica, signo o ritos que refuerzan la pertenencia a la comunidad.

Otros autores igualmente merecen atención en esta perspectiva se trata de los ya citados, Eric Hobsbawm y Ernest Gellner quienes plantean que las naciones son creaciones relativamente recientes, producidas para complementar y afianzar el proceso de doble revolución comenzada en el largo siglo XIX como consecuencia de las revoluciones liberal e industrial. Cuando Hobsbawm se refiere a la nación indica que al menos ha cambiado su significado «podemos aceptar que en su sentido moderno y básicamente político el concepto nación es muy joven desde el punto de vista histórico» ${ }^{30}$. Es categórico en aseverar su novedad en el mundo moderno, especialmente cuando algunos autores aprecian que en la constitución de esos Estados hay pre-existencias «donde hay o parece haber continuidades entre el protonacionalimso es muy posible que sean

\footnotetext{
${ }^{28}$ The Nation-State and Violence, California, University of California Press, 1985, p. 116.

${ }^{29}$ Ibidem, p. 121.

${ }^{30}$ Naciones y nacionalismo ..., op. cit., p. 18.
} 
artificiales ${ }^{31}$. Hobsbawm no descarta del todo las identidades protonacionales, pero no son la condición para el surgimiento de la nación y el nacionalismo, sino que lo explica a través de la acción del Estado, poniendo un acento impresionante en la acción política para la conformación de lo nacional y tal como «se ha observado a menudo, es más frecuente que las naciones sean la consecuencia de crear un Estado que los cimientos de éste» ${ }^{32}$. La revolución liberal o burguesa indeclinablemente tuvo como consecuencia la destrucción de los principios de legitimidad tradicionales vinculados a la dinastía, linaje, jerarquía nobiliaria y predilección divina. Esto produjo un peligro latente de fragmentación de los Estados y pérdida de autoridad de las nuevas clases gobernantes identificadas con la burguesía. Por esta razón, Hobsbawm señala que existió un esfuerzo consciente de parte de las elites de crear tradiciones tendientes a formar naciones, ya que consideraba la forma idónea de sustentarse como clase política preeminente, al mismo tiempo que se consolidaban los nuevos Estado-nación tras la caída de los Imperios e inicio de los procesos de emancipación. Para Hobsbawm los estados crean las naciones para controlar a la población y lo realizan por medio de la estandarización de la lengua y la invención de las tradiciones.

Estas tradiciones comprenden prácticas de carácter ritual o simbólica, entre ellas, por ejemplo, el culto al héroe, mediante el cual se inculcan valores y normas que tienen algún sustento en el pasado generando cohesión social y pertenencia a comunidades reales o artificiales. Señala el británico que la democratización de la política favorece la formación del concepto de nación, ya que los ciudadanos pueden participar de la vida política al percibirse como iguales, ya que «el acto mismo de democratizar la política, es decir, de convertir los súbditos en ciudadanos, tiende a producir una conciencia populista que según como se mire, es difícil de distinguir de un patriotismo nacional, porque si el país es de algún modo mío, entonces es más fácil considerarlo preferible a los países extranjeros» ${ }^{33}$.

\footnotetext{
31 Ibidem, p. 85.

${ }^{32}$ Ibidem, p. 86.

${ }^{33}$ Ibidem, p. 97.
} 
Es la consideración que la promoción del Estado Nacional se realiza por un lado desde arriba con las ideas y prácticas gubernamentales y, desde abajo con los sentimientos, prácticas y creencias que sustentan la comunidad. Lo anterior encuentra sustento en la famosa sentencia de Ross, según la cual «es el Estado el que hace la nación y no la nación el Estado» ${ }^{34}$, entendiendo por esto que fue la elite, controlando el Estado, la que construyó una nación para legitimarse a sí misma, contradiciendo la premisa genealógica de un mundo de naciones en la cual se afirmaba que fueron las comunidades agrupadas en lengua, etnia y suelo, las que crearon Estados para obtener la autonomía política, económica y cultural.

La intención primordial era otorgar a las nuevas sociedades un atisbo de homogeneidad, que permitiera el surgimiento de Repúblicas Oligárquicas o censitarias a lo largo de Europa. Para ello los atributos de la comunidad se enseñan como si fueran elementos compartidos, al mismo modo que tradiciones específicas que den la ilusión de trascendencia y conexión con los antepasados, se crean, re-significan y difunden para homogeneizarla en patrones comunes, dando paso a lo que Hobsbawm denomina la invención de la tradición.

El historiador H. Ross también se dedicó a estudiar las transformaciones del nacionalismo. Para ello distingue una primera etapa, a la cual denomina nacionalismo gubernamental, que fue suscitado por los estados desde el siglo XVIII, y especialmente entre 1830 a 1870 . Este posee un carácter cívico y el principio que las naciones con un territorio podían constituirse en estados soberanos. Luego vendrían otro momento entre 1870 y 1914, donde adviene el nacionalismo etnolingüístico, que promueve el derecho de la autodeterminación de las naciones y de grupos pequeños con rasgos comunes de lengua y raza. La última etapa sería la del apogeo del nacionalismo, entre 1918 a 1950, en la cual las naciones y los nacionalismos se dirigen en contra de los imperios, impulsando la descolonización.

\footnotetext{
${ }^{34}$ A History of Modern Poland, London, Ed. Alfred Knopf, 1966, p. 48.
} 
Ernest Gellner agrega una dimensión económica al proceso de invención de la nación, al señalar la necesidad que tiene el proceso de industrialización y consolidación del sistema capitalista de generar mercados nacionales donde los trabajadores posean un sistema económico común (moneda y legislación), como también códigos compartidos que fomenten la cooperación gremial y la movilidad laboral (lengua, costumbres, identidad, alfabetización). Lo sitúa como un fenómeno del siglo XIX ya que «tiene un profundo arraigo en las exigencias estructurales distintivas de la sociedad industrial»» ${ }^{35}$. Este autor distingue tres grandes etapas históricas, la pre-agraria, agraria e industrial. En la primera no existía comunidad política ni Estado. En las segundas había poca movilidad en las ocupaciones y estamentos, y, por ello, las comunidades campesinas tenían diversas culturas y eran los grupos religiosos, militares y burocráticos los que tenían acceso a la escritura. En cambio, en el mundo industrial, que constituye un mundo en constante transformación, las naciones son una necesidad, ya que el capitalismo y el comercio suponen movilidad laboral, que requiere de una cultura y lenguaje común en la cual puedan entenderse los que en ella viven. Esta comunión es elaborada por miembros de la elite recogiendo elementos de esa elite en la cual fueron formados. Se debe señalar que las sociedades agrarias y los sectores populares al adquirir la cultura común se diluyeron con la modernización. La sentencia de Gellner es muy clara: «de ello se sigue inmediatamente que el problema del nacionalismo no surge en sociedades sin Estado. Si no hay Estado, nadie, evidentemente, puede plantearse si sus fronteras coinciden o no con los lindes de las naciones. Si no hay dirigentes, no habiendo estado, nadie puede plantearse si pertenecen o no a la misma nación que nación que los dirigidos. Cuando no hay ni estado ni dirigentes, nadie puede sentirse frustrado por no satisfacer las necesidades del principio nacionalista.» ${ }^{36}$

El planteamiento de Gellner es que la nación y el nacionalismo buscan mediante la movilización social promover una economía que apunte a consolidar un mercado interno con la división del trabajo dentro de la comunidad. Y que por lo tanto la «era de transición al industrialismo estaba abocada a ser también una era de nacionalismo, un

\footnotetext{
${ }^{35}$ Naciones y nacionalismo..., op. cit., p. 110.

${ }^{36}$ Ibidem, p. 71.
} 
período de reajuste turbulento en el que, bien las fronteras políticas, bien las culturales, o ambas, habrían de modificarse para satisfacer el nuevo imperativo nacionalista que entonces, por primera vez, se estaba haciendo palpable ${ }^{37}$. La idea es que la nación presume la división del trabajo, la aparición de una clase dirigente e intelectual que construye el nacionalismo y la confección de una cultura y lengua estandarizada que, por medio de instituciones, normaliza y uniformiza a los sujetos. Para la existencia de los Estados Nacionales y sobre todo el nacionalismo Gellner señala que «la base de la vida política a de estar en la existencia de unidades culturales homogéneas y que debe existir obligatoriamente unidad cultural entre gobernantes y gobernados ${ }^{38}$.

Tanto Hobsbawm como Gellner argumentan que el concepto de nación se manipuló por parte de una elite político-económica y son contrarios a la idea que las naciones poseen una historicidad atávica o secular, sino que, por el contrario, enfatizan la característica artificial y novedosa tendente a legitimar los intereses de proyectos políticos y de clase.

En la teoría modernista la interrogante fundamental está en definir cómo se ha creado y utilizado este concepto de nación, desde un punto de vista político, cultural y social. En este sentido, la educación y la memoria se consideraron fundamentales para generar la identidad nacional. Benedict Anderson es uno de los especialistas que más intensamente ha abordado este tópico definiendo la nación como «(...) una comunidad políticamente imaginada como inherentemente limitada y soberana. Es imaginada porque aún los miembros de la nación más pequeña no conocerán jamás a la mayoría de sus compatriotas, no los verán no oirán siquiera hablar de ellos, pero en la mente de cada uno vive la imagen de su comunión» ${ }^{39}$. Y agrega en lo referente a la limitación que «(...) la nación se imagina limitada porque incluso la mayor parte de ellas, que alberga tal vez a mil millones de seres humanos vivos, tiene fronteras finitas, aunque elásticas, más allá de las cuales se encuentran otras naciones. Ninguna nación se imagina con las dimensiones de la humanidad» ${ }^{40}$.

\footnotetext{
${ }^{37}$ Ibidem, p. 116.

${ }^{38}$ Ibidem, p. 162.

${ }^{39}$ Comunidades imaginadas. Reflexiones ..., op. cit., p. 23.

${ }^{40}$ Ibidem, pp. 24-25.
} 
El aspecto gravitante en esta concepción es el problema de la construcción de esta comunidad imaginada articulada fundamentalmente en función de códigos compartidos (lengua, historia, suelo, experiencia, etnia, religión, etc.), obviando por ende los aspectos que generen divergencia en ella. Anderson, quien también bebe de la visión marxista, pero otorgándole una prioridad a los aspectos culturales y subjetivos, aporta sustancialmente en la idea de la comunidad imaginada el carácter de imaginada proviene de que, por el tamaño de la misma, sus miembros no se conocen, mas suponen que son parte de una comunidad que se imagina como limitada, vale decir, con una frontera y con el derecho a ser libre para instituirse como Estado soberano. La aparición del concepto de nación está vinculado a hechos históricos de la vida moderna como: la pérdida de la importancia del latín como lengua religiosa, la decadencia de la idea que las sociedades estaban organizadas de un modo original en rededor de un soberano; y por cierto que en esa época emergió el capitalismo que por medio de varios medios fueran conocidos y asumidos por la población y se buscó «una nueva forma de unión de la comunidad, el poder y el tiempo, dotada de sentido. Es posible, que nada haya precipitado esta busca en mayor medida, ni la haya hecho más fructífera, que el capitalismo impreso ${ }^{41}$. En este sentido, la alfabetización por medio de las instituciones educativas permitió que un número creciente de personas accedieran a la cultura escrita conectándolas entre sí e imaginando que eran parte de una misma comunidad. Pudieron comprenderse ingleses, franceses, españoles, americanos por medio de la imprenta y el papel. Anderson le otorga a esta situación un valor relevante en la generación de la conciencia nacional. Por esta razón la educación formal, los simbolismos, la diferenciación frente a un otro, la cartografía son elementos indispensables en le esfuerzo de inventar, crear y consolidar unidades nacionales.

Dentro de los intelectuales modernistas también hallamos a John Breuilly quien argumenta que, en el mundo moderno, los que ostentan el poder se dan a la tarea de conquistar y controlar el Estado. La cuestión fundamental es que lo nacional fue usado con «el objetivo de obtener y usar el poder del Estado» ${ }^{42}$. Entre los que se arrojan a la

\footnotetext{
${ }^{41}$ Ibidem, p. 62.

${ }^{42}$ Nacionalismo y estado, Barcelona, Pomares-Corredor, 1990, p. 11.
} 
faena de controlar el Estado están los intelectuales y los educadores que «a menudo son los que elaboran la categoría de nación dotándola de significado simbólico. Es su imaginación y su capacidad de comprensión la que da a la nación sus contornos y gran parte de su contenido emocional» ${ }^{43}$. Estas perspectivas constructivistas son criticables al poner énfasis en la forma en que se construye la representación de la nación, pero olvidan el sustrato social del fenómeno, lo que permitiría dar mejores señales de cómo los nacionales sienten la nación y explicar finalmente porque el nacionalismo moviliza a la población.

En este grupo de los modernistas cabe mencionar también a Will Kymilcka quien subraya la importancia del plurinacionalismo y la pluriculturalidad. Sostiene que para la formación de los Estados es clave la formación de una cultura delimitada geográficamente cuyo centro de gravedad es la lengua compartida y necesaria para poder desarrollarse en la cotidianeidad. El Estado estandariza lengua y cultura para que la población pueda desenvolverse en el mercado del trabajo. Aún cuando su mayor énfasis está puesto en que existen Estados donde la cuestión de los nacionales está supeditado al reconocimiento de los derechos liberales como la igualdad y la autonomía. Es posible la convivencia entre varias culturas en un mismo Estado siempre que no estén reñidas con intereses de la cultura predominantes siempre que sean coherentes con el liberalismo que otorga espacios de soberanía, ya que: «la aspiración moderna que representa la libertad y la autonomía, lejos de debilitar el compromiso de los individuos con su propia identidad cultural ha servido en muchos casos para reforzarlo con más ahínco. Quienes valoran su autonomía también hacen lo propio con su cultura nacional y que esto le confiere el contexto más importante en el que desarrollar y ejercitar su autonomía.» $^{44}$

En muchos Estados de raigambre liberal se reconocen los derechos como la igualdad y la autonomía. Estos valores son tan reconocidos como los de otras naciones que viven dentro de los Estados. Lo deseable es que la cultura hegemónica no tiene porque luchar

\footnotetext{
${ }^{43}$ SMITH, Anthony, Nacionalismo y modernidad, Madrid, Istmo, 2000, p.174.

${ }^{44}$ KYMILCKA, Will, Estados, naciones y culturas, Córdoba, Ediciones Almuzara, 2004, p. 49.
} 
con otras identidades siempre que sean coherentes con el liberalismo. El planteamiento del autor canadiense se centra en la distinción entre naciones cívicas y naciones étnicas, mientras las primeras son liberales, las segundas son antiliberales. Las étnicas consideran que uno de sus objetivos más elementales es la reproducción de una cultura y de una identidad etnonacional concreta, en cambio las naciones cívicas «son neutrales con respecto a las identidades etnoculturales de sus ciudadanos y definen la pertenencia nacional meramente en términos de adhesión a ciertos principios de democracia y justicia ${ }^{45}$. El reto está planteado al considerar necesario afrontar el multiculturalismo en el mundo liberal y es imprescindible, en palabras de Federico Pérez, «(...) reformar las constituciones, para dar cabida a ciertas preferencias legales, ciertos derechos individuales diferenciados mediante los cuales los miembros de un grupo minoritario puedan mantener las condiciones necesarias para preservar su identidad cultural» ${ }^{46}$.

Más que un análisis de la teoría modernista de Kymilcka, el planteamiento de Pérez constituye una propuesta política que significa poner junto a los derechos de liberalismo y democracia derechos diferenciados de acuerdo al grupo de pertenencia; en definitiva, es una ampliación de los derechos individuales y su compatibilidad con los derechos de las comunidades. El desafío es cómo incluir unas formas de vida dentro de otras y de cómo evitar que las sociedades hegemónicas impongan sus instituciones y concepciones a culturas diferentes. Es contrario al liberalismo que rechaza todo tipo de opresión, discriminación o limitación de la autonomía de las personas. El desafío es constatar qué grados de heterogeneidad cultural puede soportar una comunidad política o qué mínimos comunes se deben compartir para mantener la estabilidad de la unidad política.

Desde la perspectiva del marxismo, que ha puesto la importancia en el concepto de clase como categoría para comprender la historia marginó el tema de la nación y el nacionalismo expresado rotundamente en el Manifiesto: «(...) los obreros no tienen patria. No se les puede arrebatar lo que no tienen. Más por cuanto el proletariado debe

\footnotetext{
${ }^{45}$ KYMILCKA, Will, «Derechos individuales y derechos de grupo en la democracia liberal», ISEGORIA, $\mathrm{N}^{\mathrm{o}} 14,(1996), \mathrm{p} .7$.

${ }^{46}$ «Will Kymilcka: La defensa del nacionalismo minoritario», Astrolabio. Revista Internacional de Filosofia, No 4 (2007), pp. 62-63.
} 
en primer lugar conquistar el poder político, antes de elevarse hasta constituir la primera clase nacional (...) $\rangle^{47}$, y dado que la ideología nacional, es también una ideología de clase, configurada por las relaciones de producción y por los intereses de las clases dominantes, los intereses oficiales de las naciones burguesas, no son los intereses de sus clases explotadas. En este sentido, los trabajadores no tienen patria, lo que no quiere decir estrictamente que no la tengan.

A medida que el fenómeno de las nacionalidades fue alcanzando intensidad, Marx y Engels apelaron al requerimiento de la autonomía de los nacionales dentro del imperio ruso, austro-húngaro e inglés, incluso en el entendido de la autodeterminación de las naciones. El propio Engels mostraba que la liberación nacional era una condición para los cambios sociales y que el internacionalismo solo podía ser exitoso sobre la base de la libertad de los pueblos y en una carta aseveraba que «dos naciones tan sólo en Europa, tienen no sólo el derecho sino el deber de ser nacionales antes que internacionales: los irlandeses y los polacos ${ }^{48}$. Probablemente en esta línea de argumentación es que los movimientos de liberación nacional tuvieron tanto apoyo entre los socialistas.

Continuando en esta idea, el propio Lenin, años más tarde, sostenía que, ante la existencia del nacionalismo burgués que proclama el reconocimiento de la igualdad de derechos con niveles altos de explotación al interior de esas comunidades, es que no se debe limitar la acción sólo a la unidad de los trabajadores nacionales sino que es «preciso desarrollar una política que lleve a cabo la unión más estrecha entre los movimientos de liberación nacional y colonial con la Rusia soviética, haciendo que las formas de esta unión estén en consonancia con los grados de desarrollo del movimiento comunista en el seno del proletariado de cada país o del movimiento democrático-

\footnotetext{
${ }^{47}$ MARX Karl y ENGELS, Friedrich, Manifiesto del Partido Comunista, Santiago, Ediciones Olimpo, 2001, p. 60.

${ }^{48}$ Cit. en HAUPT, George y LÜWY, Michael, Los marxistas y la cuestión nacional, Barcelona, Ed. Fontamara, 1980, p. 24.
} 
burgués de liberación de los obreros y campesinos en los países atrasados o entre las nacionalidades atrasadas» ${ }^{49}$.

En tanto, el nacionalismo resulte victorioso, debe respetar la autodeterminación de las naciones como mecanismo para realizar la democracia total. Lenin, a diferencia de la poca importancia que entre los comunistas se otorgó a los nacionalismos le dedicó minuciosas observaciones. Con la liberación nacional y el respeto a la autodeterminación de los pueblos se debe alcanzar el desarrollo pleno de las sociedades y si no son «capaces de liberar a las naciones avasalladas (...) sobre la base de la unión libre y sin libertad de separación es una frase mentirosa, esos partidos cometerían una traición al socialismo» ${ }^{50}$. La idea central era que la aparición de la nación y de los Estados nacionales estaban vinculados a la existencia de la burguesía y que por lo tantos éstos se construyen en torno al concepto de igualdad jurídica amparada por aquella. Ante esta situación, los comunistas deben apreciar en los temas nacionales la situación real de los trabajadores que tienen existencia deplorables y oprimidas con la finalidad de denunciar al nacionalismo promoviendo la liberación y la transformación social. En este sentido, el sucesor de Lenin, Stalin, proporciona una enunciación acerca del papel de los partidos comunistas frente a los movimientos nacionalistas definiendo la nación como «una comunidad estable, históricamente formada, de idioma, de territorio, de una vida económica y de psicología, manifestada ésta en la comunidad de cultura» ${ }^{51}$. Stalin sostiene que el nacionalismo es una categoría histórica de determinada época y estrechamente vinculada al ascenso del capitalismo. De este modo, Stalin asevera que en el marco del imperialismo capitalista las burguesías nacionales desean defender sus mercados de las burguesías foráneas después del triunfo sobre las estructuras feudales. Deducción mecánica, si se ataca el nacionalismo a través de la democratización del país y el otorgamiento de derechos a la autodeterminación disminuirá el poder de las burguesías mundiales. La finalidad es la derrota del capitalismo y las burguesías, es el sentido utilitario y práctico del diseño stalinista que «incluso dentro de los marcos del

\footnotetext{
${ }^{49}$ «Tesis y adiciones sobre los problemas nacional y colonial» en Los Cuatro primeros Congresos de la Internacional Comunista, http://grupgerminal.org, 2008, p. 168.

${ }^{50}$ «La revolución socialista y el derecho de las naciones a la autodeterminación» en Obras Escogidas, Editorial Progreso, 1946, p. 346.

${ }^{51}$ STALIN, Joseph, El marxismo y la cuestión nacional, Barcelona, Anagrama, 1977, p. 40.
} 
capitalismo, es reducir al mínimo la lucha nacional, minarla en su raíz, hacerla lo más inofensiva posible para el proletariado (...). Para ello es necesario es posible democratizar el país y dar a las naciones la posibilidad de desarrollarse libremente» ${ }^{52}$. La cuestión de las nacionalidades comprendidas por Stalin como la opresión de las naciones y las minorías nacionales era una consecuencia del Imperialismo capitalista, y una oportunidad para asegurar la revolución proletaria.

Entre los innumerables teóricos adscritos al marxismo, es importante resaltar los aportes a la cuestión de la nación de dos autores: Immanuel Wallerstein y Etienne Balibar. Ambos sostienen que la nación es una construcción histórica. Wallerstein comprende a la nación como una de las tres variaciones del concepto pueblo, cada una de las cuales cumple una función en la economía del sistema mundo. Utiliza tres conceptos a saber: grupo étnico, raza y nación y lo establece de forma muy clara cuando indica que «el concepto de clase es muy diferente del de pueblo (...) Las clases son categorías “objetivas", es decir categorías analíticas, manifestaciones de las contradicciones de un sistema histórico, y no descripciones de comunidades sociales» ${ }^{53}$. El concepto grupo étnico justifica la explotación del trabajo dentro de las unidades familiares; el concepto raza justifica la explotación del trabajo que se da en las periferias; y finalmente, el concepto de nación legitima y mantiene el Estado.

Las categorizaciones de etnia, raza y nación han sido funcionales a las legitimaciones de la desigualdad y segmenta la fuerza de trabajo. Esto se ha realizado por medio de sistemas educativos que naturalizan la desigualdad en la socialización de los individuos y los colectivos y por cuestiones ideológicas que han utilizado el recurso abstracto de la igualdad que acompaña a la idea liberal de la ciudadanía que convive con una serie de desigualdades. La idea de nación es el resultado del proceso de construcción de los Estados en la economía mundo-capitalista y éstos cuando nacen «tienen problemas de cohesión. Una vez reconocida su soberanía, es frecuente que los Estados se encuentren

\footnotetext{
${ }^{52}$ Ibidem, p. 55.

${ }^{53}$ WALLERSTEIN, Immannuel, «La construcción de los pueblos: racismo, nacionalismo y etnicidad» en BALIBAR, Etienne y WALLERSTEIN, Immannuel, (eds.) Raza, Nación y Clase, Madrid, IEAPALA, 1988, p. 132.
} 
amenazados por la desintegración interna y la agresión externa. Las amenazas disminuyen a medida que se desarrolla el sentimiento nacional» ${ }^{54}$. Los gobiernos en el poder tienen interés en fomentar este sentimiento, al igual que varios tipos de subgrupos dentro del Estado y la nación está vinculada «con la superestructura política de este sistema histórico, con los Estados soberanos que constituyen el sistema interestatal» ${ }^{55}$. En Wallerstein el Estado precede la nación, la crea y legitima su unión, sin embargo, a la vez, existe una división del mundo en distintas naciones como fruto de las competencias de las burguesías en el sistema mundial económico, por lo tanto, el estado nacional y la nación nace de la competencia entre estas unidades políticas y territoriales

Un segundo exponente del marxismo contemporáneo, Balibar, crítica a Wallerstein por concebir el origen y desarrollo de la nación tan circunscrito a cuestiones económicas teniendo una impresión distinta sobre los pueblos en dicha configuración. Para él los relatos de los Estados Nacionales se «nos han presentado siempre con las características de un relato que se les atribuye la continuidad de un sujeto (...) Es una ilusión retrospectiva $(. .$.$) creer que las generaciones que se suceden durante siglos en un$ territorio más o menos estable, con una denominación más o menos unívoca se transmiten una sustancia invariable» ${ }^{56}$.

La trama que posibilita el vínculo está constituida por una multiplicidad de acontecimientos desfasados en el tiempo y entre ellos no hay una implicación determinada por pertenecer a una nación. A esto se refiere Balibar a que la nación siempre se presenta como un relato continuo y que no es más que una retórica persuasiva. Para este autor la nación fue una estrategia para conciliar a las clases heterogéneas que se enfrentaban dentro del Estado, y a su vez sirvió para articular a las burguesías en la disputa contra otros estados. Balibar se ocupa especialmente de la construcción de la subjetividad de lo nacional que «tiene que convertirse en una condición a priori de la comunicación entre los individuos y entre los grupos sociales,

\footnotetext{
${ }^{54}$ Ibidem, p. 128.

${ }^{55}$ Ibidem, p. 125.

${ }^{56}$ BALIBAR, Etienne, «La forma nación: historia e ideología» en BALIBAR, E. y WALLERSTEIN, Immanuel, (eds.) Raza, nación y clase ..., op. cit., pp. 135-136.
} 
no suprimiendo todas las diferencias sino relativizándolas y subordinándolas, de modo que prime la diferencia simbólica entre nosotros y los extranjeros viviéndola como irreductible ${ }^{57}$.

La retórica persuasiva del Estado nacional se obtiene por medio de mecanismos y prácticas cotidianas sometiéndolos a una ley común y a la enseñanza en la escuela. En este sentido el peso específico que tiene la lengua es clave y que «ninguna nación posee naturalmente una base étnica, pero a medida que las formaciones sociales se nacionalizan (...) quedan representadas en el pasado o en el futuro como si formaran una comunidad natural, que posee por sí misma una identidad de origen, de cultura, de intereses, que transciende a los individuos y las condiciones sociales» ${ }^{58}$.

Las explicaciones de la construcción del Estado nacional pasan por la creación de una comunidad nacional igualitaria y por la diferenciación con los otros que no son parte de la agrupación.

Los estados nacionales y la nación han sido también analizado como fenómenos ideológicos con autores que han visto el nacionalismo como una ideología relevando la importancia que tienen las ideas que la sustentan, las clases que la edifican y los mecanismos de difusión. Este es uno de los principales debates entre modernistas y genealogistas, saber si el grupo étnico es un dato o una construcción. Para los modernistas se trata de una construcción y para los segundos un dato objetivo. Entre los autores que han estado trabajando en torno a estos debates están Paul Brass y Elike Kedouri. El primero entiende el nacionalismo como una ideología configurada por las elites que utilizan la lengua y la raza para lograr movilizar a la población alterando sus referentes como consecuencia de la modernidad. El nacionalismo se erige como un excelente vehículo para alcanzar o consolidar el poder de las clases altas con un fin proficiente que «insiste en el uso de símbolos culturales para sí o para los grupos a los

\footnotetext{
${ }^{57}$ Ibidem, p. 147.

${ }^{58}$ Ibidem, p. 147.
} 
que pretende representar» ${ }^{59}$. Y sostiene que la gracia de los que movilizan en nombre de la nación utilizan contenidos simbólicos de la propia comunidad. Esto genera apego primordial a la lengua y otros contenidos culturales. Los apegos junto a las emociones son elementos fácilmente movilizables que es riesgoso «pero realmente importante al que puede recurrirse en el combate contra los que controlan los aparatos burocráticos» ${ }^{60}$. Cuando las elites movilizan a las masas mediante símbolos culturales se establece la identidad étnica y que, por cierto, tiene un carácter cambiante que se va adaptando de acuerdo a las nuevas demandas. Otros ven en la modernización como causante de la erosión de las diferentes etnias. Kedouri es también uno de los principales exponentes del nacionalismo como ideología, especialmente sus trabajos han estado abocados en los nacionalismos asiáticos y africanos. Es en las antiguas colonias donde la difusión del nacionalismo europeo tuvo bastante imitación. En estos espacios, sostiene que el nacionalismo es ideado por las juventudes como reacción a la pérdida de los valores tradicionales por la llegada de las potencias occidentales. La apropiación que hace la juventud de estos países a la idea de nación apela a unos referentes étnicos y ayuda a recobrar la moral tradicional. Plantea que la destrucción de las estructuras sociales tradicionales provoca «una sociedad atomizada que busca en el nacionalismo un sustituto del orden antiguo» ${ }^{61}$. Esto sostiene la idea que la nación satisface una necesidad, pertenecer unidos a una comunidad coherente y estable. En definitiva, el nacionalismo como ideología sostiene que el plantea se divide en naciones y que esas naciones se asemejan por tener características que pueden conocerse y que la única manera de legitimarse es con el autogobierno.

Estas posturas no han estado ajenas a crítica. Walter Connor crítica estas tendencias por menospreciar la importancia del sentimiento nacional y suponer que la lealtad nacional se reemplaza fácilmente por la lealtad al Estado. Plantean una reificación de la nación. Para ello esgrime que un alto porcentaje de estados son multiétnicos, pero con innumerables conflictos nacionales existentes en países como España (vascos, catalanes,

\footnotetext{
${ }^{59}$ Cit. en JAFFRELOT, Christopher, «Los modelos explicativos del origen de las naciones y del nacionalismo. Revisión crítica», en DELANNOI, Gil y TAGUIEFF, Pierre, (comp.) Teorías del nacionalismo, Paidos, Barcelona, 1993, p. 221.

${ }^{60}$ Ibidem, p. 222.

${ }^{61}$ Ibidem, p. 238.
} 
gallegos), Reino Unido (galeses, irlandeses, galeses), Italia (tiroleses) y Bélgica (valones y flamencos). Al respecto señala que «ninguna categoría particular de Estados multiétnicos ha resultado inmune a los efectos disgregadores de la etnicidad: tanto los estados autoritarios como los democráticos, tanto los federales como los unitarios, tanto los asiáticos como los africanos o americanos o europeos se han visto afectados por igual» $^{62}$.

La idea se sustenta en que la nación es un grupo de individuos que dicen tener una ascendencia común y que se autodefine como una comunidad. Esta idea proviene de un sentimiento de identificación que encuentra sus cimientos en la familia y el grupo étnico con un alto componente emotivo señalando que «la esencia de la nación no es tangible sino sicológica. Es una cuestión de actitudes y no de hechos» ${ }^{63}$. La forma del vínculo entre nación y sujeto es la distinción entre los pueblos y es su principal atributo «es el vínculo sicológico que une a un pueblo $\mathrm{y}$, en la convicción subconsciente de sus miembros, lo distingue de una forma decisiva del resto de la humanidad ${ }^{64}$. Connor se ha manifestado en contra de las tesis economicistas de la constitución del nacionalismo y sostiene que es un tema de conciencia la pertenencia a una nación y es lapidario en afirmar que el atributo de la nación «es una cuestión de autopercepción y de autoconciencia» $^{65}$.

Es lo emocional lo que relevado Connor junto a los sentimientos étnicos lo que fija lo nacional. Para un mejor estudio de estos temas propone que se analice en la constitución de los Estados Nacionales la iconografía, los discurso, la poesía, la propaganda, ya que en ellos se encontrarán las emociones nacionales. La formalización de Connor de la concientización de lo étnico cuando un grupo comparte algo en común y se autoidentifica en reacción a otros es que «establece entre ellos un vínculo psicológico caracterizado por un sentimiento de similitud y de unidad, una sensación de pertenecer a

\footnotetext{
${ }^{62}$ Etnonacionalismo, Madrid, Editorial Trama, 1998, p. 40.

${ }^{63}$ Ibidem, p. 45.

${ }^{64}$ Ibidem, p. 185.

${ }^{65}$ Ibidem, p. 233.
} 
la misma parentela» ${ }^{66}$. El autor subraya que las etnias no son naciones en estado inmanente, sino que culminación de un ciclo, cuya génesis está en la etnia y el catalizador en los contactos culturales.

La nación entendida como una realidad perenne, pero con un componente esencial de construcción remite a dos autores: Anthony Smith y Liah Greenfeld. Smith plantea la continuidad entre la identificación étnica e identidad nacional y señala que de manera muy sugestiva la primera incide sobre la segunda. Clasificó las comunidades étnicas en virtud de la trayectoria que siguen para constituirse en nación. A unas las denominó etnias laterales que son aquellas que habrían transitado hacia formas cívico territoriales de nación con la construcción de los estados modernos contando con el apoyo de la Iglesia. A unas segundas las denominó etnias verticales que ante el cometido expansionista de las primeras habrían desarrollado un fuerte nacionalismo y de las manos de las elites habrían construido naciones étnicas ${ }^{67}$.

En el modelo de Smith, las etnias devengaron en estados nacionales de forma espontánea, producto del cruce fortuito de «fuerzas históricas en el que concurren el desarrollo del capitalismo, la secularización y desde luego la construcción del Estado moderno» ${ }^{68}$. El elemento clave es el Estado moderno que actúo por intermedio de la burocracia. Smith reconoce modalidades cívicas y étnicas en la configuración de la nación, los Estados modernos y el nacionalismo. Mientras las etnias verticales se desplegaron en movimientos anticolonialistas e integradores las etnias laterales se configuraron en movimientos secesionistas. El argumento es que la nación moderna necesita preservar y cuidar los elementos de su herencia étnica premoderna, esto es «construcción en que la historia compartida, los recuerdos de un pasado común y de una cultura subjetivamente unificada,» ${ }^{69}$ juegan un papel fundamental y se constituye en datos primordiales.

\footnotetext{
${ }^{66}$ Cit. en JAFFRELOT, C. «Los modelos explicativos del origen de las naciones y del nacionalismo ... cap. cit. en DELANNOI, G. y TAGUIEFF, P. (comp.) Teorías del nacionalismo..., op. cit., p, 234.

${ }^{67}$ Vid. SMITH, Anthony, La identidad Nacional, Madrid, Trama, 1997.

${ }^{68}$ CALDERON, María Teresa, «Los términos del debate contemporáneo en torno a la nación», Revista de Estudios Sociales, №12 (2002), p. 84.

${ }^{69}$ Ibidem, p. 85.
} 
Anthony Smith es un autor que ha puesto mucho énfasis en las inteligencias como catalizadoras del nacionalismo frente al acosos de las burocracias obligándolas a volver a lo étnico para buscar una nueva legitimación que las hiciera volver al poder. Su preocupación del nacionalismo como fenómeno ideológico y producto de la modernidad coadyuvaron a la explicación que la nación y el Estado moderno son el resultado histórico de la confluencia de nacionalismo y etnocentrismo. En esta perspectiva constructivista pone énfasis en la etnia como cimiento del relato nacional caracterizándolas como «poblaciones humanas dotadas de nombre que comparten mitos sagrados sobre ancestros, historias y culturas que mantienen una asociación con un territorio especifico y un sentido de solidaridad» ${ }^{70}$. La utilización de los mitos y símbolos por la elite son la fuerza de los Estados nacionales y del nacionalismo.

En una perspectiva que se aparta de la idea de comprender la nación y el nacionalismo como productos de la modernidad, la historiadora Liah Greenfeld sostiene que la desviación de la nación, el nacionalismo, es un componente de la modernidad. Define que la relación entre sujeto y Estado nacional produce una identidad del individuo en un pueblo nacional que es visto como el portador de la soberanía, el centro de la lealtad y la base de la solidaridad comunitaria. Ese pueblo se representa como un todo homogéneo que tan sólo está dividido por clases, status, ubicación territorial, pero que estas divisiones poseen un valor secundario, lo importante y primordial es presentarse como un pueblo soberano y una comunidad de iguales. Esta autora ubica el origen del concepto de nación en la Inglaterra del siglo XVI y que desde allí se habría remitido al mundo. En el contexto de la Guerra de las Rosas que eliminó a la antigua nobleza reemplazada por una nueva nobleza integrada por funcionarios fieles a la Corona. Como su condición dependía fuertemente de la voluntad de la corona y ante el riesgo de perderla habrían inventado el concepto igualitarista de nación. De allí en adelante las elites lograron asumir la soberanía en nombre de todos con una condición democratizadora e inclusiva ya que «la adopción de la idea de nación, implicó la elevación simbólica del pueblo, y por lo tanto la creación de un nuevo orden social y

\footnotetext{
${ }^{70}$ SMITH, Anthony, Nacionalismo y modernidad, Madrid, ISTMO, 2000, p. 336.
} 
una nueva estructura» ${ }^{71}$. Esto permitió unir el viejo concepto de nación de las elites representadas en Inglaterra con el concepto de pueblo de las clases bajas.

Greenfeld plantea que la construcción de la nación se realiza en tres etapas «la etapa estructural, la cultural y el resentimiento» ${ }^{72}$. En la primera fase, un grupo descontento con sus status elabora la nación y sus componentes como un dispositivo. Esta situación genera un estado de desorden por la inseguridad no prevista. En la etapa cultural, los intelectuales resignifican ideas, inventan tradiciones e identidades pre nacionales para construir el concepto de nación. En la etapa de resentimiento las ideas de la etapa anterior alcanzan mayor solidez generando un cambio en los valores y cosmovisión. En esta última, el resentimiento puede ser provocado por cuestiones internas o agentes externos. Esa animadversión se transforma en desprecio y en la generación de una situación histórica del «sin retorno». Para Greenfeld todo esto deriva en nacionalismo, que es la base del mundo moderno, el nacionalismo construye y robustece al Estado. No siendo el nacionalismo un tema de esta tesis, hemos incorporado a esta autora por la forma en que plantea la generación de la nación y como modelo genuino para la constitución de los Estados Nacionales.

\subsection{Visiones postmodernas y recientes}

La perspectiva postmoderna desde la década de 1990 se ha convertido en predominante en las esferas intelectuales europeas y como es natural no proponen una teoría general sobre el nacionalismo, sino que más bien advierten sobre problemas culturales y políticos muy concretos de la constitución de la nación y de los estados nacionales. Entre los problemas asociados a la cuestión nacional encontramos: la existencia de los estados poli-étnicos, la desintegración de la unidad nacional y el multiculturalismo, cuestiones de género y conformación de la nación, la globalización, lo supranacional y

\footnotetext{
${ }^{71}$ GREENFELD, Liah, «Nationalism and Agression», Theory and Society, No 23 (1994) p.82.

${ }^{72}$ MARQUEZ, Martha, «Perspectivas teóricas para abordar la nación y el nacionalismo», Papel Político, vol. 16, No 2 (2011), p. 590.
} 
la identidad nacional, el rol de los grupos subalternos en la conformación del Estado nacional, la forma en que se vive lo nacional, etc.

Una de las principales críticas es acerca de la artificialidad atribuida a la nación, porque constituye una sobredimensión de la capacidad de la elite de manipular tanto los procesos históricos, como los sentimientos espontáneamente generados por la comunidad nacional, al tiempo que un desconocimiento de los factores objetivos que generan un sentimiento de pertenencia e identidad, como la etnia y la experiencia común otorgada en un suelo determinado.

Desde lo posmoderno, el problema principal, radica en descubrir los alcances o las fronteras que posee el concepto de nación dentro de una propia comunidad nacional. La historia como saber definido desde el siglo XIX suscribió tempranamente la tarea de convertirse en la responsable de darle vida al pasado o mejor dicho de narrar el pasado tal y como este se supone había acontecido. Los estudios sobre nación y narración de Homi K. Bhabha -como luego veremos- son dignos de destacar. Los relatos fueron requeridos para dar al orden emergente y proporcionar a sus gobernantes de la consagración de sacramental de la legitimidad de su accionar. Es por ello que el Estado moderno idealizó las relaciones sociales de un modo tradicional: origen común, pertenencia, disposición a defenderla y preservarla. Los aspectos retóricos mostraron una historia como la realidad vivida del pasado, ficcionaron el pasado con tal grado de justificación que incluso llegaron a plantear la idea que por la patria se debía hacer cualquier sacrificio. La nación, según Bhabha, es una imposición, fruto de las relaciones temporales, de modos de narrar la historia, y el pasado es una fuente de ejemplos pedagógicos del ser nacional Al respecto afirma que «el lenguaje de la cultura y la comunidad está equilibrado sobre las fisuras del presente transformándose en las figuras retóricas de un pasado nacional» ${ }^{73}$. Considera que las narraciones del pasado son formas de escrituras especiales para entender las torsiones entre pasado y presente.

\footnotetext{
${ }^{73}$ El lugar de la cultura, Buenos Aires, Manantial, 2002, p. 178.
} 
Un segundo aspecto tratado por Bhabha tiene que ver con la homogeneidad nacional y como los otros son integrados a esta concepción de uniformidad de la comunidad nacional. Lo plantea como un conflicto ya que «el otro nunca está fuera o más allá de nosotros; surge con fuerza dentro del discurso cultural cuando pensamos que hablamos, de la manera más íntima y natural, entre nosotros» ${ }^{74}$. La tensión está entre las diversas agrupaciones que se ven incluidas en los valores e identidad nacional frente a aquellas que no se ven representadas en esta, como pudieran ser etnias minoritarias, colectividades migrantes, regionalismos, comunidades religiosas o incluso clases sociales consideradas muy vinculadas a aspectos o valores extranjeros. La pregunta fundamental radica en establecer cómo la diversidad convive en la identidad nacional, identificando las influencias reciprocas en este proceso, al tiempo de los criterios de exclusión e inclusión en el mismo. Asegura que en los momentos de crisis «la historia y su narrativa es inoperante ya que no es posible trascender o superar dialécticamente las fuerzas del antagonismo o la contradicción social» ${ }^{75}$. Por lo tanto, el discurso de la homogeneidad ha sido retórico y que la historia se desarrolla en otro tiempo, el de la vida cotidiana y que la nación se construye toda vez que se invoca, y esa invocación es un acto preformativo.

Homi Bhabha identifica en la generación del concepto nación dos momentos que permiten su construcción y sociabilización. La primera es la denominada preformativo, entendida como la existencia de aspectos objetivos y originales que posibilitan una identidad dentro de la comunidad (etnia, suelo, valores consustanciales a la nación, experiencia histórica, etc.). Las elites necesitan de criterios objetivos que permitan una vinculación entre la comunidad para construir un concepto de nación. Señala que las elites se limitan a intentar manipular aspectos preexistentes en la comunidad, significándolos, promoviéndolos o atenuándolos, pero resulta totalmente infructuoso inventar tradiciones cual si fueran tabula rasa. Este intento de moldear las condiciones objetivas preexistentes es lo que denomina Bhabha como la etapa pedagógica de la construcción de la nación. Cuando existe una descoordinación de estos elementos

\footnotetext{
${ }^{74}$ Nación y narración. Entre la ilusión de una identidad y las diferencias culturales, Buenos Aires, Editorial Siglo XXI, 2010, p. 16.

${ }^{75}$ Ibidem, p. 45.
} 
surgen momentos críticos entre los sujetos de un mismo Estado nacional ya que estos pueden ser «tanto actos de adhesión y establecimiento, como momentos de repudio, desplazamiento, exclusión e impugnación cultural» ${ }^{76}$ en la pretendida homogeneidad impulsada por la clase dirigente. Pone en discusión el concepto de nación en tanto es «una representación cuya compulsión cultural reside en la unidad imposible de la nación como fuerza simbólica» ${ }^{77}$.

Otra visión de la posmodernidad es proporcionada por Partha Chatterjee quien frente a las incertidumbres propias de la modernidad y su posición crítica ante el sistema liberal democrático cuestiona la concepción lineal de la vida moderna como un tiempo homogéneo vacío, criticando que la formación de las naciones se habría generado por la existencia de múltiples artefactos que harían a los sujetos vivir en un tiempo homogéneo dentro de una comunidad. Para Chatterjee no hay una coexistencia de un solo tiempo, sino que realidades heterogéneas y fragmentadas y con esto critica que el Estado sea el constructor de la nación. Estima, al menos, que, en las sociedades poscoloniales, la nación y el nacionalismo se configuraron en forma muy diferente a occidente. Todos los conceptos que acompañan a las sociedades modernas como: nación, ciudadanía, democracia, sociedad civil se desarrollaron en esas sociedades poscoloniales sin tener referentes autóctonos. Esto implica un divorcio entre sociedad y Estado vínculo vigente hasta hoy en día. El proceso histórico se ha llevado a cabo no confrontado sociedad y Estado, sino que se ha desarrollado por la emergencia de otros espacios de acuerdo, por ello es que los Estados nacionales se configuraron en el mundo poscolonial «por un lado, en el espacio definido por el proyecto hegemónico de la modernidad nacionalista, $\mathrm{y}$ por el otro, en las innumerables resistencias fragmentadas hacia ese proyecto normalizado»» ${ }^{78}$.

Apreciando las tres formas de estudio -genealógico, modernistas y postmodernistaspodemos verificar la gran flexibilidad que ha caracterizado la construcción del concepto

\footnotetext{
${ }^{76}$ Ibidem, p. 46

${ }^{77}$ Ibidem, p. 11.

${ }^{78}$ CHATTERJEE, Partha, La nación en tiempo heterogéneo y otros estudios subalternos, Buenos Aires, Siglo XXI, 2008, p. 104.
} 
de nación a lo largo de su historia. Se podría señalar que una de las esencias del concepto de nación en la construcción del Estado nacional ha sido históricamente su adaptación a diversos proyectos políticos. En su trayectoria podemos ver cómo fue instrumentalizado para la independencia y construcción de los estados a lo largo de todo el siglo XIX y XX; cómo fue movilizado para alcanzar homogeneidad social o proyectos de industrialización y consolidación del mercado nacional de estados de las más diversas improntas ideológicas a lo largo de todo el siglo XX; y como actualmente, gracias a los estudios más recientes, ha sido utilizado para identificar las fronteras, y por ende, demostrar la diversidad existente dentro de los mismos estados nacionales. Quizás esta maleabilidad sea una de las razones del éxito del concepto de nación a pesar de su relativa corta historia, pero al mismo tiempo, esta naturaleza polisémica ha generado una gran dificultad a la hora de definir, conceptualizar y estudiar el concepto de nación hasta nuestros días.

En este sentido cobra relevancia la dimensión de sostener que lo nacional se estableció como una ideología desarrollada por las elites y «fundamentalmente un principio político que sostiene que debe haber congruencia entre la unidad nacional y política» ${ }^{79}$. La importancia del nacionalismo tiene estrecha vinculación con la consolidación de los estados nacionales al proporcionarle un sustento social con instrumentalización política.

\subsection{Visión de la construcción del Estado nacional chileno en el sigo XIX}

Para el mundo europeo, las teorías sobre las naciones y el nacionalismo pueden identificarse desde las distintas variables para explicar el origen de la nación: tiempo, naturaleza, causas, y función de la nación. Los análisis más recientes han abordado estas variables de formas distintas: la cuestión de la temporalidad ha dejado de ser la discusión del origen moderno para convertirse en la cuestión de la temporalidad de los relatos y de las diferencias de temporalidad entre el primer y tercer mundo. En los asuntos de la naturaleza de la nación, las visiones actuales tienden a ser constructivistas

\footnotetext{
${ }^{79}$ GELLNER, E. Naciones y nacionalismo..., op. cit., p. 29.
} 
y señalan que la nación se construye desde distintos fragmentos de memoria y relatos, y desde las múltiples resistencias a la discriminación.

Nicola Miller explica los desafíos actuales del estudio del concepto de nación en un contexto latinoamericano. Miller señala que tanto la perspectiva genealógica como antigenealógica poseen limitaciones importantes en su aplicación, ya que ambas, se pueden aplicar sólo parcialmente en la región. Identifica tres diferencias o aspectos a considerar en relativas al rol del Estado, la falta de homogeneidad étnica, y el rol de la Hispanidad en la configuración de los Estados nacionales. Establece que para la mayoría de las comunidades nacionales existía desde la colonia una conciencia de su singularidad e identidad, antes incluso de alcanzada la emancipación y conformado la institucionalidad del Estado, por lo que la historiografía sobredimensiona esta supuesta «invención de la tradición» o la subordinación de ella a la preexistencia de la institucionalidad política. Por otra parte, hay que advertir las condiciones materiales efectivas en la conformación del «imaginario nacional», al ser más fácil realizarlo en estados exitosos y estables que en aquellos afectados por guerras civiles características del siglo XIX en la región. En la etnicidad reconoce la intención de proyectos nacionales de integrar las distintas colectividades étnicas y regionalismos existentes en un solo discurso, enfatizando la búsqueda por plasmar una visión que establezca la unidad de ellas en base a un propósito histórico común enmarcado en la república y la independencia. Este esfuerzo es dual, ya que tiende al reconocimiento de las virtudes específicas de las distintas comunidades que se integran al Estado, exaltándolas en la narración y construcción de esta «nación común».

La visión del «otro», desempeña un rol primordial como contrapunto a la hora de afianzar el propio proyecto nacional. En este sentido, Miller argumenta que las fronteras de la comunidad son bastantes más tenues en Latinoamérica que en otras regiones debido a la Hispanidad, entendida como el legado: en religión, lengua, etnia y experiencia histórica producto del pasado colonial del cual emergieron todos los estados nacionales. Sin embargo, esto no significó que no se intentara diferenciar estos aspectos, especialmente en la lengua con la pretensión de originalidad argumentada en gran parte 
del siglo XIX e inicios del XX para comprobar las particularidades de la forma en que la lengua española se asumió en cada uno de los lugares de América. Esto lleva a Nicola Miller a indicar que la construcción de la nación en la «experiencia latinoamericana no fue ni basada en la imitación ni en la construcción de modelos propios, esto significa que las identidades nacionales siempre han sido variadas, siendo creadas y recreadas en un proceso continuo de negociaciones y renegociación con tanto los otros fuera, como con los otros dentro del Estado» ${ }^{80}$.

El concepto de nación en América Latina tiene características de maleabilidad, plasticidad y capacidad de adaptación a distintos fenómenos o elementos asumidos como exógenos a la nación. Es pertinente advertir que el concepto de nacionalismo deriva de una construcción particular de la nación. El aspecto más relevante es considerar que la nación y el nacionalismo han sido el instrumento político para producir cohesión ideológica y que la acción del Estado fue el ente clave para la construcción de la nación.

Es por todos conocidos que las unidades políticas con fronteras culturales fue una realidad en América latina desde la segunda mitad del siglo XIX. La formación de los estados nacionales en América Latina no tiene que ver con la idea previa de la toma de conciencia nacional, ya que, por entonces, «no existían nacionalidades diferentes con identidades étnicamente definidas, sino una sola -la española- en gran parte común a todos los actores americanos y españoles: cuando más dos: la española y la americana ${ }^{81}$. En el proceso de desintegración del Imperio español se evidenciaron ciertas identidades culturales que se originaban en los tiempos coloniales como la Virgen de Guadalupe en México, la resistencia mapuche en Chile, los incas en Perú, etc. El enaltecimiento de lo indígena, la nacionalización progresiva del territorio, las peticiones de nombramiento de autoridades americanas en los cargos políticos, la posibilidad de explotar las riquezas naturales, el amor a la patria. Son estas razones las

\footnotetext{
${ }^{80}$ «Historiography of nationalism and national identy in Latin America» en Nation and nationalism, vol. 12, $\mathrm{N}^{\mathrm{o}} 2$ (2006), p. 217.

${ }^{81}$ KÖNING, Hans-Joachim, «Discursos de identidad, Estado-nación y ciudadanía en América Latina: viejos problemas-nuevos enfoques y dimensiones», Historia y Sociedad, No11 (2011) p. 13.
} 
que llevaban a la elite a apelar a un patriotismo que sea capaz de construir un Estado propio. La construcción de los Estados nacionales en América Latina debía superar el status colonial y «crear por medio de un imaginario adecuado en la población un sentido de identificación con y lealtad frente a las nuevas entidades» ${ }^{82}$. Las elites eligieron los postulados del liberalismo como aspectos centrales de la configuración de los nuevos Estados acompañados de al menos un discurso integrador. Estos discursos solidarios con la opresión que había sufrido el indio o el afrodescendiente sirvió para cimentar la apología de la libertad y la autonomía. Como liberales, apuntaban a la igualdad política como rasgo característico demostrando que la pertenencia étnica, cultural y regional en los nuevos Estados no significaba desigualdad como en el pasado colonial. Es por ello, que el Estado se sustentó en criterios políticos y no culturales.

Al analizar la formación de los estados latinoamericanos a principios del siglo XIX existe consenso que fueron producto de entidades preestablecidas y que fue un proyecto político generado y conducido por ciertos grupos sociales y políticos. Un segundo consenso en la historiografía es que en la fase de independencia y en las etapas posteriores, el Estado precedió a la nación. Debemos subrayar que a inicios del siglo XIX la construcción de los estados nacionales son los primeros intentos por establecer naciones o estados y eran paralelos a los de Europa e incluso anteriores, el propio Anderson advierte que «el final de la época de movimientos de liberación nacional, exitosos en las Américas, coincidió más o menos con el comienzo de la época del nacionalismo en Europa» ${ }^{83}$. Probablemente no fueron estados exitosos al construirse con cimientes políticos sin consideración las cuestiones sociales y étnicas. Fueron poco exitosos, en general, en fomentar la integración política y social que requería la nueva realidad. En el sentido social seguía predominando una estructura jerárquica caracterizad por la desigualdad de la riqueza; y lo que demandaba la nueva estructura era una ciudadanía incluyente. A lo largo del siglo XIX los estados nacionales se dieron a la tarea de promover el dificultoso camino de convertirse en naciones.

\footnotetext{
${ }^{82}$ Ibidem, p. 17.

${ }^{83}$ Comunidades imaginadas. Reflexiones ..., op. cit., p. 102.
} 
La generación de diferentes proyectos políticos para la construcción de los estados nacionales provino desde las elites políticas que intentaron realizar o imponer un proyecto nacional. Frente a las exigencias de lograr la homogeneidad en poblaciones dispersas y heterogéneas, las elites se sirvieron de símbolos cívicos y del aparato educativo para alcanzar dichos objetivos. A ello debemos agregar la narrativa literaria e histórica como estimulantes de la identidad nacional, inventando tradiciones, memorias y mitos fundacionales. La mayor parte de los estados nacionales latinoamericanos coinciden en la Independencia como el hecho fundante y el punto de partida.

Entre los más importantes trabajos acerca del fenómeno del nacionalismo, América Latina ha sido considerada como una rareza y por lo general ignorada. Siempre relegada a una nota de pie. Uno de los más importantes teóricos del nacionalismo, Benedict Anderson, ha argumentado que las naciones latinoamericanas se formaron con antelación al período de la independencia por medio de dos procesos: por el peregrinaje administrativo de los funcionarios de la corona y la labor de los editores de los periódicos criollos. La historiadora británica Nicola Miller es extremadamente lapidaria en la explicación de la ausencia de investigaciones de estos tópicos en América: «América siempre ha sido una anomalía en la historia del nacionalismo. A falta de las distinciones lingüísticas y étnicas comúnmente asociados con las identidades nacionales en Europa o Asia, que carecen de un proceso seguro de consolidación del Estado, y que carecen, también, el éxito económico de los Estados Unidos y Canadá, las antiguas colonias americanas de España y Portugal han sido por lo general considerado como naciones incompletas en el mejor de los casos.» ${ }^{84}$

Con todo, el asunto es que el debate sobre el nacionalismo ha dejado al margen a América Latina, lo cual no quiere decir que la historiografía americanista se haya mantenido fuera del debate sobre la nación y el nacionalismo. Debemos destacar cada vez más, una interesante labor historiográfica sobre el nacionalismo y diversos aspectos de la construcción de las identidades nacionales en América Latina.

\footnotetext{
${ }^{84}$ "The historiography of nationalism and national identity ...», art. cit., p. 102.
} 
En el contexto latinoamericano, ya Anderson revelaba el papel precursor que la experiencia nacionalista habría jugado en la conformación o fundación de los estados modernos latinoamericanos, especialmente por parte de la elite, en un enfoque esquemático que vislumbraba a la nación como un proyecto deliberadamente creado, como parte de una construcción política y cultural ideada de antemano ${ }^{85}$. En este sentido han aparecido una serie de trabajos volcados hacia la invención de las naciones en los procesos independentistas de comienzos del siglo XIX. También ha surgido la veta más relevante para la realidad latinoamericana: el juego entre proyectos nacionales articulados por elites modernizadoras y europeizantes y las lealtades étnicas y culturales sustentadas por las mayorías populares de esos mismos países, retratado por autores como Nancy Appelbaum, Anne S. Macpherson y Karin Rosemblatt, en la obra Race and Nation in Modern Latin America ${ }^{86}$. Así, actualmente ningún país latinoamericano ha dejado de estudiar su propia formación nacional decimonónica, incluyendo, de paso, las tensiones étnicas, sociales, culturales que dichos procesos conllevan naturalmente.

Podemos señalar que, en América Latina, el examen de las ideas asociadas al Estado nacional y a la nación fueron desarrollados con gran profundidad con el advenimiento de los gobiernos democráticos en la década de 1990 y la caída de varias dictaduras militares en la región. Es así que autores como François-Xavier Guerra, Mónica Quijada, José Carlos Chiaramonte, David Brading y Hans Köning realizaron importantes trabajos sobre las ideas relacionadas con el concepto de nación en la transición del siglo XVIII al XIX ${ }^{87}$. Otros trabajos han abordado la importancia de la educación, los militares, las fiestas cívicas en la propagación de lo nacional, investigando además el papel de la prensa, las artes y la literatura como corolario de las identidades nacionales. Desde propuestas de historia conceptual se ha investigado en los

\footnotetext{
${ }^{85}$ Cfr. Comunidades imaginadas. Reflexiones ..., op., cit. pp. 92-93.

${ }^{86} \mathrm{Vid}$. APPELBAUM, Nancy; MACPHERSON, Anne y ROSEMBLAT, Karin, Race and Nation in Modern Latin America, North Carolina, The University of North Carolina Press, 2003.

87 Vid. GUERRA, François-Xavier y QUIJADA, Mónica (coords.), Cuadernos de Historia Latinoamericana. Imaginar la Nación, Hamburgo, Lit. Verlag, 1994; CHIARAMONTE, José Carlos, Ciudades, provincias, Estados: orígenes de la nación argentina, 1800-1846, Buenos Aires, Ariel, 1997; BRADING, David, Los orígenes del nacionalismo mexicano, México, Erac, 1980; KÖNING, HansJoachim, En el camino hacia la nación. Nacionalismo en el proceso de formación del Estado y de la nación de la Nueva Granada, Bogotá, Banco de la República, 1994.
} 
últimos años, asociados al concepto de nación, como revolución, ciudadanía, grupos subalternos y pueblo ${ }^{88}$.

Los Estados nacionales que se desprendieron del imperio español han sido últimamente recogidos en el debate internacional acerca del nacionalismo, y Chile en particular, ha comenzado a estar presente en la discusión, es así que examinaremos algunos rasgos centrales de la producción historiográfica relativa al fenómeno de la nación y del nacionalismo en Chile durante el siglo XIX.

La forma genealógica de concebir la identidad nacional también tuvo sus representantes en Chile, particularmente a fines de siglo XIX e inicios del XX, donde los elementos primordialistas fueron adaptados como criterios de juicio para fundamentar una nación chilena definida y diferenciada del resto de Sudamérica. El ejemplo más elocuente de esta perspectiva lo constituyen las obras de Nicolás Palacios, quien en Raza Chilena. Libro escrito por un chileno y para los chilenos, en donde exaltó las virtudes del pueblo chileno, al que consideraba una raza superior, y criticó la falta de espíritu nacional de la elite dirigente, que había entregado el control de la economía a monopolios extranjeros. Además, en este escrito pseudoantropológico e histórico pretendía comprobar cómo el chileno posee un origen étnico único, al estar formada por la mezcla de dos razas patriarcales asegurando que evidentemente «los godos y los araucanos, tan diferentes en su aspecto físico, poseían ambos, con la misma nitidez y fijeza, todos los rasgos característicos de lo que los entendidos llaman sicología varonil $(\ldots) »^{89}$. Esto era clave en el relato de Palacios, ya que dotaba al chileno de valores y una composición propia de un pueblo conquistador, gracias a que el godo que emigró a Chile, al último reino y

\footnotetext{
${ }^{88}$ Vid. SABATO, Hilda, (Coord.), Ciudadanía politica y formación de las naciones. Perspectivas históricas desde América Latina, México, FCE-El Colegio de México, 1999; BERTONI, Lilia Ana, Patriotas, cosmopolitas y nacionalistas. La construcción de la nacionalidad argentina a fines del siglo $X I X$, Buenos Aires, Fondo de Cultura Económica, 2001; ROCKWELL, Elsie, Hacer escuela, hacer Estado. La educación posrevolucionaria vista desde Tlaxcala, México, Colegio de Michoacán, Centro de Investigaciones y Estudios Superiores en Antropología Social -CIESAS- y Centro de Investigación y de Estudios Avanzados, 2007; MURILO DE CARVALHO, José, A formação das almas: O imaginário da República no Brasil, São Paulo, Companhia das letras, 1995; TENORIO, Manuel, Artilugio de la nación moderna. México en las exposiciones universales, 1880-1930, México, Fondo de Cultura Económica, 1998.

${ }^{89}$ Raza Chilena. Libro escrito por un chileno y para los chilenos, Santiago, Editorial chilena, 1918, p. 36.
} 
al más pobre de América, no vino con otro afán que combatir al indígena, un aborigen, como el mapuche, que nunca fue conquistado. Esto otorgaba al chileno una solidez de carácter único ya que:

«(...) la fisonomía moral presenta tal uniformidad en sus líneas principales, que este es uno de los fenómenos más interesantes de nuestra raza...todos sentimos y pensamos de idéntica manera en las cuestiones cardinales, sobre las que se apoyan y giran todos los demás referentes a la familia, a la patria, a los deberes morales o cívicos: es un mismo nuestro criterio moral y social.» ${ }^{90}$

Para Nicolás Palacios se trataba de conservar los valores de la raza, de tal modo que se fortaleciera una fisonomía moral estable, que se expresara en «en un pueblo fuerte, trabajador, industrial, osado, que proyecte su espíritu guerrero en el mundo moderno» ${ }^{91}$. El libro de Palacios asimila el concepto de raza chilena al de nación y establece una serie de representaciones y oposiciones binarias de patriarcado y matriarcado como, por ejemplo: industria-comercio, patria-humanidad, militares-letrados, etc. Más evidente y preclaro es cuando señala que «el padre de la raza es el conquistador godo (...) descendientes de aquellos barbaros rubios y guerreros que (...) destruyeron el Imperio Romano (...) más tarde invadieron España de donde partieron a la conquista de Chile» ${ }^{92}$. Así, el propio Palacios en su libro ya citado destaca el rol femenino indicando que «la madre de la raza es la araucana, hija de la tierra (...) botín preciado del conquistador [la mujer] en aquella lucha secular y homérica en la cual el araucano defendió sus lares (...) de la conjunción de esas razas nació la raza chilena mestiza, que deben haber nacido todos los grupos humanos llamados razas históricas» ${ }^{93}$.

Lo que realizó Palacios fue ampliar la trama nacionalista hacia la raza que se convirtió en un discurso compartido. La idea de la raza chilena fue adoptada de forma rápida, ya que integra a sectores excluidos, inventa una tradición que ayuda al mito de la excepcionalidad chilena. La matriz nacionalista es anti-liberal, y por esta razón genera una idea de ciudanía étnico-cultural más extensa que la ciudadanía política de molde

\footnotetext{
${ }^{90}$ Ibidem, p. 37.

${ }^{91}$ Cit. en SUBERCASEUX, Bernardo, «Raza y nación: el caso de Chile», A contra corriente, vol. 5 No 1 (2007), p. 46.

${ }^{92}$ PALACIOS, N., Raza Chilena. Libro escrito por un chileno..., op. cit., p. 26.

${ }^{93}$ Ibidem, p. 22.
} 
liberal. Es un discurso que apela a la unidad nacional dentro de la integración racial y que funciona al alero de la homogeneidad pretendida del Estado nacional y por cierto del ideario de la nación.

En las primeras décadas del siglo XX la equivalencia entre unidad nacional e integración en la raza chilena formó parte de un discurso predominante a propósito de escritores, políticos, militares; y por cierto intelectuales. Junto a Nicolás Palacios está Luis Orrego Luco, quien valorizaba los primeros años de la República porque habían:

\begin{abstract}
«(...) apreciado las condiciones históricas de una raza, heredadas en doscientos años de colonia...y comprendía lo prematuro de un liberalismo que pretendía, saltando por encima de las costumbres, de las ideas, de las tradiciones y del modo de ser, implantar un sistema de gobierno ampliamente democrático en un país en que muy pocos sabían leer, y nadie comprendía la noción elemental de sus derechos.» ${ }^{94}$
\end{abstract}

La razón política que los sistemas liberales eran ajenos a la raza chilena, fue una constante entre los escritos de principios del siglo XX. Incluso hubo referencia en este sentido de algunos extranjeros que fueron contratados por el Estado chileno, Eduardo Pourier refiere ante la idea de la raza chilena que es «una singular fusión de las excelencias del alma latina con el espíritu práctico y expeditivo del carácter sajón (...)» ${ }^{95}$. Un militar español en 1911 indica que «la raza chilena es la fusión de indígenas con españoles (...) el producto de la raza araucana con la gótica, en cuya fisonomía se muestran caracteres especiales de ambas razas» ${ }^{96}$. El concepto de raza y de los planteamientos de Palacios parecen formar parte del espíritu de la época. No cabe duda que estas ideas circularon en el Chile del Centenario, período salpicado de imágenes críticas, a pesar de los avances del siglo, no se puede ignorar la realidad que vivía el país. Por un lado, la opulencia de la clase dirigente se hacía notar por medio de costumbres basadas en las influencias europeas, sobre todo francesas e inglesas expresadas en términos del vestuario, la construcción de palacios, etc. Por otra parte, se evidenciaba la paupérrima situación social de las clases más bajas con nulo acceso a tal

\footnotetext{
${ }^{94}$ Chile contemporáneo, Santiago, Imprenta Cervantes, 1904, p. 125.

${ }^{95}$ Cit. en SUBERCASEUX, Bernardo, Historia de las ideas y de la Cultura en Chile. Tomo IV. Nacionalismo y cultura, Santiago, Ed. Universitaria, 2007, p. 94.

${ }^{96}$ Ibidem, p. 95.
} 
cultura urbana, por lo que su presencia en la ciudad se veía marcada por la construcción de ranchos, conventillos, cuartos redondos, cuyos principales problemas eran el hacinamiento y la insalubridad. Al mismo tiempo, hay una situación de pobreza extrema en gran parte de la población. En este panorama de desconcierto, emergen estas ideas de la nación y de las razones de la debilidad, precariedad e inviabilidad del Estado nacional. Las explicaciones raciales y su degeneración son un ambiente propicio para explicaciones e interpretaciones de raigambre nacionalista. Estas explicaciones genealogistas fueron pensadas sobre elementos que se remontan al pasado y que se construye sobre vínculos fundamentales para el ser humano como raza, sangre y familia.

La crítica nacionalista de Palacios fue retomada poco después por el periodista Tancredo Pinochet, que en 1909 publicó el ensayo La conquista de Chile en el siglo XX, en donde denunciaba la extranjerización de la economía y la falta de sensibilidad social de la elite. Refiriéndose a esta situación que en el pasado a Chile había sido conquistado «no ya con arcabuces y culebrinas, las armas de entonces, sino con trabajo y capital, las armas de ahora ${ }^{97}$. Tres años después, Francisco Antonio Encina escribió su ensayo Nuestra inferioridad económica, en donde criticó el estilo suntuario y ocioso de la elite chilena. Encina realizó una severa crítica al sistema educacional, orientado a las profesiones liberales, en desmedro de la enseñanza técnica. Entre las razones de la degeneración y crisis del Chile del Centenario vuelve sobre el tema de la raza al insinuar que:

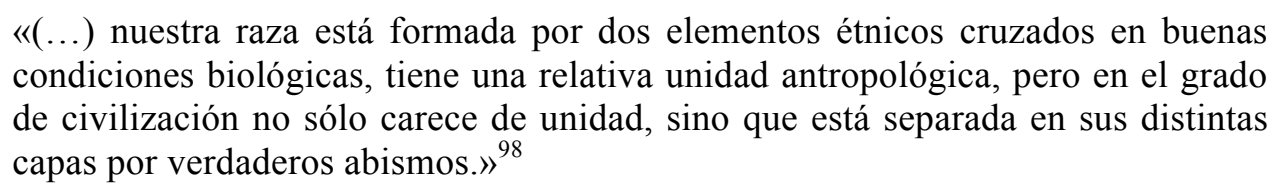

En el contexto del Centenario de la independencia, Palacios, Pinochet y Encina percibieron signos de crisis por el afrancesamiento de las costumbres, el deterioro de la

\footnotetext{
${ }^{97}$ La Conquista de Chile en el siglo XX, Santiago, Imprenta La Ilustración, 1909, p.140.

${ }^{98}$ Nuestra inferioridad económica, sus causas, sus consecuencias, Santiago, Imprenta Universitaria, 1912, p. 130.
} 
clase dirigente y la perdida generalizada de la austeridad. Todo esto redundaba en una depreciación del ser nacional y con estos principios elaboraron un pensamiento sensible a problemas de toda índole. Estos intelectuales se unieron en el hecho de denunciar una crisis originada en aspectos diversos - en los ya citados autores- como el carácter racial en Palacios, la inmigración extranjera en Pinochet y los problemas económicos debido a las carencias educaciones en Francisco Antonio Encina.

\subsection{Los estudios históricos de la formación del Estado nacional}

La comprensión de la independencia de Chile marcó el desarrollo de los estudios históricos acerca de la construcción del Estado nacional chileno. La historiografía de los siglos XIX y XX ponderó que el proceso de emancipación era consecuencia progresiva de la toma de conciencia de lo nacional en las colonias pertenecientes al Imperio español.

La historiografía chilena sobre el nacionalismo y la identidad nacional es relativamente importante, especialmente en los últimos 20 años, en donde se ha desarrollado una interesante renovación temática, metodológica y teórica en los abordajes de este problema histórico. La razón que explicaría esa ausencia anterior de estudios sobre el nacionalismo chileno responde al menos a dos factores. En primer lugar, se produjo en la segunda mitad del siglo XX, especialmente durante la dictadura militar de Augusto Pinochet, una fuerte vinculación entre nacionalismo y conservadurismo y si se quiere entre nacionalismo y militarismo. Esto llevó a que la idea de nacionalismo tuviera una connotación claramente política e incluso partidista, apartándose que la nación y el nacionalismo fueron elementos claves de la construcción de Chile en el siglo XIX.

A la multiplicidad de estudios sobre el proceso de construcción nacional en Latinoamérica en general, y en cada país que la conforma en particular, se opone el hecho que la historiografía chilena se ha mostrado muy renuente a dar cuenta, o a problematizar, la construcción del Estado nacional. La veta más tradicional de análisis ha fluctuado entre el desconocimiento parcial del problema, que remite a una especie de 
hipótesis sobre la preexistencia de la nación anterior al proceso independentista debido al aislamiento territorial del Chile colonial y la noción de un Estado todopoderoso que construye la nación desde arriba. Aquí se inscribe Mario Góngora, quien defiende la génesis estatista de la nación, forjada al calor de las empresas bélicas del siglo XIX; Sol Serrano, que plantea la visión constructiva del Estado, y Julio Pinto y Verónica Valdivia, en cuanto a la facilidad de los grupos dirigentes en traspasar su proyecto a los grupos subalternos, a pesar, de la precariedad material del período ${ }^{99}$.

Existe una versión republicana de esta misma corriente en los trabajos de Julio Heise, Simon Collier, Alfredo Jocelyn-Holt y Ana María Stuven, los cuales plantean un contraste entre la nación abstracta del pueblo ciudadano y la realidad concreta de los sectores populares -aptos o no aptos- para la ciudadanía ${ }^{100}$. La idea general es que el nacionalismo proyectó hacia la sociedad un imaginario social de enorme alcance que abarcó vastos sectores de la sociedad. A través de mecanismo simbólicos, el Estado en el siglo XIX, habría sido capaz de reemplazar la participación efectiva de un determinado cuerpo social por una participación virtual, exteriorizada a través del apego de ciertos emblemas.

La visión más izquierdista del mismo proceso no contempla al pueblo como un sector social pasivo, y pone en cuestión la pretendida unidad supra-clasista; es más, algunas niegan el aporte de este mismo pueblo a una ideación de nación decimonónica. Según lo expuesto por María Angélica Illanes, más que un proyecto consensuado de construcción de nación, la sociedad chilena se vio desgarrada por tensiones que sólo podían solucionarse por el control represivo, lo que explica la necesidad de un Estado

\footnotetext{
${ }^{99}$ Vid. GONGORA, Mario, Ensayo histórico sobre la noción de Estado en Chile, Santiago, Editores La Ciudad, 1981; SERRANO, Sol, Universidad y nación. Chile en el siglo XIX, Santiago, Editorial Universitaria, 1994; PINTO, Julio y VALDIVIA, Verónica, ¿Chilenos todos? La construcción social de la Nación, 1810-1840, Santiago, LOM, 2009.

${ }^{100}$ Vid. HEISE, Julio, Años de formación y aprendizaje políticos 1810-1833, Santiago, Ed. Universitaria, 1978; COLLIER, Simon, Ideas y política de la Independencia chilena, 1808-1833, Santiago, Ed. Andrés Bello, 1977; JOCELYN-HOLT, Alfredo, El peso de la noche. Nuestra frágil fortaleza histórica, Santiago, Ed. Planeta, 1998; STUVEN, Ana María, «La palabra en armas: patria y nación en la prensa de la guerra entre Chile y la Confederación Perú-boliviana, 1835-1839» en Mc. EVOY, Carmen y STUVEN, Ana María (eds.), La República peregrina: hombres de armas y letras en América del Sur, 1800-1884, Lima, IFEA/IEP, 2007, pp. 407-425.
} 
autoritario $^{101}$. Ante una actitud elitista que demandaba sacrificios y subordinaciones no es extraño que la masa se haya debatido en una continua rebeldía que, a veces, se traduciría en un modelo de sociedad o de nación ${ }^{102}$. En la misma lógica, las iniciativas oligárquicas, como las guerras de independencia, llamaban escasamente la atención, provocando indiferencia entre los sectores populares ${ }^{103}$; o, en otros, una marcada hostilidad, como en el caso del bandidaje de los Pincheira de Ana María Contador ${ }^{104}$. No hay cabida para sentimientos de horizontalidad social o de pertenencias compartidas que supone proyectar una nación.

Por otro lado, este vacío historiográfico se debe a una complicada y errada comprensión del proceso de independencia. La historiografía decimonónica arguyó y pensó el proceso de emancipación como consecuencia política de un hecho claro: la progresiva conciencia nacional en las colonias. Esta perspectiva del principio de las nacionalidades consiste en entender la independencia como una consecuencia lógica del proceso, y tal como lo afirma un conocido autor «era tan necesaria como el desenvolvimiento de nuestra propia naturaleza, como el desarrollo de nuestras propias fuerzas ${ }^{105}$. Esta idea generalizada impedía la indagación sobre la construcción de la nación, precisamente porque la nación ya era una realidad antes de 1810 que había emergido del largo período de latencia que había sido la época colonial. Es posible reconocer ciertos rasgos de identificación nacional presentes en los siglos precedentes, especialmente en el XVIII $^{106}$. Este fue el planteamiento central de la tesis de Jaime Eyzaguirre y refuta la emancipación chilena como producto de una maduración de la conciencia nacional, sostiene que eso era absolutamente predecible ya que «tarde o temprano el espíritu

\footnotetext{
${ }^{101}$ Vid. «Azote, salario y ley. Disciplinamiento de la mano de obra en la minería de Atacama (18171850)»; Proposiciones, $\mathrm{N}^{\circ} 19$, Santiago, SUR, 1990.

${ }^{102}$ Vid. LOYOLA, Manuel, y GREZ, Sergio, Los proyectos nacionales en el pensamiento político y social chileno del s. XIX; Santiago; Ediciones UCSH, 2002.

${ }^{103}$ Vid. LEON, Leonardo, «Reclutas forzados y desertores de la Patria: el bajo pueblo chileno en la guerra de la independencia, 1810-1814», Historia, N53, (2002).

${ }^{104}$ Vid. Los Pincheira: un caso de bandidaje social, Chile 1817-1832; Santiago, Ed. Bravo y Allende, 1998.

${ }^{105}$ LIRA, José Bernardo, La Independencia de la América ¿fue un hecho necesario o accidental?, Santiago, Imprenta del Correo, 1859, p. 24.

${ }^{106} \mathrm{Al}$ respecto se puede examinar, MEZA, Néstor, La conciencia política chilena durante la monarquía, Santiago, Ed. Universidad de Chile, 1958 y también VILLALOBOS, Sergio, Tradición y reforma en 1810, Santiago, RIL, 1961.
} 
autónomo y el progreso cultural que iba en indudable desarrollo, al amparo de un régimen pacífico y ordenado de vida, las hubiera desembocado en la completa independencia» ${ }^{107}$. Plantear la independencia como resultado natural de una conciencia nacional o protonacional constituye una exageración y un error. Evaluaciones historiográficas actuales han puesto de manifiesto la duda en tal noción por una serie de consideraciones, especialmente porque en dicha interpretación subyace la idea de encontrar por cualquier sitio gérmenes de sentimientos nacionales en el período colonial.

Las naciones deben considerarse como consecuencias de la independencia y no causas. La nación estaba por construirse por medio de un complejo proceso político, constitucional, social, simbólico, cultural e incluso semántico, y en esto las nuevas concepciones de la historia son claves para establecer la correlación entre conceptos, palabras y realidades históricas que pretenden designar. Como ha señalado FrançoisXavier Guerra, la emancipación generó «un nuevo vocabulario político y nuevas maneras de pensar al hombre, la sociedad, la autoridad, el gobierno, los valores» ${ }^{108}$, en este sentido es una revolución en el sentido más amplio de la palabra, en la medida que significó un amplio proceso de cambios culturales y políticos.

La historiografía chilena ha desarrollado una producción que ha ido superando el escollo que le impedía abordar la nación y el nacionalismo como realidades históricas con espacio y tiempo como coordenadas que coadyuvan a explicar de mejor manera los procesos históricos, de tal manera de abandonar las concepciones míticas acerca del origen de la nación. Un libro -ya citado- que no tenía como interés principal el estudio de la identidad nacional se ha convertido en el referente obligado en estas cuestiones y que sustenta una tesis que sintetiza una de las posturas preponderantes en el estudio del nacionalismo en Chile en Ensayo sobre la noción de Estado en Chile en los siglos XIXY $X X$ de Mario Góngora se indica que es el Estado quien ha forjado la nacionalidad, sin

\footnotetext{
${ }^{107}$ Fisonomía histórica de Chile, Santiago, Editorial Universitaria, 1976, p. 32.

108 «La ruptura originaria: mutaciones, debates y mitos de la Independencia» en ALVAREZ, Izakun y SANCHEZ, Julio (eds.), Visiones y revisiones de la independencia americana, Salamanca, Ediciones Universidad de Salamanca, 2003, p. 104.
} 
que el autor se haya explayado en demasía en la idea. Góngora no define ni nación ni nacionalidad, sino que se concentra más bien en la idea de Estado ${ }^{109}$.

La tesis de Góngora ha tenido una influencia notable como punto de partida para el análisis del nacionalismo en Chile, subsumiendo la nación y el nacionalismo bajo la lógica de la instauración y conformación política del Estado. Las claves de la conformación de la nación están en la educación, las fiestas nacionales y los símbolos. Es en estos ámbitos donde se han generado aportes significativos en las últimas décadas para la conformación de la identidad y el Estado nacional chileno en el siglo XIX. La educación ha sido objeto de interesantes análisis y ha sido enarbolada como una de las columnas vertebrales para «forjar una ideología nacional como fuente de legitimación política» ${ }^{110}$, permitiendo la formación de un sistema nacional de educación que respondiera a la necesidad de socializar los principios republicanos y las virtudes cívicas.

La educación servía para socializar la identidad nacional en los espacios del Chile tradicional del valle central, esta tarea se vería doblegada con la incorporación de los territorios del norte producto de la Guerra del Pacifico y en el sur la anexión de los territorios mapuches, así el Estado se vio en la imperiosa necesidad de chilenizar a esos nuevos habitantes, cuya característica pluri-étnica no sentía mucha adhesión a la identidad nacional chilena. Las fiestas nacionales o cívicas, fueron otro instrumento por el cual el Estado se valió para socializar la identidad nacional entre la población. Las primeras fiestas cívicas como el 18 de septiembre, 5 de abril y 12 de febrero fueron utilizadas para difundir en la población los valores republicanos «y fueron precisamente las manifestaciones festivas de carácter cívico que se sucedieron entre 1810 y 1830, el laboratorio donde se adoptaron, probaron, desecharon o consolidaron una serie de símbolos y ritos que ayudaron a sentar las bases de la nación chilena (...)» ${ }^{111}$.

\footnotetext{
${ }^{109}$ Cfr. Ensayo sobre la noción de Estado en Chile..., op. cit., pp. 71-73.

${ }^{110}$ SERRANO, S., Universidad y nación. Chile en el siglo ..., op. cit., p. 64.

${ }^{11}$ ZALDIVAR, Trinidad y SANCHEZ, Macarena, «Símbolos, emblemas y ritos en la construcción de la nación. La fiesta cívica republicana: Chile 1810-1830», en CID, G. y SAN FRANCISCO, A. (eds.) Nación y Nacionalismo en Chile. Siglo XIX, Santiago, Centro de Estudios Bicentenario, volumen 2, 2009, p. 73.
} 
Las fiestas nacionales vinculadas al proceso de emancipación fueron utilizadas tanto para difundir los valores republicanos como su vinculación con las hazañas bélicas. En el Chile decimonónico se inicia una larga historia de conmemoraciones militares, que no tan sólo tuvieron que ver con la independencia. Por ejemplo, tras la victoria de Chile en la Guerra contra la Confederación Perú-boliviana empezó a celebrarse la Batalla de Yungay (20 de enero de 1839), que buscaba socializar en la población el ideario militarvictorioso, la identidad nacional frente al enemigo e impregnar en el bajo pueblo la idea de la nación chilena. Es a partir de este evento que se populariza la figura del «roto» como icono del nacionalismo popular «que se evidencia cuando la heterogeneidad de todo grupo social se difumina por medio de su reducción a estereotipos (...) el roto (...) figura simplificada del mundo popular cargada de connotaciones más bien negativas» ${ }^{112}$. En este sentido, los sectores populares no actuaron como receptores pasivos de los discursos y acciones emanados desde la elite.

La historiografía tradicional chilena ha otorgado a la sucesión de guerras que experimentó el país desde tiempos de la colonia un papel muy importante en la creación de sentimientos de arraigo colectivo ya que con las «guerras victoriosas del siglo XIX, se ha ido constituyendo un sentimiento y una conciencia propiamente nacional» ${ }^{113}$. Esto ha tenido una fuerte resonancia dentro de la historiografía chilena cualquiera sea su tendencia y la explicación de este fenómeno, ya que enfatiza ciertos rasgos por sobre otros. Sin embargo, en términos generales, se le atribuye al ambiente bélico una importancia tal en la formación de la nación porque «la guerra estuvo en el centro de las grandes convulsiones revolucionarias de fines del siglo XVIII y comienzos del XIX» ${ }^{114}$. Este contexto revolucionario requirió la creación de nuevos ejércitos, y, por consiguiente, el acantonamiento de nuevos soldados, capital humano que se buscó dentro del bajo pueblo.

\footnotetext{
${ }^{112}$ CID, Gabriel, «Un ícono funcional: la invención del roto como símbolo nacional, 1870-1888», en CID, Gabriel y SAN FRANCISCO, Alejandro en Nación y Nacionalismo en Chile ..., op. cit., p. 223.

${ }^{113}$ GONGORA, M., Ensayo histórico sobre la noción de Estado en Chile..., op. cit., p. 12.

${ }^{114}$ PINTO, J. Y VALDIVIA, V., ¿Chilenos todos? La construcción social de la nación..., op. cit., p.66.
} 
Lo anterior, implicó reinventar el objetivo de lucha y las motivaciones con las que se buscara convocar al sector popular. Julio Pinto y Verónica Valdivia indican que «esto exigía estimular o crear una identificación con otros referentes simbólicos, distintos a la monarquía, para que el sector a convocar, el bajo pueblo, estuviera dispuesto a la lucha (...) la guerra debería ayudar a crear un soldado patriota y ciudadano» ${ }^{115}$. Los sectores populares resignificaron esos relatos y discursos de acuerdo a sus códigos y pautas propias, proporcionándole incluso rasgos distintivos a esas conmemoraciones como espacios de sociabilidad, especialmente las fiestas patrias ya que «si existe creación en las fiestas cívicas republicanas, ésta estaría dada por la cultura del pueblo» ${ }^{116}$. Es la liturgia popular del republicanismo. Desde los inicios de la vida republicana chilena, se crearon numerosos símbolos que anhelaban transformarse en el sustento del incipiente sentimiento patriótico que embriagaba lentamente a la población, los gestores de la República concibieron «un programa cultural que culminaba invariablemente en la adopción de grandes emblemas para las nuevas identidades sociales y políticas que la propia guerra contra la metrópoli engendraba: banderas, escudos, canciones patrióticas» $^{117}$.

Podemos afirmar que a partir de 1812 se inició una revolución simbólica nacional con la creación de emblemas, banderas, escarapelas y escudo y «todos estos elementos venían a reforzar así la idea de un nuevo orden político»» ${ }^{118}$.

Debemos destacar que la historiografía chilena ha avanzado en examinar los mecanismos de socialización de la identidad nacional y el grado de efectividad e impacto en la población. Desde este punto de vista es importante mencionar trabajos que han puesto en cuestionamiento la tesis de la unidireccional de la construcción de la nación por el Estado. En especial, los trabajos emanados desde la historia social, que

\footnotetext{
${ }^{115}$ Ibidem, p. 67.

${ }^{116}$ PERALTA, Paulina, ;Chile tiene fiesta! El origen del 18 de septiembre (1810-1837), Santiago, LOM, 2007, p. 147.

${ }^{117}$ BURUCÚA José Emilio y CAMPAGNE, Fabián, «Mitos y simbologías nacionales en los países del Cono Sur», en ANNINO, Antonio y GUERRA, François-Xavier (eds.), Inventando la nación: Iberoamérica Siglo XIX, México, Fondo de Cultura Económica, 2003, p. 435.

${ }^{118}$ ZALDIVAR, T. y SANCHEZ, M. «Símbolos, emblemas y ritos en la construcción de la nación», en CID, G., y SAN FRANCSICO, A. (eds.), Nación y Nacionalismo ..., op. cit., p. 73.
} 
han enfocado valiosos trabajos de la construcción de la nación desde los sectores populares, que han dejado de ser considerados como meros entes pasivos y receptores de los discursos nacionalizadores de la elite. El trabajo más destacado en esta arista es de Julio Pinto y Verónica Valdivia que vinieron a cubrir un vacío historiográfico. Según estos autores, los sectores populares no fueron movilizados por la causa independentista, sino más bien por la realista. Aduciendo que la coyuntura clave para que prendiera el nacionalismo popular fue la guerra contra la Confederación Perúboliviana. Sólo habrían sido incorporados desde una dimensión simbólica y cultural, por ningún motivo, política ni ciudadana ${ }^{119}$.

Para la segunda mitad del siglo XIX, la historiografía ha proporcionado trabajos que han abordado de manera muy positiva la nación desde la óptica desde abajo. Autores como Julio Pinto y Verónica Valdivia han analizado alocuciones populares en torno a la Guerra del Pacífico (1879), donde se difundió un arraigado y exitoso patriotismo popular. También en este sentido Joaquín Fermandois ha señalado que: «la Guerra del Pacífico operó en este sentido como el más importante -cemento de la sociedad-. El relato mítico (...) que quedó, influye todavía en la educación básica en Chile y, si se remueven frases de circunstancias, en casi todos los estratos etarios y en todos los estratos sociales, en ocasiones, emerge alguna dosis de chauvinismo.» ${ }^{120}$ La formación del Estado nacional se valió de variados y diversos medios y nuevamente las guerras «habrían jugado un papel fundamental en el arraigado sentimiento nacional que es posible observar en su población, y que se remontaría a sus orígenes mapuches y a la conquista española» ${ }^{121}$. Es pertinente sostener que la guerra se convirtió en un instrumento de elaboración de la identidad nacional y muy fuertemente en el mundo popular.

La formación de lo nacional no sólo está relegada a lo político-institucional. Es un tema mucho más complejo donde se mezclan en la construcción de lo nacional diversos

\footnotetext{
${ }^{119}$ Vid. ¿Chilenos todos? La construcción social de la nación ..., op.cit., p. 64.

${ }^{120}$ Mundo y fin de mundo. Chile en la política mundial 1900-2004, Ediciones Universidad Católica de Chile, Santiago, 2005, p. 36.

${ }^{121}$ PINTO, J. Y VALDIVIA, V., ¿Chilenos todos? La construcción social de la nación..., op. cit., p. 65.
} 
factores. De allí que Bárbara Silva distinga para dichos procesos una dimensión «política-discursiva»y una «cultural-simbólica» que han estado presentes desde la independencia. Estas facetas «teóricamente deberían complementarse para crear un imaginario colectivo que sustentase la identidad en construcción» ${ }^{122}$. Desde esta perspectiva se aprecian contradicciones entre el discurso inclusivo de la elite y la praxis de la exclusión política y desde la óptica cultural-simbólica, ya que, se aluden instancias de integración imaginaria en un colectivo, por medio de la creación de símbolos, ritos, mitos y estereotipos de identificación. Es en esto último donde se han desarrollado interesantes aportes para la investigación historiográfica, especialmente asociados a temas de representación.

La identidad nacional ha sido materia de varios estudios recientes. Una de esas variantes ha sido estudiar dicha identidad desde los relatos y producción literaria de chilenos que viajaron a Europa y que construyeron discursos acerca de lo chileno desde referentes culturales y no políticos. Las fuentes literarias han sido un excelente material para el análisis discursivo de la identidad de Chile ${ }^{123}$. La representación es la herramienta por medio de la cual los estudios del enfoque histórico cultural pretenden analizar la sociedad, pero también es la condición que permite que los hechos sociales sean cognoscibles, tal como lo plantea Roger Chartier en su texto sobre historia cultural como una posibilidad de «descifrar de otra manera las sociedades, al penetrar la madeja de las relaciones y de las tensiones que las constituyen a partir de un punto de entrada particular $(\ldots){ }^{124}$. Considerando que la historia por medio del estudio de las representaciones se escudriña en el sentido que los individuos y los grupos otorgan sentido a aspectos que le son propios. Otros estudios acerca de la literatura han indagado sobre la construcción de los estereotipos en las novelas románticas chilenas del siglo XIX.

\footnotetext{
${ }^{122}$ SILVA, Bárbara, «Símbolos y discursos en torno a la nación. Patria Vieja y Centenario» en Tesis Bicentenario 2004, Santiago, Colección Tesis Bicentenario/Centro de Investigaciones Barros Arana, 2006, p. 21.

${ }^{123}$ Vid., por ejemplo, SANHUEZA, Carlos, Chilenos en Alemania y alemanes en Chile. Viaje y nación en el siglo XIX, Santiago, DIBAM/LOM, 2006.

${ }^{124}$ El mundo como representación. Estudios sobre historia cultural, Barcelona, Gedisa, 1992, p. 49.
} 
Todo discurso sobre la nación y el Estado nacionales es histórico en su forma, y apologético en su esencia. Se presenta como objetivo en la realidad que describe, eliminando las huellas del poder en la cual se inscribe. La nación se constituye en un eje central y que se pretende que emerja con naturalidad para coronar la institucionalidad política. De esto depende la construcción social de la nación, y la creación de consensos como base de la reproducción o transformación del orden social. Uno de los temas estudiados ha sido la autopercepción chilena de su «excepcionalidad» constituida en una de las ideas fuerza en torno a la cual se articularon muchos discursos sobre lo nacional $^{125}$.

La excepcionalidad chilena entendida como un modelo de república de estabilidad política, enfatizada en que fue una de los estados que adquirió una reputación que la transformó en un prototipo reflejada en un periódico del Gobierno en 1841 señalando:

«la excepcionalidad honrosa de paz y estabilidad, de orden y libertad, que presenta Chile en medio de los desórdenes de la anarquía y de las demasías del poder arbitrario que afligen a la mayor parte de los estados hispanoamericanos ha debido de llamar la atención $(\ldots.) .{ }^{126}$

En estas situaciones de construcción de la nación, de articulación en torno a representaciones que se hacen de la nación ayudan al estado a la concertación de voluntades políticas y a la creación de poderes para llevar a cabo el nuevo orden. Es en este ámbito que la esfera de lo simbólico desempeña un papel clave en la cosmovisión que se quiere instalar por parte de los grupos que ostentan el poder ejerciendo liderazgo antes de conquistar el poder político. Esto se traduce en una lucha por imponer los términos y significados de la acción histórica que se está realizando, es la disputa por hegemonizar los espacios públicos con la simbología de la nación que se desea construir. En el caso de las naciones que emergen del mundo colonial, la elaboración de su estructura simbólica es contradictoria y paradójica. Estas naciones con «el discurso

\footnotetext{
${ }^{125}$ Vid. SEPULVEDA, Alberto, «La formación del estado nacional en Chile», en Revismar, № 3 (2010), pp. 240-251, y también SAN FRANCISCO, Alejandro, «La excepción honrosa de paz y estabilidad, de orden y libertad. La autoimagen política de Chile en el siglo XIX» en CID, G. y SAN FRANCISCO, A. (eds.), Nación y nacionalismo en Chile..., op. cit., pp. 55-84.

${ }^{126}$ El Araucano, Santiago, 9 de abril de 1841.
} 
nacionalista de los movimientos independentistas, aún cuando desafían la dominación política del orden colonial, aceptan la premisa intelectual del racionalismo moderno, que constituye el soporte cultural de tal dominación» ${ }^{127}$.

Las naciones postcoloniales persiguen transformaciones acotadas y su ruptura administrativa con la metrópolis es definida como una revolución pasiva. Uno de los estudios más interesantes es acerca de los movimientos de intelectuales del siglo XIX y sus discursos sobre identidad nacional cimentados en una denigración del pasado colonial y una sobrevaloración del presente liberal y republicano ${ }^{128}$.

Una perspectiva de análisis que ha ido en aumento es estudiar los procesos de construcción nacional a partir de la creación discursiva de los indígenas y de los héroes de la independencia. En estos procesos de construcción de héroes, la utilización de los mapuches por la república ha sido una veta bien explotada en diversos estudios destacando Simon Collier cuando refiere que: «los chilenos encontraron muchas similitudes, por idealizadas y artificiales que fuesen, entre la situación de los araucanos en el siglo XVI y la suya propia a comienzos del siglo XIX. Después de todo, los indios habían opuesta una resistencia loablemente tenaz a la opresión» ${ }^{129}$.

Un estudio similar al de Collier ha indagado sobre la inclusión instrumental del indígena ante la imperiosa necesidad de proporcionarle legitimidad a la independencia y a la construcción de lo nacional, es así que en el proceso de identificación con el pasado indígena «el vocablo araucano o los nombres de los antiguos indígenas se utilizaron para bautizar los hijos, exhortar a la victoria en la guerra, designar las imprentas, los periódicos, los barcos de la Escuadra Nacional (...)»> ${ }^{130}$. La elite visualizó con gran optimismo la idea de conformar una identidad común con los mapuches, una gran comunidad unida por un pasado gloriosos y un futuro que auguraba esplendor.

\footnotetext{
${ }^{127}$ CHATTERJEE, P., Nationalist Thought and the colonial world, Minneapolis, University of Minessota Press, 1986, p. 9.

${ }^{128}$ Vid. STUVEN Ana María, «La generación de 1842 y la conciencia nacional chilena», Revista de Ciencia Politica, vol. IX, No 1 (1987), pp. 61-80.

${ }^{129}$ Ideas y política de la independencia ..., op. cit., p. 201

${ }^{130}$ CASANOVA, Holdenis, «Entre la ideología y la realidad: la inclusión de los mapuches en la nación chilena (1810-1830)», Revista de Historia Indígena, N4 (2000), p. 25.
} 
En la génesis de los procesos de emancipación los discursos de legitimación de la nueva realidad apelaban al iluminismo racionalista decimonónico en un doble sentido estratégico. Por un lado, sirve como un horizonte legitimado de racionalidad desde donde se juzga y rechaza la dominación española, por infringir las normas de un modelo cultural que aboga por el respeto a las libertades y privilegios individuales. Pero, al mismo tiempo, propone que son los pueblos americanos quienes encarnan los valores universales de la ilustración contra la invasión bárbara ya que los pueblos contenidos en el Imperio español se habían mantenido durante todo el período colonial bastante dóciles y respetuosos con la autoridad; sin embargo, por las acciones emprendidas en contra de las Juntas de Gobierno generadas en toda América hacia 1810 y por la «atrocidad y opresión de los jefes y tropas que lo dominaron bajo el mando de Osorio y de Marcó, irritó al fin la tolerancia de los descendientes de Caupolicán, Lautaro y Tucapel» ${ }^{131}$. La tolerancia y civilidad como rasgos de los pueblos americanos, y en particular del chileno, que disienten con la brutalidad de los representantes de la Corona son pruebas de la participación en el paradigma racional de la cultura ilustrada de la cultura de los pueblos sometidos.

Así como se plantea que los elementos constitutivos del modelo ilustrado son parte del pueblo chileno, y su rasgo de pertenencia a las naciones occidentales, también se apela a la construcción de la imagen de nación con aspectos diferenciadores que marcan su identidad. El mestizaje que incluye la presencia de lo indígena se transforma en un elemento diferenciador en el perfil de la identidad nacional que le da sentido al proceso de conformación de una nación emergente combinando lo occidental, el mestizaje y lo indígena debido a que los movimientos de emancipación y los constructores del Estado nacional deben buscar raíces en el pasado para crear un espíritu nacional contra la metrópoli. Sin embargo, para poder incorporar la civilización moderna es necesario, que participen también de la racionalidad científica, técnica y política, cuestión que muy a menudo supone el abandono de todo un pasado cultural.

${ }^{131}$ EGAÑA, Juan, El chileno consolado en los presidios o filosofía de la religión, Londres, Imprenta de M. Calero, 1826, p. 286. 
La apelación a la realidad indígena como fuente de identidad, se limitó al carácter valeroso e indómito de figuras como Caupolicán y Lautaro asociados a la gesta de la independencia, al pueblo chileno y a los militares. El pasado heroico en la elaboración de la representación de la nación opera como invención de la tradición que «busca inculcar determinados valores o normas de comportamiento por medio de su repetición lo cual implica automáticamente continuidad con el pasado» ${ }^{132}$, se transforma en lo que Hobsbawm ha llamado el pasado utilizable. Los atributos de los indígenas: fuerza y dotes libertarias se han transformado en cuestiones perennes y en Chile basta mencionar a los guerreros mapuches para que gatille un imaginario colectivo constituido por una red de textos escritos y orales, donde emergen los ancestros míticos. El mito que borra las huellas históricas y políticas de su construcción o como señalara Mariategui que «la nación es una abstracción, una alegoría, un mito que no corresponde a una realidad que pueda ser definida científicamente» ${ }^{133}$. Lo mítico proporciona un patrón retrospectivo de valores morales, de un orden social y de creencias mágicas, cuya función es fortalecer la tradición e incrementar su prestigio, remontándose a un pasado cuya realidad se describe en eventos elevados y sobrenaturales.

El relato heroico, por cierto, produce efectos en la estructura simbólica del pueblo al que se propone representar. Las fuerzas de las palabras son capaces de mantener o alterar el orden social, existe una confianza en las palabras y sobre todo en quien las pronuncia. La fuerza de estas representaciones con su apelación positiva y constructiva de la identidad de la nación, son fundamentales para concitar la voluntad política en torno a un determinado proyecto político. Para construir legitimidades simbólicas es necesario llevar a cabo la conducción política de la nación, la creencia en los discursos, poderes logrados en forma épica y capacidad de difundirlo por el territorio. La elaboración discursiva le proporciona al líder características que se pretenden visualizar. Esto lo advertimos tempranamente en la figura de Bernardo O'Higgins cuando se le retrata con un «valor incomparable y a toda prueba: un fondo de probidad genial: una resolución inalterable de sacrificarse por el bien público (...) un alma franca, modesta y

\footnotetext{
132 HOBSBAWM, Eric, «Introducción: La invención de la tradición», en HOBSBAWM, Eric y RANGER, Terence (eds.) La Invención de la tradición, Barcelona, Crítica, 2002, p. 8.

${ }^{133} 7$ Ensayos de Interpretación de la realidad peruana, Lima, Amauta, 1928, p. 174.
} 
generosa $(\ldots) »^{134}$. La construcción heroica proporciona a los representantes y líderes políticos prestigio y carisma capaz de consolidar su legitimidad. En este sentido, la construcción de un discurso sobre identidad nacional supone un proceso de elaboración de identificaciones y legitimidades, con líderes épicos, personajes cotidianos que colaboren en la persuasión discursiva de la nación.

Esta formación de lo nacional es propia del periodo en el cual las naciones latinoamericanas después de la independencia, comienzan a desplegar un aparataje de concientización en torno a la nueva realidad, nueva lealtad y un nuevo deber ser de los otrora súbditos, ahora compatriotas-ciudadanos-nacionales. Uno de los mecanismos de tal concientización fue la educación en sus distintas vertientes. Esta se plantea como una necesidad de enaltecer las conciencias ciudadanas: informándolas, concientizándolas y nacionalizándolas. Lo esfuerzos realizados por los grupos gobernantes para crear la nación, romper con el pasado y generar un nuevo orden político -como ya se ha dichorequirieron de varios medios para enaltecer claramente su etapa, es por ello, que prestaron mucha atención a la educación. La educación fue pensada explícitamente desde las elites y la intelectualidad y la dirigencia estatal como un modo de socializar los principios tanto los principios republicanos como establecer una nación con identidad común para toda la población del territorio con la idea de forjar una ideología nacional que legitimara el orden político ${ }^{135}$.

Nos parece importante destacar que para nuestra investigación la educación fue un elemento clave en la configuración del Estado nacional chileno durante el siglo XIX. El análisis sobre el papel de la historia en el siglo XIX utilizada como una forma para socializar la identidad nacional en las aulas chilenas donde la utilización de la historia en dicho ámbito durante el siglo XIX permitirá comprender de una mejor forma el alto valor simbólico-cultural que ha tenido esta disciplina en la formación de los estados

\footnotetext{
${ }^{134}$ EGAÑA, J., El chileno consolado en los presidios ..., op. cit., p. 303.

${ }^{135} \mathrm{Vid}$. A este respecto DONOSO, Andrés, Educación y nación al sur de la frontera. Organizaciones mapuches en el umbral de nuestra contemporaneidad, 1880-1930, Santiago, Ed. Pehuén, 2008 y también GONZALEZ, Sergio, Chilenizando a Tunupa. La escuela pública en el Tarapacá andino, 1880-1990, Santiago, LOM, 2002.
} 
nacionales, asunto que ha sido estudiada en parte por Allen Woll ${ }^{136}$. La enseñanza de la historia fue concebida a mediados del siglo XIX como un cimiento para la educación superior y una herramienta necesaria para proporcionar cultura. También se concibió que prepararía a las personas para ser chilenos y ciudadanos ayudando de esa manera a la consolidación de Chile. A esto debemos agregar que el conocimiento de la historia ayudaría a la toma de las decisiones políticas. También la historia fue utilizada como herramienta para las luchas políticas y para dirimir los conflictos diplomáticos ${ }^{137}$.

No sólo la historia ha servido a estos propósitos, también lo ha hecho la geografía, toda nación se articula desde un territorio específico. En este aspecto ha habido interesantes trabajos sobre la construcción de la idea territorial de Chile en el siglo XIX, tanto estudiando las descripciones como las representaciones cartográficas. La representación del territorio como unitario con la idea estética y política de nacionalizar el paisaje fue también una tarea de los primeros gobernantes. Esta temática se centra en los imaginarios que se han elaborado dese la geografía con la noción de la copia feliz del Edén tan recurrente en América Latina en general y en Chile en particular. Todos esto se vinculó a una serie de iniciativas estatales de representar lo chileno en cartografías, pinturas y exhibirlas en museos.

También la educación en las costumbres coincidió con un siglo XIX en que los ideales de modernidad, progreso y civilización adquirieron fuerza en la sociedad. Es por ello que la elite chilena impulsó la formación cívica que incluyó una buena lista de comportamientos sociales, morales y políticos. De allí que también en la escuela se inculcó los estándares de civilidad para favorecer el culto a lo bello, propiciar el ciudadano modelo, aspectado en los modos correctos de vestir, comer, conversar y seguir los cánones de urbanidad. El Estado chileno consideró necesario reforzar las

\footnotetext{
${ }^{136}$ Vid. A functional past: the uses of history in nineteenth-century Chile, Lousiana, Louisiana State University Press, 1982.

${ }^{137}$ Vid. SAGREDO, Rafael y SERRANO, Sol, «Un espejo cambiante: la visión de la Historia de Chile en los textos escolares», INTERAMER, $\mathrm{N}^{\circ} 29$ (1994), pp. 6-12 y también REYES, Leonor, «¿Olvidar para construir nación? Elaboración de los planes y programas de estudio de Historia y Ciencias Sociales en el período post-autoritario», Ciberhumanitas, $\mathrm{N}^{\circ} 23$ (2002).

http://web.uchile.cl/vignette/cyberhumanitatis/CDA/texto_simple2/0,1255,SCID\%253D3541\%2526ISID $\% 253 \mathrm{D} 258,00 . \mathrm{html}$
} 
nociones de ciudadanía, memoria e identidad, estableciendo los deberes y derechos de los diversos sujetos. La escuela fue uno de los espacios desde donde estas concepciones se propagaron. Para ello se enfatizó el protagonismo de áreas temáticas como la historia nacional y la educación cívica. Estas asignaturas se orientaban a fortalecer el culto a los héroes y la construcción de la nación. Aspectos que se reforzaban mediante la introducción de una serie de ceremonias, celebraciones y emblemas en el espacio escolar. Tanto la formación cívica como la educación en costumbres y urbanidad han sido muy poco estudiados y solo existen referencias tangenciales en obras acerca de la historia de la educación chilena.

En esta situación del estado del arte nos hemos propuesto mostrar como los aspectos relativos a la construcción de la nación en el Chile del siglo XIX se han ampliado considerablemente. Lo que pretendemos señalar es que aun cuando se han hecho importantes renovaciones temáticas y metodológicas con respecto a la construcción de la nación, todavía es posible explorar y profundizar en aspectos que nos parecen claves para la construcción del estado nacional chileno como es la educación y su aporte altamente significativo en la tarea que se propusieron los hombres y mujeres del siglo XIX. La sociedad chilena en el siglo XIX experimentó procesos de transformación desde estructuras tradicionales coloniales a estructuras modernas republicanas. Esta tarea implicó la adquisición paulatina de un conjunto de atributos y capacidades cuyo control fue asumido por la elite criolla. Estos grupos lograron conformar un Estado nacional legitimado, consensuado. En este proceso debieron asumir diversas e importantes deberes para dotar de existencia al mismo Estado. Para ello generaron una institucionalidad jurídica, organizaron el territorio, delimitaron las fronteras, crearon la administración, formaron ejércitos, crearon sistemas financieros, fundaron la prensa, establecieron nuevas relaciones con la iglesia católica, definieron la diplomacia, generaron una política económica y, por cierto, organizaron y expandieron un sistema educativo. Esta última iniciativa es clave, en esta investigación, ya que fue la herramienta política del Estado y de la dirigencia política para integrar y homogeneizar el cuerpo social y construir una nación. 
Capítulo 2

El rol de la educación en la construcción del estado nacional chileno 
«La instrucción primaria dada con discernimiento o para emplear una expresión más precisa todavía, la educación primaria es pues la primera base de todo desarrollo nacional.»

Miguel Luis Amunátegui y Gregorio Víctor Amunátegui, De la Instrucción Primaria en Chile:

lo que es, lo que debería ser 


\subsection{Educación y Estado nacional: reciprocidad en la construcción de lo nacional}

En las primeras décadas del siglo XIX, la elite chilena se dirigió a la tarea de construir el Estado nacional, proceso que implicaba, por un lado, la constitución del Estado como organización suprema del poder en un territorio definido y, en segundo lugar, la conformación de una nación que involucraba otorgar a la población un sentido de pertenencia y cierto grado viable de unidad política. La nación constituía uno de esos elementos viables de unidad que era pensada en tanto comunidad imaginada como meta semiótica capaz de aglutinar los dispositivos de identidad y de signos de abstracción para el nacimiento y desarrollo del proyecto. Era una noción que trazaba fronteras para poder diferenciarse de las otras naciones y al mismo tiempo homogeneizarse. ${ }^{138}$

Los países hispanoamericanos estructuraron los signos de la nación de forma particular y acorde a su propio recorrido histórico. Uno de los primeros signos de esa estructuración se entendía necesariamente ligado a un territorio determinado. Nación y territorio estaban estrechamente unidos y se vinculaban el uno al otro y despojarla de una parte del territorio era violar su integridad física y cultural. La nación en el territorio daba sentido a ese cuerpo de hombres y mujeres ligados por lazos de sangre, matrimonio, descendencia, es decir, como una familia extendida cuyos integrantes se fusionaban por lazos profundos de lealtad y solidaridad. La nación debía ser la comunidad de hombres viviendo bajo el mismo régimen enarbolando comunión de intereses; congregación de personas en un territorio con tradiciones, aspiraciones e intereses comunes, y subalternos a un poder central que asume la tarea de mantener la unidad del grupo ${ }^{139}$.

\footnotetext{
${ }_{138}^{138}$ Cfr. ANDERSON, B. Comunidades imaginadas. Reflexiones ..., op. cit., pp.23-25

${ }^{139}$ Para ampliar el concepto de nación recomendamos KÖNIG, Joachim, «Símbolos nacionales y retórica política», en BUISSON, Inge, (ed.) Problemas de la formación del Estado y la nación en Hispanoamérica, Bonn, Inter Nations, 1984, pp. 389-405; AGUILAR, Enrique, Nación y Estado en el pensamiento de Ortega y Gasset, Buenos Aires, Ed. Ciudad Argentina, 1998; FERNANDEZ, Álvaro, La invención de la nación. Lecturas de la identidad de Herder a Homi Bhabha, Buenos Aires, Manantial, 2002; SUBERCASEUX, Bernardo, «Caminos interferidos. De lo político a lo cultural», Estudios Públicos, Nº 73 (1999), pp. 149-164.
} 
Otras vertientes sostienen que la nación no es más que un principio de unidad de la comunidad imaginada que puede llegar a conformar una teoría o doctrina política. La abstracción del concepto de nación ha sido la preocupación de muchas investigaciones que reconocen en los discursos sobre la nación la concreción de realidades históricas básicamente apologéticas. En los discursos políticos, constitucionales, culturales y educativos, la nación es presentada como un relato de la realidad objetivo, y, es por eso, que la representación por medio de imágenes se constituye en símbolos estructurales del orden social, que suelen escapar a la realidad.

Más allá de las diferencias conceptuales acerca de la nación y su construcción, el estudio de ella encierra una dificultad mayor: la forma en que se ha conformado. Ella no solo obedece a una serie de acontecimientos y fechas, sino que, fundamentalmente, a la forma en que presentan y representan en el tiempo, donde la legitimidad y la identidad son los primeros desafíos en su arquitectura. Es fundamental, la existencia de una serie de elementos institucionales que propicien la identificación y estimulen el compromiso de los habitantes con un ideal predeterminado o indeterminado, pero que de alguna manera se configura como perceptible. Para la consecución de esos ideales es imprescindible desarrollar medios y organizaciones donde la escuela, los ritos y los símbolos pasan a ser garantes de esa unidad y del proyecto.

La valoración y jerarquía de los elementos que componen la nación no responde esencialmente a patrones definidos. La nación y su materialización histórica que es el Estado nacional es una creación artificial, porque se sustentan en hechos e instituciones comprobables como plataforma del proyecto social que se diseña. De allí que el Estado nacional no necesariamente se levanta sobre la imitación cabal del pasado, sino que principalmente sobre valores idealizados en tiempos determinados y seleccionados por quienes elaboran la historia para sentar las bases del presente y del futuro de la nación. Esos elementos satisfacen la necesidad de la comunidad, aunque con el costo que la idealización configure dogmas históricos que pueden contribuir a crear, destruir o invadirla de recelos. 
Los proyectos históricos buscaban y aspiraban a la consecución de esos signos de unidad. La nación histórica o la comunidad históricamente imaginada se constituye a partir de elementos del pasado y del presente en una actitud de aceptación y rechazo. Para el caso chileno, el proyecto consistía en negar aspectos del pasado con una actitud antihispana «de los criollos, difundida ampliamente en la prensa y otros documentos oficiales y privados, fue rigurosa y dogmática, y se aplicó a todos los aspectos del Antiguo Régimen» ${ }^{140}$. Al mismo tiempo se exaltaba lo heroico y rebelde del pueblo mapuche revalorizándolo. Los gestores de la independencia ensalzaron el carácter fundacional de la emancipación y se sintieron legítimos herederos de los mapuches y «el sentimiento nacional, habiendo repelido con furia el legado de España, tuvo que volverse hacia otra fuente en busca de un mito alternativo (...). El nuevo mito patrio estaba esperándolos en el umbral bajo la forma de los indios araucanos $(\ldots)\rangle^{141}$.

El quiebre y nacimiento de Chile en torno a la independencia abrió un interesante debate referido al origen de la nación chilena y al papel del Estado en su configuración. Hasta la eternidad podríamos discutir sobre la existencia de la nación antes o después de la independencia. En nuestra opinión, lo relevante es examinar cómo los criollos comprendieron y construyeron la conciencia de identidad en el sentido de la lealtad, no hacia el antiguo régimen, sino que al que deseaban construir.

Los orígenes de los estados nacionales se pueden conceptuar de diversas formas: como formación, creación o construcción. En todos estos conceptos se esconden un proceso temporal a lo largo del cual se va configurando un tipo de Estado que tiene como objetivo final la constitución de una identidad propia. La diferencia fundamental entre estos conceptos radica en que creación y construcción responden básicamente a planes e intenciones de alguien o algunos; en cambio, formación es un término de carácter más neutral que se limita a dar cuenta de un proceso en el que el Estado va adquiriendo una forma determinada clara y distinta, admite, por lo tanto, la posibilidad que el proceso no sea un resultado intencionado, sino que consecuencia que se ha terminado por afirmarel Estado- sin responder a la intención de nadie.

\footnotetext{
${ }^{140}$ CASANOVA, H. «Entre la ideología y la realidad...», art. cit., p. 10.

${ }^{141}$ BENGOA, José, Historia del Pueblo mapuche: Siglo XIX y XX, Santiago, LOM, 2008, p.143.
} 
Frente a estas conceptualizaciones tenemos dos perspectivas posibles de comprender la construcción del Estado y de la nación. Una primera que concibe el proceso como el de la estatización de la nación; una segunda como nacionalización del Estado. En el primer caso, supone la preexistencia de la nación al Estado, y que por ello el proceso transcurre a lo largo de dos fases básicas: una inicial de autoconciencia de la nación; y una segunda en que se autoorganiza en términos estatales. Para el segundo caso, se supone que las estructuras estatales son previas a la nación y que el Estado nacional se construye en un proceso de identidad, reactivo, más o menos exitoso en la nacionalización de la maquinaria estatal. Nuestra visión del proceso chileno es más comprensible históricamente que la nación es construcción del Estado y que el sistema educativo es uno de sus pilares fundamentales. Fraguar la nación significaba interiorizar una conciencia e identidad colectiva nacional mediante la creación de nuevos elementos simbólicos y resignificando los antiguos. La construcción por parte del Estado compone dos elementos claves: por un lado, una actitud de rechazo o negación de aspectos del pasado que se difunde por diversos canales. Desde nuestra perspectiva la identidad nacional se configura con el rompimiento implícito con la Corona y la imperiosa necesidad de componerse en un objetivo común: «Más pronto y de forma más radical que en otros estados de América Latina, la inteligencia chilena dio la espalda, deliberadamente a España, rompiendo por lo menos durante un siglo los lazos culturales y afectivos con sus referentes ibéricos. Los ideólogos nacionales habían considerado a la antigua metrópoli como la única responsable de los males acumulados durante las guerras de independencia, renegando así de su propia memoria.»> ${ }^{142}$

Por otro, se exaltaba lo propio, el presente, a los conductores de la nación destacando el aspecto fundacional de la independencia «la colonia más pobre y más Oscura de la España en el Nuevo Mundo pasó a ser una república independiente, que más feliz que casi todas sus hermanas, ha aprovechado los gérmenes de su riqueza, y para alcanzar un grado de prosperidad que sin duda no se imaginaron los padres de la independencia.» ${ }^{143}$

\footnotetext{
${ }^{142}$ OSSENBACH, Gabriela, «Educación en América Latina a partir de su independencia. Siglos XIX y XX», Revista Iberoamericana de Educación, $\mathrm{N}^{\circ} 1$ (1993), p. 95.

${ }^{143}$ BARROS ARANA, Diego, Compendio elemental de historia de América, Santiago, Imprenta el Ferrocarril, 1865, p. 344.
} 
Forjar la nación significaba interiorizar una conciencia e identidad colectiva y nacional, mediante la creación de nuevos elementos simbólicos, rituales y de caracteres míticohistóricos. Este sentimiento, muchas veces cargado de una actitud antihispana de los criollos, difundida ampliamente en la prensa y otros documentos oficiales y privados, fue rigurosa y dogmática, y se aplicó a todos los aspectos del antiguo orden político. Ese carácter anti-español queda reflejado muy claramente en el primer Himno nacional de Chile, especialmente en su estrofa cuarta:

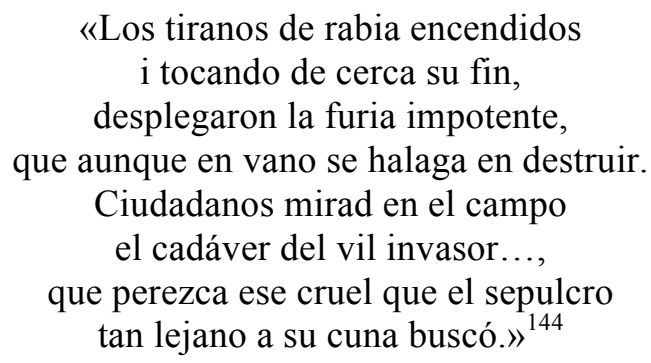

Situación aún mucho más evidente en torno a las arengas y demandas en contra de los privilegios que poseían los peninsulares antes de la Independencia. En general, los chilenos tuvieron una actitud rigurosa hacia el Imperio español. Irisarri declaraba en $L a$ Aurora:

«¿Qué bienes recibís con que los Españoles de la Península se engullan nuestros tesoros, si vosotros mismos os hacéis indigentes para que aquellos sean opulentos? Diréis que el amor a la patria; mas no es tal amor, sino un delirio, hijo de la poca reflexión; es la falta de amor a vuestros deberes más sagrados; es un espíritu de partido que se oculta al examen de vuestra razón, y es al fin un crimen contra la naturaleza.» 145

No es menos cierto que esa imagen histórica de enemistad contra el español cambió en el Himno Nacional de 1847 en la cual en su primera estrofa indica que:

«Ha cesado la lucha sangrienta ya es hermano el que ayer opresor;

\footnotetext{
${ }^{144}$ VERA, Bernardo y ROBLES, Manuel, «Canción nacional chilena», Revista las Bellas Artes, $\mathrm{N}^{\circ} 1$, (1869), pp.4-5.

${ }^{145}$ La Aurora de Chile, Santiago de Chile, jueves 29 de octubre de 1812, p.3.
} 
del vasallo borramos la afrenta combatiendo en el campo de honor.» ${ }^{146}$

El tránsito de la Colonia a la República planteó la resolución de un problema fundamental: la cuestión del poder o, más precisamente, de poder estatal, lo que suponía que un grupo social ostentaría el control de los medios de coacción política, jurídica, militar y la dirección ideológica. Correspondió, pues, a la elite conducir el proceso de transición de la Colonia al Estado nacional, tarea que implicaba la construcción del nuevo Estado, es decir, el establecimiento de un nuevo orden político-institucional fundado en nuevas formas de pensar hacer política y en nuevas bases de legitimación del poder. En segundo término, la construcción de la nación, lo que suponía crear ciertos grados viables de unidad en la población asentada en el territorio estuvieron tempranamente presentes en el horizonte político del grupo dirigente chileno.

Desde una perspectiva teórica o discursiva, los estados americanos que se desprendieron del Imperio español en el siglo XIX se dieron a la tarea de la unificación en un territorio determinado como soporte de una comunidad política integrada que se define por la gestión estatal, ya que «sin esta acción del Estado, tal comunidad no existiría, pues sus miembros serían individuos dispersos y débilmente vinculados entre sí» ${ }^{147}$. El Estado, afirmamos, que, a través de instituciones, leyes, normas, y prácticas comunes, ordena e integra a sus individuos, configura y proporciona unidad e identidad a un pueblo, en un determinado territorio y tiempo.

Un consenso unánime ha prevalecido en torno al proceso de independencia y de conformación del Estado nacional chileno, y es que dichos hechos tuvieron como «actor o sujeto histórico principal a la elite dirigente. Se piensa también que la naturaleza relativamente pacífica y exitosa de este proceso (...) se debió al papel protagónico asumido por esta» ${ }^{148}$. El Estado chileno y la elite que se consolidaron plenamente y pudieron realizar el cambio desde el sistema colonial a República. De los factores más

\footnotetext{
146 VERA, Bernardo y ROBLES, Manuel, «Canción nacional chilena ...», art. cit., p. 5.

${ }^{147}$ GODOY, Oscar, «Funciones de Integración del Estado», Revista de Ciencia Política, vol. XXII, N² (2002) p. 105.

${ }^{148}$ JOCELYN-HOLT, Alfredo, La Independencia de Chile, Madrid, Editorial MAPFRE, 1992, p. 69.
} 
relevantes para haber emprendido la tarea de la independencia y de la conformación del Estado nacional fue la unidad y cohesión de la clase dirigente.

La gracia de la elite chilena consistió precisamente en conservar la unidad necesaria para otorgarle gobernanza al nuevo país y fortalecer sus instituciones. En este sentido, el estado chileno desarrolló una acción exitosa, logrando en el siglo XIX la integración política fundamental. La nación y la nacionalidad chilena fueron producto de una evolución resultante en un Estado no étnico. Este estado nacional no se configura sobre bases étnicas, sino que, sobre unas bases jurídico-políticas, que proviene de la acción del Estado. De esta forma, la integración nacional con un sentido de pertenencia a una comunidad unida en torno a los principios políticos establecidos en las sucesivas Constituciones.

Como gran parte de las sociedades latinoamericanas en el siglo XIX la sociedad chilena experimentó procesos de transformación y liberalización significativa de sus estructuras tradicionales. Dicho proceso se desencadenó con posterioridad a la independencia generando las condiciones que permitían pensar en términos de nacionalidad en el sentido de pertenencia a un espacio cultural y territorialidad común. Ahora bien, el proceso a través del cual las naciones hispanoamericanas fueron construidas no fue preconcebido y poseyó un carácter de irreversibilidad. Tuvo su impulso inicial en los movimientos independentistas, pero también fue interrumpido, parcialmente fracasado y luego retornado y exitoso por todo el continente.

La nación hispanoamericana no es, en consecuencia, una categoría eterna, sino el producto de un largo y complicado proceso de desarrollo histórico y social donde aparecen relaciones objetivas: económicas, políticas, intelectuales, lingüísticas, culturales, geográficas, religiosas e históricas, y lo que es más importante, la reflexión subjetiva de estas relaciones en la conciencia colectiva. Aunque en esta idea de construcción del Estado, la historiografía chilena ha advertido diferentes posturas. La historiografía chilena ha abordado estos temas en un esquema muy autorreferente y con 
pocas miradas sobre referentes internacionales tanto histórico como propiamente historiográficos.

Una primera postura es que el Chile se formó como Estado nacional durante el período de la Patria Vieja (1810-1814), puesto que a partir de 1811 ocurren una serie de sucesos que entendidos como un solo proceso permiten interpretar que se ha conformado el Estado de Chile, ya que coexisten los tres elementos básicos de todo Estado, es decir, territorio, autoridad e idea de pertenencia mediante símbolos que plantean el destino común, lo que algunos autores definen también como bien común. Dentro de estos sucesos cabe destacar: la instalación del Primer Congreso Nacional, el reemplazo de la Real Audiencia por el Supremo Tribunal Judiciario, el fin al monopolio comercial con España mediante la promulgación del Decreto que establecía la facultad de Chile de comerciar con cualquier nación, el dictado del Reglamento Constitucional de 1812 y la creación de los emblemas nacionales, como la primera bandera chilena.

Al respecto, Sergio Villalobos señala que durante este período por primera vez se ponen en práctica los conceptos de soberanía popular, reconociendo así la existencia de un aparato estatal que surge a partir de una coyuntura acaecida en España, conocida como el Desastre de Bayona ${ }^{149}$.

Existe una segunda postura representada en Barros Arana y Feliú Cruz que entienden que el Estado chileno se forma a partir de la Declaración de Independencia del 12 de febrero de 1818, puesto que esta tuvo por fin consagrar a Chile como un Estado libre y soberano. En efecto, desde este acto algunos historiadores que alaban la figura de Bernardo O'Higgins entienden que nace el Estado chileno en forma definitiva y permanente, puesto que esta declaración implica un reconocimiento expreso de la soberanía popular, negando así la intervención de otros Estados dentro del territorio nacional. Frente a los actos de soberanía popular desarrollados durante el período de

${ }^{149}$ Vid. VILlaloBOS, Sergio, Chile y su historia, Santiago, Ed. Universitaria, 2003. 
Patria Vieja (1810-1814), estos los consideran como un ensayo provisorio y de duración limitada, subordinados a los resultados de la Guerra de la Independencia en Chile ${ }^{150}$.

Finalmente, existe una tercera postura, apoyada principalmente por el historiador Mario Góngora quien propone que el Estado nacional se conforma y consolida desde la era portaliana, es decir, desde 1831 en adelante, puesto que desde este período se forjan las bases de la institucionalidad de Chile ${ }^{151}$. La institucionalidad chilena se plasma según Góngora en el dictado de la Constitución de 1833 que tuvo la misión de institucionalizar al nuevo Estado que emergía, recogiendo los elementos de la época colonial y las nuevas ideas y principios que imperaban. Para este historiador todos los sucesos acaecidos con anterioridad no son más que ensayos políticos y constitucionales, en donde primaba la incoherencia, el desorden y la anarquía, puesto que existía una falta de adecuación a la realidad nacional. Su tesis es aún más profunda al esbozar que el Estado chileno es anterior a la nación.

$\mathrm{Al}$ respecto, unos importantes papeles desempeñaron las nuevas ideas derivadas de las diversas corrientes del liberalismo de fines del siglo XVIII e inicios del XIX. El modelo inglés $\mathrm{y}$, sobre todo, el francés, norteamericano y español, proporcionaron a la generación criolla de 1810-1833 un conjunto de principios básicos, los que constituirían la esencia de la causa emancipadora y, al mismo tiempo, los fundamentos considerados indispensables en la constitución del Estado nacional chileno «el sistema republicano solo puede operar con eficiencia si va acompañada de un mínimo de virtud pública, la que debe ser infundida a los ciudadanos mediante una adecuada educación» ${ }^{152}$.

La elite configuró una forma de comprender el Estado nacional que tenía como elementos centrales que los gobiernos se constituyen en virtud de un contrato y en consecuencia dependieran libremente del consentimiento de los pueblos, que la soberanía residiese en el pueblo y que esta última delegase a través de un sistema

\footnotetext{
${ }^{150}$ Vid. BARROS ARANA, Diego, Historia General de Chile, Santiago, Ed. Rafael Joves, 1884 y también FELIU, Guillermo, El pensamiento político de O'Higgins. Estudio histórico, Santiago, Imprenta Universitaria, 1955.

${ }^{151}$ Cfr. Ensayo histórico sobre la noción de Estado en Chile..., op. cit., pp. 12-15.

${ }^{152}$ COLLIER, Simon, Ideas y politica de la Independencia ..., op. cit., p.160.
} 
político la garantía de los derechos de libertad, igualdad, fraternidad, propiedad y seguridad claramente refrendados en los textos constitucionales que dieron origen a las repúblicas hispanoamericanas.

En Chile como en el resto de América Latina a inicios del siglo XIX, el proceso de independencia no aseguró la inmediata constitución o formación del Estado nacional, muy por el contrario, las nuevas repúblicas debieron esperar un par de décadas para que esta aspiración se cristalizara, la principal condición que debía cumplirse, incluyendo el diseño y funcionamiento, era la articulación de consensos activos dentro de las elites políticas con el fin de proyectar una nación que lograse superar la heterogeneidad de la sociedad, y esto como indica Alfredo Jocelyn-Holt para Chile en que «el gran acierto de la política chilena del siglo XIX, en especial en su segunda mitad fue haber sido liberal y moderada, haber auspiciado progreso, sin que ello significara inestabilidad, haber permitido grados crecientes de pluralismo en el seno de una sociedad todavía tradicional (...) en definitiva, un orden equilibrado que procuró apartarse de posibles desórdenes que podrían haberse enseñoreado de haber prosperado posturas extremas» ${ }^{153}$.

\subsection{El constitucionalismo y la idea de nación}

Los nuevos estados que emergieron en América propagaron el nuevo concepto de Estado liberal o nacional bastante extendido a causa de la generalizada influencia de los textos constitucionales europeos y donde «el constitucionalismo latinoamericano inicial se concibió asimismo como una expresión de la civilización, como una manifestación de la recepción de las nuevas ideas como demostración de que América Latina pasaba a participar del pensamiento filosófico y político del mundo moderno y civilizado, mediante el orden constitucional» ${ }^{154}$. La adopción de conceptos emanados y contenidos

\footnotetext{
153 «El liberalismo moderado chileno siglo XIX», Estudios Públicos, № 69 (1998), p. 439.

${ }^{154}$ GROSS, Héctor, «El constitucionalismo latinoamericano y la codificación en el siglo XIX» Anuario iberoamericano de justicia constitucional, No 6 (2002), p. 149.
} 
en los referentes constitucionales europeos como independencia, libertad, estado confesional, gobierno representativo republicano, sufragio limitado, etc.).

Lo notable, para el caso americano es que esto ocurrió sobre contextos históricos distintos a los europeos y que el proceso «codificador, luego de medio siglo, su desarrollo acelerado y su extensión generalizada, constituye un elemento característico de la historia de América Latina» ${ }^{155}$. Los nuevos Estados americanos iniciaron procesos muy acelerados de modernización, en los que el Estado adquirió un protagonismo muy destacado que parecía ser la única posibilidad de crear un orden nuevo. El liberalismo proclamado en Europa planteaba que el estado renunciara a la intervención en la sociedad, en América, el elemento y factor político adquirió una relevancia notable, ya que la configuración del Estado era su condición esencial. La intervención del Estado no se limitó únicamente a medidas de fomento económico, sino que fue primordialmente una búsqueda de unidad nacional y homogeneidad del espacio económico acotado nacionalmente.

Es apropiado examinar como en los primeros textos constitucionales se aludía a la nación. La primera que hace referencia es la 1818 indicaba que: «perteneciendo a la Nación chilena reunida en sociedad, por un derecho natural e inadmisible, la soberanía o facultad para instalar un gobierno y dictar las leyes que le han de regir (...).»156

Las ideas referidas a la soberanía en atributo moderno de la nación, la constitución de 1822 que en su artículo $1 .^{\circ}$ indica que la nación chilena es «la unión de todos los chilenos: en ella reside esencialmente la soberanía, cuyo ejercicio delega conforme a esta Constitución» ${ }^{157}$. Y en su artículo 2. ${ }^{\circ}$ que la nación es «libre e independiente de la Monarquía española y de cualquiera otra potencia extranjera: pertenecerá solo a sí misma, y jamás a ninguna persona ni familia» ${ }^{158}$.

\footnotetext{
${ }^{155}$ Ibidem, p. 165.

${ }^{156}$ Constitución provisoria para el Estado de Chile de 1818, Título III, Cap. 1, en Archivo O’Higgins, vol. 11, p. 78.

${ }^{157}$ Constitución politica del Estado de Chile, Santiago, Imprenta del Estado, 1822, p.1.

${ }^{158}$ Ibidem, p. 2.
} 
La idea de nación política o nación cívica fue bastante común en las regiones hispanoamericanas tras los procesos de emancipación, estas nociones de ciudadanía e institucionalidad contribuyeron a cohesionar a una población heterogénea, por ello la intencionalidad puesta fuertemente en lo político. La Constitución liberal de 1828 que no entró en vigencia en su artículo primero rotulaba que la nación chilena «es la reunión política de todos los chilenos naturales y legales. Es libre e independiente de todo poder extranjero (...) No puede ser el patrimonio de ninguna persona o familia» ${ }^{159}$.

La nación se asociaba en un sentido contractualista moderna entendida como una comunidad política fundada en la asociación libre de los habitantes de una región y ese tránsito hacia una concepción moderna es uno de los elementos claves en la fundación de las nuevas repúblicas ya que la nación moderna «hace referencia a una comunidad nueva, fundada en la asociación libre de los habitantes de un país; esta nación es ya, por encima, soberana y para sus forjadores se identifica necesariamente con la libertad» ${ }^{160}$.

El derrotero jurídico de las constituciones fue también recogido por la Constitución de 1833 y el concepto de nación experimentó algunas pequeñas modificaciones e incluso uno de los inspiradores de dicha carta homologaba estado con nación es evidente «una nación o estado es una sociedad de hombres que tiene por objeto la conservación y felicidad de los asociados (...)» ${ }^{161}$. Con la entrada en vigor de la Constitución de 1833 no hubo una definición clara respecto a la idea política de la nación.

En la Convención de 1831-1832, instancia que actuaba como comisión para redactar dicha Constitución podemos recoger la siguiente sentencia: haciendo referencia a la Constitución liberal de 1828: «En el capítulo I (de la Constitución de 1818), sin otro objeto, a mi ver, que por la manía de escribirlo todo, se comenzó por dar una definición de la palabra Nación que se aplicó a la nuestra i aunque en ella se envolvían errores

\footnotetext{
${ }^{159}$ Constitución politica de la República de Chile, Santiago, Imprenta de R. Rengifo, 1828, p. 1.

${ }^{160}$ GUERRA, François-Xavier, Modernidad e Independencias. Ensayo sobre las revoluciones hispánicas, Madrid, Editorial MAPFRE, 1992, pp. 390-391.

${ }^{161}$ BELLO, Andrés, Principio de derechos de jentes, Santiago, Imprenta de la Opinión, 1832, p. 10.
} 
clásicos, no obstante, se declaró como la primera parte del primer artículo constitucional.» ${ }^{162}$

Y prosigue en lo conceptual con una refutación férrea a que la nación haya sido creada por el Estado o la sociedad política, «(...) se quiso constitucional i tan ridículamente formar a la Nación después de ya formada, que aun no pudiendo Rousseau imaginarse una sociedad sin religión, se creyó que podía existir i constituírsele Nación considerándola como formada solo de la sociedad política» ${ }^{163}$.

El concepto de nación desde la década de 1830 en adelante fue adquiriendo una connotación más bien de carácter adjetiva que sustantiva y fue por lo mismo implícitamente asociándose a la homologación con el Estado evitando la definición. Un ejemplo y constatación de aquello son como muchas instituciones y actividades vinculadas directa o indirectamente al Estado, entre ellas Instituto Nacional, Biblioteca Nacional, Guardia Nacional, Erario Nacional, Comercio Nacional, Congreso Nacional, Ejército Nacional, etc.

Desde los años veinte del siglo XIX el Estado chileno se dio a la tarea de socializar en la población la identidad nacional y un afán de homologación en la significación de vocablos como patria, nación, Estado y Chile. Con el transcurso de los años el concepto de nación se nutrirá de las victorias guerreras, especialmente de la Guerra contra la Confederación Perú-boliviana que había sido una guerra impopular al principio para convertirse después del triunfo que quedó «relegado a un segundo plano o derechamente olvidado. El clima triunfalista y patriótico generó un espacio propicio para llevar a cabo una serie de festejos y discursos que reflejaban una serie de actitudes y un lenguaje cada vez más nacionalista» ${ }^{164}$.

\footnotetext{
${ }^{162}$ LETELIER, Valentín, La Gran Convención de 1831-1833. Recopilación de las actas, sesiones, discursos, proyectos y artículos de diarios relativos a la Constitución de 1833, Santiago, Imprenta Cervantes, 1901, p. 175.

${ }^{163}$ Ibidem, p. 176.

${ }^{164}$ CID, Gabriel, «Nacionalizando la "segunda independencia" chilena. Fiestas y discursos cívicosreligiosos en torno a la Guerra contra la Confederación, 1836-1851», Revista de Historia de Chile y América, vol. 7, №2 (2008), p. 10.
} 
La guerra será un elemento clave en la configuración y apego a la nación y la constitución de la identidad nacional consensuada y compartida y «en el siglo XIX la guerra pasa ser también un factor histórico capital: cada generación, podemos decir, vive una guerra» ${ }^{165}$.

Evidentemente que el concepto fue mutando o al menos se fue abriendo a la polémica, en especial con la llamada Generación del 42, donde «la búsqueda de referentes identitarios desde el ámbito de la cultura, por medio de la literatura, la historiografía, la educación, las artes» ${ }^{166}$, formaba parte importante de las aspiraciones de esta generación de intelectuales. El liberalismo que impregnó a esa generación con uno de los máximos exponentes, José Victorino Lastarria, quien ante la ausencia de una literatura nacional consideraba que la definición de lo nacional debía ser compleja, pero proponía una definición ecléctica, mestiza, geográfica mutable y adaptable, ya que consideraba que nuestro «(...) carácter nacional hemos de reconocer como elementos influyentes en él, tanto las costumbres (...) de los conquistadores (...) las del pueblo indígena (...) de la raza mixta que deriva su existencia (...). Los accidentes físicos (...) han debido modificar (...) las características de nuestro pueblo [ya que] influyen poderosamente no tan solo en la organización física del hombre sino también en la moral» ${ }^{167}$.

De este modo la idea de nación se fue vinculando a parámetros culturales, políticos, étnicos, geográficos. Las «naciones» se fueron concibiendo como la expresión política de comunidades de algún modo preexistentes. En la vereda opuesta estaba la idea de admitir la «nación» como una realidad histórica que había que proteger y fortalecer mediante la socialización masiva de los elementos de la patria, posición cuyos principales promotores fueron los pedagogos.

\footnotetext{
${ }^{165}$ GONGORA, M., Ensayo histórico sobre la noción de Estado en Chile..., op. cit., p. 9.

${ }^{166}$ CID, Gabriel y TORRES, Isabel, «Conceptualizando la identidad patria y nación», en CID, G. y SAN FRANCISCO, A. (eds.) Nación y Nacionalismo en Chile ..., op. cit., p. 41.

${ }^{167}$ LASTARRIA, José Victorino, Investigaciones sobre la influencia social de la conquista española y del sistema colonial de los españoles en Chile, Santiago, Imprenta del Siglo, 1844, pp. 115-116.
} 


\subsection{La educación artífice del proyecto nacional: inclusión y homogeneización}

La educación ha sido una de las obras más sólidas de la historia chilena; y su importancia pareciera no requerir demostración, sin embargo, la inquietud académica por ella ha sido menor que la trascendencia que representa. Lo que nos interesa destacar es el cometido que le corresponde a la educación en la construcción de lo nacional. Por cierto, que tal construcción, no solo se remite a las acciones que se generaron desde la educación, en ella participaron otros actores: el ejército, la prensa, la literatura, los símbolos, etc.

Acercarse a la construcción del Estado desde la educación nos parece relevante, ya que su estudio a lo largo del siglo XIX, nos aproxima a los modos en que la sociedad piensa sus idearios y parámetros, los sentidos de su actuación en el mundo, la apertura y el cierre a sus posibilidades, la luminosidad y oscuridad de sus proyectos. Estudiar el papel desempeñado por la educación constituye un objeto de estudio significativo por su carácter emblemático y simbólico en relación con la configuración del Estado nacional. Si el siglo XXI demanda una educación para la integración al mundo y el XX una educación para democratizar, el siglo XIX se sostenía en una educación que construyera el Estado nacional.

Los debates en torno a la relación Estado y educación desarrollados en el siglo XIX y en la historia reciente de Chile no son tan diferentes, si en uno pasaba por reducir el Estado como condición para que surgiera la fuerza de la sociedad y el mercado; en la sociedad del siglo XIX solo la fuerza del Estado podía reformar una sociedad que se le consideraba no apta para emprender el camino hacia la modernización.

Para conseguir la identificación que los grupos predominantes y controladores del Estado requerían fue necesario tener un sistema educativo apropiado a esos intereses. El énfasis estuvo puesto a lo largo del siglo decimonónico, con matices, en las glorias de la nación, los héroes, los padres fundadores, introduciendo el respeto por los símbolos de la patria: bandera, escudo, escarapela, himnos, valoración de la literatura chilena, el precio por el paisaje geográfico y el fortalecimiento de la formación cívica. En este 
sentido, «la nación» fue un concepto dinámico y con referentes históricos, $\mathrm{y}$, no hay duda, que fue parte importante de la argumentación político y del sentido de proyecto de la élite.

El modelo de Estado que surge en Iberoamérica tras el acceso a la independencia, asume pronto las competencias educativas, en detrimento de la Iglesia. Desde esta tribuna, la sociedad se seculariza, se afirma el concepto de nación y aparecen nuevos grupos medios que encuentran en la educación un factor de ascenso y movilidad social. Esta educación también contribuye al crecimiento económico, a medida que se inician los procesos de industrialización y diversificación productiva.

A finales del siglo XVIII se produjo en Europa una ruptura del llamado Antiguo Régimen, la cual otorgó a la sociedad su emancipación respecto del Estado absolutista y fijó límites a la acción de dicho Estado. Así las cosas, el Estado que desde el siglo XVII había procurado fundamentarse sobre criterios racionales y no teológicos, empezó a garantizar la libertad religiosa e impuso a la Iglesia su definición como asociación social separada del Estado. Con este quiebre la burguesía o sus similares, se transformó en el grupo social que accedió al poder. El nuevo Estado liberal se erigió sobre sociedades definidas como naciones. Este concepto de nación que empezó a utilizarse a partir de ahora alude a ciertos elementos comunes de la sociedad, tales como la comunidad territorial, lengua y cultura, pero no se definió su carácter clasista, sino que se concibió en principio como una unidad indivisible.

A pesar que cierto liberalismo procuró que el Estado se inhibiera en los asuntos sociales, desde un principio las necesidades de la construcción nacional apoyaron una serie de medidas estatales, y entre ellas, las de política educativa, a la que se le asigna una función importantísima.

A la educación se le atribuyen funciones tales como las de integración de los distintos grupos que conforman un territorio, la creación de una identidad nacional, social, cultural y étnico, así como, la legitimación del poder del Estado. Sol Serrano plantea 
que esta tuvo el imperativo de «forjar una nación con una identidad común a todos los habitantes de un territorio, es decir, forjar una ideología nacional como fuente de legitimación política» ${ }^{168}$. La idea es conseguir el consenso, de manera que el Estado lleve a efecto la dirección cultural e ideológica de la sociedad, consiga el asentimiento entre los diversos sectores de la sociedad.

La educación adquiere en ese sentido una significación relevante, dado su carácter de órgano óptimo para la generación de consentimiento que impulsó los procesos de secularización discutidos ardientemente en relación con la escuela laica y los problemas de la libertad de enseñanza. De otro modo «al interior del proceso cultural Ilustrado, a comienzos del siglo XIX, algunos componentes ideológicos liberales dominan en Chile y son objetivados en una institucionalidad y una práctica político-social que al tiempo de organizar administrativamente -en el ámbito de la configuración del Estado Nacional- se convierten en mecanismos compulsivos que coaccionan a la población $(\ldots){ }^{169}$.

El monopolio de la iglesia proveniente de los tiempos coloniales, y bastante poco debilitado en la primera mitad del siglo XIX, dado que esta conservó parte importante de su poder que ejercía «sobre la educación, la organización familiar y las costumbres como por la influencia en la esfera del gobierno» ${ }^{170}$. El Estado a lo largo del siglo XIX como representante de lo general rompe el monopolio ejercido por la Iglesia en materia educativa. La secularización de la política se presenta como requisito para una nación unitaria y un poder estatal indiscutido. La creación de los sistemas educativos nacionales se hizo en todo el mundo con grandes resistencias entre las que ocupa un lugar relevante la de las propias iglesias. No en vano la Iglesia estas habían sido el principal titular del monopolio de la educación formal y no podía ver con buenos ojos a su principal competidor. En general todas las iglesias, más o menos, fueron hostiles a la educación pública y propagaron la doctrina que el Estado debía abstenerse de intervenir

\footnotetext{
${ }^{168}$ Universidad y nación. Chile en el siglo XIX, Santiago, Editorial Universitaria, 1994, p. 64.

${ }^{169}$ NEIRA NAVARRO, Marcelo y BENTHAM, Jeremy, «El Liberalismo en Chile durante la primera mitad del siglo XIX», Boletín de la Academia Chilena de la Historia, № 113 (2004), p. 327.

${ }^{170}$ VERGARA, Sergio, «Iglesia y Estado en Chile, 1750-1850», Revista Historia, No 2, (1985), p. 327.
} 
en la educación, encomendando la enseñanza a la iniciativa privada, convirtiéndose por tanto en defensores de la libertad de enseñanza.

El Estado buscó de algún modo, por medio de la educación, facilitar la movilidad social y formar de acuerdo con sus intereses, a los ciudadanos. Entre sus planes también estaba formar a la población para «realizar un trabajo dentro de la estructura productiva de la sociedad, ya sea en la industria, la agricultura, el comercio, las profesiones liberales o los propios cuadros burocráticos que sostienen al Estado» ${ }^{171}$. La formación de las personas y la formación del Estado nacional fueron el sustento del nuevo principio de la legitimidad del orden político apoyado en la soberanía nacional y en la representatividad. Para el ejercicio de la soberanía y la representatividad requería la constitución de unas virtudes republicanas. En los albores de la República se concibió un sistema educativo definido socialmente de la siguiente manera «instrucción científica y literaria para los ciudadanos y la instrucción primaria para el pueblo. Ambas categorías se reunían en la regulación estatal destinada a formar un sistema nacional de educación» ${ }^{172}$. En la medida que estos principios avanzaran con la educación, la ciudadanía se extendería gradualmente.

Ante la educación particular no había oposición, pero se consideraba que esta respondía a intereses de algunos y no a la idea de construir una sociedad de homogénea, y Juan Egaña en 1807 lo ilustra claramente «debemos apartar de nuestros corazones todo sentimiento de interés particular, de crédito y autoridad, esa debilidad tan indigna del amor patriótico $(\ldots) \gg{ }^{173}$. La idea de la felicidad pública por sobre todos los intereses constituían un principio del liberalismo ilustrado del siglo XIX.

A medida que la sociedad fue adquiriendo mayor complejidad y los procesos de modernización se intentaron instaurar se fue avanzando en intensidad y cobertura. La

\footnotetext{
${ }^{171}$ OSSENBACH, G., «Educación en América Latina a partir de su independencia ...», op. cit., p. 93.

${ }^{172}$ SERRANO, Sol, «La ciudadanía examinada: el control estatal de la educación en Chile (1810-1870)», en ANNINO, Antonio y GUERRA, François-Xavier, (coord.), Inventando la nación. Iberoamérica siglo $X I X$, México, Fondo de Cultura Económica, 2003, p. 550.

${ }^{173}$ EGAÑA, Juan, «Discurso sobre el amor de la patria y la confianza y buena opinión que deben tomar los ciudadanos de sus gobiernos principalmente en los tiempos peligrosos», en SILVA, Raúl, (ed.) Antología, Santiago, Editorial Andrés Bello, 1969, pp. 147-148.
} 
concepción liberal que todos los hombres son capaces de un mismo desarrollo estaba a la base de los nuevos fundamentos constitucionales de los nuevos estados. El proyecto nacional de educación fue pieza clave en el nuevo orden político, situación que advertiremos más adelante al examinar algunos textos constitucionales y otros referentes políticos que dan cuenta de la simetría entre la idea de nación y el papel que le cabía a la educación en tamaña empresa. La sociedad chilena seguía siendo heterogénea en todos los ámbitos, y la escuela con su proyecto educativo, social y moral se transformó en un factor de unificación moral, identitaria, nacionalizadora y centro de irradiación de la pertenencia nacional.

A pesar de todas las fuerzas políticas o sociales divergentes o convergentes que existían en cada una de las regiones a la hora de los procesos de emancipación, existió un punto clave en todo esto, y en que probablemente todos coincidía: era indispensable educar al pueblo. Desde los comienzos de los estados nacionales, la concepción que existía detrás de todo esto, era transmitir conocimiento y virtudes, aspectos necesarios para que cada individuo asumiera plenamente las funciones que los marcos legales o sociales requerían. El valor de la educación se preciaba como el medio para desarrollar tradición e identidad. El propio Camilo Henríquez afirmaba en 1813 que «la instrucción es una necesidad común. La sociedad debe favorecer con todas sus fuerzas los progresos de la razón pública, y poner la instrucción al alcance de todos los ciudadanos»» ${ }^{174}$. El reconocimiento desde siempre a la educación como un medio privilegiado para la ilustración de las almas.

La propia Constitución de Cádiz de 1812, y tan extendida como referente ideológico para América proponía que se debía instalar en todo el continente «escuelas de primeras letras, en las que se enseñará a los niños a leer, escribir y contar, y el catecismo de la religión católica, que comprenderá también una breve exposición de las obligaciones civiles» ${ }^{175}$. Cuando las regiones americanas cruzaron el umbral de la modernidad

\footnotetext{
174 «Catecismo de los Patriotas», en El Monitor Araucano, núms. 99-100, 27 de noviembre de 1813, p. 147.

${ }^{175}$ Constitución Politica de la Monarquía española, promulgada en Cádiz a 19 de marzo de 1812, Cádiz, Librerías L, 2011, p. 103.
} 
política y emprendieron el viaje hacia la conformación de la nacionalidad, educar era crear los marcos legales y societales que ayudaran a legitimar los cambios que estaban ocurriendo.

La formación cívica y la enseñanza de la historia se convirtieron en los pilares fundamentales de la nueva sociedad política. El estado, por ende, debía dar educación propia y, al mismo tiempo, regular con una normativa común tanto la educación pública como la privada. El propio Henríquez escribía en el primer periódico de la nación que «necesitamos desbastarnos y pulirnos mucho para deponer la barbarie y rusticidad, que se nota en una gran parte de los pueblos de nuestro reyno. La incivilidad y la aspereza es incompatible con la industria, con las ciencias, y con el comercio (...)» ${ }^{176}$. El despertar de la nacionalidad no solo apuntaba a la información, sino que a la conciencia política y hacia donde debía apuntar el futuro, así apelaba a los chilenos: «tenemos pues que trabajar mucho para ser felices (...) El patriotismo (...) a de ser el principal blanco a que deben dirigirse las instituciones públicas.»» ${ }^{177}$

El caso chileno tiene la singularidad que el nuevo sistema político que emerge de la Independencia tiene un profundo impacto no solo en la organización del Estado, sino también en la provisión de la educación: «con la independencia, la educación no es una política, es política.» ${ }^{178}$ La educación para mucho de los forjadores de la Independencia tenía un sentido moral y político antes que intelectual, ya que por medio de ella formaba la virtud del ciudadano. La formación moral y política del ciudadano era el amor y entusiasmo por la patria y las leyes. Así, por ejemplo, Juan Egaña, redactando en 1811 un proyecto de Constitución, establecía que las autoridades debían salvaguardar la educación ya que es elemento imprescindible para el pacto social para sustentar el Estado nacional, ya que de no hacerlo «los estados degeneran y perecen a proporción que se descuida la educación y faltan las costumbres que la sostienen y dan firmeza a

\footnotetext{
${ }^{176}$ La Aurora de Chile, jueves 9 de abril de 1812, páginas 1 y 2.

${ }^{177}$ La Aurora de Chile, jueves 13 de febrero de 1812, p. 2.

${ }^{178}$ SERRANO, Sol; PONCE DE LEON, Macarena y RENGIFO, Francisca, Historia de la Educación en Chile (1810-2010), Tomo I, Aprender a leer y escribir (1810-1880), Santiago, Editorial Taurus, 2012, p. 63.
} 
los principios de cada gobierno» ${ }^{179}$. Este es un fundamento del carácter público que defendía Egaña. La educación debe quedar bajo la dirección gubernamental. Una actividad, como la educativa, no podía quedar oculta a los ojos del legislador, ya que podía confabular contra la tarea de formar el ciudadano virtuoso de la nueva República.

Aspecto bastante consensuado entre los gestores de la República, esto de la educación a la tutela y amparo del Estado y de la autoridad, «las costumbres e ignorancia de las letras no pueden remediarse si no interviene el brazo poderoso del gobierno y toma a su cargo los primeros fundamentos de la reforma de las escuelas. Es notorio que son las opiniones las que dirigen a los pueblos, y que las escuelas son la cuna donde nacen y se alimentan las opiniones, para difundirse después en la plebe $(\ldots)^{180}$ La educación tuvo un claro espíritu republicano, público y virtudes cívicas. Sostenemos que esta sufrió una aceleración en la segunda mitad del siglo XIX, lo que fue hasta cierto punto el correlato del afianzamiento del poder estatal sobre el territorio nacional. En este sentido «la educación fue un elemento crucial para culturizar en clave nacional a poblaciones pluriétnicas que no estaban en los límites originales del estado chileno decimonónico» ${ }^{181}$ y que permitieron expandirse luego de las conquistas territoriales hacia el norte con la Guerra del Pacífico y hacia el sur con la Ocupación de la Araucanía.

Entre 1830 y 1860 el Estado chileno fue escenario de dificultades para llevar a cabo su proyecto educacional, aunque no necesariamente ideológico, sino que tenían que ver con una contienda por el poder. Tanto el conservadurismo que estuvo en el poder en el período 1830-1860 que se caracterizaba por sus rasgos autoritarios y realistas como el incipiente liberalismo compartían un «(...) común sustrato ilustrado y republicano que le otorgaba a la educación una importancia primordial en el camino hacia la

\footnotetext{
${ }^{179}$ Proyecto de Constitución para el Estado de Chile, Santiago, Imprenta del Gobierno, 1813, p. 209.

${ }^{180}$ La Aurora de Chile, Santiago de Chile, 1812, № 9, pp. 1-2.

${ }^{181}$ CID, Gabriel, «La nación bajo examen», Polis, N³2 (2012), p. 4.
} 
civilización. Compartían también la idea que el estado debía ser docente y que debía normar el conjunto de la educación» ${ }^{182}$.

En el pensamiento y práctica educacional en el período, la estructura del sistema estaba en torno una jerarquía del saber y se dividía en educación científica-literaria y educación primaria. Pierre Rosanvallon frente a esta diferenciación indica que «(...) esta jerarquía no respondía solo a niveles del saber, sino que tenía también una función sociológica consistente en otorgar una educación apropiada y diferenciada de acuerdo con cada clase social: uniformidad y universalidad eran conceptos que no debían ser confundidos» ${ }^{183}$.

Este diseño fue aceptado y consensuado en lo sustancial por la elite expresado en el conservadurismo pelucón y en el liberalismo pipiolo. Esto se transformó en un consenso básico.

\subsection{La acción del Estado en el proyecto educativo decimonónico}

La educación fue uno de los pilares fundamentales de la nueva realidad que se creía inaugurada en Chile con la emancipación y junto a los acontecimientos militares y otros mecanismos como «los símbolos patrióticos (banderas, Canción Nacional, fiestas nacionales, etc.), la unidad administrativa, la educación de la juventud, todas las instituciones» ${ }^{184}$. La formación de un sistema nacional de educación se basó en los valores de la razón, la ciencia, la libertad y el progreso, eran aspiraciones criollas. Sabido es, sin embargo, que dicho sistema solo alcanzó una fisonomía más estable hacia mediados del siglo XIX. Educar al gran número de iletrados existentes en Chile era una necesidad primordial en el sistema representativo puesto en funcionamiento implementado por los constructores del Estado nacional chileno. Una de las ideas

\footnotetext{
${ }^{182}$ SERRANO, S., «La ciudadanía examinada ...», art. cit., en ANNINO, A. y GUERRA, F. (coords.), Inventando la nación ..., op. cit., p. 550.

${ }^{183}$ ROSANVALLON, Pierre, Le moment Guizot, Paris, Ed. Gallimard, 1985, p. 244.

${ }^{184}$ GONGORA, M., Ensayo sobre la noción de Estado..., op. cit., p. 12.
} 
reiteradas en los discursos de la época era que el pueblo soberano debía ser educado para ejercer efectivamente la participación.

La valoración de estar construyendo en América un nuevo sistema político novedoso y la alta estima de estar y ser parte del momento constitutivo referido al «tiempo social de articulación de la forma primordial, momento en que cuajan, se articulan y definen (...) la reproducción del orden social y político de un tiempo más o menos largo» ${ }^{185}$ construyó una autoimagen de los gestores de las Repúblicas absolutamente positiva y trascendente, tal como lo relataba uno de los próceres de la independencia chilena «(...) cuando se hallaron en la precisión de separarse de la madre patria y crear estados independientes (...) No admitieron distinción de rango, ni privilegios exclusivos; y fijaron para siempre la libertad, seguridad y dignidad popular en su célebre declaración de derechos» ${ }^{186}$.

La imperiosa necesidad de las elites de contar con estados cohesionados las empujó a buscar formas institucionalizadas para apoyar dicha faena, el sistema educativo fue clave para dotar de una mínima institucionalidad cuya referencia claves en el liberalismo. Si bien ya se había conquistado la independencia, había que generar las condiciones para el desarrollo de la libertad interna representada en la independencia individual y en el derecho a elegir a los gobernantes. La conquista de esa libertad no era por medio de las armas ni tampoco por una educación abstracta, sino por la educación en las artes del progreso, todos estos aspectos estuvieron dominados por «las posturas liberal iluministas que a su vez se plantearon como alternativas de poder político en la mayoría de los países de la región» ${ }^{187}$. Y por cierto el panorama fue que, en general, las elites no escatimaron esfuerzos con generar un sistema educativo secularizado que buscaba formar ciudadanos reflexivos y útiles para el bienestar de las naciones y comprometida con el progreso.

\footnotetext{
${ }^{185}$ TAPIA, Luis, «La producción teórica para pensar América Latina», en AGUILUZ, Maya y RIOS, Norma de los (coords.), René Zavaleta Mercado. Ensayos, testimonios y re-visiones, Argentina, Miño y Dávila Editores, 2006, p. 218.

${ }^{186}$ HENRIQUEZ, Camilo, «De las diversas formas de gobierno», La Aurora de Chile, 28 de mayo de 1812 , p. 2.

${ }^{187}$ EGAÑA, María Loreto, La educación primaria popular en el siglo XIX en Chile: una práctica de política estatal, Santiago, Ed. DIBAM, 2000, pp. 22-23.
} 
Como muchos de los países que se habían separado de España, en Chile, la preocupación por la educación fue tempranera en tomar forma y acciones concretas. El interés por elevar la cultura y educar a la población estuvo presente en los primeros momentos de la República. Esta necesidad de formar ciudadanos ya estaba incluida en los primeros escritos con la idea de exterminar los males del período colonial, ya que «en efecto, generalizando la instrucción, esparciendo los principios útiles y sólidos en toda la masa del pueblo, cultivando la razón publica, se debilitará seguramente la funesta influencia de las antiguas causas de error, y embrutecimiento ${ }^{188}$. Entonces, la educación fue percibida como el medio esencial para la formación del hombre nuevo, del ciudadano libre y, consecuentemente, del chileno. Se pensó también que educar a los individuos era prepararlos para asumir y disfrutar su libertad y, a la vez, resguardarlos del despotismo.

En los planteamientos acerca de la sociedad que se proyectaba advertimos varias dimensiones del espíritu liberal, cargado de virtudes ilustradas donde el centro de la discusión se expresó taxativamente en el campo de lo político desde los comienzos de la República. En el Gobierno de José Miguel Carrera (1812) hubo una disposición a que los conventos y cabildos abrieran escuelas para niños, cuestión que nos arroja algunos datos interesantes, ya que «cuando se levantó el primer censo escolar de la República, se halló que en la capital solo había 7 escuelas con 664 alumnos para una población de 50.000 habitantes»» ${ }^{189}$. Y en 1813 la Junta de Gobierno dictaba un reglamento que regulaba materias de enseñanza primaria que contenía algunas visiones y misiones del Estado en estos asuntos y en lo concreto establecía que «en toda ciudad, villa y todo pueblo que contenga cincuenta vecinos, debe haber una escuela de primeras letras costeada por los propios del lugar; y en caso de no haberlos, el jefe de la provincia respectiva debía proponer los arbitrios para su establecimiento» ${ }^{190}$. Estos intereses por la educación se manifestaron también en el Gobierno de O’Higgins (1818-1823) dado que decidió contratar a un inglés de apellido Thompson quién introdujo en Chile el

\footnotetext{
${ }^{188}$ HENRIQUEZ, Camilo, «Los hombres se habitúan a la esclavitud”, La Aurora de Chile, jueves 3 de septiembre de 1812 , p. 4.

${ }^{189}$ CAMPOS, Fernando, Desarrollo educacional 1810-1960, Santiago, Editorial Andrés Bello, 1960, p. 12.

${ }^{190}$ Ibidem, p. 13.
} 
método lancasteriano. Sistema que consistía en que los alumnos más adelantados debían atender a sus compañeros, lo que permitía que un solo profesor podría enseñar a cientos de estudiantes. En estos primeros momentos no hubo grandes avances ni en cobertura ni en calidad, pero es «indudable que hubo una preocupación apreciable desde los diferentes gobiernos; el espíritu iluminista y anti colonial presente en el discurso de estadistas y pensadores, visualizó a la educación del pueblo en una dimensión redentora, ligada a la formación de los ciudadanos de la nueva república» ${ }^{191}$.

En el período que la historiografía ha denominado anarquía o período de ensayos constitucionales que corresponde a 1823-1830 tampoco se avanzó mucho en materias educativas, producto del desorden político. Solo podemos señalar algunos datos recogidos en referencia muy generales como que hacia 1.830 «funcionaban en Santiago y los distritos adyacentes 26 escuelas primarias con asistencia media de 1.723 alumnos (...) en las ciudades importantes como Concepción, La Serena, Talca y Chillán existían también escuelas particulares cuyo número no hemos podido comprobar» ${ }^{192}$. Siendo un período de gran inestabilidad, solo hay algunas iniciativas muy aisladas y sin mayor impacto como la de atraer maestros europeos para que viniesen a trabaja a las escuelas existentes, especialmente para la educación secundaria; otra iniciativa es del tantas veces presidente en el período, Francisco Antonio Pinto, quien «puso especial empeño en establecer la enseñanza sobre bases sólidas» ${ }^{193}$. Otras acciones importantes en este período estuvieron tendientes a preocuparse por la educación popular, sí os estudios clásicos formaban al ciudadano gobernante, la educación popular aspiraba a modelar un nuevo pueblo que se integrara a la sociedad política.

A partir de 1830, un nuevo rango de intelectuales y activistas emergen, quienes ahora buscan gobernar los distintos sectores sociales en nombre de la nueva estructura de poder: republicana, oligárquica y censitaria que utilizarán como proyecto para crear la futura nación. La idea de República se impuso por sobre la de Monarquía, quedando

\footnotetext{
${ }^{191}$ EGAÑA, María Loreto; NUÑEZ, Iván y SALINAS, Cecilia, La educación primaria en Chile: 18601930. Una aventura de niñas y maestras, Santiago, LOM, 2003, p. 26.

${ }^{192}$ CAMPOS, F., Desarrollo educacional 1810..., op. cit., p. 17.

193 Ibidem, p. 15.
} 
claramente delimitados los componentes y apoyos de cada una de ellas. En las primeras décadas del siglo XIX, el grupo dirigente chileno se abocó a la compleja tarea de construir el Estado nacional, proceso que implicó dos cuestiones fundamentales e íntimamente relacionadas. Por una parte, la constitución del Estado como organización suprema del poder en un territorio delimitado y, por otra, la conformación de la nación, lo que suponía otorgar a la población del país un sentido de pertenencia y cierto grado viable de unidad política.

Desde 1830 la educación comenzó a tener un desarrollo interesante como parte del proyecto nacionalizador de la elite lo que implicó un «extraordinario florecimiento en las dos décadas siguientes; la enseñanza primaria, en cambio, seguirá abriéndose paso, lenta y dificultosamente, hasta llegar a su organización en $1860 »{ }^{194}$. La república conservadora logró su estabilidad después del período de desorden político que la antecedió y su institucionalización con la promulgación de la Constitución de 1833 que restringía libertades y centralizaba el poder en el presidente de la República. Esta República conservadora tenía como objetivos principales mantener el orden y la formación de un bien común y para dicha tarea, la educación era la encargada de unificar centralizadamente y de uniformar la diversidad existente en la sociedad. Aún así «forma parte del proceso de construcción republicana iniciada por la independencia» ${ }^{195}$. Esta constitución que rigió los destinos del país por noventa y dos años la convierte en un referente obligado a la hora de estudiar la educación decimonónica.

Dicha constitución establecía dos cuestiones claves vinculadas a la educación. Primero, el derecho a votación fue censitario y establecía en su artículo $8 .^{\circ}$ que «son ciudadanos activos con derecho a sufragio los chilenos que habiendo cumplido veinticinco años, si son solteros, $\mathrm{y}$ veintiuno, si son casados y sabiendo leer y escribir (...)» ${ }^{196}$. En este sentido, el carácter constitucional entre ciudadanía y escritura, compone una situación

\footnotetext{
${ }^{194}$ Ibidem, p. 16.

${ }^{195}$ SERRANO, S.; PONCE DE LEON, M. y RENGIFO, F., Historia de la Educación en Chile (18102010). Tomo I ...», op. cit., p. 85.

196 «Constitución Política de la República de Chile» Recopilación de todas las leyes, decretos, y demás disposiciones de interés general, Santiago, Imprenta Nacional, 1897, p.10.
} 
notable. En segundo lugar, la Constitución estableció el Estado Docente al declararla como una acción preferente del Gobierno y la creación de un organismo encargado de la supervisión educativa. Es el origen republicano de la relación entre educación, ciudadanía y política estatal. El artículo 153 consagra dicha voluntad en el sentido que la educación es una atención preponderante del Estado declarando como principio articulador que será el Estado quien supervisará ya que «habrá una superintendencia de educación pública, a cuyo cargo estará la inspección de la enseñanza nacional, y su dirección bajo la autoridad del gobierno» ${ }^{197}$.

En la década siguiente se abrió una época de gran actividad intelectual y política. Chile fue un lugar de residencia de muchos intelectuales y luego del triunfo conservador de 1831 hubo una suerte de «retorno a las estructuras sociales coloniales, el que se dio justamente porque respondía a valores y conceptos arraigados secularmente» ${ }^{198}$. Luego del triunfo de Chile sobre la Confederación Perú-boliviana en 1837 se inició una etapa de esplendor intelectual y político. Chile fue un lugar de asilo de intelectuales extranjeros como Bello, Sarmiento y Domeyko. También fue un período de expansión de las discusiones políticas, literarias y filosóficas; y por cierto un tiempo de organización del Estado docente encabezado por la obra del venezolano Andrés Bello, La Universidad de Chile, que sin duda es el «hecho más importante en todo el panorama cultural y educacional chileno de la época (...) fue un cuerpo deliberante, consultivo y académico, con la responsabilidad expresa de revisar toda la educación nacional» ${ }^{199}$. La llegada del ya citado Bello iba a transformarse en el centro indiscutido del mundo intelectual chileno por más de 35 años. El presidente de la República, Manuel Bulnes, en 1842 señalaba que para extender la educación en todo el territorio debía ser una institución estatal que fuera la gran vigilante del sistema educativo, ya que «(...) metodizará la educación primaria y propagará los estudios superiores, ofreciendo

\footnotetext{
197 Ibidem, pp. 46-47.

198 GAZMURI, Cristián, El 48 chileno. Igualitarios, reformistas, radicales, masones y bomberos, Santiago, Editorial Universitaria, 1998, p. 29.

${ }^{199}$ Ibidem, p. 28.
} 
estímulo de honor y gloria a los talentos, servirá de poderoso auxiliar a los trabajos que se emprendan por los diversos departamentos de la administración» ${ }^{200}$.

En esto se advierte una clara intención que la educación sea la que provea al Estado de los equipos idóneos y capacitados para la administración pública. La fundación de la Universidad de Chile como superintendencia de educación y academia científica, se transformó en el organismo que encadenaría todos los niveles de la educación. Este papel de superintendencia estaba formado por el rector y los decanos de las Facultades. La creación de la Universidad permitió generar un plan de educación para la nación y una estructura que sostuviera todo el sistema educativo. En la Universidad de Chile el organismo clave para el sistema educativo era también la Facultad de Filosofía y Humanidades encargada de la «(...) dirección de las escuelas primarias, la redacción de sus reglamentos y programa y la aprobación de sus textos de estudio. Debía inspeccionar y visitar las escuelas de la capital y de provincias y confeccionar la estadística. En la educación secundaria proponía los ramos de estudio» ${ }^{201}$.

Hasta la década de los setenta del siglo XX, hubo fiscalización por parte de entes públicos sobre las instituciones educativas privadas, esto se realizaba a través del Consejo Universitario que era el espacio institucional «donde residían las funciones de superintendencia, tenía el privilegio de otorgar los grados de bachiller y licenciado (...) se requería haber rendido los exámenes anuales de la educación secundaria, ya fuera pública o privada, ante comisiones formadas por los miembros de las facultades» ${ }^{202}$. Evidentemente, que, con esta potestad, la Universidad de Chile fijaba el currículum secundario tanto en los colegios privados como en los públicos.

Podemos considerar que la Universidad de Chile es simultánea a los procesos de constitución de las universidades modernas en el siglo XIX con su vocación por las

\footnotetext{
${ }^{200}$ Sesiones de Cuerpos Legislativos de la República de Chile, 1842, Santiago de Chile, Editorial Progreso, 1900 p. 121.

${ }^{201}$ SERRANO, S.; PONCE DE LEON, M. y RENGIFO, F. Historia de la Educación en Chile (18102010), Tomo I..., op. cit., p. 88.

${ }^{202}$ SERRANO, Sol, Universidad y nación. Chile en el siglo XX, Santiago, Editorial Universitaria, 1993, p. 70 .
} 
ciencias naturales, la investigación y el sentido utilitario de lo que allí se estudiaba, pero más importante en la satisfacción de las necesidades del Estado republicano fue la de haber sido uno de los pilares fundamentales en la de haber forjado una conciencia nacional. La creación de la Universidad tenía como misión fundamental transformar al país e incorporarlo a la modernidad, la tarea de formar una elite estatal y social capaz de conducir la construcción del estado nacional formando una identidad nacional común para integrar a las distintas clases sociales a la incipiente República.

\subsection{La expansión de la cobertura educativa a lo largo del siglo XIX}

La transición desde la sociedad de Antiguo Régimen significó que la nueva realidad política demandaba una nueva relación en los vínculos entre gobernados y gobernantes que, por cierto, fue ambigua y compleja. La educación formó parte de esa transición. Al contrario del Antiguo Régimen, el Estado nacional chileno tenía una clara vocación anti-corporativista. Desde la fundación del Instituto Nacional en 1813, con sus vaivenes y refundaciones, se transformó en el modelo nacional de educación que la elite estatal diseñó para Chile. El Estado nacional actúa como soberano en la educación tanto con el Instituto Nacional como con los liceos provinciales. La idea que prevaleció fue replicar el modelo del Instituto Nacional en el territorio nacional, pero de igual manera los cabildos, conventos u otras corporaciones pudieron fundar colegios. Esto se explica en la ambigüedad del período, establecieron políticas nacionales, pero conviviendo con poderes locales a lo largo del territorio con márgenes de autonomía.

La educación primaria era el único ámbito que pretendía ser nacional y cubrir todo el territorio. La necesidad de proporcionar educación a todos los habitantes era un deber del Estado desde mediados del siglo XIX. Pero el Estado no tenía la capacidad de hacerlo por recursos, la geografía y un país eminentemente rural. El Estado tuvo que recurrir a las autoridades locales para llevar a cabo su política. Figura clave en la implementación fueron los Intendentes, representantes del Poder Ejecutivo en las provincias quienes construyeron una red con párrocos, gobernadores, hacendados, jefes 
de policías, etc. Estos vínculos fueron protagonistas activos de la educación y las escuelas en las localidades y decisivos para la instalación en todo el territorio nacional.

En los primeros años de la República hubo escuelas, las más numerosas eran las «domésticas». En estos establecimientos un «hombre o una mujer, alfabeto enseñaba a unos pocos niños a leer y a escribir en su casa por un pequeño estipendio y por un tiempo variable e indeterminado» ${ }^{203}$. Otra forma muy extendida entre la élite eran las clases particulares y en los conventos. En estas últimas, el Gobierno proporcionaba algún material para su ejecución. Los cabildos también tenían escuelas con carácter formal, pero funcionaron de forma muy precaria.

La cobertura territorial nunca dejó de ser precaria y había escuelas donde las comunidades locales habían establecido una alianza entre vecinos, autoridad local y Gobierno. Esta relación con la autoridad central se hizo más estrecha permitiendo a los municipios obtener financiamiento para la instalación y funcionamiento de las escuelas por parte del Estado nacional. Según algunos testimonios de la época, al Gobierno le acomodaba mucho esta forma en que los municipios fueron fundando colegios y que estas se debían al «celo de los cabildos, de las comunidades religiosas y de los individuos que animados de un verdadero patriotismo han querido coadyuvar a las

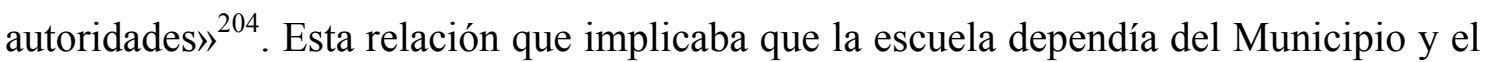
financiamiento y dirección del Gobierno central hizo que se fueron ampliando la cobertura escolar a lo largo del territorio nacional. Un hecho significativo ocurrió en 1837 que permitió ampliar la mencionada cobertura territorial de la educación. Ese año se inauguró el Ministerio de Instrucción, Justicia y Culto lo cual permitió legalizar rápidamente los actos administrativos para el cumplimiento de fundar e instalar escuelas. de dotar de escuelas a la nación bajo el amparo del estado.

La constitución de la educación pública se materializó financiándola y dirigiéndola, fortalecida aún más con la fundación en 1842 de la Escuela Normal de Preceptores la

${ }^{203}$ SERRANO, S.; PONCE DE LEON, M. y RENGIFO, F., Historia de la Educación en Chile (18102010), Tomo I ..., op. cit., p. 143.

${ }^{204}$ Sesiones de Cuerpos Legislativos, Senadores, 1835, T. XXIII, 1834-1836, p. 418. 
cual le daría mayor homogeneidad al sistema educativo que se quería implantar y a la creación de la Universidad de Chile el mismo año.

La acción esmerada del Estado implicó que la educación pública y físcal avanzara, tal como lo demuestra el siguiente cuadro:

\section{Cuadro $N^{0} 1$. Número de escuelas y alumnos del sistema de Instrucción Primaria, 1848-1906.}

\begin{tabular}{|c|c|c|c|c|c|c|c|c|c|c|c|c|}
\hline & \multicolumn{4}{|c|}{ Número de Escuelas } & \multirow[b]{2}{*}{ 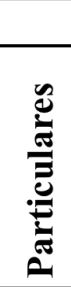 } & \multirow[b]{2}{*}{ 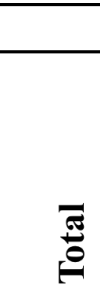 } & \multicolumn{5}{|c|}{ Número de Alumnos (matrículas) } & \multirow[b]{2}{*}{ 苞 } \\
\hline & 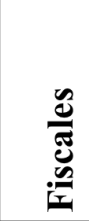 & 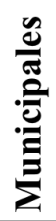 & 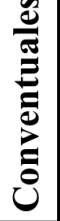 & 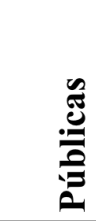 & & & 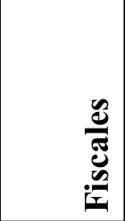 & 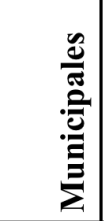 & 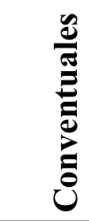 & 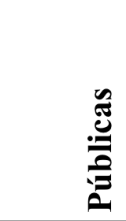 & 密 & \\
\hline 1848 & & & & & & 474 & & & & & & \\
\hline 1853 & 186 & 94 & 18 & & 273 & 571 & 8.982 & 5.433 & 1.175 & & 7.546 & 23.136 \\
\hline 1854 & 271 & 97 & 17 & & 292 & 677 & 13.329 & 5.387 & 1.287 & & 5.867 & 25.870 \\
\hline 1858 & 417 & 71 & 18 & & 252 & 758 & 21.827 & 3.789 & & & 8.085 & 33.701 \\
\hline 1860 & 486 & 80 & & & 316 & 882 & 23.882 & 4.246 & & & 11.501 & 39.629 \\
\hline 1865 & & & & 599 & 437 & 1.036 & & & & 38.439 & 12.855 & 51.294 \\
\hline 1870 & & & & 676 & 486 & 1.162 & & & & 52.945 & 20.981 & 73.926 \\
\hline 1875 & & & & 818 & 541 & 1.359 & & & & 65.875 & 23.635 & 89.510 \\
\hline 1880 & & & & 620 & 405 & 1.025 & & & & 48.794 & 15.106 & 63.900 \\
\hline 1885 & & & & 826 & 598 & 1.424 & & & & 68.894 & 28.242 & 97.136 \\
\hline 1890 & & & & 1.201 & 547 & 1.748 & & & & 101.053 & 27.517 & 128.570 \\
\hline 1895 & & & & 1.248 & 411 & 1.659 & & & & 114.565 & 25.426 & 139.991 \\
\hline 1899 & & & & 1.403 & 445 & 1.848 & & & & 106.348 & 26.194 & 132.542 \\
\hline 1906 & & & & 2.265 & 362 & 2.627 & & & & 106.736 & 38.165 & 144.901 \\
\hline
\end{tabular}

Fuente: PONCE DE LEON, Macarena, «La llegada de la escuela y la llegada a la escuela. La extensión de la educación primaria en Chile, 1840-1907» en Historia, $\mathrm{N}^{\circ}$ 43, vol. II, (juliodiciembre 2010), p. 454.

Como lo demuestra el Cuadro $\mathrm{N}^{\circ} 1$ la escuela fiscal creció menoscabando el número de las conventuales y municipales. Entre los años 1853 y 1860, las escuelas fiscales y los alumnos aumentaron casi en misma proporción de 2,6 veces. En las municipales y conventuales el número disminuyó y hacia 1860, las conventuales habían desaparecido de la estadística, ya que se habían hecho particulares. Entonces, tenemos que para los sesenta, el fisco representaba el $55 \%$ de las escuelas y concentraban el $60 \%$ de la 
matrícula de los estudiantes. La expansión territorial de la escuela se realizó por todo el país. El efecto de la política fundacional del Estado chileno fue instalar escuelas donde hubiese población reunida. Entre 1840 y 1859 la expansión fue muy intensa. En ese período se inauguraron escuelas en un número de «491 fiscales, de las cuales 252 incorporaron nuevas localidades $(\ldots){ }^{205}$. Esta política intensiva de fundaciones de escuelas se vio favorecido por un decreto de 1854 que obligaba al Estado a financiar con un $50 \%$ de los costos en infraestructura si los vecinos ponían el otro $50 \%$. De esta manera, tenemos que entre 1853 y 1906 se transitó de 571 escuelas a 2.627, de 23.136 a 144.901 estudiantes y de 1.303 personas encargadas de la educación a 2.365. Estos datos revelan la gran expansión del Estado nacional chileno en el objetivo de instaurar un sistema educativo amplio, público, administrado y financiado por el Estado. En las estadísticas se contabilizan como fiscales tenemos que después de 1860 con la Ley de Instrucción Primaria se consideraron a las escuelas fiscales y municipales como públicas. El caso de las conventuales, en general pasaron a engrosar las filas de los establecimientos educacionales particulares. La estadística también demuestra el aumento sostenido del número de estudiantes del ámbito rompiendo cierto equilibrio que se apreciaba antes de la legislación de 1860. La creciente legislación que se fue desprendiendo de la ley de Instrucción Primaria de 1860 estructuró una red de escuelas públicas en el territorio nacional que representaba en 1865 el 57,8\% y en 1906 el 86.2\% de las instituciones educativas primarias. La cobertura de estudiantes pasó de un $74 \%$ a un $73,6 \%$ para el mismo período. Esto se explica dado que las escuelas públicas debieron atender a localidades rurales dispersas mientras que las escuelas particulares estaban concentradas en centros urbanos, financiadas por la beneficencia privada o institucional $^{206}$.

\subsection{Ley de Instrucción: hacia la consolidación del sistema educativo chileno}

La Ley de Instrucción Primaria de 1860 consolidó la función del Estado en la tarea educativa. Este fue un proyecto que databa desde 1849 cuando fue presentado por el

\footnotetext{
${ }^{205}$ SERRANO, S.; PONCE DE LEON, M. y RENGIFO, F. Historia de la Educación en Chile (18102010), Tomo I ..., op. cit., p. 155.

${ }^{206}$ Vid. EGAÑA, Loreto, «La cobertura de la Educación Primaria Popular en Chile; 1890-1920», Boletín de Investigación Educativa, $\mathrm{N}^{\circ} 10$ (1995), pp. 308-319.
} 
diputado José Victorino Lastarria, quien ya planteaba que «la instrucción primaria es elemental y superior (...). Todo individuo que tenga 16 años cumplidos podrá ejercer la profesión de preceptor de instrucción primaria siempre que pueda presentar a la autoridad competente (...)» ${ }^{207}$. Para poder ser preceptor (maestro de escuela) debía estar en posesión de alguna certificación que avalara tal profesión. De esta forma, el proyecto contemplaba quien detentaba y financiaría las escuelas. Estas se podían mantener con «los fondos del tesoro nacional, por fondos municipales, por los conventos de regulares y los monasterios, por alguna fundación $(. ..){ }^{208}$ El proyecto fue enviado a la Facultad de Filosofía y Humanidades de la recién creada Universidad de Chile el cual no prosperó porque el propio Lastarria perdió el interés en el asunto.

El proyecto fue mejorado con las indicaciones de Antonio García Reyes quien agregó aspectos relacionados con inspección de las escuelas, creando los cargos de visitadores de escuelas. El proyecto de García fue presentado en 1848 y en el Congreso se le indicó que debían hacerle algunas modificaciones y en «1849, el diputado Montt, al proponer para la discusión el proyecto de su autoría, impugnó las carencias del anterior: la falta de un reconocimiento del fundamental derecho de los habitantes del país a tener una instrucción primaria gratuita, así como el deber del Estado de darles esa educación $(\ldots) »^{209}$. El citado diputado criticó el proyecto porque solo refería a educación de hombres y diseñó un nuevo Proyecto de Ley. Planteó una discusión muy novedosa.

El tema central de Montt era que la ley no debía garantizar solo la educación para los hombres, sino que todos los habitantes y establecía que el derecho a la educación «impone al Estado el deber de proporcionarla a los que se hallen en aptitud de recibirla, estableciendo escuelas en número suficiente. Ambos sexos merecen igual atención» ${ }^{210}$. Y como era un derecho debía financiarla el Estado y debía ser gratuita. Los artículos relativos al papel del Estado y una educación para todos fueron aprobados por

\footnotetext{
207 «Moción sobre arreglo de la Instrucción primaria presentada a la cámara de Diputados en sesión de 18 de agosto de 1843», en Proyectos de Ley y discursos parlamentarios. Primera serie, Santiago, Imprenta y Encuadernación Barcelona, 1907, p.13.

208 Ibidem, p. 14.

${ }^{209}$ EGAÑA, M.; NUÑEZ, I. y SALINAS C. La educación primaria en Chile: 1860 ..., op. cit., p. 16.

${ }^{210}$ MONTT, Manuel, Moción presentada al Congreso Nacional por el señor diputado D. Manuel Montt sobre la Instrucción primaria, Santiago, Imprenta el Progreso, p. 5.
} 
unanimidad. El financiamiento no fue aprobado, dado que la propuesta de Montt señala que para solventar los gastos y satisfacer la necesidad de implantarla era «indispensable un impuesto especial» ${ }^{211}$. El financiamiento enfrentó a liberales y conservadores, en especial en torno a quien debía sufragar la educación, si los privados por medio del aumento de impuestos (conservadores) o era un deber del Estado que ya estaba consagrado en la Constitución (liberales). Los conservadores manifestaban que esta debía financiarse con una contribución directa que debían pagar todos los ciudadanos y las municipalidades debían ejecutar la recaudación y la administración de dichos recursos. En este sentido, intervino el propio Montt, en 1849, ante la negativa de establecer impuesto para costear la educación afirmando que «se teme cargar al país con una nueva contribución, pero no se teme dejarlo ignorante $(\ldots){ }^{212}$ Por el bando contrario, los liberales postularon que era el Estado quien debía proveer los fondos.

El argumento de los liberales era que la Constitución señalaba que «la educación pública es una atención preferente del gobierno» ${ }^{213}$. Esa atención significaba que el gobierno debía fomentar la escuela, de acuerdo con sus recursos. El proyecto fue rechazado en la Cámara de diputados y en el Senado en 1852, siendo ya Manuel Montt, presidente de la República. El tema de atención preferente del Estado era el fondo del asunto, Montt seguía planteando que no había obligación del Estado y por lo tanto los recursos debían ser sufragados por los contribuyentes. Siendo Montt presidente volvió a poner en trámite el citado proyecto en 1857. En la discusión parlamentaria, la mayoría estuvo en contra del artículo primero. Después de una ardua discusión el citado artículo quedaría redactado de una forma distinta: «La instrucción primaria se dará bajo la dirección del Estado» ${ }^{214}$. Fueron más de 15 años de intenso debate sobre el rol del Estado en el campo educativo y finalmente en el año 1860 se aprueba la Ley de Instrucción Primaria en la cual el debate se zanjó de una forma bastante sibilina. Tuvo visos de contrasentido que en un sistema político que se hacía cada vez más liberal, la

\footnotetext{
${ }^{211}$ Ibidem, p. 12.

${ }^{212}$ Sesiones de Cuerpos Legislativos, 18 de junio de 1849, p. 57.

213 «Constitución Política de la República de Chile» en Ministerio del Interior, Recopilación de todas las..., op. cit., p. 25.

${ }^{214}$ Lo citado en relación a la Ley de Instrucción Primaria en LARRAIN, J. Ignacio y LARRAIN, J. Joaquín, Boletín de las principales leyes y decretos vigentes dictados desde enero 1 de 1870 hasta enero 1 de 1871 y recopilación por orden de materias, Valparaíso, Imprenta El Mercurio, 1871 p. 490.
} 
educación asumía de manera inversa el resguardo de la unidad nacional. Sostenemos que, en la cultura del consenso del siglo XIX, el primer artículo de la Ley hizo hincapié en la dirección estatal de la escuela. Un dilema curioso en una atmosfera liberal de la segunda mitad del siglo XIX chileno.

La Ley fue aprobada en 1860 que impuso al Estado dos asuntos de gran impacto: en primer lugar, en el artículo $4 .^{\circ}$ indicaba la cantidad de escuelas que debían existir en cada departamento «(...) las escuelas de ambos sexos que fueran necesarias, hasta llegar a la proporción de una escuela elemental de niños y otra de niñas, por cada dos mil habitantes que contuviere la población» ${ }^{215}$. Y una segunda, que probablemente constituye un acierto desde la óptica liberal, el artículo segundo establece que «(...) la instrucción que se diere en virtud de esta ley será gratuita y comprenderá a las personas de uno y otro sexo» ${ }^{216}$. Ambas obligaban al Estado a una política pública abordando los temas de cobertura y financiamiento como artífice de la cohesión de una nueva comunidad.

El Estado, por medio de la educación se consagró con la dictación de la Ley de Instrucción Primaria en la concreción de un proyecto político para la construcción de la sociedad política. A lo largo de la historia de la educación chilena, el Estado ha promovido y ha entendido la educación como un plan para conseguir la civilización, la libertad, la cohesión, la nacionalización, y finalmente la igualdad. La escuela fue un proyecto político e independiente que haya sido elitista y jerárquica no podemos rechazar la dimensión política de los constructores del Estado nacional chileno en el siglo XIX.

En la educación como objeto de estudio, encontramos una multiplicidad de vertientes culturales, sociales e ideológicas. Pese a ello, la educación y su estudio entendido como progreso moral y civilizador tendrán su más alta valoración cuando el Estado moderno comprenda que en ella tiene una importante herramienta de transmisión de sus ideales,

\footnotetext{
215 Cit. en Ibidem, p 491.

${ }^{216}$ Cit. en Ibidem, p. 492.
} 
ya que, por medio de ella, se robustece la nación uniéndola por lazos intangibles capaces de alcanzar una asombrosa cobertura. El examen de la educación en la conformación del Estado permite advertir la profundidad del debate acerca de las sociedades que se deseaban construir en el pasado. El binomio Educación-Estado nacional ha sido estudiado por la historia de la educación y por la historia política. La historia descriptiva, institucional y pedagógica caracterizaba a la primera, aunque en las últimas décadas ha habido cierta renovación historiográfica, que ha ido apreciando y descubriendo en la educación una gran posibilidad para el estudio de las ideas, de las sociedades, de las mentalidades, de la cultura e incluso de la historia económica. La educación es el punto de encuentro de varios ámbitos y dimensiones de la sociedad y buen reflejo del proyecto histórico de una sociedad.

La educación formó parte del proceso de construcción del Estado nacional que buscaba racionalizar y homogeneizar a la sociedad en función del concepto de nación. La educación era la expresión del Estado que deseaba reformar paulatinamente una sociedad tradicional y establecerla de acuerdo con los nuevos cánones y demandas del presente decimonónico. Perseguía darle cohesión a una nación en ciernes, generar vínculos de adhesión y lealtad en la población y formar unos sujetos nacionales que condujeran el país hacia la modernización. En la educación encontramos la síntesis de dos ideas que definían el camino hacia la consolidación del Estado nacional: la conformación de un sistema político fundado en la soberanía popular y el desarrollo económico sustentado en los cambios científicos y tecnológicos. Fue una trayectoria con grandes dificultades que arranca desde 1820 y que no va a culminar hasta 1880 «en un proceso de transformación que culminó después de la conquista del salitre» ${ }^{217}$. Sin duda, que existió una relación asimétrica entre el proyecto político de la nación y la constitución financiera de las nuevas repúblicas.

La expansión de la educación chilena comenzó a todas luces a partir de 1860 coincidiendo además con el período de mayor crecimiento económico del siglo XIX

\footnotetext{
${ }^{217}$ ORTEGA, Luis, «De la Construcción del Estado-nación y la política económica. Chile 1817-1890» en CID, G. y SAN FRANCISCO, A. (eds.), Nación y Nacionalismo en Chile..., op. cit., p. 145.
} 
producto del auge minero y triguero. A esto acompañaron procesos ingentes de urbanización y modernización. El Estado no solamente impulsaría la creación de escuelas primarias, sino que, además, daría un fuerte impulso a la educación secundaria. Fue en la década de los sesenta que Estado intentó con gran éxito, establecer una educación nacional, de amplia cobertura, de modo que los niños y jóvenes fuesen paulatinamente aprendiendo a leer y escribir y se convirtieran en ciudadanos. La política de uniformidad educativa, terminó por bajar el perfil a las experiencias regionales, en especial, la de Valparaíso y unificó la enseñanza completamente a fines del siglo XIX y principios del XX.

Fue el año 1865 con el dictamen de un Decreto Supremo cuando se estableció que todos los establecimientos educacionales debían elaborar sus programas de estudios, de acuerdo con el listado de asignaturas del Instituto Nacional, con la idea de evitar un sistema desordenado y disgregado. Esto se hizo con la finalidad de igualar la educación, unificar los contenidos y corregir todas los desórdenes y desacuerdos. El propio Ministerio de Justicia, Culto e Instrucción pública en dicho año señalaba que respecto al Plan de Estudio Nacional «ha venido a perfeccionar la educación que se da en los liceos y ha uniformado a todos estos establecimientos entre sí y con el Instituto Nacional $(\ldots) »^{218}$. En el mismo documento se destaca que habrá un plan nacional de estudios, $\mathrm{y}$ que las particularidades regionales serán atendidas y que «La Serena (...) tiene un curso especial de ingenieros de minas (...) El de Valparaíso (...) centro comercial de la República, tiene un curso especial de comercio (...)» ${ }^{219}$. Valparaíso, especialmente, y otras ciudades durante el siglo XIX contaron con establecimientos educacionales que recogían la inquietud de la población por una educación comercial y buscaban satisfacer las necesidades detectadas por la élite en relación con las actividades comerciales de la ciudad.

Los planteamientos regionales disminuyeron a medida que avanzaba el siglo y sobre todo desde 1860 con la Ley de Instrucción Primaria y el Decreto Supremo de 1865 -ya

\footnotetext{
${ }^{218}$ Memoria del Ministerio de Justicia, Culto e Instrucción Pública, Santiago, Imprenta Nacional, 14 de agosto de 1865, p. 144

${ }_{219}$ Ibidem, p. 145.
} 
citado, por la apuesta del Estado chileno de diseñar una política nacional de educación y por ciertas directrices de una tradición muy arraigada en la elite chilena, la supremacía de la formación humanista, política y sobre todo por la obsesión del carácter unitario del Estado nacional chileno. La autoridad centralizadora veló por una educación que reforzó la idea positivista del progreso de la nación y el proyecto del Estado simbolizaba las ideas ilustradas y liberales tendientes a incorporar a Chile a la modernización, y en este sentido, la educación, fue una obra principalmente estatal.

\subsection{La pedagogía cívica en la construcción de lo nacional: fiestas y funerales}

La unidad de la República debía ser desarrollada entre otros por la educación. La integración de los distintos grupos sociales, culturales y étnicos, la creación de la identidad nacional y la legitimación del poder del Estado serían sus funciones y tareas. La educación cooperaría en la construcción del consenso, de manera que mediante un complejo sistema de funciones se lleva a cabo el itinerario cultural e ideológico para obtener la homogeneidad de los diversos sectores sociales. La educación, en este sentido, se constituiría en un factor óptimo para conseguir el consenso. Debe indicarse, al mismo tiempo, que la educación no se limita a la mera enseñanza formal, toda sociedad tiene su pedagogía cotidiana que «es esencial para la transmisión de lo adquirido, y para la perpetuación y reproducción de las relaciones sociales que estas implican en dicha transmisión» ${ }^{220}$, que interviene en la práctica social, integra o busca integrar sus diversos aspectos.

La pedagogía cotidiana lleva a considerar la función pedagógica inherente a las manifestaciones de acción cívica: las inauguraciones de estatuas o monumentos públicos, las celebraciones de determinadas fechas, así como el entierro de algún personaje, podían servir de pretexto de un ceremonial más o menos elaborado, que se encargaba de transmitir un mensaje histórico que repetía fielmente la lección que se aprendía en las aulas de clases. Las fiestas republicanas se tiñeron simbólica y

\footnotetext{
${ }^{220}$ KAPLAN, Marcos, Estado y Sociedad, México, Universidad Nacional Autónoma de México, 1980, p.
} 213. 
estilísticamente de un nuevo pensamiento y estética y funcionó como un escenario formativo de una nueva realidad política. Desde las primeras décadas del siglo XIX se valoraban positivamente los rituales cívicos y así lo dejó plasmado un viajero sueco que visitó Chile entre 1821 y 1827, Carlos Bladth, quien relató un acto de celebración de la batalla de Maipú presidido por Bernardo O’Higgins donde indicaba que: «Durante este acto el director supremo y todos los asistentes estaban descubiertos, el coro fue cantado por todo el público - de la Canción Nacional. Luego empezó la música y un coro de niños de diez años de edad llevando una pequeña espada en una mano y un ramo de laurel en la otra, circularon alrededor del árbol simbólico, depositando cada uno su ofrenda al pie del tronco.» ${ }^{221}$

La participación escolar y de la juventud en las fiestas no es otra forma, más que la pedagogía cívica y cotidiana desplegada por las autoridades. Lo más probable que en las fiestas quedara en evidencia que el pueblo que se quería adoctrinar estaba muy lejos de los ciudadanos ideales que querían formar las elites. Las fiestas cívicas debieron ser controladas y su importancia, radicaba en los mensajes emitidos en celebraciones y de ahí el imperativo de dirigirlos y tutelarlos como los planes de estudio de las escuelas.

Entre los mecanismos e instrumentos que eligió la elite para instaurar el nuevo orden eligió dispositivos preexistentes. La liturgia colonial, la presencia de velas, banderas, representaciones teatrales, bailes «fueron tomadas del pasado colonial, lo cual determinó la similitud formal entre las fiestas dedicadas al rey y las republicanas» ${ }^{222}$. En la época de la independencia observamos el tránsito de una festividad monárquica a una de corte republicano. La fuerte tradición festival colonial, en la que las juras de fidelidad y los festejos por los nacimientos de los príncipes eran tan importantes, se adaptó a favor de la celebración de los triunfos patriotas y la fundación de la nueva República. La finalidad de celebrar la independencia como hito histórico de liberación del territorio de España y estimular el sentimiento de identidad y orgullo nacional quedó

\footnotetext{
${ }^{221}$ BLADTH, Carlos, La República de Chile 1821-1828, Santiago, Imprenta Universitaria, 1951, pp. 7475.

${ }^{222}$ PERALTA, Paulina, Chile tiene fiesta: el origen del 18 de septiembre, 1810-1837, Santiago, LOM, p. 145 .
} 
plasmado en el cartel de febrero de 1818 por la conmemoración del triunfo en la Batalla de Chacabuco ocurrida en 1817. Dicho cartel indicaba que la gran fiesta cívica que se celebrara es una dedicatoria a «los patriotas chilenos, que por su amor a la libertad de la Patria han sido víctimas del furor español» ${ }^{223}$.

Es importante consignar, no obstante, que toda la representación republicana buscaba una ruptura con el orden colonial, por ende, las fiestas a inicios de la República tenían cierta originalidad, se mantuvieron las formas, pero el fondo había cambiado rotundamente, ya que fueron diseñadas y puestas en marcha con objetivos nacionales. La simbología revolucionaria francesa fue de gran inspiración como lo fueron el árbol de la libertad, los colores rojo, azul y blanco, presente en escudo, escarapela, trajes, y fundamentalmente la bandera. Otros elementos incorporados de la Revolución francesa fueron el culto a los héroes, la canción nacional, es así que los ideales franceses permitieron «(...) proporcionar un nuevo concepto del poder, un reciente sistema de gobierno y unos símbolos inéditos, trajeron de las tierras galas el fervor patriótico de las flamantes fiestas revolucionarias, que pretendían ser solo cívicas, vaciándose de contenidos religiosos tradicionales ${ }^{224}$.

Las fiestas estaban destinadas a estimular lo nacional y a difundir entre las diferentes capas sociales el conocimiento y respeto por las nuevas instituciones y autoridades. Bladth, el viajero sueco, ya citado, relata que la conmemoración de la Batalla de Maipú, que había sellado la independencia, fue «celebrada con solemnes y alegres fiestas, carnavales y bailes» ${ }^{225}$. La fuerte tradición festival colonial -como ya se ha comentadoen la que las juras de fidelidad y los festejos por los nacimientos de los príncipes eran tan importantes, se adaptó a favor de la celebración de los triunfos patriotas y la fundación de la nueva República. La finalidad suprema era conformar una nación y las fiestas constituyeron un excelente mecanismo para mostrar las bondades que traía

\footnotetext{
${ }^{223}$ Cit. en CRUZ, Isabel, La fiesta: metamorfosis de lo cotidiano, Santiago, Ediciones Universidad Católica de Chile, 1995, p. 300.

${ }^{224}$ Ibidem, p. 296.

${ }^{225}$ BLADTH, C., La República de Chile ..., op. cit., p. 74.
} 
consigo integrar la comunidad chilena. Muy clarificador es la exaltación de un periódico con motivo de las fiestas patrias en 1834:

«(...) entreguémonos con toda efusión al recuerdo de lo que fuimos, de lo que somos y de lo que debemos ser, y entretengamos el pecho del ciudadano ese ardor sagrado que supo vencer los mayores peligros cuando hubo unión y patriotismo... y si llegase el día que en que necesitásemos reanimar el entusiasmo, recordemos que somos chilenos $(\ldots) .{ }^{226}$

El proceso que vivía Chile en esos años, y durante el siglo XIX en general, era muy parecido al que también experimentaron muchos estados hispanoamericanos. En realidad, era un proceso de carácter todavía más amplio, por cuanto Europa por supuesto también se encontraba al mismo tiempo en una época de nacionalismo y formación de identidades nacionales involucrados en guerra, organización política, cultura y símbolos patrios. Es así, que la fiesta ocupó un rol fundamental amparado en viejas prácticas coloniales con una mixtura entre Antiguo Régimen y República; y entre lo sacro y lo laico. La sociedad de principios del siglo XIX tuvo que afrontar por diferentes medios y mecanismos la formación de los estados nacionales. las fiestas patrias iban produciendo efectivamente una toma de conciencia nacional en la población, y los lugares donde se realizaban contaban con banderas y otras expresiones de chilenidad. Pero, paralelamente, si pudieran resumirse los elementos constitutivos de las fiestas, ellos eran el canto y la música, el baile y también el consumo de alcohol.

Luego de la independencia se celebraron en Chile los aniversarios de todas las batallas ganadas a los españoles, y así lo relató Ignacio Domeyko en 1838 la forma de concebir una sola fecha puesto que se «logró unir todas estas numerosas fiestas fijando para celebrarlas en un solo día, la fecha del 18 de septiembre, como aniversario del primer Consejo Nacional que proclamó la Independencia de Chile» ${ }^{227}$. De esta forma quedó para la posteridad que septiembre fuese el mes de la Patria.

\footnotetext{
${ }^{226}$ El Minero del año 34, La Serena, No 2, 24 de septiembre de 1834, p. 7.

227 «La fiesta del Aniversario de la Independencia de Chile», Mapocho, No1, (1963), p. 2.
} 
En todo caso, está claro que entre las antiguas fiestas reales y las nuevas celebraciones republicanas hubo cierta continuidad. La República no podía erradicar completamente el pasado, ni podía generar un ritual original en torno a los flamantes valores republicanos que querían implorarse como sustento del nuevo Estado nacional. Los nuevos gobernantes promovieron las fiestas y celebraciones en el que «encontraron cabida prácticamente todos los elementos festivos propios de las celebraciones en honor del Rey» ${ }^{228}$. Como en muchos aspectos de la transición del Imperio español a la República hubo continuidad.

Las fiestas y las celebraciones se transformaron en la conexión entre el grupo dirigente y los sectores populares para la incorporación de estos al proyecto nacional. De este modo la autoridad permitió las celebraciones siempre que estas confluyeran en el plan como el 18 de septiembre y prefirieron «tolerar, permitir y aun estimular el tipo de expresiones festivas que en cualquier otro momento (...) habrían sido reprimidas por bárbaras y conducentes al desorden» ${ }^{229}$. Festejar los hitos de la construcción de la nación fue una cuestión bastante temprana y bien planificada, que no eran diseñados para el simple esparcimiento, sino que tuvieron un claro objetivo tanto de legitimidad como de perennidad en la conformación del poder.

La continuidad entre las fiestas de la corona y las fiestas republicanas era coherente con mantener el orden existente. La planificación del ritual, la ceremonia, la fiesta contrastaba con la idea de festividad de las clases populares que tenían un carácter más espontáneo. Evidentemente, esto plantea finalidades distintas entre el sentido que la elite le otorgaba a la fiesta y el que le asignaban los sectores populares, ya que los razonamientos y significación en relación con esto «varían según el lugar, la época, los participantes y muchos otros factores, por lo que no podemos dar un sentido único a este tipo de expresiones» ${ }^{230}$. En esto último, está la clave de la tarea emprendida por la clase gobernante, ya que fue capaz de captar la gran influencia de la vida festiva

\footnotetext{
${ }^{228}$ CRUZ, I., La fiesta: metamorfosis de ..., op. cit., p. 307.

${ }^{229}$ PINTO, J. y VALDIVIA, V., ¿Chilenos todos? La construcción social de la nación..., op. cit., pp. 204-205.

${ }^{230}$ PURCELL, Fernando, Diversiones y juegos populares. Formas de sociabilidad y crítica social. Colchagua, 1850-1880, Santiago LOM, 2000, p. 19.
} 
colonial con extensos calendarios de asueto, aun cuando los temas festivos eran monárquicos y religiosos.

El predominio de lo religioso en la festividad que impregnaba de magia, espiritualidad que permitía el contacto entre lo mundano y lo divino, cuestión fundamental en las sociedades de Antiguo Régimen donde la experiencia festiva-religiosa determinaba el tiempo, el calendario, las estaciones, los ciclos de la vegetación, en definitiva, es el tiempo cotidiano el que transcurre entre el tiempo festivo, «porque es el tiempo cotidiano el que se desarrollaría entre dos planos del tiempo festivo y no el tiempo festivo el que se extiende entre dos planos del tiempo social» ${ }^{231}$. La continuidad desde los sistemas religiosos a los sistemas nacionales en lo festivo fue condición importante para la construcción de lo nacional. La secularización que demandaba el Estado nacional como sistema cultural sugiere una enérgica aproximación con la imaginería religiosa y tal como lo señala uno de los grandes teóricos del nacionalismo «si la imaginería nacionalista se preocupa tanto por la muerte y la inmortalidad esto sugiere una fuerte afinidad con imaginería religiosa» ${ }^{232}$. Tenemos que comprender que los preceptos religiosos fueron claves a la hora que a clase gobernante los utilizó para desarrollar nuevas lealtades sobre la cimiente de viejas prácticas con nuevos significados.

Debemos ser conscientes de la paradoja entre un sistema cultural monárquico y uno republicano, ya que «en ciertos sentidos fundamentales, la monarquía formal se opone a todas las concepciones modernas de la vida política» ${ }^{233}$ constituyendo una diferencia monumental entre súbdito y ciudadano. Es por medio de la festividad que el sentimiento nacional fue trasmitido hacia los sectores populares mediante mecanismos distintos al que plasmaron las elites chilenas en los inicios del siglo XIX. Por ello es que la fiesta equipararía la persona del rey al de la nación, posibilitando la toma de conciencia nacional; y es por esta razón, que las autoridades republicanas asemejaron las celebraciones de la colonia y los contenidos simbólicos que se generaron en ese mundo

${ }^{231}$ CRUZ, Isabel, «Lo sagrado como raíz de la Fiesta», Revista Humanitas, № 2 (1996), p. 5.

${ }^{232}$ ANDERSON, B., Comunidades imaginadas. Reflexiones ..., op. cit., pp. 27-28.

${ }^{233}$ Ibidem, p, 27. 
y tiempo. La transmisión de lo nacional no buscaba la incorporación de los otros sectores sociales de modo horizontal, sino que de manera jerárquica y estamental muy similar a los tiempos coloniales. La transición de la colonia a la república dejó un enorme vacío de poder que turbó a la elite, que veía con mucha preocupación el sitial de privilegios que poseían. La amenaza al orden no siempre estuvo centrada en la lucha contra la monarquía, sino que por el latente peligro de los grupos subalternos. El propio Anderson plantea que «uno de los factores que impulsaron el movimiento para la independencia de Madrid (...) era el temor de las movilizaciones políticas de la clase baja» ${ }^{234}$. Es perfectamente posible pensar que las Primeras Juntas de Gobierno hayan sido instauradas salvaguardando el orden y al rey ante el peligro de las asonadas de los sectores populares.

Todas estas ideas de continuidades y cambios nos indican el extraordinario pragmatismo propio de las clases mercantiles que se hicieron con el poder desde los inicios de la independencia; y en este sentido, la nación y la república haya sido la única forma posible de desplazar el orden monárquico manteniendo el poder. Se trataba de utilizar los elementos disponibles en que «la elite no dudó en aceptar un orden legitimante como el republicano, porque lo podía matizar mediante mecanismos electorales censitarios» ${ }^{235}$. Esta idea es una combinación de pragmatismo de la elite y exclusión de la gran mayoría de la población. La apelación a las festividades como instrumento de incorporación a lo nacional era más que una estrategia una necesidad. De este modo, la fiesta con su repetición periódica constituyó una forma de cautivar la atención de todos los sectores de la sociedad al proyecto nacional.

\subsection{Los funerales republicanos: liturgia del Estado}

La independencia había sido un campo de acción privilegiada para una generación de hombres que podían postularse al rango de padres fundadores del Estado nacional. El culto laico a los padres de la patria era una expresión del patriotismo decimonónico

\footnotetext{
${ }^{234}$ Ibidem, p. 78.

235 JOCELYN-HOLT, A., El peso de la noche..., op. cit., p. 131.
} 
capaz de inspirar en la sociedad una conciencia nacional y adhesión al orden republicano. La muerte constituía el momento más adecuado para ingresar en la historia, y estos muertos sirvieron al propósito de la elite chilena, ya que modelaron una serie de valores éticos que nutrieron el imaginario de lo patrióticamente aceptable. Es así que estos santos laicos se insertan en los anales de la historia, en el santoral cívico y en el calendario de las fiestas de la Patria. El Estado nacional chileno también utilizó la sacralización de las figuras emblemáticas por medio de los funerales y la muerte y el homenaje pasaban entonces a encarnar el concepto de nación. Era una referencia de identificación donde los honores rendidos permitían autentificar la representación material del pasado; y al mismo tiempo el rito ceremonial se encargaba de fijar el poder de evocación y propaganda apropiada para el imaginario colectivo.

Desde los inicios de la República, la elite y sus líderes tuvieron la intención de construir naciones valiéndose de las apropiadas imágenes de los héroes que construyó una serie de alegorías muy portentosas: «Lautaro era comparado con Escipión, mientras Caupolicán se equiparaba a la figura de Hércules. Así desde los inicios el liderazgo revolucionario hizo patente su intención de construir naciones valiéndose de las apropiadas imágenes ofrecidas por las vidas ejemplares de los Fabios, los Catones y los Horacios, sin importar el real anclaje de esa tradición en el horizonte local.»» ${ }^{236}$

El funeral republicano, se convirtió en enseñanzas vivas de pedagogía republicana y espacios apropiados para la actualización de problemas e inquietudes que perturbaban a las naciones en los años que prosiguieron a la emancipación. Si bien los funerales no fueron una invención republicana, fue en ella, en que se revistió de formas y símbolos que enriquecieron a las embrionarias naciones. Honrar a los muertos era enaltecer y conmemorar las hazañas militares y civiles que curiosamente tenían la finalidad de proyectarse hacia el futuro. El funeral de estado como ceremonia tenía una finalidad educativa para fomentar aspectos de naturaleza simbólica como fomentar la reconciliación política, restablecer las jerarquías sociales, favorecer la creación de un

${ }^{236}$ Mc EVOY, Carmen, «El funeral de Estado y la invención de la tradición republicana en América del Sur», en Mc EVOY, Carmen, (ed.), Funerales Republicanos en América del Sur. Tradición, Ritual y Nación, 1832-1896, Santiago, Centro de Estudios Bicentenario, 2006, p. XIII. 
imaginario nacional, definir los términos de la discusión política y, sobre todo, permitir que, por medio del muerto, la nación lograra purificar los reproches que le afligían. El éxito del funeral como estrategia didáctica republicana estuvo siempre asociada a la participación popular. En la sociedad chilena del siglo XIX donde el analfabetismo era preponderante, el ritual funerario orientado a los sentidos y sensibilidades, se transformaron en una de las mejores herramientas ideológicas de gran utilidad para la unidad política.

Uno de los primeros funerales con carácter de Estado fue el del ministro Diego Portales, quien había sido uno de los grandes gestores de la estabilidad política de Chile, pero que con el correr del tiempo fue ganándose antipatías muy fuertes, especialmente cuando, en 1837, el Congreso le otorgó facultades extraordinarias, a raíz de la declaración de Guerra a la Confederación Perú-boliviana. Esto hizo de Diego Portales un hombre muy poderoso y temido por su carácter autoritario. El ideario republicano, para algunos sectores de la elite se encontraba amenazado y se forjó entonces la idea que Portales era la antípoda de la República, ya que «la suspensión de los derechos constitucionales, el receso de la opinión pública, las indefensiones ante los consejos permanentes fueron sembrando una sensación de ilegitimidad en la oposición» ${ }^{237}$. La ideología republicana constituía el referente de consenso en la elite y este ambiente debilitó la figura del ministro y durante los preparativos de la escuadra hacia Perú, se urdió el plan para asesinarlo, motín liderado por el coronel Vidaurre, su hombre de confianza. Éste mandó arrestar al ministro y su comitiva. El batallón de amotinados llevó encadenado a Portales y su amigo Necochea a la ciudad de Valparaíso en la noche del 5 al 6 de junio. En medio de la trifulca, un soldado llamado Florín hizo bajar del carruaje al ministro y ordenó hacer fuego contra él. Recibió dos balazos, y murió, estos hechos tuvieron gran repercusión, era en algún sentido el primer asesinato político de la República, a pocos días del hecho, el periódico oficial señalaba que:

«(...) el asesinato del señor Portales son ciertamente de aquellos grandes hechos que muy de cuando en cuando espantan el universo (...) la feroz maldad de los

\footnotetext{
${ }^{237}$ ARELLANO, Juan Carlos, «La invención del mito de Diego Portales: la muerte y el rito fúnebre en la tradición republicana chilena», Atenea, N 503 (2011), p. 151.
} 
monstruos (...) sirva de experimento consolador y satisfactorio de la moral y de las virtudes patrióticas de todo un pueblo.» ${ }^{238}$

Con el asesinato, los diarios de la época iniciaron una propaganda resaltando las virtudes cívicas del fallecido, era lógico que su muerte se convirtiera en un símbolo que otorgara mayor fuerza a los que se encontraban combatiendo en la guerra. La muerte del ministro fue convertida en un acto de socialización de la nación; y desde el principio de su muerte se comenzó a sellar el carácter mítico y contradictorio en torno a su figura. Aun cuando, el propio gobierno comenzó a construir la idea del gran hombre. La muerte se constituye en el primer paso a la inmortalidad y el acto funerario lo estampa y lo convierte en un instrumento político.

Los funerales y los discursos dirigidos a la opinión pública fueron encaminados en función de fortalecer la imagen de la institucionalidad política y del Gobierno, y fue elaborado «para reforzar la legitimidad del régimen conservador con un elaborado manejo de escena hecho a la medida para lograr el máximo efecto» ${ }^{239}$, como una razón más para fortalecer la causa de la guerra que tanto se había empeñado el ministro asesinado. La pompa fúnebre fue larga y circuló por las principales avenidas de Santiago y el ministro del Interior pronunciaría un encendido discurso destacando virtudes, y especialmente su amor incondicional por la patria: ¿Quién puede blasonar de más noble desprendimiento que el rico propietario que troncó la tranquilidad de su retiro por (...) los negocios públicos (..), sin estipendio alguno (...) no aspiró ni a los premios honrosos (...) ¿Quién ha hecho el bien de un modo más gratuito, más completamente desinteresado?» 240

Al funeral también se presentaron el presidente de la República y sus ministros, los presidentes de ambas cámaras legislativas y otras importantes autoridades públicas. La presencia de todas las autoridades de la República eran la encarnación presente para dar la despedida. En la ceremonia religiosa el obispo de Santiago destacó del ministro

\footnotetext{
${ }^{238}$ El Araucano, 30 de junio de 1837, p. 4.

${ }^{239}$ COLLIER, Simon, La construcción de la República, 1830-1865. Política e ideas, Santiago, Ediciones Universidad Católica de Chile, 2005, p. 94.

${ }^{240}$ El Araucano, 30 de junio de 1837, p. 1.
} 
aquellas virtudes que sirvieran como ejemplo y símbolo a la joven república: «tú nombre augusto será escrito con caracteres de oro en los fastos más honrosos de la Patria, y el corazón de sus hijos eternamente lo conservara marcado con un sello indeleble de sincero amor.» ${ }^{241}$ Los funerales de Diego Portales simbolizan la fundación del mausoleo republicano transformándose en la primera víctima de la República y la guerra, y en su primer héroe. La muerte y su funeral habían cumplido con el objetivo inmediato de valorar la guerra y situarlo en el panteón republicano, esto legitimaba el orden imperante y su inmortalización. El ministro finalmente terminó convirtiéndose, para bien o para mal, en un verdadero mito que difícilmente pasará al olvido.

Un segundo ejemplo es el funeral de Bernardo O’Higgins, quien había fallecido en 1842 en Lima; y en 1864 se iniciaron los trámites para la repatriación de su cuerpo, proceso que culminó finalmente en 1869 con el entierro del héroe el 13 de enero de 1869. En el sepelio, José Antonio Argomedo, procurador municipal de Santiago dirige las siguientes palabras en el funeral del Padre de la Patria: «En los tiempos antiguos y modernos, entre todos los pueblos, los últimos deberes a favor de los muertos han sido una obligación religiosa y popular (...) se necesita más que pronunciar el nombre de O’Higgins, para hacer, un elogio y medir la inmensa gratitud que le debemos. Él fue sin duda, el hombre predestinado a la redención de su pueblo.» ${ }^{242}$

El traslado de los restos al cementerio con la participación de los santiaguinos constituía un acto de redención y de pedagogía republicana. Argomedo proseguía en su alocución enalteciendo el patriotismo:

«Enorgullezcámonos, pues, con poseer las preciosas reliquias de aquel a quien todo lo debemos. Recuperamos con ellas una parte que nos faltaba de nosotros mismos, y al emprender este corto peregrinaje iremos acostumbrándonos a llegar a la tumba de O’Higgins, para pedir a sus manes en las graves crisis, que nos inspiren exaltación al

\footnotetext{
${ }^{241}$ Oración fúnebre pronunciada por el presbitero Rafael $V$. Valdivieso en las exequias que se celebraron en la santa Iglesia de la Catedral por el alma del finado señor ministro de la guerra don Diego Portales, Santiago, Imprenta La independencia, 1837, p. 43.

${ }^{242}$ La corona del héroe: recopilación de datos y documentos para perpetuar la memoria del General Don Bernardo O'Higgins, mandada a publicar por el exministro de Guerra don Francisco Echaurren, Santiago, Imprenta Nacional, 1872, pp. 131-132.
} 
patriotismo, aliento en las arduas empresas, prudencia y calma en nuestras efímeras discordias. ${ }^{243}$

Una de las funciones fundamentales que el Estado chileno y sus líderes políticos fueron concebir símbolos unificadores capaces de perpetuar en el tiempo y el espacio. O’Higgins muerto se transformó en el símbolo desde la cual se debía refundar la República como señalaba Vicuña Mackenna con ocasión de la inauguración de una estatua para el héroe, en 1870 que:

«(...) la vida de aquel ilustre Capitán fue de una sola pieza... jamás vaciló, jamás tuvo miedo, jamás escondió su pecho a los peligros... No sería fácil encontrar en los anales americanos una existencia más unida y más compacta en la acción del patriotismo, en la lealtad de la idea y en la constancia de un propósito.» ${ }^{244}$

El héroe se convertía así en un referente simbólico con la idea de solidificar la identidad nacional. La identidad nacional en construcción tenía que ver imperiosamente con la construcción de un sujeto; y O'Higgins en el siglo XIX chileno fue el referente obligado en ese imaginario.

La conversión de la muerte y el uso de los muertos como vehículos políticos fueron una estrategia de pedagogía cívica. Los funerales de Estado interpelaban el presente y especulaban sobre el futuro, era un instrumento que marcaba y encarnaba la autoridad y los límites del nuevo Estado. Estas disposiciones no son solo ejercicios de rutina, muestran un ceremonial que garantiza una presencia oficial significativa y es probar la capacidad efectiva que tiene el Estado de penetrar en la sociedad civil. Es el espacio donde se recrea el vínculo entre gobernantes y gobernados. Los funerales de Estado eran un homenaje oficial al muerto y el inicio de la memoria oficial y la oportunidad en que el Estado daba muestras de poder. Para las elites, la ceremonia y los discursos eran la prueba de su legitimidad y las del régimen. En los funerales de Estado, el muerto pierde rápidamente su condición de sujeto particular y deviene completamente en un ser público. Esta combinación biológica e ideológica es la «noción gráfica que el gran hombre se ha sacrificado por su patria y que a través de su muerte se fusiona con

${ }^{243}$ Ibidem, p. 135.

${ }^{244}$ La inauguración de la estatua ecuestre del Capitán Don Bernardo O'Higgins en mayo de 1872, Santiago, Imprenta Nacional, 1872, p. 4. 
ella» ${ }^{245}$. Esta unificación cuerpo y nación son símbolos de la unificación y el progreso del Estado nacional.

Los ritos funerarios desempeñaron un papel interesante en el proceso de integrar facciones en conflicto, dado que estos rituales proyectan un lenguaje capaz de expresar ideas opuestas y acomodar diferencias y contradicciones. En definitiva, «el funeral de Estado era consecuentemente, el punto en que se unían dos ritos de pasajes diferentes: el cuerpo del gran hombre y del pueblo que participaba en la ceremonia» ${ }^{246}$. Su sentido pedagógico subrayaba las formas ordenadas y respetuosas ante los muertos, la autoridad, el orden, y por supuesto el Estado nacional. Los discursos pronunciados en los funerales estaban impregnados de la palabra cívica e institucional que inspirada en el liberalismo pretende suplir la antigua sociedad jerarquizada por una más homogénea e igualitaria. Es sintomático que en los discursos fúnebres se enaltezcan sus méritos y consagración al bien público y no su linaje o nacimiento haciendo hincapié en las realizaciones concretas en la vida pública del muerto. Se destaca una y otra vez el esfuerzo personal, ser artífices del progreso y la construcción de la nación, hombres serenos y carentes de furias personales.

\subsection{La educación en la construcción del sujeto nacional}

Las escuelas fueron las que principalmente desempeñaron a lo largo del siglo XIX la función de nacionalizar a la población. La educación en los estados nacionales buscaba facilitar la movilidad social y formar adecuadamente a los sujetos para poder realizar un trabajo en la estructura productiva de la sociedad, sea en la industria, la agricultura, el comercio, las profesiones liberales o en la estructura burocrática del Estado, aunque hubo efectivamente un predominio de las funciones estrictamente políticas de la educación en estos Estados.

\footnotetext{
${ }^{245}$ TURNER, V, Dramas, Fields, and metaphors, Symbolic action in Human Society, London, Cornell University Press, 1974, p. 234.

${ }^{246}$ GAYOL, Sandra, «La celebración de los grandes hombres: funerales gloriosos y carreras post mortem en Argentina», Quinto Sol, vol. 16, No 2 (2012), p. 13.
} 
A medida que fue avanzando el proceso de modernización de los estados nacionales las funciones sociales y económicas fueron adquiriendo mayor relevancia conforme la sociedad se tornaba más compleja. En un principio, al gestarse los sistemas educativos nacionales, el nuevo Estado tenía como fundamento general la creencia que todos los hombres, independientemente de su procedencia, poseían la capacidad de un mismo desarrollo de racionalidad y, que, por tanto, debían considerarse jurídicamente iguales en lo político. Para el nuevo orden político, la educación nacional era un componente necesario y por medio de la escuela ayudaría a la conformación de la unidad nacional. Los estados nacionales iberoamericanos en el siglo XIX asumieron un mayor número de funciones que sus pares europeos donde por dinámica social y económica pudieron desenvolverse, sin exigir durante un largo tiempo la intervención extraordinaria del actor estatal $^{247}$. En el capitalismo tardío que se desenvolvía en América Latina, por el contrario, solo desde la esfera estatal parecía posible cohesionar los profundos desgarramientos de la sociedad; y particularmente desde el inicio del período independiente hubo que encarar el fenómeno de la coexistencia de varias sociedades en el interior de un país; y ante tal fragmentación y disgregación socioeconómica el Estado debía asegurar no solo la unidad territorial-administrativa, sino procurar igualmente la dinámica económica, la representación política y el cimiento ideológico que vincula y reúne las fuerzas centrífugas.

La nación como construcción del Estado plasmada en la invención de tradiciones y costumbres, en ritual folclórico, las fiestas, los cultos a los héroes son los medios por los «cuales se inculcan ciertos valores y normas por medio de la repetición (...) y, a través de ellas se establecen símbolos de cohesión social o de pertenencia a comunidades reales $\mathrm{y}$ artificiales» ${ }^{248}$. Se inventan tradiciones en tanto que son también una rememoración de algo, que dan cuenta del surgimiento de un hecho, un antes y un después. La invención por tanto ayuda a imaginarse un porvenir colectivo que se lo construye a través de instrumento como la iglesia, la escuela, la familia, etc.

\footnotetext{
${ }^{247}$ Vid. ZERMEÑO, Sergio, «Las fracturas del Estado en América Latina», en LECHNER, Norbert, (ed.), Estado y Política en América Latina, México, Siglo XXI, 1983, pp. 60-86.

${ }^{248}$ MARQUEZ, Martha, «Perspectivas teóricas ...», art. cit., p. 576.
} 
Cuando el Estado se dio a la tarea de la construcción de lo nacional, ¿cómo imaginó a ese sujeto nacional chileno?, ¿qué atributos debían tener? La construcción de sujetos nacionales, única constatación real que la nación existe, se inicia desde el romanticismo, el optimismo positivista y la pedagogía decimonónica y en el convulsivo panorama que se estaba planteando en el mundo occidental en el siglo XIX, frente a esto, América contribuyó con una enorme particularidad a «la enorme heterogeneidad de las poblaciones a partir de las cuales había que configurar ese nuevo sistema fundado en la soberanía popular» ${ }^{249}$, y esa construcción se realiza a partir de «un mosaico de gente, incluso más complejo que el que enfrentan las naciones europeas de la época, debido a la división entre españoles e indios, entre criollos y peninsulares y por el mestizaje. En el siglo XIX, dada la expansión de la legitimidad política, fue un período bastante preocupado por los principios de libertad, igualdad con un escenario de heterogeneidad poblacional, sociedades con una altísima percepción de jerarquización social y por la igualdad en el imperio de la ley.

Todos estos factores se fusionaron en la tendencia general de homogeneización de las poblaciones. La homogeneización de la población fue asumida como política de Estado, precisamente cuando se asumió que esto llevaba el imperativo que la gente se autorreconociera formando parte de una unidad y se valoraba la homogeneidad e incluso podemos aseverar que en el siglo XIX la heterogeneidad de las poblaciones era sinónimo de atraso, en tanto que la homogeneidad se identificaba con la capacidad para el progreso y la civilización. En esa construcción intervienen varios actores: lingüistas, legisladores, historiadores, sociólogos y pedagogos, entre otros, liderados todos ellos por el poder político. La construcción de la nación no es una tarea en abstracto, sino que se materializa en la fundación del sujeto nacional. Este se identifica y adquiere conciencia de su relación con el mundo a partir de la vinculación que realiza con el Estado por medio de la educación.

\footnotetext{
${ }^{249}$ QUIJADA, Mónica, «La caja de Pandora. El sujeto político indígena en la construcción del orden liberal», Historia Contemporánea, No 33 (2006), p. 606.
} 
El siglo XIX creyó firmemente en la magia de la ley, las instituciones y las constituciones fundada en ciudadanos virtuosos, responsables y patriotas. En general, en nuestra historia de la educación la opción fue por la homogeneización y en eso la educación era la matriz, ya en 1811 Manuel de Salas ${ }^{250}$ señalaba frente al papel de la educación en tanto ayuda a asumir con serenidad el presente y el futuro y que si el país no se daba el trabajo de educar a su población y no disponer de hombres:

«(...) capaces de ejecutarlas, de perpetuarlas y adelantarlas, serán efímeros e imperfectos. La educación de la juventud y que esta se críe entre ejemplos de virtudes y lecciones de ciencias, es el único arbitrio sólido y justo de hacer florecer los reinos y felices a sus habitantes. ${ }^{251}$

Manuel de Salas consideró la educación como el único camino que llevaba al desarrollo del individuo y al progreso de la sociedad; y debía orientarse hacia la formación de ciudadanos con profundos valores nacionales y responder a las necesidades propias de cada país.

La construcción del sujeto en virtud del aporte a la construcción del estado y la nación era el principio general, pero también es posible advertir como la educación debía ser el proveedor de los administradores del Estado. Y en el funcionamiento del Estado, la educación es clave, ya que sin ella «no hay opinión, espíritu público, ni hombres que constituyan el estado (...) ni se cubren las necesidades de este» ${ }^{252}$. A su vez, en algunos escritos del siglo se sostiene la desigualdad como atributo para dotar de educación, se distinguía la jerarquía social que no deja de ser una paradoja en un siglo cargadamente liberal. Se señalaba que en Chile existían dos grupos sociales definidos de la siguiente manera:

«(...) la clase pobre que vive del trabajo mecánico de sus manos (...) [que no le] permiten tomar parte efectiva en los negocios públicos (...) [y una segunda] clase que desde la infancia se destina para formar el Cuerpo Gubernativo de la República

\footnotetext{
${ }^{250}$ Manuel de Salas y Corbalán (Santiago, 19 de junio de $1754-28$ de noviembre de 1841) fue un destacado educador y patriota por la causa de la independencia de Chile. Es considerado uno de los fundadores de la república.

${ }^{251}$ SALAS, Manuel de, Argumentos para la creación del Instituto Nacional, en Sesiones de Cuerpos Legislativos, Santiago, Imprenta Cervantes, 1886-1908, Tomo I, p. 316.

${ }^{252}$ Ordenanzas del Instituto Nacional, Literario, económico, civil y Eclesiástico del Estado, Sesiones de Cuerpos Legislativos, Santiago, Imprenta Cervantes, 1886-1908, Tomo I, p. 316.
} 
(...) La instrucción pública debe también dividirse (...) Instrucción primaria para la primera, e Instrucción superior para la segunda.» ${ }^{253}$

Andrés Bello, también pensó en una educación segregada, una para los que van a dirigir la nación y otra para quienes deben trabajar y obedecer y que no todos deben tener la misma educación «es preciso que todos tengan alguna (...). Hay en todos los pueblos una desigualdad de condición, de necesidades, de método de vida. A esas diferencias es preciso que se amolde la educación para el logro de los interesantes fines a que se aplica ${ }^{254}$. Y prosigue en la idea que los conocimientos impartida debe ser adecuada y útil y que la educación dirigida a los pobres «no debe tener más extensión que la que exigen las necesidades de ellas: lo demás no solo sería inútil, sino hasta perjudicial, porque (...) en el curso de la vida, se alejaría a la juventud demasiado de los trabajos productivos» ${ }^{255}$. Esta concepción de Bello y compartida por parte importante de la elite configurara un sistema educativo diferenciador en lo que se estudia y sus fines y la homogenización nacionalizadora que ha tenido el sistema educativo.

La heterogeneidad de Chile con la presencia de los indígenas también refleja cómo en el país en el siglo XIX se pensó que las diferencias desaparecerían mediante la destrucción de los aspectos elementales indígenas y que «su integración en una ciudadanía comprometida y homogénea, abocada a la construcción de patrias ricas y socialmente sanas» ${ }^{256}$. En 1871, bien entrada la República, se firmó un tratado entre un cacique indígena y el Intendente de la Región de Arauco en donde el compromiso estuvo marcado por la idea de la difusión de los ideales republicanos para que «los caciques que tuvieran hijos varones, entregarán dos de ellos al Intendente de la provincia de Arauco para que sean educados en Santiago (...) y puedan más tarde difundir la civilización entre los indígenas» ${ }^{257}$. Para los indígenas la situación educacional con la

\footnotetext{
${ }^{253}$ DOMEYKO, Ignacio, Memoria sobre el modo más conveniente de reformar la instrucción pública en Chile, Santiago, Ed. Semanario de Santiago, 1842, p. 214.

${ }^{254}$ BELLO, Andrés, «Sobre los fines de la educación y los medios para difundirla», en BELLO, Andrés, Obras Completas. Temas Educacionales, Caracas, Fundación La Casa de Bello, 1982, p. 659.

${ }^{255}$ Ibidem, p. 663.

${ }^{256}$ QUIJADA, M., La caja de Pandora..., op. cit., p. 635.

${ }^{257}$ Cit. en MENARD, André, «La escritura y su resto (el suplemento mapuche), Historia Indigena, N8 (2004), p. 72.
} 
llegada de la República a sus territorios implicó ser forzados a integrarse al modo republicano con la idea que se adaptaran y homogeneizaran.

Para esa construcción del sujeto nacional la figura de Sarmiento quien vivió en Chile proporciona información interesante acerca de lo que el Estado nacional proyectaba en este ámbito ${ }^{258}$. Sarmiento tiene en mente el modelo norteamericano, entiende perfectamente que sin una educación primaria generalizada estas sociedades americanas no progresarán. En el año 1852 aseveraba que el rol de la escuela para sería un buen mecanismo para cambiar «en una sola generación la capacidad industrial del mayor número, como su moralidad y sus hábitos. Está probado, fuera de toda duda, que el saber leer, es motivo de producir más y mejor en las fábricas» ${ }^{259}$. Todavía en 1900 Valentín Letelier es quien seguía abogando por una educación que sea modeladora, transformadora y capaz de construir un sujeto nuevo y que esta debe ser capaz de construir un sujeto que esté dotado «de modos de obrar, de pensar y de creer; de gustos, tendencias, aptitudes y criterios que, convirtiéndose en hábitos suyos, constituyan su modo de $\operatorname{ser}(\ldots))^{260}$.

La interrogante entre los constructores del Estado nacional chileno era: ¿cómo se construye ese nuevo sujeto? La posibilidad de aceptar dos lealtades al mismo tiempo planteaba la cuestión del límite territorial y simbólico de la historia común. El nacional de un Estado, no es tal, si no es dentro del Estado. No hay subjetividad moderna. La gran batalla por la subjetividad y por el tipo de sujeto se dio en el campo de la

\footnotetext{
${ }^{258}$ Domingo Faustino Sarmiento (Argentina, 15 de febrero de 1811 - Paraguay, 11 de septiembre de 1888) fue un político, escritor, docente, periodista, militar y estadista argentino, presidente de la Nación Argentina entre 1868 y 1874 . Debido a la victoria federal en su provincia, en 1831 se vio obligado a emigrar hacia Chile, donde realizó distintas actividades para subsistir. En 1836 se le permitió volver a la Argentina. En 1840 es nuevamente exiliado en Chile donde se dedicó de lleno a la actividad cultural. Escribió para los periódicos El Mercurio, El Heraldo Nacional y El Nacional; y fundó El Progreso. En 1842 fue designado por el entonces Ministro de Instrucción Pública, Manuel Montt Torres, para dirigir la Escuela Normal de Preceptores, la primera institución latinoamericana especializada en preparar maestros. También impulsó el romanticismo, llegando a polemizar con Andrés Bello. Su labor como pedagogo fue reconocida por la Universidad de Chile, que lo nombró miembro fundador de la Facultad de Filosofía y Humanidades; y en 1845 el presidente Manuel Montt Torres le encomendó la tarea de estudiar los sistemas educativos de Europa y Estados Unidos.

${ }^{259}$ SARMIENTO, Domingo Faustino, «Los Maestros de la Escuela», Monitor de las Escuelas Primarias, 15 de octubre de 1852 , p. 67.

${ }^{260}$ Filosofía de la Educación, Santiago, Imprenta Cervantes, 1912, pp. 40-41.
} 
educación, por ello enfrentó a la iglesia en la disputa por una educación laica. Pero, ¿qué ocurría con la fe de ese nuevo sujeto? La medida era clarísima: la fe quedaba reducida a lo privado, la familia y la Iglesia. Ambas posturas están imbuidas del espíritu del siglo: el positivismo. Linealidad, sentido de la historia e incluso con componentes escatológicos. Lo que estaban disputando ambas instituciones -iglesia y estado- era quien tenía el derecho a educar al sujeto nacional. La dependencia o autonomía de los individuos con respecto a Dios o si se quiere la autonomía o dependencia con respecto al Estado. Este debate es central en las discusiones a lo largo del siglo XIX chileno. El asunto era complejo y de naturaleza política.

Los conservadores fueron los más críticos a la expansión del Estado y los más sensibles a la definición de sus límites, mientras los liberales le dieron al Estado un cometido civilizador y democratizador que los llevó a defender sus prerrogativas. La oposición educación laica versus educación religiosa, la importancia de la educación, el tipo de educación que se requería de acuerdo con las características de la nación, los modelos extranjeros fueron alguno de los problemas e interrogantes y el modelo de educación, por cierto, no estuvo desligado de otros problemas como la cuestión social, la salubridad, la vida y las costumbres, etc. La utopía del sujeto nacional que se deseaba construir especialmente desde el laicismo y la construcción y reconstrucción del sujeto en su vertiente nacional, racional y laica ocultaba una nueva devoción.

En este proceso de formación de lo nacional y de los nacionales se conjugan elementos subjetivos y objetivos, los cuales como hemos visto comportan territorio, lengua, etnia, entidad política, unidad administrativa, etc., hasta la voluntad o la soberanía que remite a una construcción e incluso un vínculo que hace sentirse parte de una colectividad. Dicho proceso desembocaba, parafraseando a Anderson en una «comunidad políticamente imaginada», esto en la medida que la vinculación de sus miembros excede la presencia de todos, lo que implica transitar de una comunidad concreta a una más abstracta. ${ }^{261}$ En esto se puede aceptar la fórmula del proyecto ideado por la elite, pero para que se constituya en nación, debe existir cierta horizontalidad, un sustrato colectivo

${ }^{261}$ Cfr. ANDERSON, B. Comunidades imaginadas. Reflexiones ..., op. cit., pp.23-25. 
que permita que la nación sea imaginada por todos o al menos por una mayoría. De tal forma los habitantes logran un grado de integración; y en este sentido, los individuos toman parte en el proceso de construcción nacional. La presencia de los sujetos es necesaria para el proyecto.

La escuela estaba destinada a «la formación de un hombre nuevo estaba indisolublemente ligada a la formación de la nueva nación. Si la virtud era el principal valor individual y colectivo, la educación era el medio idóneo para formarla» ${ }^{262}$. El sistema educativo estaba ligado a la virtud y a la moralidad de los individuos como al éxito de la nación y tal como lo proclamaba el primer periódico chileno que «el cultivo útil de los talentos es inseparable de la grandeza y felicidad de los estados» ${ }^{263}$. La enseñanza debía ser pública para garantizar la vinculación entre los individuos; y que además permitiera enlazar en una sola moral a todo el cuerpo social. La educación debía contribuir a «cohesionar el estado con la nación, al gobierno con los gobernados, a las leyes con los ciudadanos» ${ }^{264}$. La educación será el campo de batalla donde se lidiará el debate acerca de las características del sujeto en el nuevo Estado nacional. La Iglesia sostenía una educación espiritual y trascendente desde la óptica católica, mientras que sus opositores respaldaron una educación temporal y laica.

En un escrito de 1834 y repartido en las escuelas, José Javier Guzmán manifestaba la idea de cómo debía ser la educación y lo que se esperaba de ella. Es una obra fundada en el diálogo entre un tío y su sobrino. El primero señala su ideal de escuela, inspirada en una moral de base religiosa «donde se enseñase la práctica de las virtudes evangélicas, morales y cívicas de cuya observancia pende la felicidad individual y la de todo el Estado (...) [ideas que son aceptadas por el sobrino con satisfacción al asumir] las obligaciones de cristiano y ciudadano» ${ }^{265}$. Era una sociedad que debía zanjar la dualidad estado-iglesia.

\footnotetext{
${ }^{262}$ SERRANO, S., Universidad y nación. Chile en el siglo ..., op. cit., p. 41.

${ }^{263}$ La Aurora de Chile, jueves 9 de abril de 1812, p. 1.

${ }^{264}$ SERRANO, S., Universidad y nación. Chile en el siglo ..., op. cit., p. 42.

${ }^{265}$ GUZMAN, José Javier, El Chileno instruido en la historia topográfica, civil y política de su país, Santiago, Imprenta nacional, 1834, p. 124.
} 
La catolicidad de la sociedad chilena era una situación real a inicios de la independencia y la Iglesia era la institución social más fuerte «tanto por el control que ella ejercía sobre la educación, la organización familiar y las costumbres, como por su influencia en la esfera del gobierno» ${ }^{266}$. La Iglesia ocupó un lugar importante en estas materias, ya que la parroquia, que, por lo general, administraba una escuela, base la iglesia, es advertida como un agente civilizador que le permite articular la tríada, base moral, orden social y educación. Desde la segunda mitad el siglo XIX la Iglesia advirtió con preocupación la secularización de la educación y por medio de la Revista Católica inició una dura crítica porque según ella la educación debía ser confesional y no debía predominar la educación científica por sobre la moral. La Revista Católica era una publicación que presentaba la visión oficial católica sobre los problemas culturales que implicaba la inserción de Chile en la modernidad política.

Comenzaba una dura competencia entre Estado e Iglesia que acabó al menos en el plano legal con la dictación de las llamadas Leyes Laicas de la década de 1880 y con la separación definitiva del Estado de la Iglesia en la Constitución de 1925. La Revista Católica contrapuso en sus escritos la civilización a la fe como un absurdo y apeló a: «¿Qué es lo que la multitud entiende ahora por civilización? El reinado de la razón con independencia de la fe. Tal es la última expresión de las aberraciones del entendimiento humano en la época que atravesamos.» ${ }^{267}$ Argumentaba que la civilización, el racionalismo, el progreso es la negación de la fe y el camino a la condena. La Iglesia no solo se oponía al concepto irreligioso de civilización, también lo hizo en contra de la libertad y el progreso y en la misma Revista Católica lo declaraba explícitamente ya que son: «(...) dos deidades a quienes rinde culto los hombres de todos los partidos. Libertad y progreso repiten el publicista, el literato y el jurisconsulto: libertad y progreso contestan el valiente guerrero, el laborioso hacendado y el humilde obrero.» ${ }^{268}$ El gran problema, afirmaba la publicación religiosa, era que la semántica de ambos conceptos estaba siendo hegemonizada por el liberalismo secularizador, pervirtiendo así sus significados originales ya que:

\footnotetext{
${ }^{266}$ VERGARA, Sergio, «Iglesia y Estado en Chile, 1750-1850», Revista Historia, № 20 (1985), p. 327.

${ }^{267}$ «La Iglesia y sus enemigos», Revista Católica, No 462 (1856), pp. 1.773-1.774.

268 «Como entienden algunos la libertad y el progreso», Revista Católica, № 460 (1856), pp. 1.658-1.659.
} 
«(...) hay liberales cuyo programa se reduce a esta última expresión: licencia para todo. Hay progresistas cuya bandera tiene por lema: intereses materiales, y hay liberales progresistas que no comprenden la libertad y el progreso sin el odio ciego a las instituciones religiosas, cuyo exterminio sería para ellos el principio de la civilización.» ${ }^{269}$

La Iglesia estaba en medio de un escenario tendiente a secularizar la sociedad y la opinión del catolicismo ante el temor de la destitución de lo religioso en general, y de lo católico en particular del espacio público arremetía con todo en contra del liberalismo y lo acusaba de una ideología intransigente y proponía «perseguir a la Iglesia, desprestigiar a sus ministros, entregarlos a la burla y al desprecio, he ahí el modo de hacer triunfar la libertad» ${ }^{270}$. La libertad ni el progreso según la publicación no puede conciliares con el fanatismo y la intolerancia, y en esto la Iglesia lo veía como un atentado a la libertad de enseñanza que tanto preconizaban unos y otros según la ocasión y la oportunidad. Arengaba que solamente la Iglesia era el medio para encontrar la verdadera libertad y no «de la libertad impía, de la libertad anárquica, de la libertad salvaje, de la libertad egoísta que es la ruina de las sociedades, sino de la libertad cristiana que, por el contrario, representaba la dicha y prosperidad de las naciones» ${ }^{271}$. El mundo católico y su iglesia demandaban una cuestión clave para la formación de los ciudadanos que fuese universal y trascendente requiriendo la propiedad de la educación no solo privada, sino que además la pública con la finalidad de realizar su labor evangelizadora.

El Estado nacional debía construir ciudadanos cuya identidad más poderosa debía ser nacional en contra de la que promovía la Iglesia. Los poderes públicos son algo que no tiene significación, ininteligible, ilegítimo, si no arrancan del fondo de la misma naturaleza para la construcción de grandes hombres, libres, responsables y moralmente aceptables. Y aun cuando las funciones del Estado se realicen en lo externo no logrará ejercer de manera conveniente esas funciones si echa en olvido o desdeña el

\footnotetext{
${ }^{269}$ Ibidem, p. 1.660 .

${ }^{270}$ «Algunas ideas acerca de la libertad», Revista Católica, № 208 (1850), p. 308.

271 Ibidem, p. 309.
} 
fundamento de la seguridad individual y social, la suprema explicación del derecho, es decir, la religión. En consecuencia, a estas ideas apelaban los católicos.

Si la nación convertida en Estado o el Estado que quiere hacer una nación no construía sujetos cuya identidad más fuerte fuese nacional se constituía en un estado débil, porque en esa situación, la identidad más fuerte sería universal y trascendente. Ese nuevo sujeto nacional debía sustituir la antigua identidad, se debía construir una nueva fe, ya no en la providencia de Dios, sino en la razón y portador de una nueva esperanza, simbolizada en progreso, libertad y civilización. Cuando algunos autores que han analizado el fenómeno de la nación y el nacionalismo advierten que este se cobija en aspectos de solidaridad y compromiso hacia un todo y no hacia alguien determinado «sino hacia un colectivo soberano, que construyen los propios individuos, y que se organiza aquí y ahora como Estado» ${ }^{272}$. Esa lealtad preconizada y requerida por el Estado estaba muy vinculada a un sentimiento de amor propio que se transforma en un sentimiento idealizado hacia la patria.

Los primeros próceres de las independencias americanas utilizaron la idea de amor a la Patria como un vínculo de lealtad, y bastante original para el siglo XIX. Una proclama denominada Rasgo Patriótico apuntalaba que «la patria no es solo la porción territorial donde cada uno nace, sino el cuerpo político, donde debajo de un régimen civil estamos unidos con los vínculos más fuertes a una misma legislación» ${ }^{273}$. El amor a la Patria es un valor cívico que se aprende en primer lugar en el hogar, luego se nutre en la escuela y se va perfeccionando hasta que llegamos a ser personas útiles a la sociedad. Es toda una simbología sagrada expresada en la bandera, el árbol, el pájaro nacional; en su himno, en un escudo, reflejo de nuestra cosmovisión; en sus fiestas cívicas.

\footnotetext{
272 ROSALES, José María, «Patriotismo constitucional: sobre el significado de la lealtad política republicana, ISEGORIA, N 20 (1999), p. 142.

${ }^{273}$ Papel encontrado entre las pertenencias personales de Bernardo de Vera y Pintado durante el proceso iniciado en su contra en 1810. Su autoría se atribuye a Francisco Antonio Pinto. http://www.bicentenariochile.cl/index.php?option $=$ com_content\&view $=$ article\&id $=82:$ rasgopatriotico\&catid=10:independencia-de-chile\&Itemid $=\overline{9}$
} 
La nación y el sujeto nacional son creaciones políticas revestidas de nuevas lealtades, y muy tempranamente, en 1813 se señalaba en el Monitor Araucano que «el gobierno no distingue en los ciudadanos su suelo nativo, sino sus virtudes y amor público, que son el verdadero patriotismo y las únicas bases que sostienen el Estado» ${ }^{274}$. La educación en ese marco cumplió más que una función política y económica. La homogeneización le otorgaba estabilidad interna y con su fuerte contenido moralizante se dirigió a formar un tipo de hombre capaz de cumplir roles políticos dados en la formación secundaria; y productivos con la formación primaria. Si una república debía educar a sus hijos, se acordó que la primera misión era extender la matriz identitaria y homogeneizante a toda la comunidad. El territorio incomunicado y una población heterogénea se convirtieron en un desafío para quienes comprendieron como prioritario impulsar el sentimiento de fidelidad a la patria. Se consideró en el proyecto de conformación de la nación que los hombres debían tener conductas intachables en lo público y lo privado y que los valores como «la honra, la honestidad, el cumplimiento de las obligaciones familiares, el respeto a las leyes y las autoridades, el amor a la patria, fueron sinónimos de buen ciudadano» ${ }^{275}$. Una educación que estaba orientada en fines moralizantes perseguía la obtención de buenos ciudadanos.

Expandir la escuela e integrar al mayor número de habitantes se convirtió en una estrategia, cuyo motivo estaba en preparar para el futuro, como trabajador en lo económico y como ciudadano en lo político. En uno de los textos que mejor retrata la forma en que se desempeñaba la educación en el siglo XIX se señalaba el valor que tenía para los individuos la educación para formarlo como hombres útiles a la nación y que si son buenos alumnos y se instruyen en:

«(...) elaborar sus tareas escolares con exactitud... a ser castigado si no la termina o a ser premiado si lo realiza correctamente, se convertirá, probablemente, en un individuo honorable, que cumplirá su palabra, realizara sus tareas metódicamente y

\footnotetext{
${ }^{274}$ El Monitor Araucano, 8 de abril de 1813, p. 19.

${ }^{275}$ LIONETTI, Lucía, «La función republicana de la escuela pública: la formación del ciudadano en Argentina a fines del siglo XIX», Revista Mexicana de Investigación Educativa, vol. X, No 27 (2005) p. 12 .
} 
sin retraso, y procurara imprimir el sello de la excelencia en todo aquello que emprenda.» ${ }^{276}$

La conformación de la nación, del sujeto y de la identidad nacional se buscaba en el siglo decimonónico por medio de instituciones educativas establecidas como espacios fundamentales para la enseñanza y el aprendizaje de lo público, también se perseguía que los niños que asistían a la escuela pudieran influir en sus familias, ya que «al llevar a ella los nuevos conocimientos y hábitos adquiridos en la escuela (...) se irradiarían los cambios que el grupo dirigente había definido como los adecuados y correctos para la sociedad chilena» ${ }^{277}$. Es la escuela la que representa un papel fundamental en la transmisión a la sociedad de valores colectivos, normas, rituales, difusión de símbolos y sentimientos de pertenencia a una comunidad diferenciada por tradiciones, etnias, lenguaje u otros factores de integración.

Los estados nacionales articularon y valoraron la escuela y otras instituciones como espacios privilegiados para la enseñanza, el aprendizaje y la producción de saberes y artefactos públicos, dado que la educación forma, moraliza, los entrena para el trabajo y para el comercio y ello trasunta en que «se abren nuevas escuelas, se fundan bancos y se construyen vías de ferrocarril, lo que indicaría que el país está en la senda apropiada del progreso» ${ }^{278}$. En esta línea François Xavier Guerra postula que por medio de la «escuela se trasmiten los cimientos ideológicos de la enseñanza (...) [y puede] formar ciudadanos leales e industriosos. Es decir, individuos políticos nuevos, leales a la nación, que actúen como agentes económicos autónomos»» ${ }^{279}$. Convencidos del valor del saber y la enseñanza, el Estado veía en la educación uno de los medios más eficaces a través del cual la naciente república en construcción podía alcanzar el horizonte de civilización, progreso e integración nacional.

\footnotetext{
${ }^{276}$ AMUNATEgUI, Miguel y AMUNATEGUI, Gregorio, De la Instrucción Primaria en Chile: lo que es, lo que debería ser, Santiago, Imprenta del Ferrocarril, 1856, p. 143.

${ }^{277}$ MONSALVE, Mario, Fuentes para la historia de la República, Vol. IX. Documento para la historia de la Instrucción Primaria, 1840-1920, Santiago, Editorial Centro de Investigaciones Barros Arana, 1998 , p. 19.

${ }^{278}$ El Ferrocarril, 2 de mayo de 1860, p. 14.

${ }^{279}$ México del Antiguo Régimen a la revolución, México, Fondo de Cultura Económica, 1995, p. 205.
} 
La idea de educar a la población se situó al centro de la conformación de la República como de la nueva ciudadanía, como cimiento para el desarrollo económico y social del país. La educación fue un ideario emergente que fue pensada como un medio de perfectibilidad del hombre en el camino de la libertad, la felicidad y el progreso. Ella debía formar al hombre nuevo, ese hombre que podía hacer tabla rasa del pasado, suprimirlo para inventar un futuro ${ }^{280}$, y sostenemos que, en la historia de Chile, jamás la educación estuvo más al centro de la concepción del estado nacional que se quería construir.

\subsection{La educación nacional: liberalismo, progreso y civilización}

En el proceso chileno, desde muy temprano, en 1812 y como parte de las transformaciones políticas introducidas en Chile dentro del proceso de organización del Estado independiente presentó un gran despliegue de medidas legales, decisiones políticas, y discursos destinados a desarrollar la educación como parte del nuevo proyecto político. El cúmulo de importantes medidas que adoptaron los primeros gobiernos autónomos, a pesar, de su precaria estabilidad, evidencia la preocupación constante por dictar una importante cantidad de normas sobre instrucción pública, enseñanza y otros ${ }^{281}$.

El discurso y el proyecto de país estuvieron amparados en las ideas de modernización y liberalismo. El desarrollo económico, los derechos civiles, el imperio de la ley y, en suma, la modernidad ocuparía un lugar clave en el republicanismo clásico. Chile, precisamente por padecer en menor medida los trastornos de los países vecinos, proporciona un excelente caso para estudiar en detalle un aspecto central del fenómeno en cuestión, que es la educación bajo un sistema republicano que busca acceder a la

\footnotetext{
${ }^{280}$ Cfr. SERRANO, S., Universidad y nación. Chile en el siglo ..., op. cit., p.38.

${ }^{281}$ Los siguientes textos legales fueron dictados los años 1812 y 1813: «Enseñanza de niñas» (21 de agosto de 1812), «Enseñanza de las primeras letras» (30 de diciembre de 1812), «Enseñanza Pública» (12 de enero de 1812), «Instrucción Primaria» (18 de junio de 1813). Vid. ANGUITA, Ricardo, Leyes promulgadas en Chile. Desde 1810 hasta el $1^{\circ}$ de junio de 1913, Santiago, Imprenta, Litografía y Encuadernación Barcelona, 1913. El Instituto Nacional se fundó el 27 de julio de 1813, y tras una breve clausura, reinició sus actividades en 1818 hasta nuestros días. La Biblioteca Nacional pasó a ser pública el año 1876.
} 
modernidad. Felicidad, progreso, libertad era el patrimonio que había que construir y la obligación del gobierno republicano y en eso «la educación adquirió cierto carácter utópico y se depositaron en ella las esperanzas de regeneración del individuo y de la nación» ${ }^{282}$. En los discursos sobre educación asoman con frecuencia los conceptos de civilización, progreso e integración nacional.

El rol civilizador de la educación fue bien entendido por quienes contribuyeron a formar el sistema público chileno de educación. Así, Andrés Bello, al crear la Universidad de Chile, los hermanos Amunátegui al institucionalizar la educación y tantos otros sostenían que no se podía construir una sociedad moderna sin educación, y que esta no podía subsistir sin normas y sin instituciones. El educador argentino Sarmiento -ya citado- escribía a mediados del ochocientos que «(...) el sacerdote, al derramar el agua del bautismo sobre la cabeza del párvulo, lo hace miembro de una congregación (...). El maestro de escuela, al poner en las manos de los niños el silabario, lo constituye miembro integrante de los pueblos civilizados del mundo (...)» ${ }^{283}$. Hacer pasar al pueblo de la barbarie, la incultura y la ignorancia a otro estadio definido como superior, caracterizado por prácticas de conducta, hábitos y modales civilizados, laboriosos, disciplinados, higiénicos, ahorrativos, instauró el fundamento en este tipo de discurso, que desde esas visiones planteó la forma en que se pudo impulsar la modernización. Fueron, sin duda, anhelos por acercar a Chile al modelo europeo o norteamericano.

Civilizar era también la forma de desempeñar el control y la tranquilidad social y era concebida como una manera de «evitar revoluciones futuras (...) la mejor forma de acabar con las revoluciones actuales es enseñar las primeras letras a los adultos» ${ }^{284}$. Por cierto, que este fue un discurso presente a lo largo del siglo XIX. Manuel Montt, por ejemplo, siendo ya presidente de la República, señalaba este rol de la educación es la manera óptima de asegurar el futuro de la nación es con educación, ya que así se logra la eliminación de «la ignorancia que defiende las preocupaciones funestas y traba los pesos de la industria. Ahoga el espíritu público y opone los mayores obstáculos a toda

${ }^{282}$ SERRANO, S., Universidad y nación. Chile en el siglo ..., op. cit., p. 38.

${ }^{283}$ SARMIENTO, D., «Los Maestros de la Escuela» ..., en op. cit., p. 68.

${ }^{284}$ AMUNATEGUI, M. y AMUNATEGUI, G. De la Instrucción Primaria en Chile ..., op. cit., p. 44. 
especie de progresos» ${ }^{285}$. La confianza en la educación como garante del esplendor futuro estuvo grabada a hierro en las autoridades decimonónicas. Y refriéndose al valor de los profesores denota que los acervos que son muy escasos aun cuando tienen una disposición encomiable ya que:

«(...) penetrados de la importancia de su cargo, se consagran a desempeñarlo animados de verdadero celo... y con el entusiasmo y ardor que inspira la conciencia de lo útil y patriótico de la obra que se emprende, preparando por la educación el provenir de las nuevas generaciones. $\rangle^{286}$

Estos discursos indicaban la aspiración de imponer el modelo para lograr la deseada homogeneización de la sociedad en hábitos, gustos, valores, conductas, en definitiva, normar las culturas divergentes. Desde esta perspectiva, la educación de la población era el eslabón indispensable en la cadena de la nacionalización de las costumbres.

Chile en el XIX inauguraba su independencia de la Corona española y, participaba de las utopías sociales, económicas y culturales europeas, proyectando una imagen que poco a poco dibuja el Estado nacional que se concreta en la República. Los ideólogos del nuevo Estado veían en la educación la posibilidad que la sociedad chilena se incorporara a esa nueva realidad, echando mano a la educación para hacerlos conscientes de sus obligaciones y conocedores de sus derechos, sustentando en esas formas de igualdad, que promovían los liberales del siglo; leales y comprometidos con el proceso de modernización que requería la nueva nación. La construcción de un nuevo orden en lo político, lo económico y lo social solo sería posible a partir de la formación de otra mentalidad, de otro ser moral en esa masa ignorante y pobre; del desarrollo de un vasto programa civilizador cuya bandera favorita sería la de proporcionar los rudimentos de la lectura, de la moral cívica y de la religión a todo el pueblo.

Filósofos, legisladores, maestros de escuela, se dieron a la tarea de pensar la construcción del sujeto nacional virtuoso, de regularla, de plantear métodos, programas

\footnotetext{
${ }^{285}$ Cit. en CAVIERES, E., «Modernización, transformaciones sociales y educación. Experiencias del pasado, consideraciones sobre el presente», Cuadernos de Historia, $\mathrm{N}^{\circ} 17$ (1997), p. 185.

${ }^{286}$ MONTT, Luis, Discursos, papeles y correspondencia de Manuel Montt, Santiago, Imprenta Cervantes, 1905, Tomo II, p. 161.
} 
y contenidos, así como las alternativas más concretas para renovar las prácticas escolares. Amunátegui estaba convencido que los males de la población se vencían con educación, ya que siendo alfabetos se ahuyenta los vicios y los males y:

«muchos por matar el tiempo se entregan a esas pasiones brutales, en cuya satisfacción pierden el dinero, el honor y la vida, y frecuentemente el dinero y la vida de su mujer y de sus hijos. Enseñémosle a leer, para evitar su ruina y la de su familia.» ${ }^{287}$

Pero los sueños de transformación social y las utopías educativas de los pensadores chilenos del siglo XIX, se toparían con algunas complejidades de la realidad del país, con los problemas de financiamiento, los altibajos de la economía nacional y las vicisitudes propias del naciente Estado. Además, los programas educativos del siglo XIX se vieron atravesados por disputas permanentes entre liberales y conservadores, que asumirían, cada cual, a su manera, la contienda por la educación. En medio de todo ello, a pesar de todo, se logró construir la escuela que la nación heredaría.

La tarea ordenadora que emprendió la educación estatal privilegió algunos valores sobre otros propiciando el programa de construcción social. El sentido del negocio, ocupación, industriosidad, utilidad del conocimiento, se apodera cada vez más de la vida social. Esto se proyecta en la producción de modelos educativos orientados por la actividad y el orden, donde niños y jóvenes encuentran el sentido de la actividad y del trabajo; se impulsa lentamente la promoción de hábitos, industria y habilidades técnicas de los educandos. No solo se esperaba producir un sujeto nacional, sino un trabajador ordenado y capaz, haciéndose eco de las reiteradas denuncias de inactividad, desocupación y que tales males debían ser castigados. Pereza y atraso debían ser penalizados y la prosperidad de un pueblo «estriba menos en sus riquezas naturales que en los conocimientos que poseen los ciudadanos; y el pueblo no puede adquirir estos conocimientos más que en las escuelas gratuitas al alcance de todas las clases y condiciones sociales» ${ }^{288}$. Trabajo, progreso y la percepción del mundo desde la ciencia y las verdades positivistas poco a poco se irían imponiendo, así como el desarrollo de

\footnotetext{
${ }^{287}$ AMUNATEGUI, M. y AMUNATEGUI, G., De la Instrucción Primaria en Chile ..., op. cit., p. 22.

${ }^{288}$ ALFONSO, José, Colección de Documentos relativos a la Sociedad de Instrucción Primaria de Santiago, Santiago, SIP, 1857, pp. 231-232.
} 
una conciencia cívica y nacional, que tendía al amor a la patria y a sus instituciones, y una concepción integral del desarrollo humano.

Tales ideas ampliaron el espectro de materias de estudio entre las que se introducirían la instrucción moral y cívica, lengua nacional (escritura y lectura), lecciones de aritmética, ciencias físicas y naturales, geometría, geografía, historia, dibujo, canto, gimnasia, labores manuales en los currículos chilenos desde el siglo XIX. Las ideas de trabajo y progreso como columnas vertebrales de la educación fueron señaladas en su momento por Miguel Luis Amunátegui al enfatizar la importancia de la labor educativa en el progreso de Chile, señalando que el gran enemigo de la nación y del progreso era la ignorancia «que impide el desarrollo rápido y completo de la civilización en Chile, la ignorancia que lo domina todo, la ignorancia madre de la ineptitud para el trabajo, de la imprevisión para el porvenir, de las preocupaciones, de los vicios» ${ }^{289}$. Educación, República y Progreso eran la trilogía que podía generar en Chile la ansiada modernización.

Insignes educadores chilenos fueron enérgicos en reiterar el papel de la educación como agente de progreso de lo necesario que es instruir en herramientas prácticas a la población y que la adquisición de las primeras letras en la escuela es provechosa para la industria y permiten mejorar las condiciones materiales de la población ya que «la lectura, la escritura y el cálculo suministran a muchas familias el pan de cada día» ${ }^{290}$. Con estas premisas, el criterio de una educación como motor del progreso económico e industrial del país, se intentó aplicar a todo el país. La educación considerada como mecanismo para preparar a la vida laboriosa del hombre formaba parte del discurso sobre lo que debía ser la educación chilena. La evaluación acerca de si esos discursos impregnaron a la educación chilena constituye un debate que es abordado en Chile en las primeras décadas del siglo XX y sobre todo en la crisis del Centenario.

\footnotetext{
${ }^{289}$ Ibidem, p. 236.

${ }^{290}$ AMUNATEGUI, M. y AMUNATEGUI, G., De la Instrucción Primaria en Chile ..., op. cit., p. 37.
} 
La crisis del centenario de la independencia de Chile puso de manifiesto la desconexión que existía entre educación y crecimiento económico, y no siendo este un tema de la $\mathrm{r}$ de que no es tema de esta investigación señalaremos solo un botón de muestra. Francisco Antonio Encina, destacado historiador y político chileno, fue uno de los que encarnó la preocupación por la descontextualización de la educación chilena al entrar al siglo XX. Los cambios globales en el advenimiento del siglo XX provocaron un intenso debate sobre el rol que le correspondía a la educación en el desarrollo del país. Frente a aquellos que todavía sostenían la educación humanista, Encina auspició que se debía reorientar la educación a actividades productivas y que la enseñanza intelectual, clásica y que en este tipo de «enseñanza se alejan deliberadamente los ideales que conducen a la actividad económica para no desvirtuar sus fines» ${ }^{291}$, argumentando que los preceptos ilustrados y los desfases de la realidad nacional preparaban tan solo para profesiones liberales o empleos públicos; y que se había despreciado por mucho tiempo los asuntos económicos, y que tal desprecio impedía el crecimiento de la nación. Los postulados de Encina no eran más que el reflejo de las exigencias de quienes representaban a la nueva era industrial.

Los Estados nacionales del siglo XIX - y en gran parte del siglo XX- hicieron suya la idea de la educación como agente civilizador, de progreso y de integración. Desde la perspectiva de la integración, el Estado concebirá la educación como elemento primordial para la obtención de nuevas lealtades y procurar que las clases medias y superiores tuviesen un fácil acceso a la enseñanza secundaria y universitaria, que eran la base del nuevo régimen.

La educación como factor de integración política y actor relevante en la socialización política fue el que mejor supo generar una nueva lealtad al nuevo régimen, fue un elemento importantísimo para el reclutamiento de la elite política que el Estado necesitaba, incluso fue la base de la integración vertical geográfica entre las diferentes regiones del país. Incluso la propia formación del Estado nacional va conectada

${ }^{291}$ Nuestra inferioridad económica..., op. cit., pp. 146-147. 
inexorablemente a la creación de los sistemas educativos: por la construcción del aparato administrativo del Estado, por la función que desarrollaron reuniendo en su interior las creencias que legitimaban el poder del nuevo Estado y porque además los sistemas educativos desempeñaron un rol fundamental en el despliegue y desarrollo del propio Estado. La instalación de los Estados nacionales colocó a la educación en el seno del proceso: los sistemas educativos nacionales del siglo XIX asumieron la responsabilidad primera en el impulso político del Estado. La supervivencia y consolidación del Estado nacional fue una obra propia del sistema educativo.

En el siglo XIX y en el contexto de la construcción de los estados nacionales -como ya sabemos- la educación se encargó de forjar la conciencia nacional. Entendida esta como un proceso que implica sujetos, contextos, tiempos con la visión de perpetuar lo colectivo, que hace que se propicie una identidad nacional como un matriz axiológica en donde se comparten símbolos, lenguaje, cultura, espacio, y en definitiva una nación y un Estado. Todo esto implica conocimientos, autodefiniciones, enlaces afectivos, reconocimientos y autocríticas para conservar y fortalecer la cultura inacabada, nuestra comunidad imaginada. La institucionalidad creada por el Estado, llevó a cabo, todo un proceso de homogeneización social para una sociedad que se encontraba en camino a dicha construcción. La educación debía ser asimismo instrumento formidable de cohesión social y nacional y el Estado debía impulsar y crear sistemas educativos nacionales asignándoles una serie de funciones, actuando como crisol de asimilación de una serie de subculturas e integrándolos en una cultura nacional ${ }^{292}$.

Aunque muchas de las funciones de la educación revistieron una gran importancia, se debe destacar que siendo el siglo XIX el siglo de las nacionalidades, la educación cumplió un papel integrador de grandes proporciones. Siendo el esquema general de los nuevos estados el carácter liberal, ningún Estado se manifestó de manera pasiva en la constitución de las nacionalidades. Como lo ha indicado el propio Hobsbawm para la construcción de los Estados, este utilizó medios coercitivos como el ejército; y en otras

\footnotetext{
${ }^{292}$ Vid. GONZALEZ; Sergio, Chilenizando a Tunupa. La escuela pública en el Tarapacá andino, 18801990, Santiago, Centro de Investigaciones Diego Barros Arana, 2002.
} 
utilizó instrumentos pacíficos como la educación para nacionalizar las sociedades. En el siglo XIX germina el Estado nacional como vínculo entre ciudadanía y Estado venciendo a otras fidelidades o lealtades que se demandaban. De esta forma, el estado exigía entonces una educación elemental de masas o "cuando menos que estuvieran alfabetizadas, la lengua era el requisito fundamental de la nacionalidad (...) [y los estados formaron naciones] para mantener un patriotismo nacional y ciudadanos homogeneizados lingüística y administrativamente» ${ }^{293}$. En ese proceso y por esos medios la educación se convertiría en la institución nacionalizadora más idónea, pues desde el punto de vista del Estado, la escuela presentaba otra preeminencia «y era que podía enseñar a los niños a ser buenos súbditos y ciudadanos. Hasta el triunfo de la televisión, ningún medio de propaganda podía compararse en eficacia con las aulas» ${ }^{294}$.

El Estado fue el que asumió la responsabilidad de la educación, porque, tal como señala Weinberg, «la consolidación de la nacionalidad como el de las instituciones democráticas, requiere de un proceso de homogeneización que permita a la sociedad integrarse al concepto de nación» ${ }^{295}$. El grupo dirigente chileno veía en el Estado y en la educación la posibilidad que la sociedad superara todos sus inconvenientes y construir sujetos leales y comprometidos con el proceso de modernización. La conformación del nuevo orden político, económico y social solo era posible a partir de otra actitud, de la integración con otros sujetos y del desarrollo de un programa civilizador proporcionándoles a la población los rudimentos de lectura, moral cívica e historia nacional.

\footnotetext{
${ }^{293}$ HOBSBAWM, Eric, La era del imperio, 1875-1914, Buenos Aires, Crítica, 1998, p. 159.

${ }^{294}$ Ibidem, p. 160.

${ }^{295}$ Modelos Educativos en la Historia de América Latina, Buenos Aires, Kapelusz, 1984, p. 11.
} 
2.11 Los recursos en educación: presupuesto, escuela y demás aspectos relacionados con el alumnado

\subsubsection{El presupuesto}

¿Cuánta población fue cubierta por la educación chilena? ¿Qué éxito tuvo la educación chilena en la conformación del Estado nacional? Son interrogantes que permiten evaluar históricamente el papel de la educación en la conformación del Estado nacional. Las inauguraciones e hitos de la educación chilena fueron bastante comunes en el siglo XIX. En 1813 -como ya sabemos- se fundó el Instituto Nacional, tomando en sus manos la articulación y dirección de la educación nacional. En 1837 fue creado el Ministerio de Justicia, Instrucción y Culto. La Escuela Normal de Preceptores y la Universidad de Chile -ya aludidas- se fundaron en 1842. La Escuela Normal de Preceptoras en 1852 y en 1860 se dictó la Ley de Instrucción Primaria. No fueron nada despreciables los resultados de la labor estatal en educación. Estas creaciones fueron altamente significativas al tener al mismo tiempo que enfrentar las resistencias de sectores conservadores, de la Iglesia; sin olvidar las dificultades materiales para poder implantarlas.

A comienzos de la vida independiente la educación estuvo marcada por un fuerte énfasis clásico y humanista. El eje del plan estaba inspirado en gran medida por Ignacio Domeyko y en su concepción educativa daba énfasis la enseñanza del latín dado que «sin el conocimiento de latín y de su gramática, dificulto que alguien aprenda con perfección el castellano y los inmensos recursos que presenta este idioma que se ha formado y perfeccionado sobre el latín» ${ }^{296}$. Sostenía que el estudio de la literatura y las lenguas clásicas, y particularmente el latín, influía, en el espíritu público y el patriotismo de los habitantes. Para esa generación, el modelo republicano debía ser afianzado a partir de las sólidas lecciones de moral cívica elaboradas por los clásicos por medio de la educación, lo cual era ventajoso para «tomar en consideración el bien moral del país, la estabilidad del orden y las instituciones, la formación del carácter

\footnotetext{
${ }^{296}$ Memoria sobre el modo más conveniente de reformar..., op. cit., p. 218.
} 
nacional $(\ldots) »^{297}$. Esto no quiere decir que en los primeros tiempos no existiesen postulados divergentes, pero en aquellos tiempos fue este el pensamiento predominante.

Resulta difícil delimitar el o los momentos en que ese modelo educativo tradicional comenzó a cuestionarse. La verdadera oposición entre ese modelo clásico de educación no venía necesariamente de fuentes ideológicas, sino que de problemas prácticos. En primer lugar, la escasa formación elemental, que hacía prácticamente imposible el avance en asignaturas tan sofisticadas como la enseñanza del latín. Cabe recordar que el latín no era solo una asignatura en el currículum, sino que la columna vertebral de la educación secundaria. En segundo lugar, el problema estaba en la formación y papel del profesorado. Estos, compensados a un mínimo nivel, no poseían mayor formación académica y tendían a abandonar la profesión apenas surgían alternativas laborales. Pero, aún más importante, era que estos debían enseñar varias materias al mismo tiempo, lo que hacía imposible la especialización requerida por las asignaturas más difíciles y avanzados. En tercer lugar, el plan de estudios suponía la existencia de laboratorios, bibliotecas y textos de estudios. En cuarto lugar, y quizás es esto lo más importante, no había demanda por el contenido clásico e intelectual del programa de estudios humanísticos. El modelo clásico de educación cada vez respondía menos a los requerimientos de la sociedad de la segunda mitad del siglo XIX. Podemos sostener que esa erosión de lo clásico se debió en gran parte al deseo de padres, apoderados, estudiantes, y también de algunas grandes figuras educacionales, por una educación práctica que permitiese a los jóvenes acceder a empleos mercantiles, agrícolas, mineros y administrativos que reflejaban la creciente modernización del país. Este último fenómeno era particularmente claro en provincias, en donde los factores antes mencionados se agudizaban, y en donde el énfasis en una educación práctica era aún más acentuado. Centros mineros, comerciales o agrícolas como La Serena, Valparaíso, Talca y Concepción exigían contenidos educacionales más adecuados a las realidades regionales, y representaron una gran fuente de resistencia al plan de estudios humanísticos.

${ }^{297}$ Ibidem, p. 216. 
Entre los varios debates que se desarrollaron en el Chile del siglo XIX en torno al tipo de educación que se debía implantar, no vemos en esto una discusión entre unos defensores de la colonia que le daban importancia del latín y el desarrollo de un currículo orientado a las carreras que representaba a liberales modernizadores, sino que el producto de una segunda generación republicana, que había superado las demandas de la independencia y buscaba mecanismos prácticos de expansión del sistema educacional como también el desarrollo económico. Dicho de otra forma, no existe una diferencia fundamental entre las propuestas de educación clásica y educación moderna, sino que un énfasis diferente en los contenidos educacionales de un republicanismo que deriva del liberalismo ${ }^{298}$.

En torno a 1840, puede estimarse los comienzos del sistema educacional chileno. Una destacada estudiosa de los temas educativos indica que «la formación de un sistema educativo primario estatal durante la segunda mitad del siglo XIX forma parte del proceso de formación y consolidación del Estado chileno posterior a la lucha de la independencia» ${ }^{299}$, especialmente en los gobiernos de Manuel Bulnes (1841-1851) y Manuel Montt (1851-1861) se echaron las bases de la institucionalidad educativa chilena.

La fundación de la Universidad de Chile, en 1842 -como ya se ha dicho- representó la voluntad del Estado por crear un ámbito académico nacional; y el deseo de otorgar al sistema educacional una primera estructura organizativa. Esta Casa de estudios superiores durante más de un siglo fue la rectora de las políticas estatales en educación superior y, al mismo tiempo, desempeñaba la función de superintendencia de educación secundaria. Esto quiere decir, que los planes y programas de estudio y el control de su cumplimiento estaban bajo su cuidado. La fundación de la primera Escuela Normal

\footnotetext{
${ }^{298}$ De hecho, fueron precisamente aquellos mejor formados en un plan humanista, y, además, eximios latinistas, como los hermanos Amunátegui y Diego Barros Arana, que encabezaron las transformaciones del currículum. Esto contribuyó a que el latín y el contenido humanista de la educación chilena no desaparecieran del todo (la eliminación del primero no ocurrió hasta 1880), y que se lograse una oferta educacional más ajustada a la demanda nacional.

${ }^{299}$ EGAÑA, Ma. L., La educación primaria popular..., op. cit., p. 19.
} 
(1842) bajo el impulso de Sarmiento, futuro presidente de Argentina, fue expresión de la voluntad estatal de responsabilizarse de la educación de las nuevas generaciones.

En esa época cualquier iniciativa educacional solo podía surgir del seno de la elite, que agrupaba a los políticos, a los intelectuales, a los eclesiásticos, a los terratenientes y al mundo del comercio y las finanzas ${ }^{300}$. Por ese motivo, toda iniciativa era vertical y desde la cúspide de la pirámide social se irradiaba hacia abajo como provechoso para el resto de la sociedad al amparo de las concepciones de la elite. Lo anterior explica que las primeras medidas educacionales cubrieran, en primer lugar, a los grupos más acomodados de la estructura social y haya sido una educación secundaria limitada la que recibiera gran parte del presupuesto. Antes de una educación primaria generalizada, las prioridades se concentraron en el mundo universitario y en una educación secundaria vigilada por la universidad y con programas humanistas de formación a imagen de los planteamientos enciclopédicos ilustrados que regían la universidad. Entonces la educación secundaria era una extensión del mundo universitario clásico y sus profesores una prolongación del modelo catedrático.

¿Por medio de qué instituciones se extendió la educación? ¿Y a cuánta población afectó? A mediados del siglo XIX el Estado fue considerado como la única institución capaz de movilizar recursos y crear condiciones para superar el desorden y el retraso imperante. Esta prioridad atribuida a la creación del Estado obligaba, por una parte, a la mencionada constitución de ejércitos nacionales frente a la influencia de los caudillos locales, así como a la consolidación de los límites territoriales y, por otra a la construcción de un sistema educativo nacional y a la ratificación de la exclusión de las masas populares de las decisiones políticas. Un análisis de las estadísticas disponibles manifiesta la orientación estatal por financiar la educación chilena desde su organización institucional; y la educación comenzó a rendir frutos en presupuesto y cobertura después de la segunda mitad del siglo XIX, aunque muchas de las medidas se

\footnotetext{
${ }^{300}$ Vid. STUVEN, Ana María, La seducción de un orden: las elites y la construcción de Chile en las polémicas culturales y políticas del siglo XIX, Santiago, Ediciones Universidad Católica de Chile, 2000.
} 
hayan desarrollado en períodos anteriores. Los presupuestos destinados por el Estado a la educación pasaron de 104.488 pesos chilenos en 1845 a \$6.582. 984 en 1890 .

El Estado nacional chileno tuvo recursos para sostener y financiar el sistema educativo. Un estado que invirtió sostenidamente recursos a lo largo del siglo XIX, sobre todo después de 1885 cuando el esplendor del salitre permitió aumentar el presupuesto de 2.327.770 de pesos a 6.582.984, o dicho de otra manera incrementar en 2,8 veces la inversión en esos últimos 5 años. No cabe duda que el comercio exterior fue imprescindible para sufragar la educación y que Chile en 1845 incrementó el valor porcentual destinado a dicha partida desde un 4,7\% del presupuesto de la nación a un $9,8 \%$ en 1890. El incremento del gasto en educación aumentó espectacularmente en primaria, en 1845 representaba el 21\% del presupuesto en educación; en 1870 el 39,9\% y en 1890 el 57,3\%. Las escuelas chilenas fueron obra del Estado, y tuvieron una expansión considerable no solo por la acción estatal, sino que también por la demanda creciente de la población. No es casualidad que, en aquellos períodos de mayor bonanza, producto de la exportación del trigo en 1855-56, o del salitre después de la década de 1880 dichos presupuestos experimentaran crecimientos significativos. 
Cuadro No 2. Presupuesto de Instrucción Pública de la Nación, 1840-1890. (valor moneda 1890)

\begin{tabular}{|c|c|c|c|c|c|c|c|}
\hline Año & Primaria & $\begin{array}{l}\text { Secundaria } \\
*\end{array}$ & $\begin{array}{l}\text { Superior } \\
* *\end{array}$ & Especial & Otros & $\begin{array}{l}\text { I. } \\
\text { Pública }\end{array}$ & Nación \\
\hline 1840 & 6.489 & & & & & & \\
\hline 1841 & 6.158 & & & & & & \\
\hline 1842 & 13.421 & & & & & & \\
\hline 1843 & 11.980 & & & & & & \\
\hline 1844 & 22.480 & & & & & & \\
\hline 1845 & 22.450 & 51.339 & 8.696 & 13.616 & 8.386 & 104.488 & 2.215 .238 \\
\hline 1846 & 27.944 & 55.363 & 8.997 & 19.292 & 8.676 & 120.271 & 2.404 .155 \\
\hline 1847 & 27.062 & 42.160 & 9.857 & 14.249 & 8.646 & 109.951 & 2.410 .086 \\
\hline 1848 & 21.754 & 36.302 & 8.218 & 12.745 & 8.362 & 87.381 & 2.479 .896 \\
\hline 1849 & 22.197 & 34.426 & 7.518 & 11.841 & 13.880 & 79.162 & 2.330 .104 \\
\hline 1850 & 25.919 & 25.881 & 7.628 & 14.615 & 14.082 & 113.282 & 2.189 .831 \\
\hline 1851 & 31.377 & 20.543 & 7.497 & 20.992 & 11.735 & 83.937 & 2.186 .706 \\
\hline 1852 & 37.847 & 54.747 & 7.759 & 31.418 & 14.422 & 146.411 & 2.328 .602 \\
\hline 1853 & 49.488 & 65.055 & 9.040 & 30.506 & 31.954 & 186.042 & 2.989 .196 \\
\hline 1854 & 73.567 & 73.167 & 9.555 & 37.070 & 43.433 & 241.174 & 4.022 .902 \\
\hline 1855 & 97.786 & 49.420 & 9.942 & 48.000 & 44.746 & 248.444 & 3.787 .250 \\
\hline 1856 & 120.944 & 56.180 & 9.492 & 57.318 & 37.383 & 286.510 & 4.053 .422 \\
\hline 1857 & 132.694 & 62.809 & 10.328 & 61.763 & 41.413 & 316.591 & 4.667 .938 \\
\hline 1858 & 120.268 & 109.416 & 9.040 & 59.395 & 54.414 & 352.578 & 4.317 .712 \\
\hline 1859 & 136.442 & 117.955 & 9.255 & 66.924 & 66.746 & 397.322 & 4.257 .477 \\
\hline 1860 & 151.398 & 88.573 & 10.178 & 59.454 & 46.942 & 342.730 & 4.722 .275 \\
\hline 1861 & 147.575 & 85.986 & 9.834 & 56.394 & 40.529 & 340.109 & 4.710 .125 \\
\hline 1862 & 168.734 & 89.670 & 10.350 & 63.311 & 43.427 & 374.692 & 4.746 .332 \\
\hline 1863 & 207.913 & 131.726 & 10.564 & 63.073 & 36.945 & 435.129 & 5.351 .965 \\
\hline 1864 & 171.840 & 102.293 & 8.915 & 50.611 & 26.950 & 361.322 & 5.550 .345 \\
\hline 1865 & 189.900 & 102.371 & 9.598 & 54.177 & 45.338 & 401.316 & 7.039 .058 \\
\hline 1866 & 195.839 & 107.975 & 9.448 & 54.044 & 38.896 & 412.693 & 6.127 .564 \\
\hline 1867 & 184.335 & 112.184 & 9.577 & 49.651 & 36.097 & 381.721 & 7.287 .490 \\
\hline 1868 & 203.042 & 114.920 & 9.577 & 50.703 & 38.632 & 416.805 & 7.935 .105 \\
\hline 1869 & 217.089 & 140.588 & 9.426 & 48.666 & 40.781 & 459.916 & 8.279 .645 \\
\hline 1870 & 175.303 & 162.510 & 9.362 & 51.916 & 39.962 & 439.049 & 7.714 .491 \\
\hline 1871 & 286.478 & 179.429 & 9.899 & 56.137 & 64.441 & 596.101 & 8.868 .235 \\
\hline 1872 & 351.744 & 186.271 & 109.543 & 75.819 & 66.398 & 685.504 & 9.424 .495 \\
\hline 1873 & 472.202 & 216.095 & 11.409 & 75.844 & 76.541 & 859.958 & 10.515 .280 \\
\hline 1874 & 505.965 & 278.231 & 11.164 & 76.544 & 74.094 & 933.484 & 12.788 .052 \\
\hline 1875 & 517.599 & 227.318 & 11.164 & 76.692 & 76.336 & 909.125 & \\
\hline
\end{tabular}

* Secundaria: Instrucción secundaria e Instituto Nacional

** Superior: Universidad de Chile 
[Cuadro No 2 (continuación)]

\begin{tabular}{|c|c|c|c|c|c|c|c|}
\hline Año & Primaria & $\begin{array}{l}\text { Secundaria } \\
*\end{array}$ & $\begin{array}{l}\text { Superior } \\
* *\end{array}$ & Especial & Otros & I. Pública & Nación \\
\hline 1876 & 489.278 & 236.519 & 11.431 & 78.601 & 68.701 & 890.411 & 13.268 .139 \\
\hline 1877 & 483.427 & 271.391 & 12.054 & 83.049 & 83.698 & 933.619 & 14.412 .544 \\
\hline 1878 & 451.378 & 255.281 & 9.460 & 75.823 & 62.184 & 854.520 & 13.595 .325 \\
\hline 1879 & 480.307 & 297.802 & 10.067 & 72.613 & 62.194 & 922.146 & 14.323 .272 \\
\hline 1880 & 471.683 & 329.923 & 11.153 & 4.183 & 165.083 & 1.021 .610 & \\
\hline 1881 & 475.148 & 335.643 & 13.550 & 4.148 & 148.588 & 1.032 .042 & \\
\hline 1882 & 539.365 & 331.805 & 12.387 & 3.706 & 186.309 & 1.141 .555 & 21.062 .291 \\
\hline 1883 & 703.873 & 413.194 & 12.641 & 7.538 & 232.142 & 1.569 .048 & \\
\hline 1884 & 932.647 & 364.394 & 174.606 & 11.957 & 189.303 & 1.868 .231 & \\
\hline 1885 & 1.168 .780 & 582.831 & 112.476 & 5.154 & 336.086 & 2.327 .770 & \\
\hline 1886 & 1.121 .879 & 520.098 & 248.192 & 4.690 & 216.620 & 2.204 .167 & 32.956 .936 \\
\hline 1887 & 1.559 .011 & 885.707 & 319.079 & 12.325 & 316.397 & 3.410 .993 & 32.476 .131 \\
\hline 1888 & 2.651 .537 & 1.328 .845 & 315.955 & 16.584 & 299.393 & 4.714 .126 & 38.259 .977 \\
\hline 1889 & 3.303 .391 & 1.606 .132 & 347.867 & 39.077 & 293.763 & 5.898 .396 & \\
\hline 1890 & 3.771 .612 & 826.418 & 530.237 & 65.615 & 805.089 & 6.582 .984 & 67.097 .808 \\
\hline
\end{tabular}

* Secundaria: Instrucción secundaria e Instituto Nacional.

** Superior: Universidad de Chile.

Fuente: SERRANO, S; PONCE DE LEON, M. y Rengifo, F., Historia de la Educación en Chile (1810-2010), Tomo I, Aprender a leer y escribir (1810-1880), Santiago, Taurus, 2012, p. 370-371.

Además, como revela el Gráfico $\mathrm{N}^{\mathrm{o}}$ 1, el porcentaje destinado a educación experimentó un crecimiento sostenido. En el período, las cifras destinadas a Educación fueron incrementándose como lo hicieron todas las partidas presupuestarias. 
Gráfico No 1 . Porcentaje del presupuesto de Instrucción Pública en el Presupuesto Total de Chile. 1845.1890.

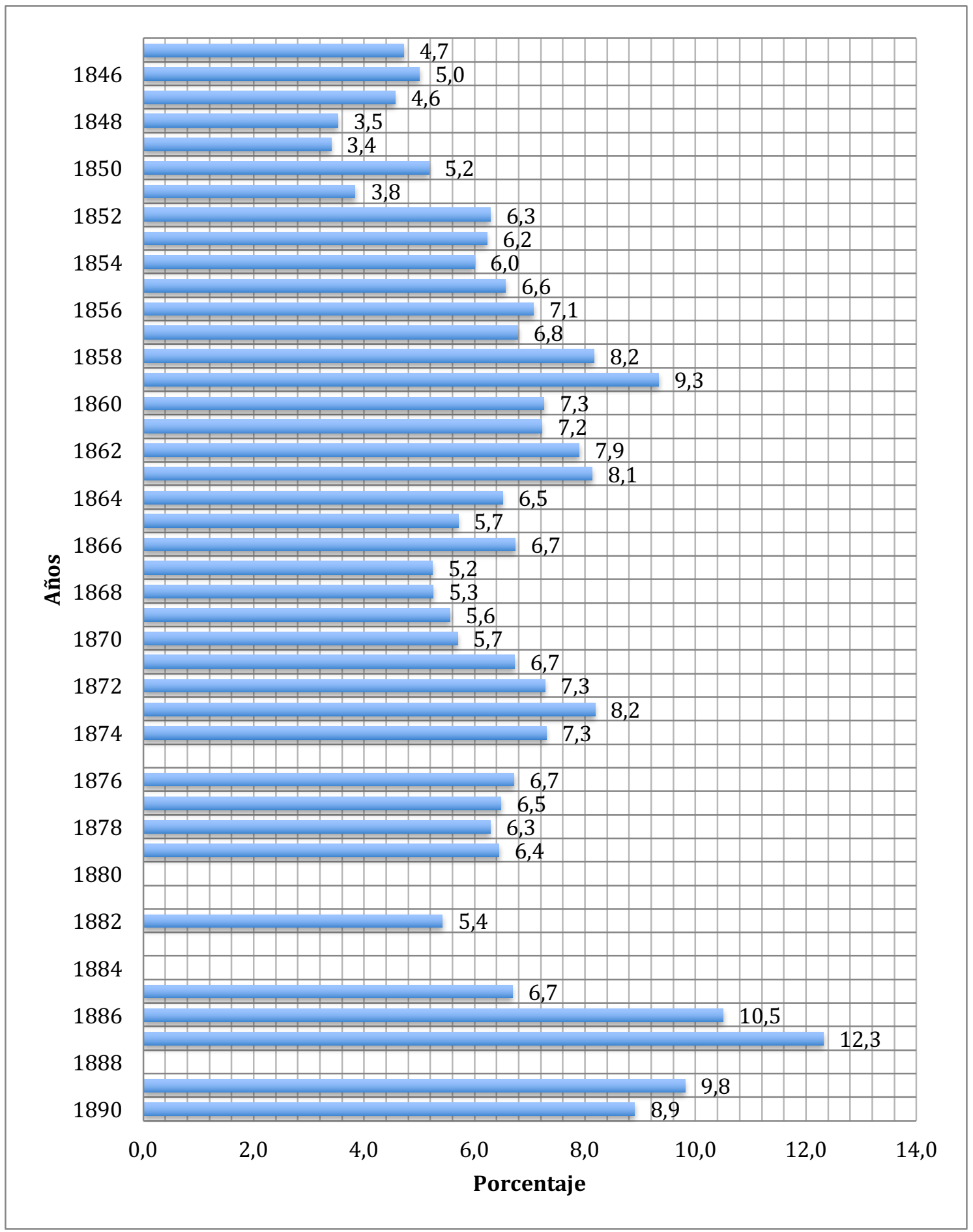

Fuente: SERRANO, S; PONCE DE LEON, M. y Rengifo, F., Historia de la Educación en Chile (1810-2010), Tomo I, Aprender a leer y escribir (1810-1880), op. cit. p. 370-371. Elaboración propia. 
En 1850 el 4,7\% del presupuesto se destinaba a Educación; en 1870 el porcentaje era de un 7,3\% con una tendencia ascendente por los próximos dos decenios para terminar en 1890 con un 9,8\%. Esta ampliación en la década de los ochenta se debió a los suculentos ingresos provenientes de la exportación del salitre que llegaron a doblar los presupuestos de la nación como se aprecia en el Cuadro $N^{\circ} 1$. De las cifras del Cuadro $\mathrm{N}^{0} 1$ y Gráfico $\mathrm{N}^{\mathrm{o}} 1$ es viable señalar que los promedios del aporte del presupuesto a educación desde 1845 son de 4,2\%, 6,5\%, 6,5\%, 6,8\% y 8,9\% para la última década. La educación primaria recibió en el mismo período un promedio por década de $24,6 \%$, $33,5 \%, 46,6 \%, 51.7 \%$ y $50.0 \%$. Las cifras indican que la estrategia de fortificar y desplegar la enseñanza primaria a lo largo del siglo fue sostenida y exitosa. Estas cifras indican la preeminencia en el presupuesto de la educación primaria con la idea de fortalecer la formación de la nación mediante la socialización y homogeneización cultural.

\subsubsection{Las escuelas: obra republicana}

Durante la época colonial la educación formal tuvo un escaso desarrollo. Unas pocas escuelas de primeras letras estuvieron a cargo de los Cabildos o de la Iglesia. Esta mantuvo también algunos colegios y seminarios. A fines del siglo XVIII y comienzos del XIX y como expresión de la ideología de la Ilustración, se fundaron la Real Universidad de San Felipe que traspasará su legado y sucesión legal en 1842 a la Universidad de Chile y otros centros; y a comienzos de la época de la independencia se creó -como ya se ha dicho-el Instituto Nacional, como institución de educación secundaria y superior, dedicada a formar las elites para el nuevo Estado. La Constitución de 1833 en vigor hasta 1925- reconoció la libertad de enseñanza y, al mismo tiempo, asignó al Estado una fuerte responsabilidad en el desarrollo y supervisión de la educación. Avanzando el siglo se fue constituyendo un sistema nacional educativo debido al carácter unitario del Estado, el sistema se organizó en forma centralizada. 
En la segunda mitad del siglo XIX el sistema educativo chileno se transformó y consolidó en público y gratuito y desde entonces se inició un gran esfuerzo por expandir la educación y especialmente las escuelas primarias lo que significó aumentar el número de escuelas por acción del Estado y por una «activa demanda social por educación que pedía escuelas y negociaba con el Estado la apertura de sus establecimientos» ${ }^{301}$. Las escuelas satisficieron las necesidades donde hubiese población concentrada, por lo tanto, se situaron en las ciudades y luego en el campo y esto de alguna manera acentuaba la diferencia entre la urbe alfabeta frente a otro rural y analfabeto.

\section{Gráfico $\mathbf{N}^{0} 2$.}

Número de Escuelas Públicas y Particulares en Chile, 1853--1906.

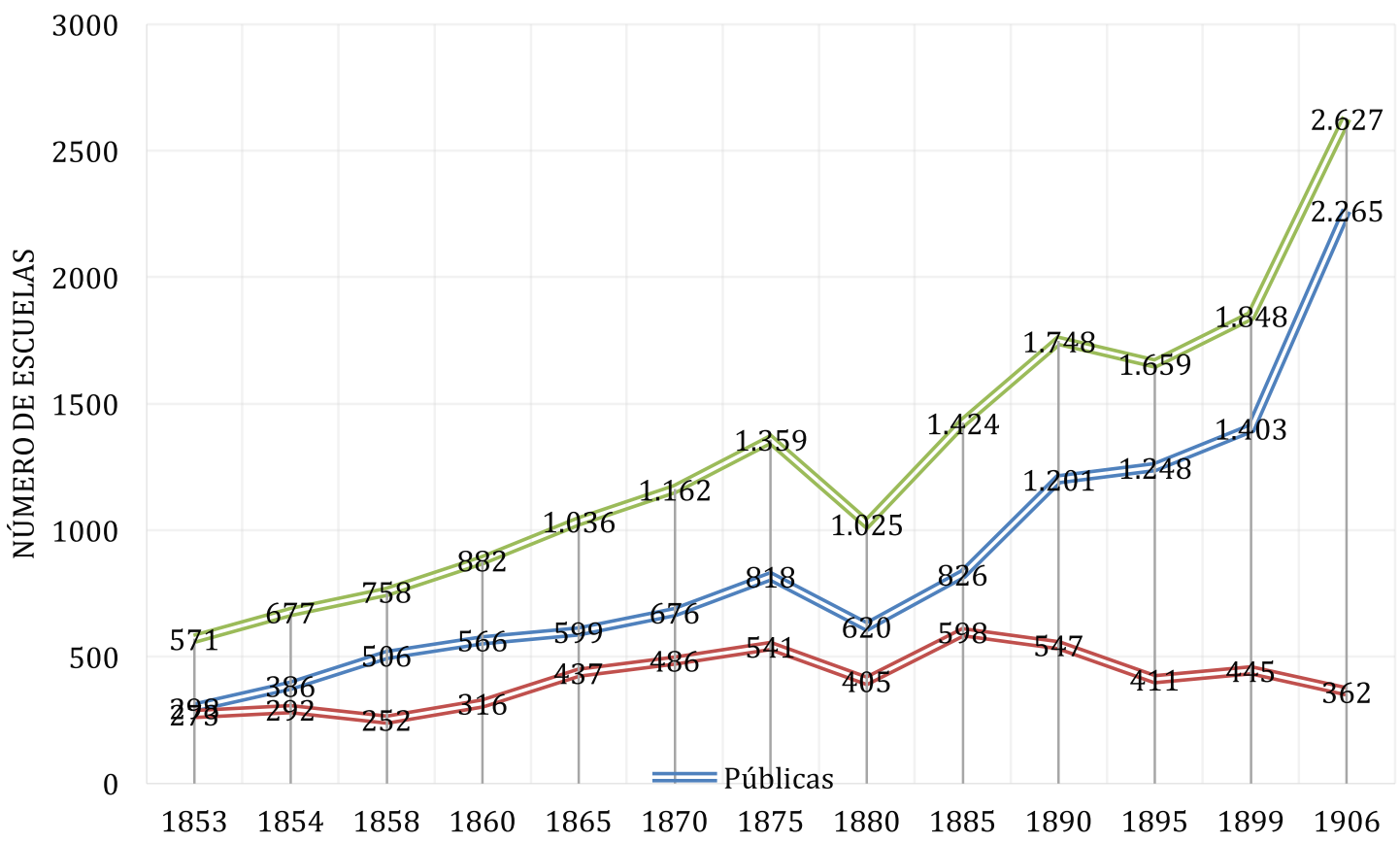

Fuente: SERRANO, S., PONCE DE LEON, M. y RENGIFO, F. Historia de la Educación en Chile..., Tomo I..., op. cit., p. 367. Elaboración propia.

\footnotetext{
${ }^{301}$ PONCE DE LEON, Macarena, «La llegada de la escuela y la llegada a la escuela. La extensión de la educación primaria en Chile, 1840-1907», Historia, No 43, vol. II (2010), p. 452.
} 
Según las estadísticas presentadas en el Gráfico № 2, entre 1853 y 1906 se pasó de 288 escuelas públicas 1.403, aumentando en 4,9 veces. Los datos son coincidentes con el gran hito de la educación chilena, la Ley de Instrucción Primaria, ya que esta legislación transformó en escuelas públicas todas las que recibían fondos fiscales. Como se ha establecido en el -ya citado Cuadro $\mathrm{N}^{\circ} 1$ sobre el «Número de escuelas ...», todas las escuelas fiscales, municipales y conventuales mantuvieron hasta 1861 y sobre estas y las que fue fundando el Estado se organizó una red de escuelas públicas que en 1860 representaban más del 50\% de los establecimientos educacionales concentrando más del $75 \%$ de la matrícula. La tendencia se mantuvo sostenida y estable hasta la década de los ochenta cuando los ingresos del salitre permitieron acelerar la construcción de escuelas. Las escuelas públicas fueron desplazando a las privadas significativamente en número, aunque siguieron atendiendo a un $20 \%$ de la matrícula a fines del siglo XIX.

Debemos matizar, no obstante, el aumento en el número de escuelas en varios aspectos. En primer lugar, si dimensionamos el número de escuelas, de alumnos, y la población en edad escolar como lo señala el Cuadro No3 -que ahora presentamos-, advertimos que el número de estudiantes creció más rápidamente que la población en edad escolar. Hubo crecimiento sostenido, pero si a fines del siglo solo teníamos dos escuelas por cada 1.000 habitantes «no era lo que requería el aumento de la población del país» ${ }^{302}$.

${ }^{302}$ Ibidem, p. 460. 


\section{Cuadro No3. Número de Escuelas y alumnos en correspondencia a la población escolar (5 a 15 años). Chile 1854-1907.}

\begin{tabular}{|c|c|c|c|c|c|}
\hline Censo & \multicolumn{3}{|c|}{ Número total } & Escuelas cada mil niños \\
\hline 1854 & 677 & 27.449 & 271.459 & 1 & 2 \\
\hline 1865 & 1.036 & 51.294 & 376.384 & 2 & 3 \\
\hline 1875 & 1.359 & 89.505 & 405.202 & 2 & 3 \\
\hline 1885 & 1.424 & 97.136 & 606.154 & 2 & 3 \\
\hline 1895 & 1.659 & 139.991 & 657.049 & 2 & 3 \\
\hline 1907 & 2.627 & 201.176 & 693.929 & 3 & 4 \\
\hline
\end{tabular}

Fuente: Censos de la República $(1854,1865,1875,1895,1907)$ y PONCE DE LEON, Macarena, «La llegada de la escuela y la llegada a la escuela. La extensión de la educación primaria en Chile, 1840-1907», art. cit., p. 459.

Un segundo problema tiene que ver con la forma en que se construyeron las estadísticas desde 1837 con la creación del Ministerio de Justica, Culto e Instrucción Pública. Las cifras están confeccionadas a partir de los informes de autoridades políticas y de visitadores a partir de 1854. El grueso de la información era proporcionado por estos visitadores quienes eran funcionarios «estatales, remunerados y activos a lo largo de todo el país, a cargo de la vigilancia de las escuelas financiadas íntegra o parcialmente por el Estado» ${ }^{303}$. Su condición de visitadores de escuelas proporcionó información fragmentada, y esencialmente no existe certeza del funcionamiento real de las escuelas y la asistencia real de los estudiantes. De acuerdo a los datos y los censos, la población en edad escolar que no asistió a la escuela fue desde un $87 \%$ en 1854 hasta un $71 \%$ en 1907 con un promedio de $80,7 \%$ y esto se debía a que la escuela no era capaz de servir a toda la población. Eso explicaría el grado de inasistencia y analfabetismo que tenía Chile a inicios del siglo XX.

${ }^{303}$ Ibidem, p. 461. 
Lo anterior nos lleva a un tercer asunto referido a la expansión de las escuelas: la ubicación de las escuelas. Chile durante el siglo XIX era un país esencialmente rural, principal escollo para implantar la política estatal de universalizar la escuela pública. Poseía una población disgregada, dispersa, con un patrón de asentamiento rural predominante en todo el territorio con alguna excepción en centros mineros del norte. El contingente mayor de población se asentaba en el centro y en torno al Valle Longitudinal con Santiago como eje central donde de igual manera predominaba una sociedad agraria. Desde la segunda mitad del XIX se produjo con el aumento de la población y un proceso relativo de urbanización como trastienda en los cambios societales que fueron de gran impacto, pero todavía a principios del siglo XX más de la mitad de la población seguía siendo rural. Como se refleja en el Cuadro $\mathrm{N}^{\mathrm{o}} 4$ que aquí presentamos, la mayor parte de las escuelas se fundaron en ciudades o en poblaciones aglomeradas y en muchos casos funcionando en forma inestable y tal como demuestra el Cuadro $\mathrm{N}^{\circ} 5$ «Asistencia media de escuelas públicas» reflejado más adelante.

El sistema para la instalación de escuela operaba a iniciativa del Estado y petición de las comunidades locales quienes en muchos casos aportaban los recursos el municipio o algún particular. Evidentemente, las escuelas se instalaron donde las comunidades tenían mayores niveles de organización. El contraste fue bastante fuerte y «evidentes entre un mundo urbano donde alrededor del $40 \%$ de los niños eran alumnos primarios, y un mundo rural con solo un $10 \%$ aproximadamente ${ }^{304}$. La estrategia utilizada por el Estado desarrollo una gran expansión de escolarización, un poco desordenada, pero con una gran diferencia entre lo urbano y rural.

${ }^{304}$ Ibidem, p. 472. 
Cuadro N4. Población Urbana y Rural en Chile según censos: 1865-1907.

\begin{tabular}{|c|r|r|r|r|}
\hline Años & $\begin{array}{l}\text { Población } \\
\text { Urbana }\end{array}$ & Porcentaje & $\begin{array}{l}\text { Población } \\
\text { Rural }\end{array}$ & Porcentaje \\
\hline 1865 & 520.663 & 29 & 1.298 .560 & 71 \\
\hline 1875 & 725.5450 & 35 & 1.350 .426 & 65 \\
\hline 1885 & 1.041 .765 & 42 & 1.465 .240 & 58 \\
\hline 1895 & 1.223 .407 & 45 & 1.472 .218 & 55 \\
\hline 1907 & 1.723 .5521 & 43 & 1.838 .996 & 57 \\
\hline
\end{tabular}

Fuente: BRAUN, Juan; BRAUN, Matías, BRIONES, Ignacio, DIAZ, José, LÜDERS, Rolf y WAGNER, Gert, Economía chilena 1810-1995. Estadísticas históricas, Santiago, Instituto de Economía Universidad Católica de Chile, 2000, p. 231.

Las escuelas primarias del Estado se destinaban principalmente a enseñar las primeras letras a los niños. En 1853 ellas matriculaban 23.136 niños y niñas, pero en 1889 ya concurrían a 139.812, lo que representaba una cobertura de $20 \%$ de las edades de 6 a 14 años. La escolarización en el Chile del siglo XIX mediante una serie de disposiciones se transformaría en obligatoria, universal y gratuita.

\subsubsection{Asistencia a la escuela}

La escolarización obligatoria, universal y gratuita tenía en sí graves limitaciones. En primer lugar, porque dicha escolarización se circunscribía solo a la enseñanza primaria o elemental. En segundo lugar, porque era considerada fundamentalmente como un deber de los padres, no siempre muy celosos en el cumplimiento de esta obligación. A continuación, mostraremos algunos ejemplos de absentismo escolar, a mediados de siglo. En 1854 el preceptor de Combarbalá se quejaba de la siguiente forma frente al ausentismo escolar: «(...) se nota en este establecimiento mucha aplicación en los jóvenes; pero la inasistencia de ellos es muy crecida; es necesario estar reconviniendo todos los días a los padres de familia para que divisen el mal que hacen a sus hijos» ${ }^{305}$. En Dalcahue, isla de Chiloé el preceptor indica que «la falta de asistencia de los alumnos es el mayor obstáculo para el progreso de la educación en este

\footnotetext{
${ }^{305}$ Cit. en Amunategui, M. y AMUNATegui, G., De la Instrucción Primaria en Chile..., op. cit., $p$. 108.
} 
establecimiento» ${ }^{306}$. En Rinconada de Silva, en el centro del país, José Mercedes Sarmiento señalaba que «uno de los más poderosos e invencibles obstáculos para el progreso de la escuela es la poca e interrumpida asistencia de los alumnos, sin vencer esta, nada podemos avanzar» ${ }^{307}$. Este mismo preceptor dirigió una misiva a Domingo Faustino Sarmiento en la que explica que después de seis años de experiencia docente está convencido que el principal problema que enfrentan las escuelas es a la ausencia de los estudiantes y que se debe fijar un número de inasistencias y que «pasado el cual el alumno contraventor deba ser expulsado de la escuela» ${ }^{308}$. El preceptor de Chillán, sur de Chile, Justo Pastor Mellado indicaba que «la disminución de alumnos que se nota en este mes nace de que en este tiempo de las cosechas sus padres los retiran para servirse de ellos» ${ }^{309}$. En el mismo tenor lo planteó el preceptor de Parral que ante la inasistencia de los jóvenes a la escuela no se logran los aprendizajes esperados y que «los padres o guardadores de ellos los separan temporalmente para ocuparlos en sus trabajos de campo.» ${ }^{310}$ Un último ejemplo es el del preceptor Rufino González que señalaba que «en este mes ha habido más inasistencia, porque los padres necesitan de sus hijos para el trabajo, a lo que se agrega la carestía de los alimentos» ${ }^{311}$.

\footnotetext{
${ }^{306}$ Cit. en Ibidem, p. 109.

${ }^{307}$ Cit. en Ibidem, p. 110.

${ }^{308}$ Cit. en Ibidem, p. 111.

${ }^{309}$ Cit. en Ibidem, p. 120.

${ }^{310}$ Cit. en Ibidem, p. 121.

${ }^{311}$ Cit. en Ibidem, p. 122.
} 
Cuadro $N^{\circ}$ 5. Asistencia media de escuelas públicas (1862-1895)

\begin{tabular}{|c|c|c|c|c|}
\hline Año & $\begin{array}{l}\text { Número de } \\
\text { alumnos } \\
\text { matriculados }\end{array}$ & $\begin{array}{l}\text { Asistencia } \\
\text { media }\end{array}$ & $\begin{array}{l}\% \\
\text { Asistencia } \\
\text { media }\end{array}$ & $\begin{array}{l}\text { \% de } \\
\text { Inasistencia }\end{array}$ \\
\hline 1862 & 37.856 & 27.361 & 72,3 & 27,7 \\
\hline \multicolumn{5}{|l|}{1863} \\
\hline 1864 & 37.798 & 29.932 & 79,2 & 20,8 \\
\hline 1865 & 38.439 & 28.302 & 73,6 & 26,4 \\
\hline 1866 & 36.902 & 27.151 & & \\
\hline 1867 & 41.111 & & & \\
\hline 1868 & 46.530 & & & \\
\hline 1869 & 49.889 & 36.239 & 72,6 & 27,4 \\
\hline 1870 & 52.945 & 38.904 & 73,5 & 26,5 \\
\hline 1871 & 54.821 & 40.738 & 74,3 & 25,7 \\
\hline 1872 & 56.417 & 39.848 & 70,6 & 29,4 \\
\hline 1873 & 59.786 & 41.856 & 70 & 30 \\
\hline \multicolumn{5}{|l|}{1874} \\
\hline 1875 & 65.875 & 45.864 & 69,6 & 30,4 \\
\hline 1876 & 65.292 & 45.630 & 69,9 & 30,1 \\
\hline 1877 & 62.467 & 43.348 & 69,4 & 30,6 \\
\hline 1878 & 60.571 & 41.195 & 68 & 32 \\
\hline 1879 & 51.545 & 35.325 & 68,5 & 31,5 \\
\hline 1880 & 48.794 & 34.089 & 69,9 & 30,1 \\
\hline 1881 & 54.470 & & & \\
\hline 1882 & 60.541 & 42.803 & 70,7 & 29,3 \\
\hline 1883 & 70.382 & 49.766 & 70,7 & 29,3 \\
\hline 1884 & 63.559 & & & \\
\hline 1885 & 68.894 & 48.321 & 70,1 & 29,9 \\
\hline 1886 & 78.810 & 47.780 & 60,6 & 39,4 \\
\hline 1887 & 81.362 & 55.813 & 68,6 & 31,1 \\
\hline 1888 & 84.385 & 35.540 & 42,1 & 57,9 \\
\hline 1889 & 92.874 & 64.513 & 69,5 & 30,5 \\
\hline 1890 & 101.053 & 67.305 & 66,6 & 33,4 \\
\hline 1891 & 95.456 & 64.737 & 67,8 & 32,2 \\
\hline 1892 & 109.909 & 71.277 & 65,3 & 34,7 \\
\hline 1893 & 113.247 & 72.899 & 64,4 & 35,6 \\
\hline 1894 & 117.489 & 72.925 & 62,1 & 37,9 \\
\hline 1895 & 114.565 & 71.091 & 62,8 & 37,2 \\
\hline
\end{tabular}

Fuente: SERRANO, S.: PONCE DE LEON, M., y RENGIFO, F., Historia de la Educación en Chile..., Tomo I..., op. cit., p. 375.

Las energías del Estado chileno se limitaron principalmente a imponer legalmente la escolarización y a financiarla, pero no a realizar un esfuerzo económico por conseguir 
efectivamente la escolarización universal. Con la dictación de la Ley de Instrucción Primaria de 1860 el Estado se convirtió en el principal sostenedor de la educación. La ley garantizaba la gratuidad y la responsabilidad fiscal con respecto a ella y así el sistema educacional quedó dotado de una estructura centralizada en que controlaba la actividad pedagógica.

La inasistencia constituyó el principal problema plasmado en la falta de instrucción primaria y un alto índice de analfabetismo de un $68,3 \%$ en 1895 . Estos altos índices de absentismo ponen de manifiesto la incongruencia entre el número de escuela, matrícula y asistencia a clases. Todo esto constata que parte importante de la población infantil y en edad escolar eran trabajadores activos.

\subsubsection{Saber leer y escribir}

Alfabetizar la población era la tarea fundamental de la acción educativa del Estado y la escuela fue su más importante agente. La finalidad suprema era enseñar a leer y escribir y la difusión de la cultura escrita constituyó «un fenómeno histórico que ha sido estrechamente asociado al desarrollo de las sociedades modernas y que se ha estudiado a través de la difusión social de la capacidad de leer y escribir en el total de la población» ${ }^{312}$. Consecuentemente hemos presentado los indicadores de alfabetización en relación con la población total y matriculados para demostrar los resultados de escolarización y la extensión de la escuela pública.

${ }^{312}$ SERRANO, S., PONCE DE LEON, M. y RENGIFO, F., Historia de la Educación en Chile (18102010), Tomo I ..., op. cit., p. 121. 
Cuadro $\mathrm{N}^{0}$ 6. Porcentaje de Alfabetos y Analfabetos en Chile. 1854-1895

\begin{tabular}{|c|c|c|c|}
\hline Años & $\begin{array}{l}\text { Alfabetos } \\
(\%)\end{array}$ & Analfabetos (\%) & $\begin{array}{l}\text { Población } \\
\text { Total }\end{array}$ \\
\hline 1854 & 13.5 & 86.5 & 1.439 .120 \\
\hline 1865 & 16.7 & 83.3 & 1.824 .358 \\
\hline 1875 & 22.9 & 77.1 & 2.084 .108 \\
\hline 1885 & 28.9 & 71.1 & 2.490 .104 \\
\hline 1895 & 31.7 & 68.3 & 2.679 .169 \\
\hline
\end{tabular}

Fuente: Elaboración propia a partir de los Censos de la República, 1854, 1865, 1875, 1885 y $1895^{313}$.

Uno de los principales elementos que estuvo presente en la conformación de la educación chilena en el siglo XIX fue la obligación de comunicarse en un idioma y para ello la alfabetización facilitó la comunicación entre la población, y de esta con la burocracia suministrando un sentimiento de pertenencia nacional. Estas cifras indican que el Estado pudo llevar a cabo una política sistemática en educación que se por la existencia de un fuerte respaldo financiero aun cuando el gasto público fue considerablemente mayor en «administración, defensa y sector financiero, pero dentro de las funciones sociales, educación aumentó progresivamente su participación e importancia» ${ }^{314}$. De esta forma el Estado pudo reducir los índices de analfabetismo entre 1854 y 1895 en 18,2 puntos.

El objetivo de enseñar a leer y escribir a lo largo del siglo XIX demuestra la importancia de la escuela en la difusión de la lectura y escritura. La mayor alfabetización evidentemente se dio en los centros urbanos por el contacto permanente que las ciudades ofrecían a sus habitantes con las escuelas y con el mundo escrito. El aumento progresivo de la alfabetización que pasó de un $13,5 \%$ en 1854 a un $31,7 \%$ en 1895 es consecuente con el aumento sostenido de los establecimientos educacionales,

\footnotetext{
${ }^{313}$ Censo General de la República de Chile levantado en Abril de 1854, Santiago, Imprenta del Ferrocarril, 1858; OFICINA CENTRAL DE ESTADISTICA, Cuarto Censo de la Población de Chile, 1865, Santiago, Imprenta Nacional, 1866; OFICINA CENTRAL DE ESTADISTICA, Quinto Censo de la Población de Chile, 1875, Valparaíso, Imprenta El Mercurio, 1878; OFICINA CENTRAL DE ESTADISTICA, Sexto Censo de la Población de Chile, 1885, Valparaíso, Imprenta de la Patria, 1890 y OFICINA CENTRAL DE ESTADISTICA, Séptimo Censo de la Población de Chile, 1895, Valparaíso, Imprenta Universo, 1900.

${ }^{314}$ SERRANO, S., Universidad y nación. Chile en el siglo..., op. cit., p. 64.
} 
ya que en 855 había 303 escuelas primarias que atendían unos 14.946 estudiantes y en 1895 existían 1.248 que atendían 114.565 estudiantes.

Los analfabetos predominaron en el mundo rural y en las periferias urbanas donde leer no era necesario para desempeñarse en economías ligadas a agricultura, minería y trabajos domésticos. Es de rigor, señalar que, en las sociedades del siglo XIX, y en la chilena, también, la alfabetización era una habilidad poco necesaria y muy poco demandada. Visiblemente el Estado financió la educación chilena y efectivamente asumió más organizadamente su papel «y la educación pudo iniciar su lento, pero bastante seguro desarrollo» ${ }^{315}$.

\subsubsection{Matrícula, escolaridad y gasto}

En 1854, la cobertura total de Primaria era de 27.449 alumnos, es decir, mucho menos del $1 \%$ de la población. La enseñanza secundaria estaba constituida por unos 720 estudiantes. En 1865 había 51.294 alumnos en Primaria y 1.579 en Secundaria. Al terminar el período esa cifra había crecido inmensamente con una población en la educación primaria de 163.792 y en Secundaria 9.693. Evidentemente, el crecimiento en cobertura educativa fue mucho más intenso que el propio crecimiento de la población. Si calculamos en virtud de tasas de crecimiento, tenemos que según los censos de población de 1854 y de 1895 , la población chilena tuvo un crecimiento de $0,86 \%$, en cambio el de cobertura educacional para niños y niñas entre 5 y 18 años, experimentó una tasa de crecimiento de $4,3 \%$.

${ }^{315}$ CAVIERES, Eduardo, «Educación y sociedad en los inicios de la modernización de Chile, 18401880», Dimensión Histórica de Chile, Nº 6-7 (1989-1990), p. 44. 
Cuadro $N^{0}$ 7. Total de alumnos matriculados en Escuelas Primarias y Secundarias, 1854-1895.

\begin{tabular}{|r|r|r|r|}
\hline Años & \multicolumn{1}{|c|}{ Primaria } & \multicolumn{1}{c|}{ Secundaria } & \multicolumn{1}{c|}{ Universitaria } \\
\hline 1854 & 28,744 & 720 & 211 \\
\hline 1865 & 55,142 & 1,579 & 384 \\
\hline 1875 & 93,278 & 2,263 & 753 \\
\hline 1885 & 102,619 & 3,290 & 1,027 \\
\hline 1895 & 152,206 & 7,329 & 1,266 \\
\hline
\end{tabular}

Fuente: BRAUN, J.; BRAUN, M., BRIONES, I., DIAZ, J., LÜDERS, R. y WAGNER, G., Economía chilena 1810-1995. Estadísticas ..., op. cit., p. 233.

La acción educativa del Estado estuvo orientada a «fortalecer la institucionalidad de la escuela, soporte básico de un sistema educativo nacional que avanzaba en su consolidación» ${ }^{316}$. El cuadro $\mathrm{N}^{\mathrm{o}} 7$ representa consistentemente el incremento de la matrícula en los distintos niveles educativos, en 1854 los matriculados en Primaria representaban un $1,9 \%$ de la población total y en 1895 ya eran un 5,6\%; en educación secundaria era mucho menor e iba de un $0,05 \%$ en 1854 a un $0,27 \%$ en 1895 ; en tanto la educación universitaria transitó en el período de un $0,014 \%$ a un $0,04 \%$. Si comparamos estos datos con la actualidad (2016) «nos arroja que en Educación Básica la cobertura es de un $99,7 \%$, en Secundaria de un $87,7 \%$ y de un 7\% en educación Superior» ${ }^{317}$. Es así que la cobertura significativa del siglo XIX fue una institución facilitadora del predominio cultural que requería el Estado nacional y la elite gobernante para que el nuevo orden que se estaba configurando se consolidara.

El cuadro $\mathrm{N}^{\circ} 8$ demuestra el esfuerzo y disposición del Estado por ampliar la cobertura escolar y cuya energía estuvo en el nivel primario con el claro objetivo de alfabetizarla. El cuadro revela las prioridades educacionales del estado chileno y que estaban determinadas por la estructura social. Hubo un afán por educar al pueblo y a una clase dirigente integrada por la elite política y social. Esto se revela en establecer que era un sistema educacional que no estaba concebida para el ascenso social

\footnotetext{
${ }^{316}$ EGAÑA, M., La educación primaria popular..., op. cit., p. 123.

${ }^{317}$ MINISTERIO DE EDUCACION, Análisis de indicadores educativos de Chile y la OCDE en el contexto de la reforma Educacional, Santiago, Ed. Ministerio de Educación, 2015, p. 10.
} 
Cuadro $N^{\circ}$ 8. Tasa de Escolaridad Total y por nivel. 1852-1900.

\begin{tabular}{|c|r|r|r|r|}
\hline Años & $\begin{array}{l}\text { Años de } \\
\text { Escolaridad } \\
\text { Promedio }\end{array}$ & $\begin{array}{l}\text { Cobertura } \\
\text { Básica }\end{array}$ & $\begin{array}{l}\text { Cobertura } \\
\text { Secundaria }\end{array}$ & $\begin{array}{l}\text { Cobertura } \\
\text { Superior }\end{array}$ \\
\hline 1852 & 0,67 & 10,27 & 0,66 & 0,10 \\
\hline 1858 & 0,73 & 14,82 & 0,94 & 0,10 \\
\hline 1864 & 0,85 & 17,52 & 1,14 & 0,17 \\
\hline 1870 & 1,04 & 26,34 & 1,23 & 0,16 \\
\hline 1876 & 1,23 & 25,18 & 1,26 & 0,27 \\
\hline 1882 & 1,42 & 21,42 & 1,29 & 0,28 \\
\hline 1888 & 1,56 & 26,87 & 1,70 & 0,32 \\
\hline 1894 & 1,68 & 33,72 & 3,13 & 0,32 \\
\hline 1900 & 1,85 & 34,88 & 4,23 & 0,31 \\
\hline
\end{tabular}

Fuente: BRAUN, J.; BRAUN, M., BRIONES, I., DIAZ, J., LÜDERS, R. y WAGNER, G., Economía chilena 1810-1995. Estadísticas..., op. cit., p. 234.

La tasa de escolaridad y la cobertura en educación secundaria y universitaria del Cuadro $\mathrm{N}^{\circ} 8$ sugieren que no estaban vinculadas a la primaria y que ésta no era el inicio de una trayectoria educativa, sino que era la fase final para la inmensa mayoría de la población. Los datos son incuestionables, si en 1852 la educación básica cubría un 10,27\% y en 1900 un 34,88\%, la educación secundaria recorrió un camino de un $0,66 \%$ a un 4,23\% y la educación universitaria de un 0,1 a un 0,3 .

El sistema educativo estaba cimentado en una profunda fragmentación, pero transformó «sustantivamente la estructura de la demanda educacional» ${ }^{318}$. La educación creció y lo realizó a un ritmo sostenido e incluso con tasas de crecimiento mayor que las que evidenciaba la población, los alumnos matriculados crecieron de 23.136 a 139.812. En ese crecimiento participaron los privados y el sector público, pero tal como lo evidencia el Cuadro $\mathrm{N}^{\circ} 1$ sobre «Número de escuelas y alumnos del sistema de Instrucción Primaria, 1848-1860», -reflejado en páginas más arriba- la participación del Estado fue mucho mayor y clave para intensificar ese crecimiento. Esto significó una transformación radical en la historia de Chile.

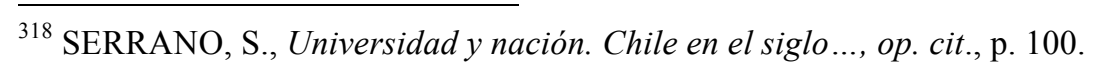


Consideramos que la relación es proporcional a los requerimientos y complejidades de las sociedades decimonónicas, las ciudades requieren tipos humanos con capacidades acordes al sistema económico y político existente. La cobertura y llegada de la escuela a todo Chile se hizo con reglamentos y con la Ley de Instrucción Primaria de 1861, pero debemos tener en cuenta, que imperaba la voluntariedad, y que recién en 1920 se decretó la Ley de Instrucción Primaria Obligatoria para los niños entre 6 y 10 años.

El siguiente cuadro representa la forma en que el Estado chileno fue impulsando y masificando la educación como una de sus tareas primordiales.

\section{Cuadro $N^{\circ}$ 9. Alumnos matriculados por nivel educacional y gasto anual público por alumno en cada nivel. 1852-1900.}

\begin{tabular}{|l|r|r|r|r|r|r|}
\hline Año & \multicolumn{1}{l|}{$\begin{array}{l}\text { Matricula } \\
\text { Básica }\end{array}$} & $\begin{array}{l}\text { Matrícula } \\
\text { Secundaria }\end{array}$ & $\begin{array}{l}\text { Matricula } \\
\text { E. }\end{array}$ & $\begin{array}{l}\text { Gastos por } \\
\text { alumno en } \\
\text { Básica }\end{array}$ & $\begin{array}{l}\text { Gastos por } \\
\text { alumno en } \\
\text { Media }\end{array}$ & $\begin{array}{l}\text { Gastos por } \\
\text { alumno en } \\
\text { E. } \\
\text { Superior }\end{array}$ \\
\hline 1852 & 23.504 & 720 & 185 & 13.943 & 314.655 & 54.054 \\
\hline 1853 & 23.636 & 720 & 139 & 16.378 & 345.384 & 239.414 \\
\hline 1854 & 28.024 & 720 & 211 & 18.418 & 344.962 & 149.175 \\
\hline 1855 & 29.308 & 730 & 216 & 17.876 & 260.893 & 140.122 \\
\hline 1856 & 31.103 & 736 & 201 & 13.514 & 307.762 & 150.308 \\
\hline 1857 & 33.531 & 1.309 & 190 & 13.731 & 164.809 & 153.294 \\
\hline 1858 & 38.385 & 1.161 & 206 & 14.119 & 292.077 & 738.789 \\
\hline 1859 & 48.327 & 1.319 & 228 & 13.571 & 267.008 & 650.789 \\
\hline 1860 & 46.826 & 1.358 & 295 & 11.653 & 195.393 & 100.186 \\
\hline 1861 & 42.411 & 1.444 & 335 & 14.728 & 189.110 & 91.331 \\
\hline 1862 & 51.403 & 1.837 & 370 & 12.78 & 135.717 & 78.556 \\
\hline 1863 & 50.771 & 1.649 & 401 & 14.664 & 191.567 & 70.941 \\
\hline 1864 & 51.372 & 1.592 & 425 & 14.986 & 172.066 & 63.289 \\
\hline 1865 & 53.563 & 1.579 & 384 & 18.428 & 193.723 & 104.957 \\
\hline 1866 & 53.591 & 1.709 & 364 & 20.037 & 183.585 & 112.481 \\
\hline 1867 & 60.151 & 1.756 & 466 & 16.426 & 176.838 & 76.907 \\
\hline 1868 & 68.619 & 1.662 & 383 & 15.569 & 198.792 & 81.907 \\
\hline 1869 & 74.25 & 1.678 & 444 & 14.565 & 232.318 & 82.155 \\
\hline 1870 & 83.785 & 1.881 & 438 & 11.742 & 239.451 & 83.692 \\
\hline & & & & & & \\
\hline
\end{tabular}


[Cuadro No 9 (continuación)]

\begin{tabular}{|l|r|r|r|r|r|r|}
\hline Año & \multicolumn{1}{l}{$\begin{array}{l}\text { Matricula } \\
\text { Básica }\end{array}$} & $\begin{array}{l}\text { Matrícula } \\
\text { Secundaria }\end{array}$ & $\begin{array}{l}\text { Matricula } \\
\text { E. }\end{array}$ & $\begin{array}{l}\text { Superior } \\
\text { Gastos por } \\
\text { alúsica }\end{array}$ & $\begin{array}{l}\text { Gastos por } \\
\text { alumno en } \\
\text { Media }\end{array}$ & $\begin{array}{l}\text { Gastos por } \\
\text { alumno en } \\
\text { E. } \\
\text { Superior }\end{array}$ \\
\hline 1871 & 81.921 & 1.969 & 435 & 15.892 & 236.752 & 119.706 \\
\hline 1872 & 86.855 & 2.120 & 503 & 16.872 & 205.551 & 64.788 \\
\hline 1873 & 90.714 & 1.813 & 646 & 19.214 & 259.195 & 52.213 \\
\hline 1874 & 90.882 & 2.066 & 731 & 21.122 & 291.345 & 39.518 \\
\hline 1875 & 91.015 & 2.263 & 753 & 22.284 & 278.538 & 48.915 \\
\hline 1876 & 87.232 & 2.091 & 777 & 19.808 & 208.673 & 36.337 \\
\hline 1877 & 84.225 & 1.937 & 943 & 18.711 & 266.882 & 28.388 \\
\hline 1878 & 82.486 & 1.794 & 862 & 20.021 & 295.160 & 27.096 \\
\hline 1879 & 66.718 & 1.938 & 871 & 17.540 & 273.556 & 25.196 \\
\hline 1880 & 65.288 & 2.082 & 780 & 16.657 & 225.780 & 25.389 \\
\hline 1881 & 74.206 & 2.225 & 880 & 18.074 & 215.267 & 27.804 \\
\hline 1882 & 83.543 & 2.405 & 920 & 20.138 & 239.056 & 30.434 \\
\hline 1883 & 95.295 & 3.007 & 955 & 20.451 & 232.685 & 28.714 \\
\hline 1884 & 91.589 & 3.029 & 847 & 31.113 & 204.469 & 232.609 \\
\hline 1885 & 99.329 & 3.290 & 1.027 & 23.046 & 163.421 & 479.005 \\
\hline 1886 & 108.728 & 3.053 & 1.026 & 21.034 & 305.919 & 401.746 \\
\hline 1887 & 110.69 & 3.624 & 1.034 & 28.674 & 373.149 & 551.425 \\
\hline 1888 & 112.694 & 3.387 & 1.123 & 59.711 & 590.111 & 372.932 \\
\hline 1889 & 125.318 & 3.981 & 1.175 & 67.410 & 604.857 & 716.234 \\
\hline 1890 & 131.125 & 3.833 & 1.297 & 66.365 & 322.261 & 733.74 \\
\hline 1891 & 122.461 & 3.992 & 731 & 53.842 & 246.378 & 997.696 \\
\hline 1892 & 141.615 & 5.614 & 1.243 & 40.730 & 184.154 & 449.803 \\
\hline 1893 & 136.438 & 5.888 & 1.216 & 25.578 & 157.011 & 268.312 \\
\hline 1894 & 149.479 & 6.557 & 1.169 & 19.786 & 164.659 & 228.042 \\
\hline 1895 & 144.877 & 7.329 & 1.266 & 28.745 & 289.946 & 390.901 \\
\hline 1896 & 144.849 & 7.490 & 913 & 40.891 & 335.623 & 830.722 \\
\hline 1897 & 137.476 & 8.217 & 983 & 37.097 & 257.725 & 682.161 \\
\hline 1898 & 128.152 & 8.652 & 1.059 & 33.252 & 205.443 & 489.849 \\
\hline 1899 & 138.736 & 9.141 & 1.140 & 32.320 & 193.369 & 403.728 \\
\hline 1900 & 163.792 & 9.693 & 1.228 & 41.299 & 220.619 & 506.972 \\
\hline
\end{tabular}

Fuente: BRAUN, J.; BRAUN, M., BRIONES, I., DIAZ, J., LÜDERS, R. y WAGNER, G., Economía chilena 1810-1995. Estadísticas históricas, op. cit., p. 234. 
Esto quiere decir que el Estado tuvo una capacidad de convencimiento impresionante y que la población se sintió cautivada por la escolaridad. Chile gastó más en primaria que en otros niveles, aunque el costo por alumno era proporcionalmente más alto en secundaria y en la Universidad. Esto es reflejo de la intencionalidad de la elite chilena por educar que significaba formar una clase dirigente con los estratos medios y superiores. En 1852 el Estado chileno gastaba 13.943 pesos chilenos mientras que en uno de secundaria gastaba 314.655 pesos chilenos, aunque esa relación fue disminuyendo a lo largo del siglo, es claro que el esfuerzo estaba en dotar a Chile de unos grupos medios fuertes, instruidos, competentes y con fuerte espíritu nacional. En 1900 esa relación era de 5,3 veces más gasto en primaria que en secundaria frente a las 22,5 veces que representaron los gastos de secundaria respecto a primaria en 1852. En lo referente a la educación Superior los gastos hasta la década de los ochenta son muy disimiles y no hay existió una tendencia ni a la baja ni al alza. Desde 1884 se manifestó una clara tendencia al alza y es muy clara se gastó mucho más en educación superior que en cualquier otro nivel. Esto prueba que el énfasis estuvo puesto en los niveles secundarios y universitarios, en términos de infraestructura, calidad, y en el gasto por estudiante.

La escuela fue el brazo político y simbólico del Estado expandiéndose por todo el territorio y los estudiantes fueron al principio pocos, pero siempre en ascenso. La escuela tuvo una doble función, por un lado, integraba y alfabetizaba, pero al mismo tiempo se fue convirtiendo en un factor de segregación social. El modelo de Estado que organizó América Latina, definido «Estado oligárquico», es decir, como una forma de organización en la cual la sociedad política en este período no transcurrió por los cauces auténticos de democracia y que se definió con una limitada representatividad política y una reducida base social de apoyo. El Estado fue consolidando un modelo basado en el orden y el progreso y a pesar de su reducida base social los grupos oligárquicos emprendieron tareas modernizadoras, entre las que se cuenta el desarrollo y fomento de los sistemas de instrucción pública nación. La enseñanza en primaria cumplía el objetivo simple de civilizar en habilidades básicas de saber leer y escribir, invirtió en construcción y estatización de escuelas. Para las comunidades y localidades disponer de 
una escuela los incorporó en la trama institucional del Estado e incipientemente generó los lazos y vínculos políticos y sociales con todo Chile. La educación se enarboló como agente de integración, homogeneidad y factor clave de consolidación de los intereses del Estado y su estudio contribuye a identificar modos específicos del proceso interno de construcción estatal y nacional.

Si la integración nacional se dificultaba por las vías del acceso a la propiedad o el derecho a voto, la educación realizó importantes aportaciones para la construcción de la nacionalidad. Si bien es cierto, que las clases sociales pobres, sobre todo la gran mayoría campesina, fueron escasamente afectadas, el desarrollo educativo tuvo fuertes implicaciones a fines del siglo XIX y principios del XX en la emergencia y ampliación de las clases medias.

En Chile, pese a las dificultades de los primeros años de vida independiente, y la falta de una tranquilidad necesaria para el desarrollo cultural, prendió en el ánimo de los gobernantes la idea de extender la educación a todo el pueblo, a fin de provocar la renovación social. Se creía en la bondad de la ley como agente modificador de las costumbres y en la eficacia de la educación en cuanto fijadora de hábitos. La educación fue utilizada en este caso como mecanismo de consenso y conformación de un tramado relacionado íntimamente con el grado de poder político y material asumido por el Estado. En todo caso, países como Chile la pronta estabilidad política dio lugar a la creación de un sólido sistema educativo y como hemos podido apreciar fueron variados los aspectos de la vida social, política y cultural donde la educación tuvo y ha tenido gran incidencia.

En suma, la identidad nacional construida desde la enseñanza y el aprendizaje por medio de lo patriótico y cívico desempeñaron un papel fundamental en la legitimidad y transmisión de valores. El aprendizaje patriótico, civilizador y la idea de progreso que representaba la educación fueron los principales apoyos en la construcción del Estado nacional. Los sistemas educativos nacionales contribuyeron de la misma forma a otros aspectos de la integración nacional, dado que la administración educacional apoyó la 
presencia del Estado en todo el territorio y logró integrar las regiones periféricas. Dado que en Chile como en el resto de América Latina la unidad nacional consistió en la centralización del aparato estatal y en una instancia simbólica, y no en el acceso más o menos generalizado a la propiedad o a la participación política, por ello, la política educativa cobró una enorme relevancia como medio para la generación del consenso. Desde todas estas perspectivas, la función que el Estado cumple en el campo de la educación tiene un significado muy importante. La educación cumplió funciones de integración de los distintos grupos, la generación de una identidad nacional. Se trata, en definitiva, de conseguir el consenso, de manera que el Estado no se reduzca a ser un aparato de mando e incluso de represión, sino que, mediante una compleja red de funciones que llevó a efecto la dirección cultural e ideológica de la sociedad, consiga el consenso entre los diversos sectores de la sociedad. La educación adquiere en ese sentido una significación relevante, dado su carácter de órgano óptimo para la generación del consenso. 


\section{Capítulo 3.}

La enseñanza de la Historia, la Geografía, la Urbanidad y la Formación de la Ciudadanía chilena en la construcción del Estado nacional chileno 
«Marchad nunca a ciegas mi Patria no ignorante en brazos del pasado tu espíritu abandones

El libro de la Historia comprende y ve adelante, la Europa lo descifra: escuchad sus lecciones. Lo fataliza Vico, Bossuet lo profetiza Guizot lo desarrolla y Herder lo profundiza. Modernos inspirados que en ese Álbum divino de un Dios ven los decretos, y nuestro gran destino» Jacinto Chacón, Discurso redactado con motivo de la oposición a las cátedras de Historias y Literatura del Instituto Nacional. 


\subsection{La enseñanza de la Historia: referentes y funciones}

Desde mediados del siglo XIX, el Estado chileno asumió la responsabilidad de la educación con un sentido «civilizador» y «moralizador» del pueblo. La enseñanza de Historia de Chile, Geografía, y de la Constitución del Estado, se convirtió en un recurso para persuadir a los ciudadanos a que participasen del sistema político a través del sufragio. Se trataba de construir la identidad nacional fundamentada en el aprendizaje de lo patriótico, lo cívico, y de la transmisión de valores asociados a ello.

A pesar de las particularidades y de los diversos elementos y factores que existieron en los estados nacionales que surgieron después de la independencia, había un punto clave y coincidente para todos: era indefectible educar a la población. Debía, la educación, trasmitir conjuntamente con el conocimiento, las virtudes necesarias para que cada habitante asumiera su nueva función en el incipiente y nuevo Estado. Tal como fue señalado en el Catecismo Político, difundido en 1810 respecto al valor de la educación en la instrucción de los jóvenes es fundamentalmente liberalizadora ya que cuando los hombres conocen sus derechos, el orden social, respetan las instituciones «detestan la esclavitud, la tiranía y el despotismo, aspiran a la noble libertad e independencia, y al fin lo consiguen con medidas sabias y prudentes (... ) ${ }^{319}$, y en el diario El Progreso, antes de la primera mitad del siglo se leía que «no hay nada más útil para un hombre destinado a servir a su país que el conocimiento de la historia (...) un medio ideal para unir lealtades individuales a las de la nación»» ${ }^{320}$.

Cuando América y Chile habían decidido avanzar hacia la modernidad política y a la constitución de estados nacionales, educar representaba la generación de marcos de referencia que favorecerían y legitimaban los cambios que estaban ocurriendo. Este mayor protagonismo de la educación constituida en la «tarea prioritaria del Estado y la meta social más importante en la medida que permitirá que las incertidumbres propias

\footnotetext{
319 AMOR DE LA PATRIA, Catecismo Político Cristiano, Santiago de Chile, Editorial del Pacifico, 1975 , p. 1

${ }^{320}$ El Progreso, 14 de febrero de 1843, p. 21.
} 
de un ideario nuevo y poco consolidado» ${ }^{321}$ no tuvieran consecuencias de desestabilización socio-política y cuyo énfasis estuvo orientado a la necesidad que el nuevo orden republicano fuese conocido y aceptado por los nuevos ciudadanos. La enseñanza de la Historia y de la Geografía se convirtieron, entonces, en las columnas de la ansiada nueva realidad, no se trataba solamente de informar sino de formar, en los conceptos de historia patria, ilustración y virtudes cívicas. La pregunta era clara, ¿dónde se inculcarían estos preceptos? y la respuesta era obvia en las salas de clases

El consenso por el deber del estado con la educación, se concretó bien entrado el siglo XIX cuando se consagró la enseñanza de la Historia en el currículum escolar y así Chile «manifestó su preocupación por la enseñanza de la historia y la geografía nacional haciéndolas asignaturas obligatorias a partir de la Ley de Instrucción Pública de $1860 »^{322}$. Su enseñanza no estuvo ausente de problemas. El principal problema que enfrentó la enseñanza de la Historia tuvo que ver con referentes epistemológicos y concepciones disciplinarias, es decir, el corpus historiográfico. En el siglo XIX chileno, el debate sobre la historia estuvo determinado por la valoración que hacía la elite del pasado, lo cual dio origen a dos posturas. La primera, planteada por los conservadores, que el presente y el futuro eran una prolongación del pasado, y una segunda por liberales, quienes lidiaban por la eliminación del pasado para poder construir el presente y el futuro. Las diferencias entre ambas posturas no son radicales ni excluyentes y podemos señalar que en ciertos casos «las mismas filosofías son selectivamente acogidas por ambos bandos y aplicadas según los propios fines y criterios ${ }^{323}$, y aunque la distinción entre liberales y conservadores es bastante tentadora, sostenemos que en la práctica dichas posturas tuvieron matices.

Los dos personajes que monopolizaron la discusión en torno a la idea de la historia, Andrés Bello y José Victorino Lastarria, no podemos considerarlos, en extremo

\footnotetext{
${ }^{321}$ STUVEN, Ana María, La seducción de un orden: Las elites y la construcción de Chile..., op. cit., pp. 111-112.

${ }^{322}$ SERRANO, Sol, «Enseñanza de la Historia e identidad nacional: un vínculo a historizar desde la experiencia chilena», Encounters, vol. No 15 (2014), p. 213.

${ }^{323}$ SALAZAR, Augusto, ¿Existe una filosofia de nuestra América?, México, Editorial siglo XXI, 1969, p. 19.
} 
conservadores o liberales. El primero, que nunca negó el pasado y participó activamente en los gobiernos conservadores, creó nuevas instituciones como la Universidad de Chile que respondía más a una iniciativa de corte liberal ilustrada que a una continuación del pasado; y el segundo apoyó en 1861 a la fusión liberal-conservador que aspiraba a llevar un candidato a la presidencia de la República. Las concepciones de la historia que estuvieron en disputa son altamente pertinentes para comprender y analizar, ya que las formaciones ideológicas decimonónicas no se restringen a la cuestión liberalconservadora, sino que «representan los sistemas dominantes correspondientes a las respectivas oligarquías, o de alguna forma constituyeron el marco general en el cual se debatieron las cuestiones de la cultura escrita» ${ }^{324}$. Las dos posturas se definían por sus posiciones frente al pasado. Unos luchando en contra y otros aceptándolo como algo positivo. Los conservadores quisieron atesorar el pasado y asirse a las tradiciones. Los pensadores liberales, en cambio, no asimilaron el pasado, no hubo intención de conservarlo, se negó porque correspondía rechazar ya que «eso no es ni lo que queremos ni lo que debemos ser» ${ }^{325}$. Entre los pensadores liberales buscaban cimentar un nuevo orden y el principal objetivo era consolidar la Independencia y para ello no se debía tener referencias al pasado colonial.

El siglo fue una centuria de gran producción en cantidad y calidad de obras históricas y es en ese siglo que la disciplina histórica «adquirió rango profesional y universitario, y los historiadores produjeron trabajos de gran aliento que procuraron ofrecer la historia de sus respectivas naciones $(\ldots)\rangle^{326}$. La discusión estuvo centrada entre Historia filosófica e historia narrativa para indagar en el pasado y dichas reflexiones estuvieron inspiradas por las lecturas de Herder, Voltaire y Hegel.

La historia filosófica tenía como horizonte la construcción de la ciencia de la humanidad y el objeto del estudio de la historia no eran sólo los hechos del pasado, sino que sus relaciones, causas y efectos. Estos historiadores procuraron encontrar leyes y

\footnotetext{
${ }^{324}$ GONZALEZ, Beatriz, La historiografia literaria del liberalismo hispanoamericano del siglo XIX, Madrid, Ed. Casa de las Américas, 1987, p. 48.

${ }^{325}$ ZEA, Leopoldo, El pensamiento latinoamericano, Barcelona, 1976, p. 31.

${ }^{326}$ DAGER, Joseph, «El debate en torno al método historiográfico en el Chile del siglo XIX», Revista Complutense de Historia de América, vol. 28 (2002), p. 98.
} 
principios generales que explicaría los hechos. En cambio, la historia narrativa estaba preocupada de subrayar la especificidad de cada época. Este modelo resaltaba la historicidad y, por lo tanto, negaban la posibilidad de encontrar leyes o principios generales del comportamiento de los hombres y de los hechos históricos y su elección fue contar como ocurrieron los hechos. Esta polémica desarrollada en Europa en las primeras décadas del siglo XIX y con el arribo del positivismo la discusión permaneció; en el caso chileno el debate sostenido entre Andrés Bello y José Victorino Lastarria fue un eco de lo que ocurría en Europa. La concepción de la historia como ciencia de la humanidad en un sentido metafísico, y la otra, la narrativa como ciencia concreta y empírica habría de marcar a los pensadores chilenos, quienes tomaron posición según la visión que tenían sobre el pasado. Estas posiciones no sólo tenían que ver con su idea de la historia, sino con el presente en que estaban insertos. El problema surgió en el momento en que los liberales trataron de debatir la postura oficial del gobierno que hacía sobre la independencia y sus consecuencias. En la postura de la historia narrativa estuvo Andrés Bello quien sostenía que el trabajo del historiador debía poner claro los hechos, describirlos, sondear sus causas y consecuencias y que la búsqueda de leyes generales es sólo en el ámbito de la naturaleza y que sólo por el estudio de las individualidades «podemos remontarnos a la síntesis que las comprendía y formula» ${ }^{327}$. La postura de Bello exige que los estudios históricos no avancen por la vía de las generalizaciones sino por la descripción historicista y minuciosa de los acontecimientos, incluso en la inauguración de la Universidad de Chile en 1842 lo había manifestado, especialmente cuando refiere al método histórico sosteniendo que el propio Herder en sus estudios no suplanta los hechos con teorías ni por «medio de previos estudios históricos [y que] sustituir a ellos por medio de deducciones y fórmulas sería presentar a la juventud un esqueleto a vez de un traslado vivo del hombre social» ${ }^{328}$. La idea fundamental de Bello es que la explicación de las ideas debe estar precedida de los hechos.

\footnotetext{
${ }^{327}$ Obras Completas, vol. VII. Opúsculos literarios y Críticos II, Santiago, Impreso por Pedro Ramírez, 1884, p. 101.

${ }^{328}$ BELLO, Andrés, «Discurso Inaugural de la Universidad de Chile, 17 de septiembre de 1843», Anales de la Universidad de Chile, Santiago, Universidad de Chile, 1843, p. 150.
} 
En 1845 Bello en un texto vuelve a acometer con mayor vehemencia la posición de los liberales y sobre todo la de Lastarria cuando señala que:

«(...) nuestro siglo no lo quiere: exige que se le diga todo; que se le reproduzca y se le explique la existencia de las acciones en sus diversas épocas y que se dé a cada siglo pasado su verdadero lugar, su color y significación.»» ${ }^{329}$

Los hechos manifiestan las ideas y no las ideas manifiestan los hechos. Su idea de la filosofía de la historia queda explicita cuando interpeló que la filosofía de la historia es una ciencia de la humanidad, en general, pero que la historia es una ciencia concreta que se ocupa de cuestiones particulares, de sociedades y hombres en marcos temporales acotados, y ello «hace en cada hombre-pueblo, una idea que progresivamente se desarrolla vistiendo formas diversas que se estampa en el país y en la época» ${ }^{330}$. En ese mismo escrito desarrolla una embestida implacable contra la filosofía de la historia señalando que no se trataba de cuál era el mejor modo de escribir historia e interpela señalando:

«(...) ¿por cuál de los dos métodos deberá principiarse para escribir nuestra historia? ¿por el que suministra los antecedentes o por el que deduce las consecuencias? ¿por el que aclara los hechos o por el que deduce las consecuencias? ¿por el que aclara los hechos o por el que los comenta y resumo.»» ${ }^{331}$

Bello estaba convencido que la historia de Chile no estaba escrita, y que, por lo tanto, la nación chilena no era la humanidad en abstracto, sino que explicar la historia de Chile, tenía especificidades y que ésta debía ser explicada por sí misma. Y lo que se le debe exigir a todo escrito de historia es que dé cuenta de la «importancia de los hechos y consideran la exposición del drama de social viviente como la sustancia y alma de la historia» ${ }^{332}$. La disputa de un tipo de historia de corte liberal tenía pocas posibilidades de éxito frente a los grupos conservadores que con o sin razón, su posición era distinta: estaban en el poder. Andrés Bello estaba convencido que la investigación y los relatos históricos se sustituían por deducciones o ideas generales era una amenaza para

\footnotetext{
329 «Modo de escribir la Historia» en Obras Completas..., Volumen VII..., op. cit., p. 107.

${ }^{330}$ Ibidem, pp. 112-113.

${ }^{331}$ Ibidem, p. 119.

${ }^{332}$ Ibidem, p. 112.
} 
resucitar el pasado, y que lo genérico en vez de lo especifico proporcionaría «un esqueleto en vez de un traslado vivo del hombre social, sería darle una colección de aforismos en vez de poner a su vista el panorama móvil de las instituciones, de las costumbres» 333 . Bello anteponía el estudio de los hechos a la explicación global.

Los liberales no se centraban en hechos históricos, sino que, en sus causas y efectos, para descubrir leyes y principios que estaban a la base de manera de desentrañar el sentido de la historia. En este tipo de historia eran recurrentes las referencias conceptuales propias del pensamiento ilustrado europeo como: progreso, razón y libertad. Estos conceptos permitían analizar críticamente y asumir una postura frente al pasado. El principal expositor de la tendencia liberal en su conceptualización acerca de la historia fue José Victorino Lastarria quien no tiene una obra en la cual exponga sus preceptos conceptuales acerca de la historia. Sin embargo, al amparo de su vasta obra se puede advertir el sentido que la historia tenía para el pensador. Tenemos la convicción que la Ilustración europea fue la gran inspiradora de Lastarria y de los liberales, en general. La historia era el medio y no el fin para explicar el triunfo del hombre sobre la naturaleza. No trataba los hechos, sino que los principios para obtener de ella una lección: educar a los jóvenes y demostrar, por medio de la historia, cual podría ser el porvenir, el futuro. Así se refirió a la razón por la cual la sociedad debía acudir a la historia como depositaria de la experiencia para sacar lecciones de la desgracia ya que de ella se pueden conocer las leyes inmutables de la felicidad, de la declinación y sobre todo como enseñanza para atisbar «las influencias del pasado que pueden detener su progreso, los errores que deben encaminarla a su ruina y en fin, sólo en ella puede estudiar la marcha que ha seguido y el grado y posición que ocupa en la escala de las naciones (...) Los hombres públicos (...) [que deben] encargarse de la difícil tarea de dirigir un estado, deben por esta razón conocer a fondo la historia del pueblo cuya ventura se les encomienda» ${ }^{334}$. La historia era para Lastarria la forma en que se podía alcanzar el progreso y la felicidad, pero sobre todo lo que ilumina su pensamiento es la idea de la perfección del hombre. Entre los liberales era común las referencias morales y

\footnotetext{
333 «Discurso Inaugural de la Universidad de Chile, 17 de septiembre de 1843» ..., art. cit., p. 150.

${ }^{334}$ LASTARRIA, José Victorino, Investigaciones sobre la influencia social de la Conquista y del sistema colonial de los españoles en Chile, Santiago, Imprenta del Siglo, 1844, p. 11.
} 
éticas acerca del hombre y que éste debía buscar en el pasado maneras conservar, organizar y perfeccionar las integridades.

En la disputa con los conservadores sobre su visión del pasado y los pocos progresos que lograba la sociedad chilena se debían fundamentalmente a la relación disonante entre las costumbres de los chilenos con las leyes y organización del Estado que las podía garantizar., ya que las «leyes y las costumbres que esas mismas leyes habían radicado en la Colonia, sólo conspiraban al único fin de mantenerla en servidumbre impidiendo en ella el conocimiento y el deseo de una condición mejor (...)»> ${ }^{335}$. Los liberales construyeron una imagen negativa del período colonial, especialmente por la subyugación al poder monárquico y al religioso que impedían el crecimiento moral de los pueblos. La crítica de José Victorino, era que aún se conservaban hábitos coloniales, y que éstas habrían conspirado para que Chile se mantuviera fuera de la civilización y de la modernidad. La clave estaba en hacer un cambio profundo en las costumbres para que las ideas ilustradas se pudiesen realizar.

Las premisas ilustradas marcaron la idea que Lastarria tenía de la historia. Evidentemente también estaba salpicado por el positivismo, en la noción de encontrar en ella, las leyes mecánicas que rigen al hombre y a la naturaleza, y por eso se podía aprender del pasado. Para el liberal, el tránsito de la Colonia a la República había sido nefasto ya que la instalarse España en América «trasplantó a ellas todos los vicios de su absurdo sistema de gobierno, vicios que se multiplicaron infinitamente por causas que tenían su origen en el sistema mismo.» ${ }^{336}$, pero destacaba que ese mismo espíritu que había logrado la Emancipación, estaba el elemento refundacional de las instituciones. Para salir del letargo no sólo había que potenciar las industrias y las ciencias exactas, sino que se debía educar e ilustrar el pueblo. Lastarria defendió una filosofía de la historia que buscaba el sentido de la historia, y aplicó los principios europeos del progreso, la razón, la libertad del individuo y como éstos debían desenvolverse en la realidad chilena. Aunque no negaba del todo la particularidad de lo chileno,

\footnotetext{
${ }^{335}$ LASTARRIA, José Victorino, Bosquejo histórico de la Constitución del Gobierno de Chile durante el primer periodo de la revolución desde 1810 hasta 1814, Santiago, Imprenta Chilena, 1847, p. IX.

${ }^{336}$ LASTARRIA, J. V., Investigaciones sobre la influencia social de la Conquista..., op. cit., p. 34.
} 
vinculándolo con el romanticismo, en el sentido de la relación que debía existir entre las instituciones y las costumbres del pueblo y de cómo la geografía, la situación orográfica, la naturaleza física determinaron el carácter del pueblo. Sobre lo inmanente y lo historicista señalaba:

«¿Qué podré decir sobre el carácter nacional? ¿Es acaso el resultado de las costumbres o influye por el contario en ellas imprimiéndoles su tipo y trazándoles su curso? Creo que es recíproca esta influencia, porque si bien no cabe duda en que el carácter de un pueblo modifica y aún determina muchas veces fijamente sus costumbres, tampoco las hay en que estos a su vez modifican el carácter, porque es evidente que una actitud que nos repugna y nos inspira horror al principio, puede llegar a sernos natural con el transcurso del tiempo.» ${ }^{337}$

Y en la vertiente romántica de su pensamiento aseveraba que:

«Los accidentes físicos de la localidad por otra parte también ha debido modificar indudablemente las inclinaciones características de nuestro pueblo, porque es evidente que la latitud, la situación orográfica y en fin el aspecto físico de la naturaleza influye poderosamente no tan sólo en la organización física del hombre sino también en la moral.» ${ }^{338}$

Lastarria reprodujo la idea de progreso bajo la mirada ilustrada, que le permitía negar el pasado para enaltecer su presente, y además criticar al presente. En el autor también hay mixtura que se sintetizan de la siguiente forma. Las ideas universales de la ilustración y dado el no cambio que experimentaba la sociedad chilena es que tuvo que yuxtaponer el pensamiento ilustrado con premisas románticas. Andrés Bello -como ya se ha dichorepresentaba una postura moderada con la intención de no activar los ánimos del pueblo y volver al estado ambivalente de la Anarquía chilena (1823-1830). Para Lastarria el proceso de Independencia no había sido completo, ya que no se había logrado la independencia socio-cultural. Ambos autores reprodujeron las ideas que estuvieron en Europa para actualizar e instaurar una modernización, que tuvo rasgos de originalidad.

La importancia de la disputa radica, en gran medida, a la funcionalidad de la historia, y como ésta asumió una importancia en el campo de lo político, es decir, en el modo de

\footnotetext{
${ }^{337}$ Ibidem, p. 115.

${ }^{338}$ Ibidem, p. 116.
} 
construir una nación en relación a su pasado y la «discusión no era, pues, puramente académica: era en el fondo, política. Pero los diferentes planos que la cuestión implicaba no fueron nítidamente discernidos» ${ }^{339}$. No es el modo como comprendieron al hombre lo que hace que Lastarria trate de fundar una sociedad liberal ni Bello una de corte conservadora, sino que su postura respecto a lo político que emanaron sus formas de conceptualizar al hombre, la libertad y la historia. Podemos estimar que tanto Bello como Lastarria partían de premisas opuestas, objetivos políticos enfrentados, la educación de la población estuvo en el horizonte de ambos. La discusión sigue abierta en lo que refiere al triunfo de las posturas. Para algunos el método de Andrés Bello marcó la historiografía chilena hasta muy entrado el siglo XIX. En las obras de Diego Barros Arana, Miguel Luis Amunátegui y de la mayor parte de la producción historiográfica del siglo XIX puede apreciarse la opción el ad narrandum como lo indica Sergio Villalobos ya que «los historiadores universitarios de los primeros años fueron discípulos de gran maestro o recibieron su influencia, con la sola excepción de Lastarria. Ellos adoptaron el método narrativo, lo pusieron en práctica en sus obras y contribuyeron a imponerlo» ${ }^{340}$. El más insigne historiador chileno del siglo XIX, Diego Barros Arana, indicaba que: «siempre he creído que lo que se llama historia filosófica, es el asilo de los que no quieren estudiar la historia, de los que quieren hacer de esta ciencia un conjunto de generalidades y declamaciones vagas e inútiles (...) [y] que la historia sin hechos bien estudiados y $\sin$ documentos, es completamente inútil $\mathrm{y}$ absurda.» ${ }^{341}$ Para otros, si bien, los historiadores chilenos estudiaron el pasado, se ocuparon tanto o más por construir el presente y planear el futuro, lo que habría quedado plasmado en el tipo de obra que escribieron. Afirman que Andrés Bello no obtuvo el triunfo, ya que los historiadores venideros, si bien ensalzaron la objetividad en el relato, fueron hechas derechamente con intencionalidades políticas. A ese pasado le habrían dado un uso funcional ${ }^{342}$. Andrés Bello concibió la libertad ligada al orden, optó por el método narrativo, que implicaba una investigación serena del pasado, sin

\footnotetext{
339 OYARZUN, Luis, El Pensamiento de Lastarria, Valparaíso, Editorial Jurídica de Chile, 1953, p. 215. ${ }^{340}$ Historia del Pueblo chileno, Tomo I, Santiago, Instituto de Estudios Humanísticos, 1980, p. 16.

${ }^{341}$ Cit. en DONOSO, Ricardo, Barros Arana, educador, historiador y hombre público, Santiago, Editorial Universidad de Chile, 1931, p. 107.

${ }^{342}$ Vid. BRADFORD, Burns, «Ideology in Nineteenth Latin American Historiography», Hispanic American Historical Review, vol., 58, No 3 (1978) pp. 409-431, y también WOLL, Allen, A functional past. The Uses of History in Nineteenth-Century Chile, Lousiana, Louisiana State University Pres, 1982.
} 
compromisos ideológicos vinculados a las rupturas radicales con el pasado. No fue un triunfo rotundo, pero marcó profundamente la forma en que se escribió la historia en el siglo XIX. La historia ad probandum aportó lo suyo, ya que estableció las conexiones caudales que explicarían el devenir histórico.

La preponderancia del relato narrativo de la historia se explica debido a que muchos de los historiadores fueron actores de primer plano en las disputas políticas del Chile decimonónico. Como parte de una elite directamente implicada en el proceso creador del Estado nacional, tenían plena conciencia que eran portadores de un mensaje que sobrepasaba los límites del mero relato. En una carta del argentino Bartolomé Mitre al chileno Diego Barros Arana refiriéndose a la tarea de la construcción de lo nacional aseveraba que «nos debemos recíprocamente los trabajadores, que diseminados en este vastísimo continente americano estamos comprometidos en una obra común de que todos somos solidarios, y cuya unidad ha de revelar algún día a la posteridad, si no por nuestro nombre, al menos por nuestros resultados» ${ }^{343}$. Todos estos historiadores, asumieron el dilema de plantearse el tema de los orígenes y de la construcción del presente, de la cual se autodefinieron como los demiurgos.

\subsection{La construcción nacional del territorio}

La historia debía explicar, y demostrar, además, una de las preocupaciones fundamentales de quienes detentaban el poder, precisar las bases territoriales de las recientes naciones. Se hacía necesario disponer de un censo de los recursos disponibles dada «la necesidad de negociar trazados de fronteras con los Estados vecinos hacía imperativo un conocimiento de los límites geográficos que habría que reivindicar» ${ }^{344}$. En el contexto de la organización de las repúblicas, el papel de las geografías y representaciones cartográficas permitieron comprender mejor el proceso de configuración de los estados nacionales. Muchas naciones en el siglo XIX encargaron

\footnotetext{
${ }^{343}$ DONOSO, R., Barros Arana, Educador..., op. cit., p. 108.

${ }^{344}$ HARWICH, Nikita, «La Historia Patria», en ANNINO, A. y GUERRA, F. (eds.), Inventando la nación: Iberoamérica ..., op. cit., p. 536.
} 
estudios minuciosos del paisaje geográfico, casi todos bajo el modelo de investigación científica de Alexander Von Humboldt, es así que exploradores como Claudio Gay, Alcide d'Orbigny, Antonio Ramondi o Agustín Codazzi describieron los territorios de Chile, Bolivia, Venezuela y Nueva Granada.

Estos estudios contribuyeron a la creación de las repúblicas sudamericanas desde el conocimiento geográfico. Los gobiernos encargaron historias naturales que acabaron convirtiéndose en historias nacionales que junto a las descripciones científicas y sobre todo «las representaciones cartográficas que ellas permitieron elaborar, constituyen elementos esenciales del proceso de representación, conocimiento y control de los territorios de los noveles estados ${ }^{345}$. Con la geografía se buscó definir también una identidad nacional. Estas nuevas elites que tenían en sus manos la configuración de los estados, se hicieron la pregunta de: ¿cómo compaginar el rechazo a lo español con un discurso histórico no consensuado? y al mismo tiempo, diferenciarse identitariamente con los vecinos. El territorio ofrecía una buena oportunidad de cohesión. Es así que, desde muy temprano, y «tan luego como la Independencia nacional pareció definitivamente afianzada, se pensó en mandar hacer estudios más latos y especiales» ${ }^{346}$ con la idea de trazar y nacionalizar el espacio nacional.

En 1823, el Director Supremo de la República de Chile ${ }^{347}$, Ramón Freire, estableció en un decreto que se realizar una expedición científica para examinar todo el territorio, sus recursos naturales de modo de tener un registro exacto de las características del territorio nacional. La finalidad de Freire no era sólo apropiación del espacio sino como convertirlo en productivo, ya que permitiría conocer:

«(...) los puntos en que sean navegables los ríos y los lugares a propósito para el establecimiento de fábricas, los puertos, canales y caminos que puedan abrirse para facilitar la comunicación y comercio, designando los medios para fomentar la agricultura y los territorios a propósito para el cultivo de las primeras materia e

\footnotetext{
345 SAGREDO, Rafael, Geografía y nación. Claudio Gay y la primera representación cartográfica de Chile, Estudios Geográficos, vol. LXX (2009), p. 232.

${ }^{346}$ BARROS ARANA, Diego, Obras Completas, Tomo XI, Estudios históricos-biográficos, Santiago, Imprenta Cervantes, 1911, p. 247.

${ }^{347}$ Director Supremo fue la denominación asignada a comienzos del siglo XIX y hasta 1826 a la primera autoridad unipersonal que se desempeñó como jefe de Estado y de Gobierno en Chile.
} 
industrias, y proponiendo por último los arbitrios más adaptables para conseguir estos fines.» ${ }^{348}$

Las intenciones de Freire no se concretaron entre otras razones por el período de gran inestabilidad política que experimentó Chile de 1823 a 1830. Y cuando se habían disipado las esperanzas que Chile contara con una cartografía y una descripción científica del territorio, se contrató a Claudio Gay por el Gobierno chileno en $1830 \mathrm{y}$ tardó 12 años en recorrer y registrar la geografía chilena cuya obra demoró unos cuarenta años en ejecutarse fruto de un arduo y asiduo trabajo. El naturalista francés fue contratado con la misión de «hacer un viaje científico por todo el territorio de la república, en el término de tres años y medio, con el objeto de estudiar la historia natural de Chile, su geografía, geología, estadística y cuanto contribuya a conocer las producciones naturales del país (...)» ${ }^{349}$. El contrato contemplaba la entrega de una historia natural de Chile que comprenda la descripción de flora, fauna, minerales y toponimia acompañada de láminas y mapas con anotaciones sobre clima, humedad, temperatura de todas las provincias. El papel desempeñado por Gay es de la mayor relevancia pues «da origen a la geografía chilena, en el sentido de definir el espacio nacional y diferenciarlo de otros por sus fronteras, sustrayéndolo así de la visión geográfica continental, regional (...)» ${ }^{350}$. Los trabajos de Gay en mapas, cartografía, láminas y las descripciones contribuyeron a configurar el espacio de la nueva república y a registrar la idea de territorio nacional.

La Historia y la Geografía son saberes del tiempo y el espacio y se desarrollaron como materias afines en el siglo XIX y altamente imbricadas para definir y perfilar identidades y «como saberes nacionales y nacionalizadores en la cultura del Occidente liberal del siglo XIX» ${ }^{351}$. No son los únicos elementos de las diferentes identidades, pero realizaron aportes decisivos en la construcción de las mismas.

\footnotetext{
${ }^{348}$ BARROS ARANA, D, Obras Completas, Tomo XI, Estudios históricos..., op. cit. p. 248.

${ }^{349}$ BARROS ARANA, Diego, Don Claudio Gay, su vida y sus obras. Estudio biográfico y crítico, Santiago, Imprenta Nacional, 1876, p. 34.

${ }^{350}$ SAGREDO, R., Geografía y nación. Claudio Gay ..., op. cit., p. 256.

351 PEREZ GARZON, Juan, «¿Por qué enseñamos Geografía e Historia? ¿Es tarea educativa la construcción de identidades?», Revista de la Educación: Revista Interuniversitaria, № 27 (2008), p. 39.
} 
La unión de Historia y Geografía tiene que ver con procesos que se dieron en el siglo XIX a saber: institucionalización de estos saberes en los establecimientos educativos de varios niveles, formación de asociaciones de profesionales de historiadores y geógrafos. La enseñanza de la Historia debía ser capaz de generar nuevos nacionales y ciudadanos; y la geografía no sólo describir el espacio, sino que nombrar espacios políticos, justificar las fronteras estatales y argüir las decisiones de ocupación y defensa del territorio. Ambas materias se convirtieron en funcionarios claves de los estados nacionales del siglo XIX al dar soporte y cumplir tareas cívicas. Por ejemplo, gracias a la identificación con el espacio geográfico, los estados nacionales llevaron a cabo decisiones políticas en torno a los conflictos bélicos. La Historia y la Geografía se habían implantado en el sistema educativo para dar cohesión a los nuevos estados soportando las fronteras, un modo de ser nacional, una esencia cultural y una esencia política. El nacionalismo historiográfico chileno y la ideología geográfica del territorio dieron sustento discursivo y político al Chile decimonónico.

La Geografía y la Historia se emplearon en la tarea de enseñar la idea del territorio y del pasado común respectivamente. En este sentido, y es lo más importante, es que, con estas dos columnas vertebrales, en Chile, se desplegó una «Pedagogía Cívica» en los espacios públicos y privados, en ritos cívicos y en la escuela, en manuales escolares y cartografía, en la literatura costumbrista y libros de paisaje, y por una iconografía de personajes típicos de corte urbano, rural, aristócratas y burgueses, y un largo etcétera. El estado nacional extendió asimismo una política de memoria con elementos nacionales en monumentos, conmemoraciones, fiestas, nombres de calles y plazas. De manera que la enseñanza de la Historia y la Geografía coadyuvaron a elaborar un discurso nacional productor de identidad chilena sostenido en pasado, la historia y en un espacio, la geografía. El estado chileno, como la mayor parte de los estados en el siglo XIX, a uno y otro lado del Atlántico, se hicieron del control de la historia y del territorio como objetivo primordial. 


\subsection{El lugar de la Historia en el currículum escolar}

El Chile del siglo XIX es partícipe de las utopías sociales, económicas y culturales europeas que proyectó un futuro Estado moderno que se concretó en la República con la idea de ser capaz de garantizar la justicia y la igualdad. Las elites por medio del Estado sostuvieron la posibilidad que se superaran todos lo males que provenían -según sus representantes- de la ignorancia y del oscurantismo que había vivido gran parte de la población durante los tres siglos coloniales. El gran paso vendría dado por la instrucción de los ciudadanos haciéndolos conscientes de sus obligaciones, derechos $\mathrm{y}$ comprometidos con el proceso de modernización que requería la nueva nación chilena. La construcción de la República sería posible a partir de la formación de otra mentalidad, de otro ser moral en esa masa ignorante y pobre en otras palabras, del desarrollo de un vasto programa civilizador cuya bandera favorita sería la de proporcionar los rudimentos de lectura y moral cívica.

Por lo demás, los contenidos escolares, razón de ser de la enseñanza básica, constituyen un importante indicio de la manera en que la sociedad chilena daba sentido a su vida. Si durante los tres siglos que duró la Colonia, el mundo se interpretaba a través de las verdades religiosas y la lógica de la salvación, correspondientes a la enseñanza de primeras letras que se realizaba a fines del XVIII, paulatinamente se introducen un sentido de utilidad en el aprendizaje integrando rudimentos de lectura, de escritura y de cálculo, así como aquello que tuviera que ver con el comportamiento moral y civil con la costura y el bordado para las niñas y el dibujo para los niños.

La percepción del mundo a través de la ciencia y de las verdades positivas que poco a poco se fue imponiendo, así como el desarrollo de una conciencia cívica y nacional, que tendía al amor a la patria y a sus instituciones, y una concepción integral del desarrollo humano, amplió el espectro de materias de estudio entre las que se introducirán la instrucción moral y cívica, lengua nacional (escritura y lectura), lecciones de cosas, aritmética, ciencias físicas y naturales, geometría, geografía, historia, dibujo, canto, gimnasia y labores manuales 
Ahora bien, el hecho que la modernidad se orientara a establecer un nuevo orden social implicaba, a la vez, un cuidadoso control para fomentarlo y conservarlo. En la historia de la educación chilena es sostenible que la enseñanza de la Historia, la Geografía en conjunto con otras instancias públicas constituyeron los promotores de la identidad nacional y del nacionalismo. Desde aquel siglo XIX, la historia proporcionó el principio narrativo fundamental para la historia y tanto la historiografía como la enseñanza de la Historia fueron mecanismos privilegiados para el logro de lo nacional. A pesar de grandes similitudes que tuvo este proceso a lo largo de América Latina, este se institucionalizó en distintos momentos en el siglo XIX.

En el continente americano las referencias al pasado fueron distintas, el caso chileno era muy diferente al de México o Perú. Chile era una tierra marginal y periférica; y una de las colonias más pobres del Imperio, dependiente de Perú y con una impronta de tierra belicosa, se hacía difícil recurrir a los elementos clásicos del nacionalismo romántico o ilustrado, por lo tanto, fue la Independencia, el eje articulador y originario del Estado nacional chileno, el acto fundante. La historia nacional comenzaba con la emancipación del Imperio español y aun cuando la enseñanza de la Historia «no entró en los estudios colegiales de la mano de grandes narrativas nacionales, como suele indicarse, sino antes y como primer objeto no fue la formación de una identidad nacional sino la formación moral de sus hombres dirigentes» ${ }^{352}$. Sin embargo, el Estado chileno declaró su interés oficialmente por la enseñanza de la Historia y la Geografía con carácter de obligatoria en el currículum recién en la Ley de Instrucción Primaria de 1860 indicando que se enseñara en las Escuelas Normales -que era donde se formaban los profesoresderecho, geometría, cosmografía, física y química «historia sagrada, de América y en especial de Chile (...)» ${ }^{353}$. A ellos había que agregar dogma, música vocal, elementos de agricultura, vacunación y pedagogía teórica y práctica, por esta razón suponemos que estaba integrado en el curriculum escolar.

\footnotetext{
${ }^{352}$ SERRANO, S., «Enseñanza de la Historia e identidad nacional ...», art. cit., p. 211.

${ }^{353}$ Ley de Instrucción Primaria, Boletín de las Principales leyes y decretos vigentes redactados desde enero 1 de 1860 hasta enero de 1871, Valparaíso, Imprenta El Mercurio, 1871, p. 491.
} 
Los cursos de Historia en el mundo escolar chileno tuvieron poca cobertura. En primer lugar, esos cursos estaban al final de secundaria y la cobertura de educación secundaria era muy baja. De un 0,66\% en 1852 a un 4,2\% en el 1900 (ver Cuadro No 8 «Tasa de escolaridad total y por Nivel»). En segundo lugar, los altos índices de inasistencia a clases eran muy altos, en promedio en la segunda mitad del siglo fue de un $35 \%$ (véase Cuadro $\mathrm{N}^{\circ} 5$ «Asistencia media de escuelas públicas, 1862-1895»). En tercer lugar, la asignatura se incorporó a los grados de Primaria en 1882 e introduciendo Educación Cívica. En cuarto, la efectiva preparación de los profesores para enseñar estos contenidos, ya que en general se instruía «lo que el preceptor o preceptora podía o sabía enseñar, problema que será relevado por los Visitadores»» ${ }^{354}$. El Reglamento de 1883 que ordenó el currículum estableció que en las escuelas elementales se dictarían clases de lectura, escritura, catecismo, aritmética sistema de pesos y medidas, gramática, nociones de agricultura, higiene, música, gimnasia y «geografía, historia sagrada y de Chile $(\ldots) »^{355} \mathrm{y}$ en las escuelas superiores se enseñaría lectura, escritura, religión y moral, gramática castellana, retórica, aritmética, sistema de pesas y medidas, álgebra, geometría, dibujo lineal; «geografía dando mayor extensión a la de Chile y de América; nociones generales sobre la constitución política del Estado, nociones de cosmografía y de geografía física; historia de Chile y de América; historia sagrada y elementos e historia universal (...)» ${ }^{356}$. Además de una serie de otras asignaturas; es significativo que explícitamente se declaró que «en las escuelas de niñas se sustituirá la enseñanza de las nociones de álgebra, geometría, dibujo lineal y constitución por la de economía doméstica, costura, bordado y labores de aguja y al crochet» ${ }^{357}$, en una clara y evidente distinción de género.

Es presumible pensar que lo nacional se desarrolló en otros ámbitos, de carácter más informal, o si se quiere fuera de la escuela. También debemos consignar que había una distinción rotunda entre lo que estudiaban los hombres y las mujeres. La enseñanza de

\footnotetext{
${ }^{354}$ EGAÑA, M., NUÑEZ, I. y SALINAS, C., La educación primaria en Chile..., op. cit., p. 84.

355 «Reglamento para la enseñanza y Régimen de las Escuelas Elementales», en PONCE, Manuel Antonio, Prontuario de Legislación escolar. Recopilación de leyes, decretos, circulares y resoluciones sobre instrucción Primaria, Santiago, Imprenta Ercilla, 1890, pp. 141-142.

${ }^{356}$ Ibidem, pp. 158-159.

${ }^{357}$ Ibidem, p. 159.
} 
la Historia estaba antes de 1882 en Secundaria. Las niñas sólo estudiaban primaria y cuando se crearon los Colegios públicos para Niñas hacia 1890 y si bien estudiaban Historia igual que los hombres, existió una diferencia radical ya que los colegios «femeninos no estudiaban educación cívica sino economía doméstica» ${ }^{358}$.

Hacia fines de siglo XIX, la marginación de amplios sectores de la población apreciada en la educación era enorme. Entre estos marginados estaban los indígenas cuya situación educativa era de absoluto abandono, particularmente para los mapuches. Después de la ocupación militar de la Araucanía, despojados sus tierras, aquellos fueron forzados a integrarse al modo de vida de la República. No hay escuelas en su propia lengua; no hay foco en el desarrollo de su cultura y de la región; no hay políticas ni financiamiento dirigido, sólo la opción de adaptarse. La premisa del Estado era que terminaría por asimilarse y que la escuela no tenía mucho sentido en la cultura indígena. Recién las misiones y el Estado entraron en a Araucanía en el siglo XX. Al parecer, por variados testimonios, la estrategia utilizada por el Estado chileno era seleccionar a algunos miembros de las familias indígenas «para asistir a la escuela a quienes parecían más capaces, permitiendo contar con un letrado que se ocupara de la relación con las instituciones estatales, que escribiera y leyera las cartas recibidas, etc. $\gg{ }^{359}$. Las presiones ejercidas por el Estado y los colonos para ocupar los territorios indígenas hicieron inevitable la necesidad de saber leer y escribir. Es en ese contexto que se demandó al Estado el establecimiento de escuelas en las comunidades, junto a otros medios de alfabetización. Estas escuelas para niños y niñas que formó el Estado chileno, ya en el siglo XX, fueron alfabetizados, evangelizados, pero sobre todo preparados para oficios manuales. Esta educación, también, aunque de forma tardía intentó aculturizarlos y nacionalizarlos, pero no tuvo éxito en el largo tiempo.

De manera sintética, en lo concerniente a la cobertura de la enseñanza de la Historia podemos advertir heterogeneidad entre hombres y mujeres, entre mapuches y chilenos,

\footnotetext{
${ }^{358}$ Ibidem, p. 214.

${ }^{359}$ POBLETE, María, «Prácticas Educativas misionales franciscanas, creación de las escuelas en territorio mapuche y significado de la educación para los mapuches-huilliche del siglo XVIII y XIX», Espacio Regional, vol. 2, N6 (2009) p. 32.
} 
entre ricos y pobres, entre Primaria y Secundaria. Esa heterogeneidad no niega en el largo tiempo la creación de un sentimiento nacional que se haya generado en las escuelas chilenas del siglo XIX y esa tarea se construye en el siglo decimonónico, pero se expande en cohesión en el siglo XX.

\subsection{Los textos escolares de Historia y Geografía}

Las identidades nacionales - como en el caso de Chile- se construyen como resultado de la instrucción escolar junto a otros instrumentos de socialización, como los ritos cívicos, las fiestas, los símbolos, entre otros, que transmiten informaciones y desarrollan hábitos y actitudes. En el ámbito escolar no es sólo el adoctrinamiento que se puede ejercer a través de explicaciones del profesorado en clase, sobre todo en momentos de control ideológico, sino también por otros medios más sutiles, entre los que encontramos las descripciones geográficas e históricas. No sólo lo que se refiere al país en concreto, sino también la descripción de lo otro, que sirve como contraste de las características que definen la identidad patria. En este sentido, los manuales escolares han sido un instrumento de socialización nacionalizadora, por consiguiente, los alumnos leían y memorizaban tópicos que eran muchas veces coincidentes con la opinión dominante. La educación formal, en su modalidad tradicional, ha tendido a trasmitir a las nuevas generaciones una versión recortada o simplificada del conocimiento historiográfico en su interpretación acomodada a las visiones o intereses de quienes detentan la autoridad política, cultural y educacional. Los textos escolares han constituido con el tiempo uno de los mejores instrumentos para visualizar que pensaban e hicieron los que tomaron la decisión de usarlos. El estudio de los textos escolares ofrece un campo interesante para la historia de la enseñanza de la Historia. Son materiales muy apropiados y de gran riqueza para estudiar la preponderancia intelectual, los debates y conflictos políticos y sobre todo la forma de la narrativa histórica que en muchos casos no era más que narrativa política. Para el caso chileno, como en la mayor parte de los países hispanoamericanos, los textos muestran con gran transparencia los debates políticos, la idea y función de la historia y la visión del pasado y el presente. En la forma de trasmitir la historia preponderó la posición de Andrés Bello de corte narrativo cuya 
fundamentación estaba en la «exhaustiva recopilación de fuentes, en la crítica filológica y en una sólida narrativa, erudita y minuciosa» ${ }^{360}$. No por ser narrativa y excesivamente descriptiva impedía que como todo trabajo histórico tuviese un punto de vista e interpretación. Los historiadores chilenos del siglo XIX estuvieron ligados estrechamente a la enseñanza de la Historia de Chile, dado que la mayor parte de ellos eran funcionarios de la Universidad de Chile y escribieron textos que fueron utilizados en las aulas chilenas en dicho siglo. Incluso el propio Andrés Bello en 1848 advertía que: «(...) la historia de Chile es para nosotros demasiado importante para no merecer un curso especial $(\ldots){ }^{361}$. Por tanto, uno de los elementos más importantes en el sistema educacional chileno eran los textos escolares. El flamante intelectual venezolano hacía notar tempranamente, siendo Rector de la Universidad, que lo que más importa en los colegios es «la elección y revisión de los textos. Este es un punto que no debe confiarse al juicio del Director y profesores de la Escuela, por idóneos e ilustrados que sea» ${ }^{362}$. Y en la misión y función de la Superintendencia de la Universidad, los textos debían ser presentadas al Consejo Universitario quien los autorizaba, rechazaba o modificaba. Cuando eran aprobados, los editaba para ser distribuidos en los establecimientos públicos y además eran vendidos de forma subsidiada.

En el año 1853, el Estado chileno estableció la distribución de textos escolares «para que se vendan a las personas pudientes, y se den gratuitamente a las menesterosas» ${ }^{363}$. Los textos debían ser vendidos y distribuidos por las autoridades políticas tanto intendentes como gobernadores. Las familias debían acreditar si no disponían de los recursos para comprarlos y esta forma daba cuenta de una intención bastante moderna y liberal respecto a quienes podían acceder gratuitamente a los materiales educativos. Evidentemente este decreto extendido con una visión muy recomendado para generar

\footnotetext{
${ }^{360}$ SAGREDO, Rafael y SERRANO, Sol, «Un espejo cambiante: la visión de la Historia de Chile en los textos escolares, INTERAMER, No 29 (1994), p. 6.

361 «Memoria correspondiente al curso de la Instrucción pública en el quinquenio 1849-1853», Anales de la Universidad de Chile, IX, 1854, p. 3.

362 «Memoria presentada al Consejo de la Universidad por el Rector de la misma», Anales de Universidad de Chile, Santiago, Imprenta Chilena, 1854, pp. 7-8.

${ }^{363}$ AMUNATEGUI, M. y AMUNATEGUI, G., De la Instrucción Primaria en Chile ..., op. cit., pp. 211212.
} 
condiciones esenciales para organizar las condiciones básicas para desarrollar la instrucción primaria. Es de suponer que un sistema de reparto ideado de esta forma tenía grandes posibilidades que no llegasen a sus destinatarios. Esta desconfianza se hace plausible cuando los hermanos Amunátegui añaden que «para evitar cualquiera abuso en la venta o distribución de los libros elementales, podrían adoptarse las siguientes precauciones y otras análogas. Todo libro llevaría su precio apuntado en las tapas»» ${ }^{364}$. La distribución y disponibilidad de los libros en los educandos fue un asunto de la mayor preocupación entre la documentación examinada.

El precio de venta fue otro tema que impedía un acceso más expedito a los textos. Existieron múltiples quejas a propósito de la variación de precios que incluso llegaron hasta el Gobierno, luego que «los que tienen que comprarlos los hacen a un precio demasiado subido y que excede tal vez otro tanto de su legítimo valor» ${ }^{365}$. Hubo serios problemas con la distribución y en el momento en que el Estado deseo normar y fiscalizar la impresión de los textos hizo que se generaran disputas «entre los pocos profesionales que habían tenido hasta el momento autoridad para imprimir estos textos $\mathrm{y}$ apara fijar ellos mismos precios y cantidades» ${ }^{366}$. Esto último generó un gran descontento entre los libreros e incluso se barajó la idea que el propio estado imprimiese los textos y dispuso imprimir varios textos. Frente a esta situación intervinieron los liberales para frenar esa posibilidad «si el gobierno, se ha dicho, se hace fabricante o comerciante de libros, y los vende al precio de producción o de adquisición por mayor, arruina a los especuladores privados de esta mercancía. A más de eso, los arruina sin provecho para la Instrucción Primaria» ${ }^{367}$. Se produjo especulación, ya que los vendedores de libros esperaron que se agotaran los libros distribuidos por el gobierno, comenzaron a vender los suyos que habían comprado al propio gobierno, es decir, los especuladores compraban la mayor parte de los libros obligando a los consumidores a adquirirlos. Entre los muchos problemas en las escuelas chilenas en el siglo XIX

\footnotetext{
${ }^{364}$ Ibidem, p. 213.

${ }^{365}$ Cit. en ROMERO, Esteban, El discurso de la Patria: la historia de Chile en la sala de clase (18431880), Tesis para optar al grado de Licenciado en Historia, Santiago, Pontificia Universidad Católica de Chile, 1994, p. 30.

${ }^{366}$ SCHURDEVIN-BLAISE, Chloé «Los manuales escolares como fuente de la Historia Chilena (18501860)» Boletín Americanista, Año LVII, No 57 (2007), p. 267.

${ }^{367}$ AMUNATEGUI, M. y AMUNATEGUI, G., De la Instrucción Primaria en Chile ..., op. cit., p. 210.
} 
estuvieron la falta de mobiliario y la pobreza de los alumnos que impedía la compra de los útiles escolares, pero como establecen los hermanos Amunátegui que los pobres «no tienen con que comprar sus libros; por consiguiente, la autoridad debe proporcionárselos. Los ricos no encuentran donde comprarlos; por consiguiente, la autoridad debe vendérselos» ${ }^{368}$. Hubo muchas dificultades, la tenencia de textos escolares fue una de ellas.

Si el Estado tenía serias dificultades para distribuir los textos tampoco en Chile existían demasiadas librerías donde adquirirlos. En torno a 1874 un librero en Santiago se quejaba que, habiéndose agotado en el comercio, al precio de 40 centavos la última edición del Compendio de Historia de América y especialmente de Chile de Gaspar Toro, «se me ha comunicado que dicho compendio se halla totalmente agotado en el depósito de libros de la Instrucción Primaria» ${ }^{369}$. De modo que hubo dos inconvenientes, por un lado, el acceso a los libros como consecuencia de una oferta insuficiente por parte del Estado y en segundo lugar una dificultad en la distribución hacia el territorio nacional. Fuera de las librerías, que eran pocas y desabastecidas en el territorio - como ya se ha dicho- «no hay en Chile más que una sola librería particular que contenga un número de volúmenes bastante considerable, la del señor Manuel Carvallo, que cuenta 12.000 obras selectas y variadas» ${ }^{370}$. En las primeras décadas del siglo XIX la mayor parte de los libros importados que se comercializaban en Chile eran escasos, y distribuidos por tiendas minoristas. Hubo cambios importantes a mitad de siglo cunado en Valparaíso comenzaron a funcionar librerías regentadas por inmigrantes y similar situación ocurrió en Santiago y la «mayoría de los títulos procedían de Francia, Bruselas, Madrid, Barcelona y Leipzig, los editados en el país no llegaban al $1 \%{ }^{371}$.

\footnotetext{
368 Ibidem, p. 209.

${ }^{369}$ Cit. en ROMERO, E., El discurso de la Patria: la historia de Chile en la sala de clase (1843-1880). Tesis para optar al grado de Licenciado en Historia ..., op. cit., p. 28.

${ }^{370}$ AMUNATEGUI, M. y AMUNATEGUI, G., De la Instrucción primaria en Chile ..., op. cit., p. 224.

${ }^{371}$ SUBERCASEUX, Bernardo, Historia del libro en Chile. Historia del libro en Chile. Desde la colonia hasta el bicentenario, Santiago, LOM, 2010, p. 73.
} 
La tenencia y disposición de libros tanto en librería como en bibliotecas era exigua, estas últimas no existían en ninguna provincia. Los únicos lugares que disponían de libros eran algunos liceos como el «Concepción y Talca que poseen algunas cuantas docenas de libros, que, según tenemos entendido, duermen pacíficamente en sus estantes, sin que nadie inquiete su largo y profundo descanso» ${ }^{372}$. Existían solo bibliotecas en la capital y fundamentalmente en instituciones religiosas, una de las más importantes era la de los Dominicos que llegó a tener unos 8.000 volúmenes, la biblioteca de los Tribunales de Justicia poseía unos 2.000 volúmenes y la Biblioteca Nacional estaba formada por unos 22.000 ejemplares. El gusto por la escritura a nivel nacional era bastante pobre y de ello se quejaban los hermanos Amunátegui e incluso «vergüenza da decirlo, pero es la verdad. Todos los amigos de la Ilustración, todos los buenos ciudadanos deben contribuir en la medida de sus fuerzas a la extirpación de tan funesta indolencia intelectual» ${ }^{373}$. Como hemos podido apreciar, si bien existían bibliotecas en la capital de la República, estas eran escasas, reservadas para algunos y al parecer poco asistidas por la población en general, y por los estudiantes, en particular. Si en Santiago el panorama no era muy alentador, en provincias era peor.

Si cotejamos las impresiones anteriores con los niveles de con los niveles de cobertura en educación a lo largo del siglo XIX, que si bien aumentaron (véase Cuadro $N^{0} 4$ «Escolaridad Total y por Nivel. 1852-1900») junto a los altos índices de ausentismo, («Cuadro Nº Asistencia media de escuelas públicas»). Estamos claros que el acceso a los libros era dificultoso y con muy baja cobertura y que las bibliotecas no constituían una alternativa viable para el cometido y en general, las bibliotecas del siglo XIX por su solemnidad y por las colecciones que cobijaban, estuvieron prácticamente reservadas para la elite. Los textos no llegaban por disponibilidad y pésima distribución. Los problemas asociados a la disponibilidad de los textos guardan relación en primer lugar con un problema geográfico, dada la extensión del territorio y los problemas evidentes de comunicación en el Chile decimonónico; $y$, en segundo lugar, reflejaba un problema de gestión del Estado en la distribución. A fines del siglo XIX aún persistía el problema

\footnotetext{
372 AMUNATEGUI, M. y AMUNATEGUI, G., De la Instrucción primaria en Chile..., op. cit., p. 225.

${ }^{373}$ Ibidem, p. 226.
} 
y así lo hicieron saber las autoridades de la ciudad de Linares que no tener libros redundaba directamente en la calidad de la educación y apela a que la situación sea solucionad, ya que comprendiendo que el «Inspector General por sus quehaceres no haya tenido tiempo de remitir los libros, pero esas faltas de tiempo en perjuicio de un servicio tan importante como la educación deberán ser subsanados de algún modo» ${ }^{374}$. El Estado chileno como todo estado incipiente, tenía serios problemas de gestión y ello redundó en un acceso bastante escuálido de los niños y niñas a los textos escolares.

En lo anterior, vemos dos cuestiones que son importantes para el análisis histórico. La mala difusión de los libros y la especulación en los precios de los mismos demuestran un Estado poco prolijo y preocupado en la distribución de los textos. Aún cuando el Estado invirtió parte importante de su presupuesto en educación como lo demuestran y existiendo una preocupación por su parte de la educación, políticos e intelectuales intentaron poner este asunto en la agenda pública y plantear medidas para optimizar el sistema educativo. Empero, esto no significó que la elite estuviera dispuesta a desarrollar una educación masiva y de calidad y esta inquietud «de las elites por la educación del pueblo a lo largo del siglo XIX se presentó cruzada por las contradicciones que se manifestaron en la baja cobertura alcanzada y en las precarias condiciones en que se desarrolló esta educación» ${ }^{375}$. Compartiendo la baja calidad de los elementos educativos, lo de la cobertura fue una política si bien lenta y con una inasistencia endémica, no es menor que sentó las bases para cobertura mayor en el siglo posterior. Una de las claves del poco empeño estatal y de la elite por la educación es que la «educación primaria, en términos de desarrollo económico y productivo no era evidente para las elites; el pueblo realizaba el trabajo que se requería con bajos o nulos conocimientos escolares $(\ldots)\rangle^{376}$. El tipo de trabajo no precisaba mano de obra disciplinada e instruida. Y para la gran mayoría de la población la inserción en el mundo laboral o político no estaba asociado a los niveles de escolaridad, y sólo a fines del siglo XIX y principios del XX con la ampliación de la burocracia estatal, nuevos

\footnotetext{
${ }^{374}$ Archivo Nacional (AN), Fondo Ministerio de Educación. Inspección General, vol. 294, № 268, Linares, Julio de 1887.

${ }^{375}$ EGAÑA, M., La educación primaria popular..., op. cit., p. 123.

${ }^{376}$ Ibidem, p. 124.
} 
sistemas productivos y sus demandas es que la instrucción y la educación adquirió valor como vehículo de cambio y promoción social.

La tenencia de libros en los escolares no tuvo una amplia difusión por culpa de la ineficiencia del Estado y por las transacciones financieras que terminaron por alterar el sentido de la lecto-escritura en la población chilena en el siglo XIX. Esto nos lleva, entonces a analizar los textos escolares en su contenido para descubrir las representaciones de la identidad nacional y la narrativa histórica que contiene.

\subsection{Los contenidos de los textos escolares: pasado y nación}

La historiografía chilena de los siglos XIX y XX ha sido el fundamento en el diseño e implementación del currículum escolar de Historia y Geografía divulgando su visión a los estudiantes. Los contenidos y los objetivos de la educación en este sector de aprendizaje están expresados en textos escolares, los cuales han logrado transmitir un consenso cultural y constituir la percepción de la realidad por parte de profesores y estudiantes. El conocimiento histórico y geográfico ha sido una narración solemne que remite a una continuidad de la trayectoria occidental transatlántica del siglo XVI cuyo «discurso histórico ha descifrado los destinos de la nación, con sus autoridades, sus voces clásicas y sus silencios no menos elocuentes» ${ }^{377}$.

Los textos escolares trasmitían a los estudiantes una imagen tamizada y consensuada sobre un tipo de sociedad y visión de hombre que un grupo de personas concibe, diseña, imprime y distribuye, lo cual se enseña a niños y jóvenes. Es una herramienta poderosa que se usa en educación y que en el siglo XIX y el manual constituye el «soporte, el depositario de los conocimientos y de las técnicas que en un momento dado una sociedad cree oportuno que la juventud debe adquirir para la perpetuación de sus

\footnotetext{
${ }^{377}$ SALINAS, Maximiliano, «Tú no eres nada/Tú no eres mapuche ni español. La descolonización del conocimiento histórico en América del Sur: el caso de Chile», Docencia, No 47 (2012), p. 44.
} 
valores» ${ }^{378}$ y se transformó en el principal canal de vínculo entre el Estado, los profesores y los estudiantes.

La producción historiográfica del sigo XIX, que estaba a la base de los textos escolares, era liberal-positivista caracterizada por la reconstrucción minuciosa de hechos, epopeyas, revisión de fuentes y documentos con una adopción cierta del positivismo como concepción de relato, de liberalismo como posición política y no es menor que los autores de los relatos históricos en el siglo XIX fueran actores y testigos privilegiados del curso de la historia con una visión crítica del pasado colonial y consideración de la Independencia como el hecho fundante de la nación.

En función de lo anterior, los textos escolares analizados en este apartado son: $E l$ Manual de Historia de Chile de Vicente Fidel López; Compendio de la Historia civil y eclesiástica de Miguel Luis Amunátegui; Compendio de la Historia del Coloniaje e Independencia de América de Miguel de la Barra y Compendio elemental de Historia de América de Diego Barros Arana. Los textos escolares eran refrendados por la Universidad de Chile, a través de sus facultades; y en su seno se examinaban todos aquellos libros presentados para ser adoptados como textos de estudio o de complemento a la enseñanza. Entre 1843 y 1879 la Universidad aprobó más de un centenar de trabajos sobre caligrafía, lectura, economía doméstica, geografía, filosofía e idiomas. Cabe mencionar: Método gradual de lectura de D.F. Sarmiento, El libro de oro de las escuelas de J. V. Lastarria (1863), el Manual de preceptores, traducido del francés por Rafael Minvielle (1845), Manual de Historia de Chile de Vicente Fidel López (1845), Tratado de geografía elemental de Manuel Olavarrieta (1859), Curso de filosofía moderna de Ramón Briseño y Compendio de gramática Castellana de Andrés Bello, entre otros. Por otra parte, Ignacio Domeyko nos hace otro sugerente recuento señalando que entre 1854 y 1875 se presentaron 121 libros, 17 de enseñanza superior, 52 de secundaria y otros 52 textos elementales y libros de lectura para escuelas primarias y «de ellos, aproximadamente un $80 \%$ fueron aprobados y el resto retirados

\footnotetext{
${ }^{378}$ CHOPIN, Alain «Pasado y Presente en los manuales escolares», Revista de Educación y Pedagogía, vol. XIII, No 29-30 (2001) p. 210.
} 
por sus autores, rechazados o destinados a correcciones» ${ }^{379}$. Los estudios históricos son los que mostraron el mayor desarrollo en la época. Estimulados por ley los trabajos no se hicieron esperar. Todos los años se designaba a un autor para que leyese un trabajo histórico.

Por lo que a nosotros respecta, no haremos una descripción detallada de los textos usados en la enseñanza de la Historia de Chile ni en los de Geografía, sino que más bien, procederemos a destacar elementos y factores alrededor de los cuales el estado quiso construir identidad nacional. Estos textos, en términos generales, privilegiaron la narración política de grandes epopeyas, historia militar y grandes personajes. En general, los textos no ensalzan el pasado indígena, aunque si hacen referencia a su valentía, arrojo y rebeldía de los mapuches; y se advierte en unos más que en otros, la negación al pasado colonial. Lo que predominó fue el hecho fundante, la Independencia y la construcción exitosa de la República. Como sabemos, los autores de los textos destinados al uso por parte de los estudiantes en las escuelas chilenas en el siglo XIX pertenecieron a la elite culta y educada de la sociedad chilena que tuvo tanto educación secundaria como profesional.

El primer texto escolar de Historia de Chile (1846) fue del historiador, abogado y político argentino Vicente Fidel López. Este personaje se dedicó a escribir en periódicos y desarrolló labores académicas en la Universidad de Chile, estuvo a cargo de una serie de proyectos culturales junto a varios exiliados argentinos, entre ellos Sarmiento. Los otros autores de textos escolares ocuparon altos cargos públicos en el Gobierno, el Parlamento y la Universidad de Chile. Miguel Luis Amunátegui se desempeñó como historiador y político, fue ministro de Justicia, Culto e Instrucción Pública publicando el decreto que autorizaba a las mujeres a rendir exámenes válidos en la Universidad de Chile, fue profesor del Instituto Nacional y de la Universidad, fundador de la Sociedad de Instrucción Pública para combatir la alta tasa de analfabetismo y también se desempeñó como diputado. Miguel de la Barra fue Decano de la Facultad de Filosofía y

379 Cit. en MELlAFE, Rolando; REBOlledo, Antonia, y CARDENAS, Mario, Historia de la Universidad de Chile, Santiago, Ediciones de la Universidad de Chile, 1992, p. 98. 
Humanidades de la Universidad de Chile, Cónsul General en Francia y París y diputado de la República. Diego Barros Arana historiador, político liberal, profesor en el Instituto Nacional y la Universidad de Chile y en varias ocasiones desempeñó cargos diplomáticos ${ }^{380}$. Este examen sobre los autores de textos escolares en el siglo XIX permite aseverar que en sus libros se plasmó la visión de las elites con una perspectiva histórica sustentada en la idea de progreso, ilustración y positivismo y aquellos autores privilegiaron la narración de los grandes acontecimientos de historia militar, política y de personajes importantes con la idea de transmitir la excepcionalidad de la historia chilena como consecuencia de la independencia.

A pesar de los matices propios de cualquier sociedad hubo en el siglo XIX un esfuerzo decidido por presentar a Chile como una gran excepción. La excepcionalidad chilena fue caracterizada por la elite en términos de paz, estabilidad, orden y libertad, en contraposición a los «desórdenes de la anarquía y de las demasías del poder arbitrario que afligen a la mayor parte de los estados hispanoamericanos, ha debido llamar la atención de cuantos se interesan en el bien de la humanidad y los adelantamientos de la civilización $(\ldots)\rangle^{381}$. La cita ilustra la posición preponderante de la elite chilena con declaraciones de autoafirmación. Lograda la estabilidad política después de 1831, las explicaciones del sector dirigente buscaban consolidar una posición política interna en oposición a los diez años anteriores de inestabilidad y también como una prolongación para el resto del siglo XIX. El relato de la excepcionalidad estuvo dado por varias razones: primero, mermar históricamente las realizaciones anteriores a $1820 \mathrm{y}$

\footnotetext{
${ }^{380}$ Sobre Vicente Fidel López: LETTIERI, Alberto, Vicente Fidel López: la construcción históricopolítico de un liberalismo conservador, Buenos Aires, Editorial Biblos, 1995; MADERO, Roberto, La Historiografia entre la República y la Nación. El caso de Vicente Fidel López, Buenos Aires, Catálogos, 2005; PICCIRILLI, Ricardo, Los López. Una dinastía intelectual. Ensayo histórico literario.1810-1852, Buenos Aires, EUDEBA, 1972; HUALDE, Margarita, «Vicente Fidel López, político e historiador (18151903)» en Revista del Instituto de Historia, vol. 11 (1966-67), pp. 23-44, y también SANUCCI, Lía, «Vicente Fidel López: filiación de sus ideas», en Trabajos y comunicaciones, No 19 (1969), pp. 177-203. Sobre Miguel Luis Amunátegui: ORREGO, Augusto, Amunátegui, Santiago, Imprenta de la Época, 1887; MORLA, Carlos, Don Miguel Amunátegui, 1828-1888, Paris, Imprenta Lahure, 1890; BARROS ARANA, Diego, Miguel L. Amunátegui 1828-1888, Paris, A. Lahure, 1890; COCCA, Ximena y ROBINOVICH, Paola, Juristas chilenos del siglo XIX. Miguel Luis Amunátegui Aldunate, Santiago, Universidad de Chile, 1993, y ESPEJO, Juan y BARCELO, Juan, Álbum del Instituto Nacional, 18131913. Publicado con motivo de su primer centenario, Santiago, 1916. Sobre Miguel de la Barra: AMUNATEGUI, Domingo, Formación de la nacionalidad chilena, Santiago, Ediciones de la Universidad de Chile, 1943.

${ }^{381}$ El Araucano, Santiago, 9 de abril de 1841, p. 5.
} 
especialmente los tiempos coloniales; segundo, destacar el aporte e importancia de Diego Portales en la construcción de la República; tercero, contraponer el desarrollo y consolidación institucional de Chile frente a las dificultades que debieron enfrentar los demás países hispanoamericanos, $\mathrm{y}$, cuarto, la propia historiografía que tempranamente desde el siglo XIX destacaron la calidad de las instituciones, el desarrollo democrático del país y su evolución constitucional. La postura historiográfica positiva ha cambiado drásticamente en los últimos años argumentando que el desarrollo histórico de Chile es un contrapunto de continuidades y quiebres; estabilidad y sangrientas guerras, gobiernos civiles con una significativa relevancia de los militares en la vida pública ${ }^{382}$. Si bien hubo posturas diversas y contrarias a la imagen de la excepcionalidad de Chile, no es menos cierto que hubo una energía decidida por presentar a la nación en el siglo XIX como una singularidad en el concierto americano, especialmente después de 1820 por medio de la prensa, en los discursos políticos y en la escuela. La inestabilidad política se transformó en fortaleza y tal como lo mencionaba un periódico en 1830 «esa transición repentina de un estado de la guerra más desastrosa al de la paz más imperturbable (...) es una prueba convincente que el carácter chileno ama el orden y el sosiego y que aborrece las turbulencias y las inquietudes ${ }^{383}$. Esta visión fue hegemónica en el sector gobernante a lo largo del siglo XIX y parte importante del siglo XX.

El primer texto escolar para la enseñanza de la Historia fue aprobado por decreto del Rector de la Universidad de Chile el 7 de mayo de 1845 «compuesto por don Vicente Fidel López» ${ }^{384}$. El informe de autorización argüía que la obra tenía merecimientos suficientes para ser ocupado en las escuelas y en la enseñanza de la historia por su «gran

\footnotetext{
${ }^{382}$ Algunas investigaciones y publicaciones sostienen que Chile no fue un país excepcional durante el siglo XIX al menos desde un foco político y social. La idea preponderante es que la sociedad chilena en el siglo XIX constituyó una transición desde la Colonia a la República caracterizada por la creación de una nueva institucionalidad que otorgó más poder y fuerza a la elite chilena permitiéndole conformar un Estado ordenado y próspero. Esta postura ha sido desarrollada por JOCELYN-HOLT, Alfredo, « ¿Un proyecto nacional exitoso? La supuesta excepcionalidad chilena.», en COLOM, Francisco (eds.) Relatos de la nación. La construcción de las identidades nacionales en el mundo hispánico, Madrid, Vervuert, 2005, pp. 417-438; PINTO, Julio, La formación del Estado y la nación, y el pueblo mapuche. De la inclusión a la exclusión, Santiago, Centro de Investigaciones Diego Barros Arana, 2003; SALAZAR, Gabriel, Construcción de Estado en Chile (1800-1837). Democracia de los «pueblos». Militarismo ciudadano. Golpismo oligárquico, Santiago, Editorial Sudamericana, 2005, entre otros.

${ }^{383}$ El Araucano, Santiago 17 de septiembre de 1830, p. 3.

${ }^{384}$ Anales de la Universidad de Chile, Santiago, Universidad de Chile, 1846, Tomo 2, 1845 , p.8.
} 
sencillez de narración, corrección de estilo, método claro y un templado laconismo que le da la extensión que corresponde a una obra de su género» ${ }^{385}$. El libro de López está dividido en cuatro partes y consta de 167 páginas. El primero trata acerca del objeto de la historia, el territorio y las razas. La segunda aborda la conquista española hasta la independencia. En el apartado tercero adopta el concepto de revolución para el proceso de independencia y el último apartado refiere a las campañas de O'Higgins y San Martín, la renuncia de O’Higgins a la primera magistratura del Estado, el nombramiento de Freire, es decir cubre hasta 1829.

Vicente Fidel López fue parte de una generación de historiadores que no trabajaron con documentos, porque no los tienen ni organizados ni clasificados y sobre todo porque no le otorgaron mayor relevancia. La mayor parte de los historiadores de los primeros años de la República sintieron y se forjaron «en el flujo íntimo de aquellos que se sienten autorizados para dar una versión ajustada de los sucesos, por haber participado como testigos o actores de la historia a la que han contribuido» ${ }^{386}$. El propio López declara su desdén por los documentos, y replicaba que grandes historiadores como Salustio, Tácito, Tucídides «ni fueron archivistas, ni documentaron los hechos de enlace que vinculan las series que vivifican su narración $(\ldots)\rangle^{387}$. La postura y visión era clara en López los documentos no importan, lo sustancial es el valor y alcance de los hechos.

El uso de fuentes y documentos históricos era entendido por López como la forma en que otros debían estudiar historia, ya que al no haber sido testigos ni protagonista de los hechos y para poder satisfacer «esta necesidad natural de los espíritus aplicados y curiosos, porque no tendrían otro medio de conseguirlo que consagrar todo su tiempo a rastrear esos sucesos en una multitud de libros y de documentos (...)» ${ }^{388}$. Los comentarios y relatos con lo que escribe la historia son formalizados como auténticos y veraces e incluso sin mayor rigurosidad y revelados por el propio López que frente a un

\footnotetext{
${ }^{385}$ ROJAS, Ricardo, Historia de la Literatura americana y argentina, Buenos Aires, Librería de la Facultad, 1929, p. 63.

${ }^{386}$ MADERO, Roberto, La Historiografía entre la República y la Nación. El caso de Vicente Fidel López, Buenos Aires, Catálogos, 2005, p. 9.

${ }^{387}$ Ibidem, p. 5.

${ }^{388}$ LOPEZ, Vicente Fidel, Historia de la República Argentina, su origen, su evolución y su desarrollo político hasta 1852, Buenos Aires, Imprenta y Librería de Mayo, 1881, p. V.
} 
documento simplemente «copio este perímetro de un papel suelto, y sin autoridad conocida que me hizo ver en Chile el señor Álvarez Condarco, diciéndome que lo había tomado del Ministerio de Guerra de Buenos Aires, allá por 1816 o $1815{ }^{389}{ }^{3}$. En el caso de López su reivindicación no es por las evidencias históricas, sino que, por ser testigo privilegiado de la historia, que era su propia vida, y que debía ser considerada como un deber la trasmisión a las generaciones futuras, puesto que:

«(...) el olvido va destruyendo la verdad fugitiva de los sucesos y va borrando a toda prisa el rostro de los personajes que figuraron en ellos. El recuerdo vivo de los movimientos, se pierde fatalmente más y más, a medida que las generaciones que figuraban en el drama van cayendo en el sepulcro, ignoradas por los nietos que le suceden $(\ldots) .{ }^{390}$

El exiliado argentino era partidario de una historia filosófica, lo cual se plasma en los objetivos de su texto y que la enseñanza de lo histórico estaba destinada a hacer hombres de bien y «ciudadanos dignos de una república civilizada. He aquí todo lo que trato de enseñaros, pues debéis saber que de nada más os vais a ocupar que de estudiar los progresos que vuestra patria ha hecho en la carrera de la civilización y de la libertad» ${ }^{391}$. La historia de Chile era del pueblo civilizado en alusión directa al pensamiento sarmientino. Era la historia de la estirpe española y de sus descendientes, y por cierto de todos los que viviesen de ese modo.

La dualidad «civilización-barbarie» de Sarmiento invadía por todos lados la obra de López. Los indios que habían resistido al dominio español, habían sido conminados a los territorios del sur donde seguían viviendo en estado de barbarie. Todo el relato sincrónico y cronológico desde la llegada de los conquistadores, la resistencia indígena, la fundación de Santiago y de otras ciudades; los acontecimientos de la mal llamada Guerra de Arauco y la obra de los civiles militares y civiles españoles «demuestran, aunque paulatinamente, los pasos con los que íbamos a la civilización europea los

\footnotetext{
389 Ibidem, p. 193.

${ }^{390}$ LOPEZ, Vicente Fidel, La Revolución argentina. Su origen, sus guerras y su desarrollo politico hasta 1830, Buenos Aires, Imprenta y Librería de Mayo, 1881, pp. 1-2.

${ }^{391}$ LOPEZ, Vicente Fidel López, Manual de Historia de Chile, Santiago, Imprenta El Progreso, 1846, p. VII.
} 
habitantes de una tierra cubierta poco antes con la barbarie» ${ }^{392}$. López construye un relato sincrónico, progresivo y lineal. En cuanto al juicio acerca de los pueblos indígenas, la sentencia es definitiva, no deben ser considerados como parte de la Historia de Chile dado que «la historia de Chile es la Historia de los sucesos relativos a la raza española de la que formamos parte nosotros» ${ }^{393}$. También comparte la idea que la historia es patrimonio de los pueblos grafos que son los que tienen historia y que los ágrafos al no tener escritos sus sucesos «por esto, no tienen historia, sino tradición» ${ }^{394}$. Señala que indios y chilenos, aunque hayan nacido en el mismo territorio no son similares, puesto que los aborígenes:
«(...) no son miembros de nuestra sociedad, no son nuestros compatriotas, porque no tienen nuestro idioma, ni nuestra religión, ni nuestras leyes, ni nuestras inclinaciones, ni nuestra fisonomía, en fin; así que no entran a formar parte de nuestra nación ni tienen lugar ni empleo en nuestra sociedad. Los indios a quienes los españoles quitaron estas tierras en que hay pueblos, haciendas, teatros, iglesias, caminos, eran bárbaros y no civilizados como sus enemigos.»» ${ }^{395}$

Es peculiar que López otorgue a los españoles ese rasgo de civilidad cuando el sentimiento antihispanista fue bastante extendido en gran parte de los intelectuales y políticos luego de la independencia. Se debe estipular, además, que esa distancia con los indígenas se debía en parte, a que éstos habían apoyado la causa realista en las guerras de independencia; y comenzaron a ser vistos como enemigos de la República. López se hace parte de la tendencia mayoritaria entre la elite y los intelectuales en considerar que la nación era herencia del pasado colonial y no del distante mundo precolombino.

El Manual se inicia con la llegada de los españoles a territorio americano, en este caso chileno y López se aparta un poco de la tendencia liberal, en reconocer que las poblaciones civilizadas de las naciones latinoamericanas descendían de los españoleseuropeos, pues les otorga virtudes y méritos a los españoles en la construcción de la nueva República, en cambio, la idea compartida era no considerar a los hispanos como padres de la patria. Respecto a los mapuches destaca a ciertas figuras como Caupolicán,

\footnotetext{
392 Ibidem, p. 6.

${ }^{393}$ Ibidem, p. 26.

${ }^{394}$ Ibidem, p. 6.

395 Ibidem, p. 25.
} 
Lautaro, Galvarino, Janequeo, entre otros. Del primero cuenta que es «un indio que, sin duda, debemos mirar como un bárbaro lleno de arrojo y de inteligencia (...) era corpulento, astuto y extraordinariamente forzudo, cualidades que todas las naciones bárbaras estiman en mucho» ${ }^{396}$. A Lautaro lo describe como un indio, que, a pesar de haber sido formado por españoles, tomó partido por los bárbaros. Y frente a la muerte de Lautaro por parte de Villagra, lo aprecia positivamente debido a que:

«(...) tuvo la fortuna de derrotarlo y matarlo en el año de 1556; y fue tal el júbilo que causó esta victoria, que se celebró en todas las colinas españolas: Desalentó mucho este suceso a los araucanos y sobre todo a Caupolicán: la pérdida de Lautaro era para ellos realmente irreparable.» ${ }^{397}$

La idea hegemónica que la constitución de la nación chilena es mezcla de la hidalguía española y la bravura del indígena encuentra sus orígenes como discursos en casi todos los textos escalares del siglo XIX.

En la segunda parte de la obra, López, se centra en lo que es la parte sustancial del texto, que es la revolución que finaliza con la independencia. Los hechos son contados con énfasis en batallas, y en personalidades destacadas como Carrera, O'Higgins y San Martín. Vicente Fidel López a lo largo del texto asevera definir la nación chilena -ya comentada-en oposición a los indígenas, en línea con la distinción entre civilización y barbarie e incluso enfatiza solo la emancipación como el hecho fundante ya que, «los primeros acontecimientos con que empezó la formación de la verdadera nación chilena, de la única que lo sea, pues no debéis mirar como tal a las tribus de salvajes que poblaban estas tierras antes de la venida de los europeos» ${ }^{398} \mathrm{y}$, por lo tanto, fue la Independencia el momento clave.

Vicente Fidel López en la «Introducción» de su obra se dirige a los alumnos enfatizando la oportunidad de estudiar promoviendo el ideario liberal de la educación como un aspecto prioritario. López por medio del texto de estudio plantea que educar a la población era garantía de progreso político, económico, y principal agente para formar

\footnotetext{
${ }^{396}$ Ibidem, pp. 54-55.

${ }^{397}$ Ibidem, pp. 62-63.

${ }^{398}$ Ibidem, p. 118.
} 
individuos e integrarlos a los nuevos vínculos políticos y societarios que implicaba el acceso de Chile a una vida independiente. La educación para López fue enarbolada como una gran obra e inversión de la República puesto que:

«(...) la razón porque la Patria se interesa de tal modo en que sus tiernos hijos aprendan i estudien, que consagra serios cuidados, gasta grandes cantidades de dinero, i ocupa sabios de todas clases (...) para llegar a ser ciudadanos dignos de una república civilizada.» ${ }^{399}$

López asume el texto y su autoría como una obra colectiva, de testimonio y protagonismo de la elite puesto que «esta idea no me pertenece, sino que pertenece exclusivamente a V.S, que fue quien me la sugirió, he creído que habría sido injusto que yo me nombrase autor de este corto trabajo (...)» ${ }^{400}$. López perteneció al grupo de historiadores de la independencia que, a su vez, fueron actores y testigos de su historia. Es experiencia viva que al mismo tiempo es una práctica y representación de lo colectivo que organiza «una percepción, que clasifica, juzga y actúa sobre aquello que constituye, en el presente, el pasado» ${ }^{401}$. Fue un modo de hacer historia no sólo estrechamente vinculado a sus actores y testigos, sino que a las particularidades de las narraciones de los individuos. Los comentarios y relatos con los que construye su historia son formalizados como fuentes y documentos.

Con la idea del hombre como ser que actúa en el tiempo, éste autor usa la historia en la perspectiva del ad probandum, como maestra de vida y como una sucesión de acontecimientos afirmado en que «debéis saber que de nada más os vais a ocupar que de estudiar los progresos que vuestra patria ha hecho en la carrera de la civilización y de la libertad ${ }^{402}$. Patria y Nación fueron conceptos bastante utilizados por López y nótese cuando expresaba que:

«Vuestra patria es una nación compuesta de varios pueblos, cada uno de estos pueblos es una reunión de familias vivas ... de modo que lo que tratáis de conocer

\footnotetext{
399 Ibidem, p. 4.

${ }^{400}$ Ibidem, pp. V-VI.

${ }^{401}$ MADERO, R., La Historiografía entre la República y la Nación..., op. cit., p. 11.

${ }^{402}$ LOPEZ, V., Manual de Historia de Chile..., op. cit., p. V.
} 
es la vida de nuestra patria, es decir, que es lo que nuestros compatriotas han hecho en el tiempo en que han vivido $(. ..) .{ }^{403}$

La nación es la continuación de las fusiones españoles-chilenos y españoles europeos vinculándolo con un pasado europeo y civilizado, era la idea predominante que España había unido Chile a la historia universal occidental y cristiana y que la nueva república «cuya joven bandera flamea con donaire entre las banderas de las demás naciones civilizadas, no es otra cosa que una sociedad formada con elementos tales que la hacen fundamentalmente española» ${ }^{404}$. En todo el recorrido del texto advertimos una exaltación vigorosa de la nación chilena, como lugar de anclaje y que en nombre ella se construye el relato de los hechos dignos de recordar. La idea de continuidad con el pasado colonial-español, lo aparta de la corriente liberal y lo vincula más bien al ámbito conservador, en el sentido de la valoración positiva del pasado. Es también parte importante de su discurso la excepcionalidad de Chile, la barbarie representada por los indígenas y, por cierto, la apelación a los estudiantes como futuros ciudadanos. El texto de López en sus alcances de difusión y lectura real son difíciles de rastrear, su valor para este estudio reside en conocer y comprender los hilos discursivos del entramado que conforma esa representación en la etapa fundacional del Estado chileno.

En 1856, el profesor del Instituto Nacional, y uno de los grandes intelectuales e historiadores del siglo XIX, Miguel Luis Amunátegui, publicó, con aprobación de la Universidad, Compendio de la Historia politica y eclesiástica de Chile. La Comisión encargada de revisar el texto informó que la obra cumple con los objetivos que se le encomendaron que era de elaborar un texto «para el aprendizaje de la historia del país (...) [y que el autor] ha querido ceñirse al papel de narrador severo en lo concerniente a los sucesos que pudieras suscitar pasiones políticas u odios de partido ${ }^{405}$. El texto de Amunátegui adscrito a la historia narrativa, aún siendo un liberal es un texto muy sobrio en juicios y se atañe a descripciones detalladas de los sucesos.

\footnotetext{
${ }^{403}$ Ibidem, p. 6.

${ }^{404}$ Ibidem, p. 54.

${ }^{405}$ Cit. en AMUNATEGUI, Miguel Luis, Compendio de la Historia política y eclesiástica de Chile, Valparaíso, Imprenta El Universo, 1856, p. 4.
} 
La obra está dividida en dos partes. La primera consta de catorce capítulos que van desde el descubrimiento del Perú por parte de Francisco Pizarro hasta 1826 con el ascenso de Ramón Freire al cargo de Director Supremo de Chile y el reconocimiento de la independencia por parte de España en la firme idea de sostener que con ello termina el período de la emancipación nacional. La segunda parte consta de tres capítulos referidos al ámbito eclesiástico. Este aparatado, a su vez, se divide en tres capítulos: el primero refiere a la introducción del cristianismo en Chiles hasta la constitución de Santiago en Arzobispado; el segundo sobre las autoridades religiosas (obispos) que existieron en Chile hasta el siglo XVIII; y el último capítulo versa sobre las distintas órdenes religiosas establecidas en Chile. El esquema general de los capítulos es como se aprecia en la página 6 que trata sobre el descubrimiento y conquista:

«Capitulo I. Francisco Pizarro y Diego de Almagro. Compañía que ésos celebraron con Luque para el descubrimiento del Perú. Tentativas de los socios para realizar su proyecto. Viaje de Pizarro a España. Desavenencia y Reconciliación de éste con Almagro. Situación el Perú al arribo de los españoles. Prisión de Atahualpa. Rescate que ofrece ahora obtener la libertad. Distribución del rescate entre los españoles. Muerte de Atahualpa. Invasión de Alvarado.» ${ }^{406}$

Amunátegui inicia el texto con la conquista dejando de lado el período prehispánico. Lo indígena aparece de dos formas en su relato, primero, en la conquista, la Colonia y la independencia asociados a las luchas libradas en el sur del territorio, también son reiteradamente mencionados como habitantes o simplemente moradores y que cuando los españoles avanzaron hacia el sur en 1550 «llegaron a esta parte de Chile que era la más poblada, la más fértil, la más bella; pero sus moradores eran más aguerridos y amantes de su independencia que los de la parte boreal»» ${ }^{407}$. En el texto de Amunátegui considera la categoría de chilenos con prescindencia de lo indígena y son continuamente las referencias con adjetivos de aguerridos, resistentes, soberbios, valientes, hostiles, destructivos, insurrectos e indómitos, y por cierto bárbaros y salvajes.

El autor argumenta que a medida que va pasando el tiempo, los araucanos han ido perdiendo su vigor y actividad guerrera dado que habían ido adquiriendo signos de

\footnotetext{
406 Ibidem, p. 6.

${ }^{407}$ Ibidem, p. 31.
} 
civilización por su apertura a la religión cristiana y la educación de los españoles, aunque en una intervención como diputado ante la falta de política para ocupar los territorios señalaba que había que asegurar una mejor población. Las tierras ocupadas por los indígenas estarán civilizadas el «día que haya en él la suficiente población cristiana, diré así, para dominar a la población indígena o bárbara $(\ldots){ }^{408}$ y que de todas maneras la mejor manera era con población mixta para finalmente pacificar y civilizar esas tierras. En la descripción de los quehaceres de los indígenas Amunátegui refiere que estos no han podido resistir los «trabajos forzados que les imponían los españoles para el laboreo de las minas. Como no formaban un solo pueblo, sino un conjunto de tribus que solían aliarse en las circunstancias graves $(\ldots)^{409}$. La razón del agobio no estaba en lo forzado de los trabajos, sino que en la falta de disciplina, organización y mando entre los indígenas. Las referencias a la participación de los indígenas en la Independencia, es decir, en el acto originario de Chile fueron muy pocas y recordados en el bando de los realistas cuando Vicente Benavides, un militar chileno que se «levantó sobre esta base tan diminuta y miserable una montonera imponente con araucanos y otros forajidos españoles, y comenzó las hostilidades, como era propio de un hombre $\sin$ fe y $\sin$ entrañas» ${ }^{410}$. En los relatos de la Independencia el indio queda excluido y relegado a la imagen de bárbaro y contrario a la República. La independencia fue un hecho ajeno a los indígenas, sin embargo, éstos estuvieron envueltos en las guerras entre españoles y chilenos, especialmente cuando los enfrentamientos se desarrollaron hacia el sur. En Amunátegui y otros historiadores de la época existió una profunda contradicción, si bien por un lado eran enemigos de la civilización identificados como páganos, idólatras, polígamos, y por tanto enemigos de la cristiandad, y en cambio por otro lado se les ponía como antecedente inmediato de la lucha contra España. Los indígenas aparecen germinando los antecedentes de la nacionalidad, aunque, especialmente, los mapuches adhirieron mayoritariamente al bando español y lucharon contra los fundadores de la nacionalidad. Una actitud contradictoria frente al indígena.

\footnotetext{
${ }^{408}$ Cit. en Sesiones del Congreso Nacional, Valparaíso, Imprenta Progreso, 1865, p. 544.

${ }^{409}$ AMUNATEGUI, Miguel Luis, Compendio de la Historia politica ..., op. cit., p. 32.

${ }^{410}$ Ibidem, p. 137.
} 
Siendo el Compendio de Amunátegui, excesivamente descriptivo, ofrece algunas interpretaciones interesantes acerca de algunos acontecimientos, por ejemplo, la Independencia, interpretada como la mayor parte de los historiadores del siglo XIX como el cimiento del Estado nacional chileno. El relato comienza con la invasión de Napoleón a la península narrada en el texto más como un asunto entre Francia y España, que en una dimensión más global del problema. Señala que el rey Carlos IV había entregado el reino al valido Manuel Godoy en detrimento de su hijo Fernando y «que el pueblo había tomado partido por este último, que se había puesto al frente de la oposición a Godoy»» ${ }^{411}$. Sitúa el asunto, por tanto, en una dimensión peninsular y no en un asunto de mayores dimensiones y continúa que frente a este descontento, el emperador de los franceses, Napoleón que aspiraba al trono español habiéndose ofrecido como mediador entre padre e hijo había logrado «no sólo que aceptasen sus buenos oficios, sino también que uno y otro, de grado o por fuerza, abdicasen a favor de José Bonaparte, hermano de Napoleón» ${ }^{412}$. La concepción histórica de Amunátegui adjudica un rol clave a los sujetos, a sus decisiones y resolución en los conflictos. Cuando se refiere a las causas de las independencias sostiene una interpretación del fenómeno a imitación de las Cortes que se habían instalado en España, a propósito, de la invasión napoleónica y usurpación del trono, es que en América y en Chile imitaron esa postura ya que, «aquella novedad en el régimen gubernativo agradaba tanto más a los habitantes del Nuevo Mundo, cuanto que la política suspicaz de España los había tenido hasta entonces completamente excluidos en los negocios públicos» ${ }^{413}$. Las disputas internas por los puestos de Gobierno debido a la discriminación a favor de los españoles enviados como representantes de rey de España ha sido una explicación recurrente desde los albores de la República. Los criollos deseaban tener mayores cuotas de participación en la toma de decisiones. Los principales empelados eran españoles europeos, siendo muy raro que un americano ocupase un alto puesto. Así la mayoría de los criollos se esforzaba con empeño en organizar juntas nacionales que les dieran injerencia en la administración de su país. De las explicaciones sobre las razones de la

\footnotetext{
411 Ibidem, p. 89.

${ }^{412}$ Ibidem, p. 89.

${ }^{413}$ Ibidem, p. 90.
} 
Independencia, la cuestión asociada a los cargos públicos ha predominado en la historiografía, y es en el texto de Amunátegui, donde se estrena dicha explicación.

La concepción de la historia en Amunátegui no se explicita en el Compendio, y para ello hemos revisado en otros documentos información que nos dé más luces sobre este asunto. En 1852, en el discurso de recepción de Amunátegui a la Universidad de Chile, advertimos visiones acerca de la historia de América y de Chile que irradian su Compendio, en el Discurso en la Universidad de Chile declara frente a la historia de tres siglos coloniales que han sido:

«(...) tres siglos de esclavitud y veinte años gastados en la lucha contra España... Decir que el coloniaje no fue para los criollos más que un sueño letárgico, es una metáfora que la repetición ha gastado, pero que no por eso deja de ser muy verdadera. Aquello no era vida, sino inercia. ${ }^{414}$

El balance y la perspectiva frente a la Colonia fue lapidario entre los liberales decimonónicos predominando la asociación de aquellos siglos con la idea de una larga siesta histórica. La visión negativa de la Colonia se contraponía a la que se tenía acerca de la independencia y enalteciendo a los personajes que participaron de dicho proceso, pues habían sentado las bases para la instauración y consolidación de los gobiernos y de la necesaria organización del Estado con posteridad al desmoronamiento del orden colonial. Siendo un liberal, la alta estimación que tenía sobre el período de la independencia era evidente aseverando que «es una lucha gloriosa, en la cual no faltan los hechos heroicos, los sacrificios, los ejemplos de abnegación, $\mathrm{y}$ aún de magnanimidad, pero es una guerra como tantas otras que han sostenido los pueblos oprimidos contra aquellos que los tiranizaban ${ }^{415}$. Las guerras de independencia eran para Amunátegui muy similares a las europeas.

Al igual que Vicente Fidel López, manifiesta que Chile es un traslape de la cultura española-europea, realizaron reiteradamente analogías entre los acontecimientos

\footnotetext{
414 «Discurso de recepción de Don Miguel Luis Amunátegui en la Facultad de Filosofía y Humanidades de la Universidad de Chile», Anales de la Universidad de Chile, 1852, serie 1, p. 462.

${ }^{415}$ Ibidem, p. 463.
} 
europeos y americanos, puesto que en ambos existió la negación de la presencia cultural indígena, la convicción que tanto el coloniaje como la independencia no poseyeron características propias y originales, y que por lo tanto la sociabilidad chilena era una imitación de la sociabilidad europea y que los chilenos «nos esforzamos por hacer lo más exacto posible. Ni nuestra religión, ni nuestras instituciones, ni nuestra lengua, ni nuestras costumbres, ni nuestras preocupaciones son indígenas»» ${ }^{416}$. Para Amunátegui, la conquista y la independencia son los grandes y únicos momentos dignos de ser relatados, ya que en ellos se revela el tesón y la creatividad de los individuos que el despotismo colonial habría contenido. Es decir, dos acontecimientos que habían puesto a Chile en el concierto internacional y el segundo que lo había y transformado en una República.

En el año 1857, el académico de la Universidad de Chile, Miguel De la Barra con la aprobación de la Universidad, publicó Compendio de la Historia del coloniaje e independencia de América. Obrita aprobada por el Consejo de la Universidad para texto de estudio en los colegios de la República ${ }^{417}$. El texto escolar fue publicado en dos partes, entre los años 1857 y 1858. Es un texto que comprende la conquista y descubrimiento de todas las regiones de América continental e insular. El método es narrativo, aunque, sin embargo, contempla dos cuestiones dignas de apreciar. Lo primero, es que emite juicios para cada uno de los grandes procesos que abarca la obra: descubrimiento y conquista, colonia e independencia. Un segundo aspecto que se hace muy visible es concebir la historia como la acción de determinados hombres modelos de virtudes; y que sus acciones son determinantes para el derrotero de la misma. Revisemos algunos ejemplos:

Sobre los indígenas, el autor se circunscribe a describir características generales de los indígenas a la llegada de los españoles dominada por los enfrentamientos bélicos entre españoles e indígenas. La narrativa del enfrentamiento es permanente y predominante

\footnotetext{
${ }^{416}$ Ibidem, p. 464.

${ }^{417}$ Compendio de la Historia del coloniaje e independencia de América. Obrita aprobada por el Consejo de la Universidad para texto de estudio en los colegios de la República, Valparaíso, Imprenta y Librería europea, 1869.
} 
en De la Barra y que «sucede muchas veces que tan pronto edifican aquellos una ciudad, cuando estos la destruyen, tan pronto la paz por una y otra parte, cuando un motivo cualquiera basta para romperla» ${ }^{418}$. La visión del autor en relación al indígena era negativa y se refiere al indio como «perezoso, el indio se creía feliz recostado en una hamaca, rodeado de su familia, sin moverse, sin pronunciar una palabra. La poltronería era el término final de sus aspiraciones» ${ }^{419}$. Cuando se refiere a las relaciones de esclavitud y de captura de prisioneros arguye que la finalidad de los españoles era cristianizarlos y civilizarlos y que las causas «no eran otras que la necesidad de someterlos a un amo cristiano para que les enseñase los principios de la religión y las reglas de su moral, y la escasez de brazos para trabajar en las minas» ${ }^{420}$. A la hora de evaluar las acciones emprendidas por los conquistadores en contra de los nativos afirma que no eran necesarias, pero que los aborígenes estaban empeñados en «evitar a todo trance semejante condición, lo que hacía interminable la guerra por uno y otro lado e inútiles todas las medidas que se tomasen en su contra, siempre que no tendiesen a cortar de raíz las causas que la motivaban» ${ }^{421}$. Las resistencias de los indígenas a los trabajos de los españoles fueron vistas no en oposición a los vejámenes, sino que a la negación de tener que ser civilizados.

En relación a López y a Amunátegui, De la Barra incorporó temáticas prehispánicas. En virtud del pensamiento imperante, que se puede resumir en la idea que las naciones latinoamericanas eran herencia del pasado español y que todo lo anterior a la independencia y a la Colonia era sólo el preludio de la historia nacional. Este autor incorpora en el relato las características bélicas y viriles de los indígenas, como por ejemplo de Caupolicán decía que era un gran «guerrero, astuto y valiente, de una musculatura admirable.» ${ }^{422}$ La vinculación entre las características de los indígenas: rebeldía y libertad fueron conceptos muy apreciados por los liberales, ya que, estos los conectaban con sus propias acciones en tiempos de las guerras de independencia.

\footnotetext{
${ }^{418}$ Ibidem, pp. 44-45.

${ }^{419}$ Ibidem, p. 53.

${ }^{420}$ Ibidem, p.54.

${ }^{421}$ Ibidem, pp. 24-25.

${ }^{422}$ Ibidem, p. 56.
} 
De la Barra de algún modo, se conecta con los otros autores de textos escolares, ya que cuestiona determinadas acciones de los españoles, no con la finalidad de tomar partido por los indígenas, sino para dejar de manifiesto las arbitrariedades del conquistador que ocasionaron la emancipación de las colonias de España. Por ejemplo en el cometido del Virrey Francisco Álvarez de Toledo ejecutor de la muerte de Tupac Amaru ${ }^{423}$ refiere que éste no tuvo «consideración alguna con el desgraciado Tupac-Amaru y le hizo condenar a muerte con algunos de sus más fieles partidarios (...) grande fue la indignación causada en la corte por la noticia de estos crímenes.») ${ }^{424}$ La narración prosigue cuando el rey Felipe II manda a buscar al Virrey haciéndole saber el crimen que cometió, lo interpela diciéndole: «sal de aquí: yo no te había nombrado verdugo de reyes, sino gobernador de un pueblo y protector de los desgraciados que en él se hallasen.» ${ }^{425} \mathrm{La}$ incorporación de un relato que objeta la actuación de los españoles no se encuentra en los otros manuales de historia utilizados por las escuelas chilenas en el siglo XIX, aunque también es una narración que tiene el correlato de ensalzar la magnanimidad del monarca español.

Curiosamente, en tiempos de la independencia, el elemento indígena desaparece del relato histórico de la nación. El texto escolar de De la Barra es el primero que menciona la era prehispánica y sólo en la introducción, entendida como un elemento anterior a la República. El reconocimiento de las características de los indígenas implicaba trasladar esos atributos a tiempos remotos vinculados a las acciones que emprendieron otros hombres en contra de la dominación, pero con final distinto: una nación. Este era el discurso y relato de los liberales. El relato del texto asume la historia de Chile como el cúmulo de hazañas y virtudes de hombres cuya acta de fundación es la independencia. La idea del letargo colonial que habría sido interrumpido positivamente por la Independencia es distinguida por el autor cuando expresó que «ningún suceso

\footnotetext{
${ }^{423}$ Túpac Amaru I (?, circa. 1542 - Cuzco, 1572), último soberano inca. Después de la conquista española del Perú, los incas se habían refugiado en el reducto de Vilcabamba. En 1558 el inca Sayri Túpac se sometió a los españoles y se trasladó a Lima; pero su hermano Titu Cusi Yupanqui se quedó en Vilcabamba, encabezando un grupo de indios resistentes. Un ejército español asaltó Vilcabamba en 1572. La familia del inca intentó huir, pero fue perseguida y capturada. El virrey hizo que trasladaran al Cuzco al soberano inca, al que hizo bautizar antes de ejecutarle públicamente.

${ }^{424}$ BARRA, Miguel de la, Compendio de la Historia del coloniaje e independencia de América ..., op. cit. p. 40.

${ }^{425}$ Ibidem, p. 41.
} 
extraordinario turbó la marcha de los establecimientos hasta la época de la emancipación de las colonias españolas y portuguesas» ${ }^{426}$. La independencia es la etapa más importante para De la Barra ya que puso fin a la esclavitud y al vasallaje sucedido por un «gobierno propio, representativo y popular; a los privilegios y prerrogativas de los europeos, la igualdad ante la ley, y las restricciones del comercio y de la industria, la más completa libertad» ${ }^{427}$. Valora que la Independencia se debió al impulso dado por las ideas ilustradas, y por la lucha ganada en los campos de batalla. Sustenta con claridad, las razones que habrían explicado la ruptura de las colonias con la metrópolis, sobre todo que España mantuvo inexorablemente a los criollos fuera de sus propios negocios durante los trescientos años de la Colonia y que incluso «natural era, por consiguiente, que éstas se aprovecharan de la primera ocasión que para ello se les presentase. Así es que apenas se supo de la usurpación de José Bonaparte y la elección de juntas provinciales en la metrópoli, todas, trataron de imitar este ejemplo, instalando gobiernos semejantes» ${ }^{428}$. La idea preponderante en De la Barra es el rol de los personajes, y a la hora de explicar razones de la Independencia muestra que los impulsores eran «hombres de ideas liberales, educados casi todos en las escuelas de la filosofía francesa, donde habían aprendido las doctrinas que acababan de trastornar la más grande y poderosa de las monarquías» ${ }^{429}$. Enalteció que los primeros dirigentes de la nación eran hombres dueños de una amplia cultura, conocedores de todas las doctrinas filosóficas y políticas de la época, idealizaron una patria grande y próspera.

Las referencias a personajes claves de la Historia de América y de Chile contenidas en el texto de De la Barra son frecuentemente aduladores. Sobre el prócer venezolano, Simón Bolívar escribió: «(...) un hombre extraordinario apareció entonces al frente de la revolución, el único tal vez que podía oponerse a la España por sus talentos y valor en aquellas circunstancias... Dotado de una perspicacia y fuerza de ánimo admirables.» ${ }^{430}$ La evaluación que realiza es digna de un epitafio «tuvo siempre dos grandes modelos que imitar, Washington y Bonaparte; y cualesquiera que sean las críticas que se hagan o

\footnotetext{
${ }^{426}$ Ibidem, p. 23.

${ }^{427}$ Ibidem, pp. 102-103.

${ }^{428}$ Ibidem, pp. 204-205.

${ }^{429}$ Ibidem, pp. 204-205.

${ }^{430}$ Ibidem, p. 158.
} 
la suerte de los países cuyos cimientos colocó, su nombre brillará siempre en el porvenir al lado de aquellos cuya gloria envidiaba» ${ }^{431}$. Parte del esfuerzo de políticos e intelectuales por construir los cimientos de la nación chilena y en América fue instrumentalizar la memoria y los relatos políticos y bélicos para crear héroes fundadores de la nacionalidad. La exaltación de lo heroico respecto a la Independencia fue atribuido al esfuerzo heroico por sobre las acciones colectivas, las razones históricas y políticas que desencadenaron el proceso de Emancipación que experimentaron las naciones hispanoamericanas. Sobre José Miguel Carrera, prócer y destacado participante en las guerras de Independencia, jefe de gobierno, primer general en jefe del ejército y figura controversial de la historia chilena dado el no consenso sobre su republicanismo, aunque no existen dudas sobre sus ideales independentistas. De la Barra relata la situación en que aparece Carrera, en medio de la inestabilidad política y lo sitúa como un hombre que viene a poner orden por sobre sus aspiraciones personales, ya que «la voluntad de Carrera fue entonces el gobierno del país, que, sin bases constitucionales de ninguna especie, había permanecido entregado al capricho de sus mandatarios desde los primeros días de Revolución: algunos justos reclamos dieron por resultado el primer ensayo constitucional que hemos tenido $(\ldots) »^{432}$. La construcción del héroe desprendido y del restaurador constituye un recurso narrativo en este y casi todos los historiadores del siglo XIX. Predominó la idea de una historia conducida por personajes encadenados en forma sucesiva que con sus buenas acciones contribuyeron a la construcción de la República. En este sentido, con el fin de crear y reforzar la historia patria, las naciones asignan a los personajes que han realizado gestiones importantes calificativos incomparables como héroes, libertadores, próceres, insignes, ilustres prohombres a los que venera y respeta por dignidad y virtud. Bernardo O’Higgins ejemplo de enaltecimiento distinguido con el apelativo de Padre de la Patria. Sobre este personaje de la Independencia, el autor lo plasma así ante la obligación de tener que renunciar en 1823 al cargo de Director Supremo de la Nación cuya acción estuvo motivada no por la ambición ni el egoísmo, sino que por el patriotismo y cual Cincinatti se habría retirado de la vida pública «a la vida privada como un héroe, dando a su patria

\footnotetext{
${ }^{431}$ Ibidem, p. 13.

${ }^{432}$ Ibidem, p. 211.
} 
una nueva muestra de su cariño y abnegación (...) que había elevado al rango de nación independiente y soberana y donde dejaba recuerdos imperecederos ${ }^{433}$. El texto de De la Barra fue escrito en 1869 después de largas controversias entre ohigginistas y carreristas, y es en ese contexto que se explica el Compendio. Desde 1860 que los liberales tenían el control del poder y se empeñaron en la decisión de incluir a muchos de los personajes históricos en una suerte de historia nacional consensuada y positiva. Diego Portales fue un comerciante, ministro de Estado y una de las figuras fundamentales de la organización de la República, pero a la vez un personaje controvertido. De la Barra lo retrata como uno de los primeros hombres públicos de América, como hombre clave en poner fin a la anarquía política post-independencia, como un hombre de ideas autoritarias que instauró un régimen autoritario y presidencialista gracias a la materialización de su pensamiento en la Constitución de 1833 y que desde el gobierno instauró un modelo de poder Ejecutivo fuerte, apoyado en fuerzas sociales como la aristocracia y la Iglesia Católica. Por todas y muchas más realizaciones del ministro es que «Chile debe por sus trabajos una eterna gratitud y con ellos consiguió establecer el orden político que actualmente existe» ${ }^{434}$. Todos estos íconos de la historia debían concitar un alto nivel de adhesión y transformados en personajes paradigmáticos de las virtudes que se desearon enfatizar como elementos de la identidad nacional. Carrera, O'Higgins y Portales representaban el hilo conductor de una historia sucesiva y exitosa en la concreción de un proyecto político de organización política refrendada en un Estado nacional republicano.

De la Barra fue un autor de texto con una visión clara del momento que se estaba viviendo, de tranquilidad y esplendor, y que ello era consecuencia de las acciones pasadas realizadas por célebres hombres, lo podríamos denominar una visión histórica de carácter consecutiva y progresiva.

El texto escolar más importante y significativo que se utilizó en el siglo XIX fue el Compendio Elemental de Historia de América de Diego Barros Arana. El texto fue

\footnotetext{
${ }^{433}$ Ibidem, p. 225.

${ }^{434}$ Ibidem, pp. 227-228.
} 
publicado en 1857 y aprobado por la Universidad como consta en el Informe extendido por el Consejo Universitario que la destacó como una obra magnífica acerca de la conquista y el descubrimiento, de la formación de las nuevas naciones «y de esa lucha gigantesca de los hombres de otra raza con los conquistadores del viejo continente. Todos los pueblos de América pueden estudiar en ella sus orígenes, encontrando, por decirlo, así su fe de Bautismo.» ${ }^{435}$. Barros Arana siguió en sus investigaciones y publicaciones el método narrativo aconsejado por Andrés Bello, de modo que su concepción de la historia, propia del siglo XIX, exponía y ordenaba con imparcialidad los hechos históricos, sin interpretaciones ideológicas, poniendo en el centro la pretendida verdad histórica.

El texto escolar de Barros Arana cubre un arco temporal que va desde los pueblos precolombinos hasta el final de la independencia. Barros advierte el objetivo que su obra estaba destinada a cubrir la carencia de los estudios de América en los establecimientos educacionales y por lo tanto su libro buscaba «remediar este mal. Aunque su redacción se resiente de la precipitación con que ha sido escrito, contiene las noticias que conviene comunicar al estudiante $(\ldots) \gg{ }^{436}$. Barros Arana fue el mayor exponente del método narrativo con un encadenamiento lógico de los hechos históricos. Junto a ello también desarrolló una aguda crítica, problematización de la historia, especialmente con el método de crítica filológica; y desarrolló una especie de instinto para desentrañar de testimonios confusos y contrapuestos de información. En reiteradas ocasiones a falta de testimonios y fuentes históricas eran salvadas con deducciones lógicas «en que el peso del raciocinio y el buen criterio se imponen con facilidad» ${ }^{437}$. Este autor poseía una mente ordenada que le proporcionó la posibilidad de construir y producir el relato en el que cada hecho, lugar y personaje está en su lugar.

La noción e idea del oficio del historiador quedó plasmada en el prólogo de una de las obras más importantes y señeras de la Historia de Chile en cual Barros Arana reconoció

\footnotetext{
435 «Bibliografía. Compendio de la Historia de América por Don Diego Barros Arana. Noticia de esta obra», Anales de la Universidad de Chile, 1865, Tomo 26, enero-junio, p. 635.

${ }^{436}$ Compendio de Historia de América, Santiago, Imprenta del Ferrocarril, 1865, pp. III y IV.

${ }^{437}$ VILLALOBOS, Sergio, Historia del Pueblo chileno..., op. cit., p. 20.
} 
el valor de la historia filosófica pues proporcionaba una mejor relación con el pasado, explicaba de mejor manera la forma de ser de un pueblo y que la historia narrativa con la sucesión de los gobernantes, de las batallas y de la descripción detallada de los hechos, ya no satisfacían a los lectores. La historia filosófica era un «género de historia, instructivo e interesante para los lectores cultos, no es todavía propiamente popular» ${ }^{438}$. Admitía el valor y pertinencia de la historia filosófica, pero argumenta que los lectores no están preparados para ese tipo de narración, por ello opta por el método narrativo, probablemente muy acorde con la finalidad general de la difusión de la historia tanto en los círculos letrados como en la escuela. Y lo declara abiertamente puesto que «he adoptado de propósito deliberado el sistema narrativo (...) [y que la historia filosófica] No puede existir sino a condición que la historia haya pasado por las otras fases, de que haya establecido definitivamente la verdad (...)» ${ }^{439}$. El método narrativo de Barros Arana era motivado por el respeto a los hechos y a los lectores. Las opiniones personales no eran muy frecuentes o evidentes, más bien confiaba en que la exposición objetiva de los hechos y que fueran los lectores y estudiantes los que extrajesen las conclusiones e interpretaciones.

La explicación objetiva de los hechos no siempre se alcanzaba, pues se develaba en sus páginas al pensador liberal que era a pesar de su esfuerzo por la objetividad. La obra en general de Barros Arana que dio cabida a aspectos culturales, sociales y económicos es una obra cuyo hilo conductor es la historia de los acontecimientos políticos y de la acción gubernativa. La claridad en el objetivo de Barros Arana de contar los hechos tal como sucedieron y de narrar la verdad quedó plasmada al final de dicho prólogo cuando puntualiza el mérito de su libro, de la utilidad para el conocimiento de la historia nacional y que en ella los lectores «chilenos hallarán en él un cuadro de los acontecimientos de nuestro pasado en que no escasean las noticias recogidas en las fuentes más autorizadas, y expuestas con el sincero propósito de no escribir más que la verdad» ${ }^{440}$. La verdad era buscada porque, en cierto sentido, los conceptos y hechos que

\footnotetext{
${ }^{438}$ BARROS ARANA, Diego, Historia General de Chile, Santiago, Editorial Nascimiento, 1930, Tomo Primero, p. XIV.

${ }^{439}$ Ibidem, pp. XIV-XVI.

${ }^{440}$ Ibidem, p. XXIII.
} 
construyen la historia proporcionaban certidumbres, y el liberalismo decimonónico como paladín occidental erigía un fuerte vínculo entre el lenguaje escrito y el mundo por medio de teorías o la simple exposición de los hechos.

El texto de Barros Arana suministró una visión sobre la conquista y la presencia española como una etapa más evolucionada que la del pasado indígena. En cuanto a los indígenas, a diferencia de los autores tratados anteriormente, los incorpora desde tiempos remotos en una dimensión incluso temporal cuando en la Parte Primera del Compendio acerca de los primitivos habitantes de América titula «Oscuridad del origen de los primitivos habitantes de América» ${ }^{441}$. Las ideas de Barros Arana adolecían de precisión temporal y eran absolutamente generales respecto a las características culturales sobre el mundo indígena.

A la falta de investigaciones y fuentes históricas que avalaran su exposición e interpretación, Barros Arana concluyó respecto a los habitantes precolombinos que, primero, «el hombre habita la América desde tiempos tan remotos que, no siendo posible encuadrarlos en ningún sistema cronológicos, se les ha dado la denominación de prehistóricos, y sólo pueden combinarse con los períodos geológico» ${ }^{442}$; segundo «la civilización americana (...) se ha formado y desarrollado en su suelo, y ha pasado por alternativas de adelanto y retroceso que produjeron en un largo transcurso de siglos, la grandeza, la caída y la reconstrucción de vastos y poderosos imperios»; y tercero que: «las lenguas americanas parecen igualmente, formadas en este continente; y no sólo pueden asimilarse o acercarse a las de los otros continentes a cuyas poblaciones se les atribuía un origen común, sino que estaban divididas en lenguas enteramente diversas entre sí e irreductibles a un centro lingüístico único.» ${ }^{443}$ En sus apreciaciones, los indígenas eran situados en tiempos remotos, conllevan un error al considerar al hombre americano como autóctono del continente. No es menos cierto que sobre el origen del hombre americano en el siglo XIX no había explicaciones concluyentes. Al mismo tiempo, existió en Barros Arana una concepción lineal y de progreso de las culturas y

${ }^{441}$ BARROS ARANA, D., Compendio de Historia..., op. cit., p. 1.

${ }^{442}$ Ibidem, p. 3.

${ }^{443}$ Ibidem, p. 3. 
las civilizaciones. Es cierto que los datos que manejaba Barros Arana están interpretados de acuerdo a la teoría evolucionista que predominaba en la segunda mitad del siglo XIX. Sus conceptos de progreso, de desarrollo civilizador sostienen la antigüedad del hombre americano y el desarrollo cultural de los indígenas que lograron crear grandes civilizaciones. El autor al situar a estos pueblos en «tiempos remotos» no los considera como parte de los nuevos estados nacionales, y que los hallazgos hechos a la fecha en pinturas, escritura jeroglífica, ruinas de palacios, fortalezas, palacios, templos, ciudades no eran más que objetos misteriosos y que por si «no bastan para formar la historia ordenada de las antiguas naciones del Nuevo Mundo, sino un cuadro vago y general de las transformaciones porque estas habían pasado» ${ }^{444}$. La idea compartida en el siglo XIX que las culturas americanas no habían llegado a configurar estados superiores de civilización con las contadas excepciones de los aztecas e incas. Al final de su presentación Barros anuncia que antes de explicar el Descubrimiento y Conquista de América «por los europeos, vamos a dar a conocer sumariamente el estado social de aquellos imperios, y de las poblaciones que por su estado de atraso no habían alcanzado a formar verdaderas nacionalidades ${ }^{445}$. Recurrentemente, Barros Arana describe a los indígenas como holgazanes, bárbaros, e incapaces.

Para el caso particular de los indios chilenos señalaba que estaban condenados a desaparecer por ser una sociedad sin Estado y condenados a vivir como bárbaros. No tenían la noción de propiedad privada, por lo tanto, están impedidos del progreso, aunque hayan nacido en una tierra llena de recursos y Su única virtud era la habilidad en la guerra, su imperturbabilidad ante el dolor. El autor los describe de la siguiente forma: «esos salvajes eran miembros de diversas tribus más o menos belicosas que solían aliarse en circunstancias supremas.» ${ }^{446}$ Pedro de Valdivia, quien afianzó el asentamiento de los españoles en Chile fue muerto por Lautaro, un mapuche, Barros Arana se refiere a la muerte del conquistador del siguiente modo: «(...) su cadáver fue destrozado y comido por los salvajes. El ilustre conquistador sucumbía desastrosamente a la edad de cincuenta años, cuando había satisfecho las aspiraciones de su vida (...) pero había

\footnotetext{
${ }^{444}$ Ibidem, pp. 3-4.

445 Ibidem, p. 5.

${ }^{446}$ Ibidem, p. 220.
} 
fundado una colonia bien modesta por entonces, pero destinada a ser el origen de una nación que lo recuerda con respeto y amor.» ${ }^{447}$ El texto que llegó a las aulas no contemplaba mayores concepciones sobre los indígenas, sólo un largo detalle de sus características, es por eso, que hemos vuelto a revisar otros textos para apreciar su impresión de los indígenas chilenos en su Historia General.

Sobre sus ideas filosóficas y antropológicas de los indígenas menciona que los antiguos habitantes del territorio eran «inhábiles para procurarse los recursos que proporciona la civilización por imperfecta que sea, incapaces de vencer las dificultades que a su desarrollo oponían las condiciones climatológicas del territorio, vivían repartidos según las leyes impuestas por las condiciones del mundo exterior» ${ }^{448}$. No les reconoce ninguna aptitud a los aborígenes chilenos, prosiguiendo con los relatos de sus antecesores, en términos del escaso desarrollo que poseían, según Barros Arana. La explicación de por qué los indígenas no habían alcanzado niveles superiores de cultura y civilización por su abandono al trabajo expone que dichas tareas «exigían cierta previsión y un desarrollo intelectual del que carece el hombre salvaje, y que no poseían los más antiguos de Chile de que hay recuerdo en la historia» ${ }^{449}$. Y finalmente se pronuncia sobre una idea presente entre los intelectuales europeos y americanos sobre el buen salvaje, la idea que las sociedades están encaminadas al desarrollo y estadio cultural superior pues todos deben transitar «la desesperante lentitud de la más espantosa barbarie al estado de la civilización relativa en que hoy los vemos en las sociedades más adelantadas luchando siempre por el progreso para realizar los destinos de la humanidad» ${ }^{450}$.

Para Barros Arana, como para otros ya citados, los indios eran diferentes a los chilenos, miembros de otra raza y considerados enemigos, bárbaros, autores de tanta desgracia, y es por ello que el indio heroico quedó relegado al poema épico de Alonso de Ercilla, La Araucana $^{451}$, y en la fantasía popular. De vez en cuando hay elogios a los indios mapuches por su valentía en casi todos los escritos del siglo XIX representados como

\footnotetext{
${ }^{447}$ Ibidem, pp. 221-222.

${ }^{448}$ BARROS ARANA, Diego, Historia General de Chile I, Barcelona, Red Ediciones, 2016, p. 61.

449 Ibidem, p. 61.

${ }^{450}$ Ibidem, p. 75.

${ }^{451}$ La Araucana, Santiago, Imprenta Cervantes, 1888.
} 
defensores simbólicos de la autonomía y libertad, pero, tal como lo establecía un personaje coetáneo de Barros Arana que de «ahí a presumir como lo hicieron los próceres de la Independencia, que nuestras raíces están en él hay una gran distancia» ${ }^{452}$. La exclusión del indígena de los relatos de la nación fue evidente en el sentido que no forman parte de la Historia de Chile. Barros Arana contribuyó a profundizar la grieta entre los indígenas y las élites dirigentes de la naciente República. Los indios ausentes de la historia y estigmatizados como bárbaros que se oponían al progreso fue una obra atribuida a los historiadores del siglo XIX sin exclusión. La denominación usada por Barros Arana para referirse a los indios como salvajes eran conceptos e ideas contrarias a las ideas liberales de progreso, civilización y crecimiento. Era la asociación clásica discursiva de oposición entre civilización y barbarie. Aun cuando cumplan con los requisitos altamente valorados en la Independencia, de resistencia y heroísmo, fueron adjetivos que se anularon con su ignorancia y barbarie. El concepto de salvaje empleado por Barros Arana se asocia a la memoria de la independencia sustentada por los liberales, en la que «la imagen del indio era una imagen fraterna al enemigo español» ${ }^{453}$. La situación del indígena en los relatos históricos es rápidamente reemplazad por ubicar a los indios en el bando de los españoles.

Sobre la independencia, nuestro autor participa de la idea de la poca probabilidad que en una colonia pobre y menos preparada como la chilena se haya desarrollado un movimiento emancipatorio. En esto apreciamos el discurso chileno de la excepcionalidad y de la originalidad, ya que «ninguna era más pobre y atrasada; y, sin embargo, su revolución se hizo con bastante orden y una vez alcanzada la Independencia, Chile se adelantó a todas sus hermanas en la regularización del gobierno y en el establecimiento del paso bajos sólidas bases» ${ }^{454}$. La reflexión barriana otorga importancia a los pilares sobre los cuales se asienta el Estado moderno: estabilidad política y singularidad han sido parte integrante del relato preponderante en los estudios

\footnotetext{
${ }^{452}$ ERRAZURIZ, Crescente, Historia de Chile sin gobernador 1154-1557, Santiago, Imp. Universitaria, 1912, pp. 420-421.

${ }^{453}$ NARVAJA de ARNOUX, Elvira, «Discurso pedagógico y discurso político en la construcción del objeto Nación Chilena. El Manual de Historia de Chile de Vicente Fidel López», Cuadernos de Recienvenido, $\mathrm{N}^{\mathrm{o}} 22$ (2000), p. 42.

${ }^{454}$ BARROS ARANA, D., Compendio elemental de Historia..., op., cit., p. 401.
} 
acera del siglo XIX que sin duda son herederos de la historiografía liberal -positivista del siglo XIX. Barros fija una de las explicaciones paradigmáticas de la historia de Chile al convertir la pobreza y el desamparo como virtudes y razones para que se haya concretado el proyecto republicano, ya que esto hizo que Chile «recibiera una herencia menor de vicios y de corrupción, y de que, al constituirse en República independiente, se viera libre de muchas de las llagas que han demorado la organización de los otros pueblos del Nuevo Mundo» ${ }^{455}$. Ha existido consenso historiográfico en que el caso chileno por su éxito comparativo se haya debido a la conciliación entre tradición y modernidad y que el paso de colonia a república haya sido uno de las más suaves del continente. Las secuelas por las guerras de Independencia resultaron menos graves en Chile que en el resto de Latinoamérica. Barros Arana será uno de los historiadores del siglo XIX que inaugura la idea que en Chile hubo caudillismo, regionalismo e inestabilidad política pero que duraron relativamente poco y no produjeron efectos negativos perennes. Tampoco hubo rebeliones sociales y la autonomía nacional no se vio amenazada a lo largo del siglo y el grupo que ascendió al control del nuevo estado en las primeras décadas sería el mismo a fines de aquel siglo.

El discurso historiográfico de Barros Arana sostuvo que la independencia creó un nuevo orden que reemplazó al orden colonial español y que esa transición rompe con el pasado pero que logra mantener en el poder a las viejas elites tradicionales, lo que redundó en una ruptura sin grandes sobresaltos y menos grandes convulsiones sociales y políticas. Cuando indagaba en quienes recayó la responsabilidad de conducir la Emancipación del Imperio y el triunfo de la causa se debe a que «(...) la Revolución no tenía más que conquistarse el apoyo de los grandes propietarios, en cuyos corazones existía el amor a la patria (...). Era pues necesario guiar estos instintos de descontento; y esta fue la obra de algunos espíritus superiores $(\ldots){ }^{456}$. Otra explicación original y muy extendida a lo largo de la historia de la historiografía chilena es que el proceso de Independencia se logró por la presencia y capacidad de los miembros de la elite y por sus altos grados de consenso, en esto también Barros Arana es el demiurgo pues la Independencia se habría

\footnotetext{
${ }^{455}$ Ibidem, p. 401.

${ }^{456}$ Ibidem, p. 402.
} 
llevado a cabo «casi siempre con orden. La anarquía popular, el desenfreno de las masas, no se hicieron sentir nunca. Hombres de un rango superior fueron los directores del movimiento revolucionario» ${ }^{457}$. Las razones sobre la temprana consolidación de Chile como estado nacional las explica por medio de la tranquilidad de Chile: O’Higgins gobernó en paz seis años consecutivos (1818-1823). La explicación de este hecho se encuentra en el carácter tranquilo y laborioso del pueblo chileno, y en el sistema de gobierno adoptado por el Director Supremo. O’Higgins gobernó por si mismo o con la ayuda de cuerpos deliberantes de reducidas facultades, de tal modo que la suma del poder público residía casi exclusivamente en sus manos. En el exterior alcanzó a hacer de Chile, que hasta entonces había sido la colonia más pobre y atrasada de la España, el pueblo más respetado a la vez que el más influyente de la América del Sur.

Los epítetos avanzan de la excepcionalidad a constituirse en ejemplo para proseguir con el panegírico a la figura de O’Higgins pues «trabajó un celo vigoroso por el desarrollo material y moral de la nación (...) O’Higgins gobernó con moderación y templanza, administró los escasos caudales del estado con una economía casi constante y ejecutó verdaderos prodigios con muy mezquinos recursos» ${ }^{458}$. Acerca de mejores sistemas político es enfático en aseverar que todavía la sociedad no está madura para regímenes democráticos plenos y para ello utilizó la figura del Director Supremo para evidenciar la sensibilidad compartida por la elite chilena y es que el propio O’Higgins «había llegado a convencerse profundamente (...) creía al mismo tiempo que la verdadera república no podía plantearse de repente, y que era menester esperar que el tiempo y la educación del pueblo permitieran establecer un sistema de libertad franca y sólida» ${ }^{459}$. En la caída del gobierno de O'Higgins destaca la entereza y la grandeza del Director para dejar el cargo y no llevar a Chile a una guerra civil. Cuando O'Higgins es conminado a presentarse a una Asamblea para que diera explicaciones que terminaron finalmente con su renuncia, describe la escena como una memorable reunión en que el prócer «conservó esa digna entereza que poseen los hombres que por largos años han contado con el respeto y amor

\footnotetext{
${ }^{457}$ Ibidem, p. 402.

${ }^{458}$ Ibidem, pp. 441-442.

${ }^{459}$ Ibidem, p. 442.
} 
del pueblo; pero no queriendo luchas más tiempo contra tantas resistencias, entregó el mando de que estaba investido a una ajunta de gobierno» ${ }^{460}$. La renuncia de O’Higgins se presentó como un gesto del mandatario en pos de evitar una mayor confrontación indagó poco en las razones que llevaron a la salida del Director.

Barros Arana es un relator homérico, en el sentido de haber escrito pasajes de la historia chilena que han quedado inscritas a fuego, pues cuando la independencia se consolidó, a pesar que Chile era una colonia muy pobre, «pasó a ser una república independiente, que, más feliz que casi todas sus hermanas (...) y para alcanzar a un grado de prosperidad que sin duda no se imaginaron los padres de la Independencia» ${ }^{461}$. La idea de Barros Arana compartida por toda la historiografía liberal era que Chile fue un caso excepcional de estabilidad política durante más de seis décadas desde 1830. Las características que habrían favorecido la quietud: era un territorio compacto, sin población indígena al norte del río Biobío, con la mayor parte de la población concentrada en la zona central del país, un poder político consensuado y aceptado y sin asonadas regionalistas.

Las consideraciones de Barros Arana se han mantenido incólume en la historiografía más contemporánea: Simon Collier y Julio Pinto son buenos ejemplos de esa permanencia. El primero -en colaboración con William Sater- estableció que la estabilidad chilena se debió a una estructura social simple que «no se vio complicada por agudas divisiones de intereses económicos en el interior de la clase alta. Tampoco la diversidad regional tuvo mucha significación» ${ }^{462}$. El segundo, Julio Pinto, aseveró que a pesar de algunas distracciones federalistas o regionalistas terminó por imponerse con «relativa facilidad la idea de unidad en torno a un gobierno central, con poderes y facultades para decidir el futuro de Chile desde la capital (...) el sistema unitario se impuso sin mayor dificultad ${ }^{463}$. De todas formas, en la elite chilena hubo una idea temprana de forjar la nación y de considerar a Chile como un destino diferente a otras

\footnotetext{
${ }^{460}$ Ibidem, p. 443.

${ }^{461}$ Ibidem, pp. 444-445.

${ }^{462}$ COLLIER, Simon y SATER, William, Historia de Chile 1808-1994, Madrid, Ed. Cambridge, 1998, p. 57.

${ }^{463}$ La formación del Estado y la nación ..., op. cit., p. 95.
} 
comunidades hispanoamericanas. A la autonomía fue una decisión sin retroceso y es claro que los sectores elitistas concibieron desde fechas tempranas con intereses no enlazados con otras regiones. Estos intereses sumados a los conflictos bélicos facilitaron la construcción y estabilidad del país.

La idea de educar para forjar la nación y fortalecer el Estado fue un tema preponderante en Chile y en forma bastante anticipada bajo un modelo e inspiración jerárquico puesto que «la educación, las leyes y las costumbres jamás deben contradecirse. También es igualmente cierto: que en todos los estados las costumbres del pueblo se conforman a la de sus jefes» ${ }^{464}$. Las explicaciones históricas de las singularidades del caso chileno fueron dadas porque los sectores económicos chilenos poseían una cohesión y homogeneidad y controlaban el agro, la minería y el comercio con lo que imposibilitaron la aparición de fuerzas sociales diferentes al proyecto unitario. No existieron elites regionales que disputaran el poder y control del Estado a las elites nacionales.

Barros Arana subrayó que la construcción del Estado nacional se debió a la acción de una elite minoritaria, cohesionada con los mismos intereses económicos que comprendieron la necesidad de controlar mediante el Estado. La diferencia fundamental con el resto de América Latina es que desde el inicio se trazó una coalición al interior de la elite que diluyó todas las facciones sectoriales y regionales.

De las fuentes que emanan de las instituciones educativas, os manuales escolares son de gran importancia para el estudio de la formación de las identidades nacionales. En ellos queda vaciada las concepciones históricas que han tenido aquellos que detentaron y detentan el poder. La escuela es un lugar de socialización y de formación de nacionales y de ciudadanos $\mathrm{y}$, por consiguiente, la elaboración de textos es fundamental, ya que en ellos están expresados los valores de la elite dominante. La razón de porque ocurre esto, encuentra asidero en la idea que el conocimiento y su difusión están imbricados con el poder y que, en cada período de la historia, los que tienen el poder, distribuyen y

${ }^{464}$ Ibidem, p. 114. 
legitiman ese conocimiento de la mejor forma que les parece. Los historiadores y los fabricantes de textos escolares en el siglo XIX son los mismos estaban insertos en relaciones de poder. La cuestión fundamental no es ¿qué es el pasado? o ¿qué es la historia?, pareciera ser que el asunto fundamental es ¿para quién se escribe la historia? En esto hemos tomado la reflexión del historiador inglés Keith Jenkins cuando señala que: «(...) la historia es un discurso cambiante y problemático, que aparentemente trata sobre un aspecto del mundo, el pasado; este discurso es producido por un grupo de trabajadores (historiadores)... cuyos productos, una vez, puesto en circulación, están sujetos a una serie de usos y abusos que lógicamente son infinitos, aunque en realidad, por regla general, se corresponden con las bases del poder que existen en un momento dado $(\ldots) . »{ }^{465}$

Hemos estudiado los contenidos de manuales de historia conscientes que la cobertura y la mala distribución hicieron difícil que estos fuesen conocidos por la mayoría de los estudiantes del siglo XIX. Los hemos analizados a nivel de contenidos para percibir las representaciones de la identidad nacional de la elite, las representaciones de los otros (indígenas), los hechos históricos que fueron evaluados como importantes, la visión que tenían acerca de los personajes en la historia, la autoimagen que tuvieron de Chile y como esas eran trasmitidas por medio de la escritura a los niños y jóvenes.

\subsection{La representación de la Geografía en los textos escolares del siglo XIX}

La Historia junto a la Geografía han sido disciplinas escolares que han dado soporte a las identidades nacionales. La Geografía reprodujo por medio de los mapas, las descripciones y lo lindes de las fronteras el concepto de Chile. La geografía también contribuyó a lo largo del siglo XIX a elaborar un discurso de lo nacional apegado a un territorio. Se construyeron representaciones geográficas para «construir discurso que afianzasen las correspondientes identidades y transmitiesen lealtades históricas e

\footnotetext{
${ }^{465}$ Repensar la Historia, Madrid, Editorial Siglo XXI, 2009, p. 34.
} 
idearios territoriales» ${ }^{466}$. De hecho, lo más notable hasta hoy es la defensa de las fronteras, las cuales se hicieron intocables y la unidad se convirtió en indivisibilidad.

Los textos escolares usados en Geografía tuvieron las mismas vicisitudes que los manuales de Historia, en cuanto a cobertura y distribución. Tres son las obras que interesa revisar. Curso elemental de Geografía de José Victorino Lastarria (1838), Cosmografía. Descripción del Universo conforme a los últimos descubrimientos de Andrés Bello (1848) y Elementos de Geografía Física de Diego Barros Arana (1863 con re-ediciones en 1871, 1874, 1881, 1888, 1900). Estos autores fueron los más usados en las escuelas públicas chilenas del siglo XIX. Podemos afirmar, sin embargo, que dichos autores, a la luz de los contenidos contemplados en sus textos corresponden a intenciones y contenidos muy diversos.

El Manual de Andrés Bello es un texto puesto en el estudio del Universo con temas que van desde las primeras nociones de la tierra, del sol, de la luna, cometas, estrellas hasta el calendario. Es una exposición completa y detallada del espacio geográfico al amparo de una explicación cosmográfica y astronómica. Bello refiere en la presentación del texto que espera que sea de gran utilidad para todas las personas que quieren conocer las maravillas del universo y lo concibió como un texto básico a la manera de un «curso de cosmografía bastante elemental para la juventud de nuestros colegios, me lisonjeo, con todo, de que podría servir a los profesores que no hayan hecho un estudio especial de la astronomía (...)» ${ }^{467}$. Escribió el Manual conforme a los últimos descubrimientos y en quince capítulos estudió la forma, dimensiones y movimientos de la Tierra, el Sol, la Luna, los planetas y las estrellas. Más aún, disertó sobre la gravitación universal, los cometas, los aerolitos y, finalmente, sobre el calendario, exponiendo los métodos para el cálculo de la fecha de Pascua. Utilizó la literatura científica más actualizada de la época, como por ejemplo las obras del inglés John Herschel, del francés François Arago y las revistas Foreign Quarterly Review y Nautical Almanac.

\footnotetext{
466 PEREZ GARZON, Juan, «¿Por qué enseñamos Geografía e Historia? ¿Es tarea educativa la construcción de identidades?» ..., art. cit., p. 45.

${ }^{467}$ Cosmografía o descripción del universo conforme a los últimos descubrimientos, Santiago, Imprenta La Opinión, 1848, p. 38.
} 
Las materias contenidas en su Cosmografía no sólo eran de naturaleza científica, sino que también dan cuenta de la visión que tenía Andrés Bello de política, educación, orden social, leyes y el rol del conocimiento en la sociedad. El libro expone la realidad de la naturaleza del cosmos y sobre el imaginario social. Uno de los conceptos más importantes en el siglo XIX es la noción e ideario de «Progreso» y cuando refiere que el cronometro que no señala exactamente el tiempo, esto se puede corregir mediante la técnica y la tecnología porque «los progresos de las artes han llegado a perfeccionar de tal modo este precioso instrumento $(\ldots) »^{468}$. Las ideas de Bello sobre los adelantos en materia tecnológica representan la mejora de la perfección humana y un conocimiento más certero de la naturaleza. La idea de la mejora es frecuente en su discurso puesto que «compárese los peligros de la antigua navegación con la seguridad de la nuestra, y niéguese, si es posible, las inmensas ventajas de la industria moderna» ${ }^{469}$. El manual más que dar cuenta de los componentes del universo, sino que más trata de los instrumentos y cambios tecnológicos para darlos a conocer. En todo caso, el progreso entendido como ideario político del siglo XIX es asumido como «una visión del futuro que reemplazase el pasado, y que fuera cualitativamente mejor $(\ldots)\rangle{ }^{470}$ era la forma de comprender el tiempo que se vivía, principalmente por los avances técnicos y tecnológicos que tanto entusiasmo e impacto provocaron en dicho siglo. Era ese espíritu el que estaba recogido en la obra de Bello.

Otros conceptos abordados en su Cosmografía fueron la idea de nación y civilización. La idea de civilización estaba en Andrés Bello asociada al uso de los recursos técnicos y tecnológicos, especialmente el uso del calendario, la medición del tiempo era un rasgo de la modernidad decimonónica, refiriéndose al año equinoccial indicaba que este «año se llama equinoccial, porque se mide por la vuelta del sol al equinoccio de Aries, y civil, porque es el que sirve para la medida del tiempo en las naciones civilizadas $\gg{ }^{471}$. La idea y uso del calendario lo ligaba a la antigua Roma en virtud del republicanismo y con el mundo cristiano occidental, ya que «según costumbre de la mayor parte de los pueblos

\footnotetext{
${ }^{468}$ Ibidem, p. 4.

${ }^{469}$ Ibidem, p. 39.

${ }^{470}$ STUVEN, A., La seducción de un orden ..., op. cit., p. 119.

${ }^{471}$ Cosmografía o descripción del ..., op. cit., p. 70.
} 
cristianos se cuentan las horas de 1 hasta 12 , principiando la primera serie a la medianoche, y la segunda a mediodía» ${ }^{472}$. Progreso y civilización junto a la apología de la técnica y los instrumentos nos indicaba que Bello dio a conocer su pensamiento respecto a sus concepciones y las existentes en su época. La Cosmografía es un tratado astronómico que evidenció el devenir científico y las concepciones propias del venezolano.

En virtud de lo anterior, en el texto de Andrés Bello podemos apreciar la visión acerca de la educación, la principal motivación al escribir la Cosmografía es justamente educacional, ya tal como lo señalaba en sus primeras páginas que «me atrevo a esperar que este trabajo será de alguna utilidad a las personas de toda edad y sexo que se deseen formar una idea de las estupendas maravillas de la creación en el departamento científico que más en grande las presenta» ${ }^{473}$. Debemos agregar que la educación astronómica revistió alguna importancia para la elite gobernante y en el diario oficial de la época se informaba que: «(...) el estudio de la Cosmografía será obligatorio para los alumnos del tercer año del curso de Matemáticas del Instituto Nacional.» ${ }^{474} \mathrm{La}$ educación astronómica era parte del curriculum, inclusive el año 1852 se fundó el Observatorio Astronómico Nacional como un establecimiento científico «destinado a suministrar datos para el adelantamiento de la astronomía práctica, y que al mismo tiempo sirviese de escuela para aprendices de esta ciencia» ${ }^{475}$. Podemos considerar que al estar inserto en el curriculum fue una materia de Estado su presencia en el ámbito escolar. La Cosmografia fue un texto con importantes referencias educativas, tecnológicas y científicas y evidenciaron -como ya se ha dicho- la cosmovisión de Bello y de su época acerca de la sociedad y el conocimiento.

El texto de Bello aborda los temas astronómicos, muy distinto en intención y contenido de los textos de Lastarria y de Barros Arana, autores que revisaremos con mayor detenimiento, dado que fueron más utilizados y se relaciona con la idea de la geografía

\footnotetext{
${ }^{472}$ Ibidem, p. 57.

${ }^{473}$ Ibidem, p. 4.

${ }^{474}$ El Araucano, jueves 29 de septiembre de 1853, p. 1.

${ }^{475}$ MOESTA, Carlos, Observaciones astronómicas hechas en el Observatorio Nacional de Santiago de Chile en los años 1853, 1854 y 1855, Santiago, Imprenta El Ferrocarril, 1859, p. 1.
} 
como parte esencial de la construcción de la identidad nacional. Estos dos autores poseían una acepción sobre la geografía que tiene matices interesantes. José Victorino Lastarria concebía la Geografía como una ciencia que:

«(...) por medio de la descripción matemática, física y política del globo terrestre, nos la da a conocer y nos suministra una idea del género humano del que formamos parte... Divídase por consiguiente en geografía matemática... y en geografía política, cuyo objeto es darnos a conocer las divisiones que han fijado los hombres en el mundo, considerando en cada una de ellas su población, costumbres, gobiernos, religiones y demás particularidades.» ${ }^{476}$

Lastarria ponía énfasis en la acción del hombre en el espacio y adscrito a la filosofía de la geografía, en cambio Barros Arana puntualizaba respecto a la geografía, «que los modernos han tomado de los griegos, significa en su etimología más literal, descripción de la Tierra. Según esta significación, la geografía no es una ciencia, un arte o una teoría: es simplemente una obra descriptiva (...)» ${ }^{477}$. Barros Arana adscrito en parte a la geografía narrativa, compartiendo la misma división que Lastarria, ubica a la geografía política como un área distinta y sobre todo poco científica. En ambas obras se apreciaba que tanto lo filosófico como lo narrativo estuvieron presente en los textos que diseñaron para las escuelas chilenas. A continuación, veremos la forma en que el discurso geográfico cooperó en la identidad nacional. Son dos aspectos que nos parecen determinantes para dicho propósito: sobre el paisaje y su excepcionalidad y el componente humano de la nación.

La elite dirigente chilena intentó explicar las singularidades y bondades de la nacionalidad por la excepcionalidad del paisaje dado que «el problema de la nación fue una de las consecuencias del proceso emancipatorio, y no una de sus causas, como argumentó hasta bien entrado el siglo XIX la historiografía chilena, uno de los fenómenos a partir de los cuales se fue construyendo una retórica de la singularidad

\footnotetext{
${ }^{476}$ Lecciones de Geografía moderna escritas para la enseñanza de la juventud americana, Valparaíso, Imprenta del Mercurio, 1846, p. 7.

${ }^{477}$ Elementos de Geografia fisica, Santiago, Imprenta Central de Mariano Servat, 1888, p.1.
} 
nacional fue el territorio» ${ }^{478}$. La idealización y exaltación del territorio nacional fue una práctica temprana en la historia de Chile en lo que podríamos denominar: nacionalización de la naturaleza, que se constituyó al menos, en lo discursivo, en una importante clave en la vinculación entre medio geográfico e identidad nacional, dado que en esos procesos la elite y luego la comunidad de nacionales le atribuye o le inventa al territorio particularidades.

En función de lo anterior, Lastarria destacó la diversidad climática, la cercanía y presencia del mar como factor moderador de las temperaturas y «el clima es muy variado, pero al mismo tiempo sano y agradable (...) hay un gran número de ríos $\mathrm{y}$ torrentes, cuyas aguas saludables y de buen gusto surcan con precipitación la superficie del territorio, fecundándolo (...) la benignidad del clima, la abundancia de aguas, las sales y demás partículas fecundantes $(\ldots){ }^{479}$. Si en la descripción halagüeña y poética de Lastarria apreciamos las bondades del clima, Barros Arana es más lacónico señalando que «no hay un país de constitución física más marcada y original que la Chile. Una larga faja de territorio que mide solo dos y medio grados de longitud en su mayor anchura (...) de una gran diversidad de climas: tales son sus características más esenciales y distintivos» ${ }^{480}$.

Lo interesante es que en el contexto del siglo XIX donde el nacionalismo se mezclaba con el romanticismo haya sido frecuente la idea que la naturaleza era excepcional, de inspiración superior y que era de carácter único y nacional. En esto creemos que el romanticismo tuvo mayor influencia sobre estos relatos del paisaje chileno. El propio Lastarria señalaba refiriéndose a que la geografía como factor de modificación de «las inclinaciones características de nuestro pueblo, porque es evidente que la latitud, la situación orográfica y en fin el aspecto físico de la naturaleza influye poderosamente no tan sólo en la organización física del hombre sino en la moral» ${ }^{481}$. Esta vinculación

\footnotetext{
${ }^{478}$ CID, Gabriel y VERGARA, Jacinta, «Representando la "copia feliz del Edén” Rugendas: paisaje e identidad nacional en Chile, siglo XIX» Revista de Historia Social y de las Mentalidades, vol. 15, No 2 (2011), p. 111.

${ }^{479}$ Lecciones de Geografía moderna ..., op. cit., p. 106.

${ }^{480}$ Elementos de Geografí..., op. cit., p. 364.

${ }^{481}$ Investigaciones sobre la influencia social de la Conquista..., op. cit., p. 116.
} 
entre territorio e identidad nacional se fomentó por medio de la educación cuyo sistema patrocinado por el Estado, cada vez mejor organizado y controlado se propagan unos sentimientos a ideales culturales pertenecientes a la nación chilena. La geografía les brinda una manera de analizar y representar la nación. La información geográfica representada mediante una prosa y retórica contribuyeron a reproducir el aprecio por el incipiente Estado nacional. Como todo texto para estudiantes y profesores poco importaba que fuera un catálogo de datos, proporcionaba una visión general de la geografía poniendo a disposición de los chilenos un instrumento concienciado de una identidad geográfica inexistente con anterioridad. La geografía, junto a su función educativa, es significativo reconocer su dimensión política e ideológica.

Cuando nuestros autores describen los ríos no se guardan calificativos positivos sobre ellos, Lastarria con su tono bucólico los retrata como aguas saludables y de buen gusto que gracias a las precipitaciones dan lugar a bosques que «mantienen constantemente en los terrenos de Chile una singular y prodigiosa fertilidad (...)» ${ }^{482}$. Barros Arana es mucho más pomposo al referirse a la zona central de Chile, ya que es «la región más rica y feraz del territorio y aún podría decirse que es uno de los más ricos y productivos del mundo entero» ${ }^{483}$. Los esfuerzos manifestados en ambos libros se caracterizaron por ser memorísticos y basadas en un verbalismo que muestran una predilección por sustentar datos y vocabulario.

La necesidad de exaltar el territorio nacional fue una preocupación de la dirigencia política chilena, dicha preocupación se plasmó en una serie de comisiones científicas y de científicos contratados por el estado para realizar estudios y registros del paisaje; y, por lo tanto, fue un elemento clave en el imaginario chileno decimonónico para explicar las singularidades de la identidad nacional. Su significado social es muy relevante. Son obras que proclamaron la existencia de un lugar dotada de cualidades de su entrono presentados de manera muy singular con una sociedad activa, diligente, ingeniosa que ha sabido y/o tiene una gran oportunidad de superar las limitaciones y sacar provecho

\footnotetext{
${ }^{482}$ Lecciones de Geografia moderna ..., op. cit., pp. 107-108.

${ }^{483}$ Elementos de Geografía..., op. cit., p. 367.
} 
de los diversos recursos existentes en el suelo, llegando a crear uno de los estados más prósperos de América Latina. En ambos autores abundan las descripciones de la flora y fauna del territorio nacional, y es muy singular cuando se refieren a los animales. En el relato predomina un énfasis en señalar que Chile no es un país tropical y Barros Arana indicaba que «son muy pocos los mamíferos indígenas de Chile. En las cordilleras del norte y del centro abundan los guanacos rumiantes de figura esbelta y que se domestican fácilmente» ${ }^{484}$. A su vez, Lastarria realizó una descripción sobre el caballo, que adquiere relevancia en la idea tan extendida en la dirigencia chilena, de lo europeizante que era y «los caballos aventajan en fuego, valor, agilidad y belleza a los de Andalucía, de cuya casta descienden, y por esto son reputados como los mejores de América; el ganado de cuerno es mayor y más robusto que el de Europa (...) las ovejas muy estimadas por sus finas y largas lanas» ${ }^{485}$. Barros Arana, al respecto prosiguió en el mismo tenor, especialmente en la idea de negar la fauna autóctona y resaltar la traída por los europeos pues estas importadas «por el hombre, los caballos, los bueyes, las ovejas, las cabras, los corderos, los cerdos, los perros y los gatos, se han propagado considerablemente: los caballos poseen generalmente una belleza de formas muy notable y una gran robustez para el trabajo» ${ }^{486}$. Si esto es concurrente, apreciamos una interesante coincidencia respecto a animales peligrosos, no obstante, siendo las «especies de reptiles muy numerosas en Chile, pero ninguna es venenosa o dañina para el hombre» ${ }^{487}$. En la misma línea, Lastarria hacía «notar que en Chile no se encuentran serpientes, animales carnívoros venenosos ni ninguna especie de los bichos que tanto molestan en otros países» ${ }^{488}$.

Las interpretaciones románticas de la nación han vinculado estrechamente la identidad nacional con el territorio, la naturaleza y el paisaje y han percibido el territorio como un recipiente del pasado en el presente, una expresión simbólica y material de la historia por venir de los grupos humanos que en ella se instalen proporcionándole un significado identitario colectivo a determinados paisajes y lugares así tenemos que la cordillera de

\footnotetext{
${ }^{484}$ Ibidem, p. 393.

${ }^{485}$ Lecciones de Geografía moderna ..., op. cit., pp. 108-109.

${ }^{486}$ Elementos de Geografia..., op. cit., p. 395.

${ }^{487}$ Ibidem, p. 396.

${ }^{488}$ Lecciones de Geografía moderna ..., op. cit., p. 109.
} 
Los Andes, el Valle central, el Pacífico, el desierto de Atacama y un largo etcétera no son sólo accidentes geográficos sino que forman parte de la nacionalización geográfica del paisaje.

Si se nacionalizaba e idealizaba el paisaje natural lo mismo ocurrió con el paisaje cultural, precisamente, la presencia del hombre en el territorio también fue nacionalizado y no cabe duda que en la comparecencia de la producción e invención de la identidad nacional en tanto sujeto nacional debía ser descrito de acuerdo a los cánones que la elite definiese. Los manuales de Geografía diseñados para ser ocupados en los colegios construyeron la idea compartida por la elite y aceptada por los chilenos: no descendemos de los habitantes existentes antes de la llegada de los españoles. La idea de la chilenidad en estos textos guarda relación con los españoles y europeos. La operación es de la siguiente manera, primero los invisibilizó pues «no hay documento ni tradición que nos enseñe cómo ni cuándo se pobló este país, de donde vinieron sus primeros habitantes o de qué raza antigua formaban parte» ${ }^{489}$. Si no hay documento ni evidencia no existen, un argumento muy propio del pensamiento liberal-decimonónico. Lastarria en la misma línea, pero con matices apuntaba que «el origen de los primitivos habitantes de Chile permanece olvidado como el de las demás naciones americanas» ${ }^{490}$. Existió un consenso generalizado que los aborígenes eran distintos a los chilenos.

Estos dos autores que venimos citando inician sus relatos sobre los pueblos originarios cuando estuvieron bajo el dominio incaico. Mientras uno de ellos valoraba positivamente la dominación, el otro destacaba la bravura de los indígenas chilenos que de todas maneras «la conquista peruana fue un bien para las tribus sometidas: sus costumbres se suavizaron y aquellas conocieron algunas de las comodidades que procura una civilización más adelantada y las prácticas agrícolas de un pueblo más laborioso y previsor» ${ }^{491}$. Lastarria destacaba la rebeldía cuando describe que «informado el Inca Yupanqui de las ventajosas calidades de cada región, intentó someterla a su imperio, y puso por obra su conquista; pero habiendo sido vigorosamente rechazado por

\footnotetext{
${ }^{489}$ BARROS ARANA, D., Elementos de Geografía..., op. cit. p. 397.

${ }^{490}$ Lecciones de Geografía moderna ..., op. cit., p. 110.

${ }^{491}$ BARROS ARANA, D., Elementos de Geografía..., op. cit., p. 399.
} 
la tribu de los promaucaes, que habitaban el país $(\ldots){ }^{492}$. Y cuando los españoles se adentraron en las tierras del sur de Chile, donde habitaba los promaucaes (mapuches o araucanos), Lastarria volvió a destacar su valentía «pero viendo los araucanos el peligro en que se hallaba su libertad, empuñaron sus armas y juraron morir antes de ser esclavos ${ }^{493}$. La novedad en Lastarria es que los nacionaliza, los llama chilenos, en esto indudablemente existió una carga simbólica, la rebeldía contra el invasor: antes los mapuches, ahora los criollos. Barros Arana, sigue otra línea de relato en la ponderación de los indígenas argumentando que hubo un mestizaje entre conquistadores e indígenas, puesto que:

«(...) solo la conquista española del siglo XVI vino a hacer desaparecer la pureza de la raza indígena de Chile ... Por otra parte, los pehuenches o araucanos, sosteniendo con una energía prodigiosa la independencia de su suelo, obligaron a los invasores a traer más refuerzos de soldados. Poco a poco, éstos se mezclaron con la raza indígena, y a la vuelta de algunas generaciones formaban entre ambos una sola raza.» ${ }^{494}$

Barros Arana estableció una distinción entre la población indígena considerando que los aborígenes al norte del río Biobío se habrían mezclado con los españoles y que al sur de dicho río, los mapuches habrían conservado su pureza y no se habrían mezclado con los conquistadores y que en esa zona vivían «encerradas al presente 30 ó 40.000 personas en un estado semi-salvaje, cultivando la tierra y cuidando sus ganados, pero cometiendo, cada vez que pueden hacerlo con ventaja, grandes depredaciones en los pueblos fronterizos» ${ }^{495}$. En ello radica la idea de Barros muy en sintonía con el pensamiento de Sarmiento de barbarie y civilización y su relato se constituyó en el cimiento sobre el cual se compuso la geografía humana de Chile con la pretensión europeizante debido a que la explicación del autor era que descontado los indígenas en número impreciso:

«El resto de la población, en número poco más de dos millones de habitantes, es formado por los descendientes de los españoles o europeos, pertenecientes por tanto, a la raza blanca o caucásica; y por la descendencia que ha resultado la

\footnotetext{
${ }^{492}$ Lecciones de Geografía moderna ..., op. cit., p. 110.

${ }^{493}$ Ibidem, p. 111.

${ }^{494}$ Elementos de Geografía..., op. cit., p. 399.

495 Ibidem, p. 400.
} 
mezcla de los europeos con raza indígena, descendencia compuesta por hombres más o menos blancos, pero marcados con los caracteres generales de la raza caucásica...todo Chile es poblado por una sola raza en que predomina el elemento europeo más o menos puro, que habla un solo idioma y que tiene creencias, intereses y aspiraciones análogas.» ${ }^{496}$

La relevancia que tuvo la geografía en la construcción del Estado nacional formó parte del plan educativo como factor del progreso, por medio de ella se lograrían buenos chilenos y buenos trabajadores. A ello segregó la profunda admiración por Europa y lo «europeo caló, también muy hondo, en la conciencia de nuestros grupos dirigentes. Poco a poco fuimos asumiendo una actitud de imitación que se traduciría, muy pronto, en un sueño largamente acariciado: ser en América un rincón de Europa» ${ }^{497}$. La presencia de la geografía en la escuela se debió a que el territorio fue una de las primeras cuestiones que interesó a los grupos que dirigieron la República. En ese sentido el interés estuvo dado por la conveniencia de conocerlo y de la necesidad de tomar posesión, pero interesó de sobremanera más que el territorio propiamente tal, sino que la población que lo ocupaba, importaba el contenido, o sea, la población que daría forma a la nación.

La población en el territorio era el tema central, pues la única manera de ejercer control sobre ella era activando el proceso de construcción de la nación, y, por lo tanto, hubo que transformar a los pobladores en chilenos, en vasallos del rey a fieles servidores de la patria, había que acelerar el proceso hacia la comunidad política e imaginada. La idea era construir una única nación, verdadera obcecación de la clase dirigente, nación a la cual se pretendió incorporar a los indígenas y a todos los pobladores del territorio, hayan o no nacido en el territorio. Para acelerar ese proceso se recurrió a diversos recursos, entre otros a la educación.

La importancia de la enseñanza de la geografía en la escuela en el siglo XIX radicaba en su carácter utilitario. La idea más común era la de conocer dimensiones, ubicación, riquezas del suelo patrio y que su estudio posibilitaba la formación de una idea sobre la historia natural del país. La enseñanza de la geografía apoyada en los textos de Lastarria

\footnotetext{
${ }^{496}$ Ibidem, p. 400.

${ }^{497}$ PINTO, J., La formación del Estado y la nación, y el pueblo..., op. cit., p. 96.
} 
y Barros Arana principalmente tuvieron como objetivo el fortalecimiento de la nacionalización simbólica y concreta del territorio exacerbando la identidad y el paisaje nacional.

Los contenidos estipulados en los manuales escolares del siglo XIX refieren al avance que tiene las disciplinas y también mostraron las intenciones del Estado chileno de imponer una visión conforme a los intereses del momento que geográficamente fue una visión positiva del territorio nacional. Se enfatizó lo positivo de otras culturas, tanto la incaica por haber enseñado la agricultura como la española por habernos conectado con Europa. Afirmamos que la elite liberal, declaró su interés e insistencia por difundir una cultura geográfica, en donde los niños y jóvenes no sólo debían aprender los contenidos geográficos, sino que debían valorarlos con la finalidad de la construcción del sujeto nacional que Chile requería. La geografía desempeñó un papel importante en el proceso nacional y para eso «la naturaleza debió ser dotada de sentimiento (...) ser transformada en paisaje. La territorialidad física debió ser desplazada por una territorialidad sentimental» ${ }^{498}$. Hubo que cambiar la imagen, de colonia pobre, violenta y precaria para transformarla en el ideal republicano de progreso, orden y estabilidad sintetizado en la frase del himno nacional: la copia feliz del Edén. Es por ello, que las geografías con la cartografía fueron imprescindibles para demarcar el territorio frente a los países vecinos, y fueron de gran utilidad para la creación de una conciencia nacional.

Los textos escolares utilizados en Chile en el siglo XIX mostraron con claridad meridiana las concepciones de la elite representado en las siguientes aseveraciones: la independencia como hito fundante de la República, el Imperio español que trajo la civilización, la excepcionalidad política, geográfica y étnica de Chile como factores de la consolidación temprana del Estado y sus instituciones. Todo lo anterior habría facilitado el triunfo de la nación en las dos guerras que se libraron en ese siglo: Guerra contra la Confederación Perú-boliviana en 1837 y la Guerra del Pacífico en 1879.

\footnotetext{
${ }^{498}$ VERGARA, Jacinta, «Desde el bastidor al imaginario nacional: Rugendas y la representación de la identidad chilena» en CID, G. y SAN FRANCISCO, A. (editores) Nación y Nacionalismo en Chile..., op. cit., p. 146.
} 
Si bien es cierto, que el Estado chileno puso en circulación una serie de mecanismos para crear una cultura nacional y los gobiernos claramente después de los años 30 del siglo XIX, por medio de escuelas, curriculum y pedagogía cívica estableció contenidos y cánones que contemplaba dicha la nación chilena. No sólo contempló contenidos clásicos de la enseñanza, sino que también los elementos de la nación y «en los silabarios, libros de lecturas, clases de gimnasia, educación musical aparecieron juegos tradicionales, liras y payas, comidas, cantos, bailes y paisajes de distintas regiones, así como el prototipo nacional popular: el huaso, campesino y el "roto" urbano»" ${ }^{499}$.

En el siglo XIX se construyó la imagen de Chile por parte del Estado y en el siglo XX la sociedad se apropió de la imagen. La elite y el Estado decimonónico socializaron por medio de las «imágenes» la idea de la nación cuyas «imágenes» tenían un poder y facilidad de asimilación por los diversos sectores de la sociedad, los cuales fueron utilizados como medio de adoctrinamiento. La nación requería símbolos y relatos en pro del proyecto político hegemónico del Estado y la elite que buscaban el orden, la unificación de la población, la cultura y la economía dentro de los límites nacionales. La homogeneización y racionalización de la idea de nación se realizó mediante un programa ideológico y discursivo basado en cánones europeizantes, occidentales, cristianos asentados en la singularidad y excepción de un territorio.

Los estados nacionales surgidos como consecuencia de los fenómenos de modernidad permitieron que la fusión Estado-nación operara exitosamente, pues configuró la unificación territorial y la centralización plasmada en una sola entidad, un solo Estado, una cultura, una nación y un solo grupo étnico. La construcción de lo nacional emergió desde la elite y se difundió con ayuda de mecanismos como la educación, la literatura y los símbolos patrios, y que, pese a las diferencias étnicas, religiosas, de clases y de cultura, el Estado chileno logró fundar una comunidad imaginada que se vio favorecida por un Estado ordenado, centralizado y burocrático. Este programa «se extendió a todo el país por medio del sistema educativo y los rituales cívicos» ${ }^{500}$. La consolidación del

\footnotetext{
${ }^{499}$ SERRANO, S. «Enseñanza de la Historia e identidad nacional ...», art. cit., p. 216.

${ }^{500}$ FLORESCANO, Enrique, Estado, etnia y nación, México, Ed. Taurus, 2001, p. 439.
} 
estado chileno después de 1830 sentó las bases de la difusión e inculcación efectiva de la idea de nación. La fractura del orden colonial había originado la búsqueda de un nuevo orden que fuese capaz de contener la diversidad cultural y geográfica, la heterogeneidad social, esta aspiración cristalizó en un proyecto de modernización ligado estrechamente a la construcción del Estado nacional chileno.

Las independencias en la mayor parte de los países desprendidos de los imperios europeos no debieron esperar muchos años para la cristalización del proyecto, ya que, debían fraguarse ciertas condiciones como: Estado fuerte y centralizador, articulación de los consensos en las elites en torno a un proyecto de nación que superase la diversidad existente. La independencia de la América española produjo la ruptura y desmembramiento del extenso y poderoso imperio que había construido Castilla. La independencia de España promovió en la mayoría de las nuevas republicas largos períodos de inestabilidad, guerras civiles y luchas de caudillos que impidieron el establecimiento de estados y gobiernos firmes y duraderos. En las colonias hispanas de América hubo inestabilidad debido a la «ruptura de los antiguos factores de unidad y estabilidad: obediencia a la Corona, poder de la iglesia, existencia de un aparato burocrático que operaba sin oposición en base a normas jurídicas (...) y, por último, los principios de legitimidad política y social que eran aceptados por los grupos dirigentes» ${ }^{501}$. La disgregación del Imperio español tuvo por consecuencia no sólo la separación entre españoles y americanos sino también la ruptura de la unidad americana, al disgregarse no ya en cuatro reinos, sino en numerosas repúblicas. La construcción y difusión del Estado nacional comenzó con claridad y tranquilidad en la segunda mitad del siglo XIX, y se propagó con el patrocinio del liberalismo hasta las primeras décadas del siglo XX.

El caso chileno llama la atención por su particularidad. Una colonia pobre y alejada geográficamente pudo crear con sorprendente rapidez, un sistema político basado en un estado de derecho, cuyo gobierno estaba sometido a normas y plazos con un período de dos décadas después de la independencia de inestabilidad, y que desde 1830 se

${ }^{501}$ SEPULVEDA, Alberto, «La formación del Estado...», art. cit. p. 244. 
constituiría en una república bastante estable. En ese proceso de construcción nacional la elite se sirvió de una serie de mecanismos y componentes que ampararan el proyecto político de la nación controlando y ordenando todas las fuerzas centrípetas que constriñeron a la nueva república. En el plano cultural, la escuela y los ritos cívicos ayudaron a la construcción de una «cultura nacional» compartida y homogénea. Este proyecto fue capaz de contener las distensiones y controlar todo aquello que no se consideraba parte de la nación.

En el ámbito de la escuela fue donde la intelligentsia integrada por escritores, novelistas, periodistas, historiadores, cronistas y profesores fueron centrales en la construcción de la identidad nacional actuando como movilizadores de los sentimientos nacionales. Clave en esta situación fueron los historiadores que en su mayoría fueron profesores del Instituto Nacional, ministros de Estado o parlamentarios. Estas personas fueron las que manejaron y articularon conocimiento, compendiaron ideas, sensibilidades y aspiraciones colectivas para el proyecto emanado desde el Estado. Con ellos las sensibilidades nacionales adquirieron un marcado signo historicista dada su propensión por interpretar los fenómenos y sucesos como producto de un encadenamiento de hechos que, a su vez, develan identidad y pautas identitarias. Las explicaciones históricas de la construcción de la nación, y de la unidad nacional, fueron producidas, emanadas y difundidas por las historiografías nacionales que desempeñaron el papel de conectar las narraciones con la invención de la tradición. Los relatos narrados en la esfera pública y en la escuela produjeron una densidad temporal que llenaba lo que faltaba y legitimaron políticamente la idea de nación e identidad nacional. La base fundamental de la explicación de la existencia de la nación era el pasado, fuese éste por continuidad o ruptura.

En Chile se dio la coincidencia que la historia y la geografía junto a las instituciones como la escuela fueron mecanismos desenvueltos para anunciar el anhelo sobre la nación como una comunidad de ideas compartidas sobre un pasado y un presente común. Esto permitió otorgar carta de nacionalidad a unos individuos que no la tenían y esto se hizo por la presencia de historiadores que como hombres públicos con sus lazos 
con el Estado y el poder construyeron intereses e imaginarios nacionales, y, por lo tanto, fueron actores relevantes del proceso. Son ellos los que se preocuparon por el rol que desempeñaba el pasado colonial hispano como oposición o continuidad de los nuevos estados, pusieron en los altares de la patria a los héroes, el lugar de los pueblos originarios, el origen de las poblaciones, las peculiaridades del territorio, y la incorporación o defensa del espacio geográfico.

Así las cosas, en Chile la naturaleza del Estado nacional corresponde a la construcción de la nación desde el Estado y si bien, la escuela fue acrecentado su cobertura a lo largo del siglo XIX, no podemos sostener que los discursos y relatos nacionales hayan llegado a ser escuchados y leídos masivamente. Consignando además que la asignatura de Historia y Geografía estaban en enseñanza Secundaria y de acuerdo a nuestros datos la cobertura en secundaria era de un $4,23 \%$ y «de estos un $2 \%$ terminaba la escuela, es decir, cursaba el último año en el que se enseñaba Historia de Chile» ${ }^{502}$. Es presumible que estos niños tuviesen contacto con lo nacional no en la enseñanza de la Historia antes de 1882, sino que la escuela fue el lugar donde se representaba la nación por medio de actos y celebraciones patrias junto a una serie de alusiones de la chilenidad. A nuestro juicio la escuela ocupó un lugar interesante, pero no determinante en la difusión de lo nacional, y su lugar junto a la enseñanza de la Historia es parte de un conjunto de dispositivos que el Estado nacional chileno dispuso para la concreción del proyecto. La huella más relevante es la que encontramos en los textos no en términos de su uso, sino en términos de sus relatos. Estos textos lograron impregnar los grandes sistemas simbólicos sobre los cuales se construyó la identidad nacional y parte importante del modelo educacional chileno.

$\overline{502}$ SERRANO, S., «Enseñanza de la Historia e identidad nacional...», art. cit., p. 213. 
3.7 Urbanidad y formación de la ciudadanía chilena en los manuales generales y escolares

\subsubsection{Los manuales de Urbanidad en la formación del ciudadano chileno}

A mediados del siglo XIX en el marco de la consolidación del Estado nacional, la enseñanza de la Historia, la Geografía, los cursos de Urbanidad y la Educación Cívica fueron ejes centrales de la legitimación y conservación del orden. Por intermedio de estas asignaturas se reforzó la identidad nacional, la memoria colectiva, las nociones de ciudadanía, los deberes y derechos de las personas, las instituciones estatales, el amor a la patria, el valor del trabajo, la higiene y las buenas costumbres.

La enseñanza de la Urbanidad y lo Cívico fue destacado por su carácter civilizador y formador de costumbres que debían tener las personas para el desarrollo de la sociedad. El Estado por medio de la escuela planteó que los estudiantes deberían aprender en forma colectiva con textos escolares, de modo que la escuela se dirigió a normalizar las prácticas escolares y sociales, ya que «los horarios y desplazamiento de los alumnos fueron normados, se buscó cambiar la forma de expresarse y relacionarse, descalificando las formas populares que ellos tenían y que correspondían a sus vivencias cotidianas» ${ }^{503}$. La lucha por civilizar a la población constituyó una prioridad en muchos de los miembros de la elite chilena que sostenían que debían reformarse las costumbres y superar el retraso de la población.

La intención de incorporar en la escuela estos temas fue para modificar los aspectos que la elite consideraba nefastos en las costumbres de los chilenos. El modelamiento de las costumbres se favoreció por el potencial proporcionado a la escuela como formadora de conciencias y constituyó parte fundamental del discurso civilizador, ya que por medio de la instrucción elemental se materializaba en los niños y los jóvenes la apropiación de valores morales, sociales y el gusto por el trabajo. En el sistema educativo se normalizaron gestos, actitudes y valores sociales asociados al nuevo modelo, divulgado en cartillas, catecismos políticos, textos escolares y hasta manuales de Urbanidad.

\footnotetext{
${ }^{503}$ EGAÑA, M. L., La educación primaria popular..., op. cit., p. 144.
} 
El proyecto modernizador de los estados nacionales en el siglo XIX instituyó mundos simbólicos en la idea de generar sujetos semejantes pertenecientes a la cultura europea occidental, entendidos como organismos ajustados a un mismo patrón homogeneizador que delimitaba los espacios públicos y privados. Es por esto que los catecismos y manuales en general significaron un intento por educar para incorporarlos definitivamente al proyecto político de la nación. Podemos afirmar que en el proyecto de conformación del Estado nacional uno de los cimientos fue la modelación de hombres y mujeres que debían adaptarse al nuevo modo de vida, puesto que «por ello fue necesario diseñar un nuevo entramado cultural que condujese sobre todo a los grupos dirigentes hacia un imaginario de comunidad nacional (...)» ${ }^{504}$. El proceso civilizatorio demandó prácticas discursivas orales y escritas y una nueva moral que substituyera las antiguas formas de socialización.

La vida republicana requería de la ciudad para su cometido que traería como consecuencia una nueva sociabilidad fruto de la experiencia urbana. De esta forma, uno de los conceptos relacionados con la ciudad era precisamente, el de Urbanidad, entendida como las formas de comportamiento adecuadas para saber estar en los ámbitos públicos y privados y también como una forma de mantener el equilibrio social. Por lo anterior, es que debemos tener en cuenta que la Urbanidad constituyó un tema importante en el desarrollo cultural y político de los estados en el siglo XIX.

Los primeros tratados de Urbanidad publicados en América fueron en su mayoría traducciones de manuales franceses e ingleses, aunque intentaron integrar aspectos propios de la sociedad e historia americana. En este sentido «los textos pensados para los niños y jóvenes chilenos fueron expresión, bajo filtros de estilo y selección de contenidos, tanto de tradiciones como de perspectivas de cambio que se originaban en la literatura europea, principalmente francesa ${ }^{505}$. De esta manera, modernidad, progreso y civilización podrían ser enseñados a la población por imitación y apropiación de

\footnotetext{
${ }^{504}$ RAMOS, Johana, «Catecismos y manuales de urbanidad como recurso de acción y práctica política en Venezuela, 1830-1855», Boletín americanista, vol. 66 (2013), p. 167.

505 TORO, Pablo, «Dimensiones de la confección de una juventud virtuosa: manuales de urbanidad en Chile (c.1840-c.1900)», Universum, No 27 (2012), p. 195.
} 
costumbres y formas de las culturas francófonas, germanas y anglosajonas que al mismo tiempo debían ser cristianas, industriales y modernas. El proyecto educativo fue instruir en el estilo europeo. Estos textos representaron un referente obligado sobre las formas correctas de conducta, tanto para hombres como para mujeres para configurar los lineamientos del buen ciudadano. La función de los manuales de Urbanidad fue convenir las acciones que merecían ser aprobadas o reprobadas socialmente. La edición y reedición de estos textos fueron una evidente muestra de asimilar la cultura europea como un correctivo contra la situación de atraso cultural en que se encontraba Chile.

La educación en las costumbres coincidió con un siglo XIX en que los ideales de modernidad, progreso y civilización adquirieron fuerza en la sociedad, es por ello que la elite chilena impulsó este tipo de formación que incluyó una buena lista de comportamientos. Los sectores acomodados de la sociedad chilena en la segunda mitad el siglo XIX se plantearon afianzar su poder social y económico imitando los comportamientos de los países considerados modernos. De allí, que en la escuela se inculcaron los estándares de civilidad que favorecerían el culto a lo bello, la construcción del ciudadano modelo en las buenas formas de vestir, comer, conversar y los cánones de Urbanidad.

En Chile los manuales tuvieron el mismo fin educativo y moral que en el resto del mundo con los elementos de la religiosidad cristiana caracterizado por el padre afectuoso, el hijo disciplinado, la esposa fiel y el hombre útil a la patria. En general, estos textos contemplaron tres asuntos: deberes con Dios, deberes individuales y deberes con la patria. Existió correspondencia entre el discurso religioso con el político dado que los manuales señalaban una lista minuciosa de reglas de Urbanidad y principios cívicos y morales que debían aplicarse en la vida pública y privada. Su forma discursiva era similar a un catecismo como forma de difundir las características del nuevo ciudadano merecedor de los calificativos de bien educado y civilizado. Estos manuales reposaban en el imaginario que el hombre instruido y de buenas maneras como el único que tendría éxito social. Consecuentemente, el manual poseía un fuerte poder disciplinario y fueron libros fundamentales en las escuelas siendo los profesores 
los encargados de infundir en niños y jóvenes los preceptos de la urbanidad, moral, virtud, religión e higiene. Curiosamente, buena parte de los manuales no establecieron sanciones al incumplimiento, sino relevar los verdaderos ciudadanos capaces de dar a la nación una identidad civilizada.

La difusión de manuales, cartillas, catecismos, códigos de Urbanidad, de higiene tuvieron una gran divulgación en la sociedad chilena cuya finalidad era instruir a la población en materias de cultura dado que se concibió que «el perfeccionamiento de las costumbres contribuía a estimular la felicidad y la educación en beneficio de la civilidad» ${ }^{506}$. La sociedad chilena aspiraba a funcionar enmarcada en una serie de normas que deseaban construir un tipo de hombre formado en los ideales de la educación, la moral y el trabajo como garantes del progreso social. En un manual de 1849, el autor señalaba que se había propuesto instalar en la niñez «máximas altamente morales, para que sirvan como de correctivo a la corrupción de las costumbres, que desgraciadamente cunde por nuestra sociedad» ${ }^{507}$. Los comportamientos morales se entendían como un conjunto de responsabilidades consideradas correctas y aceptadas para que los ciudadanos cooperarán en la construcción de la nueva república.

El proceso de modelamiento realizado por el Estado nacional fue ejecutado por la palabra escrita que tuvo gran poder en la sociedad chilena, a pesar de su alta tasa de analfabetismo y en donde lo escrito ostentó valor de superioridad y verdad. Por medio de la escritura «se respondía a la necesidad de ordenar e instaurar la lógica de la civilización (...) la palabra llena los vacíos: construye estados, ciudades, fronteras, modela a sus habitantes» ${ }^{508}$. Las letras requerían ser accesibles por la población con la idea de «alcanzar la modernidad y la civilización, que suponía llegar a controlar individual y colectivamente las acciones, los pensamientos, siempre desordenadas en el

\footnotetext{
${ }^{506}$ MIRANDA, Pedro, «Los manuales de buenas costumbres. Los principios de la urbanidad en la ciudad de Mérida durante el siglo XIX», Takwá, No 11-12 (2007), p. 133.

${ }^{507}$ MESTRE i MARZAL, Carlos, Consejos morales a la niñez, seguidos de las reglas de urbanidad. Puestas en verso, Santiago, Imprenta Chilena, 1849, p.4.

${ }^{508}$ GONZALEZ, Beatriz, «Modernización y disciplinamiento. La formación del ciudadano: del espacio público y privado», en GONZALEZ, Beatriz (coord.), Esplendores y miserias del siglo XIX. Cultura y sociedad en América Latina, Caracas, Equinoccio Ediciones de la Universidad Simón Bolívar, 1995, p. 435.
} 
caso de las sociedades no letradas ${ }^{509}$. Es por ello que, a partir de la segunda mitad del siglo XIX, los textos escritos adquirieron relevancia en la tarea de divulgar el ideario liberal a los sectores medios especialmente a niños y jóvenes que asistían a la escuela. El proyecto político del Chile durante el siglo XIX no sólo demandó la construcción de un nuevo Estado, sino también acciones tendientes a «racionalizar a la sociedad e incidir en los hábitos y el aspecto de sus habitantes» ${ }^{510}$. Estas acciones se realizaron por medio de un conjunto de criterios y fundamentos que regularon el comportamiento de los ciudadanos con la finalidad que se superpusieran las ideas modernas a las tradicionales. Los manuales ofrecieron un vínculo entre socialización familiar y socialización escolar que contenía un modelo de control que prescribía las conductas consideradas normales y positivas, así el manual «funciona dentro del campo institucional que despliega la autoridad del libro como la "regulación/reglamentación" de nuevas jerarquías, la sujeción cuidadosa y controlada de las subjetividades y deseos, el etiquetamiento de los impulsos espontáneos y culturales (...)» ${ }^{511}$. Los manuales funcionaron como dispositivos mediante los cuales se formaban sujetos en aras del éxito social, político y económico.

El Estado nacional requirió imponer normas a la población para que fueran cumplidas y producto de ese requisito fue que las normas de convivencia social se incorporaron en los cuerpos legislativos, códigos y decretos promulgados en los sucesivos gobiernos a lo largo del siglo XIX. Al parecer, lo coercitivo de la ley no fue suficiente, sino que fue acompañado de papelería normativa orientada a cambiar hábitos y costumbres de las personas. Dentro de la papelería normativa destacaron los textos destinados a conducir al lector a la obtención de los medios para guiarse en sociedad. La finalidad fue instruir a la población en materias de cultura, puesto que se admitía que la mejoría «de las costumbres contribuía a estimular la felicidad y la educación en beneficio de la civilidad» ${ }^{512}$ y moldear el comportamiento en pro de los procesos de modernización.

\footnotetext{
${ }^{509}$ AFANADOR, M". Isabel y BAEZ, Juan, «Manuales de urbanidad en la Colombia del siglo XIX: modernidad, pedagogía y cuerpo», Historia y Memoria, No11 (2015), p. 62.

${ }_{510}$ RAMOS, J., «Catecismos y manuales de urbanidad como recurso ...», op. cit., p. 162.

${ }^{511}$ GONZALEZ, B., «Modernización y disciplinamiento. La formación del ciudadano...», art. cit., en GONZALEZ, B. (coord.), Esplendores y miserias ..., op. cit., p. 434.

${ }^{512}$ MIRANDA, P., «Los manuales de buenas costumbres...», art. cit., p. 133.
} 
Los manuales de comportamiento también tuvieron el objetivo de normalizar la vida privada y pública, ya que no fue suficiente normar las conductas sociales, sino que se dieron a la tarea de moldear el cuerpo y la mente de cada individuo para convertirlo en un hombre civilizado. Los manuales publicados en el país estructuraron preceptos y prohibiciones en una sociedad asentada en la desigualdad y las jerarquías. Estos textos estipulaban cómo el individuo debía conocer y reconocerse dentro del espacio social que le era propio por su sexo, edad, rol social y político, suministrándole consejos sobre el modo de manejarse ante los mayores, las relaciones con las mujeres, entre alfabetos y analfabetos, entre pobres y ricos, entre superiores e inferiores. Proveían indicaciones de cómo vestirse, dirigirse a otras personas, maneras de estar en la mesa, formas de conversación, de escribir cartas, sobre lo que incumbe y los que es impropio de cada sexo. Hubo dos formas de escribirlos, primero como verdaderos manuales, vale decir, textos que son códigos de comportamiento, y segundo como libros de conducta cuya redacción en prosa o en verso incluía lecciones, parábolas, consejos y ejemplos.

Obviamente que los manuales estaban dirigidos al sector social educado, los que sabían leer y escribir, por tanto, podemos considerar que la escritura poseyó un lugar estratégico en la concreción del proyecto modernizador, pues era «una escritura que organiza la naturaleza de su propio discurso en términos de una rigurosa e interminable de tabla de reglamentos $(\ldots){ }^{513}{ }^{5}$. A partir del siglo XIX los textos y la escritura buscaron homogeneizar una cultura y en ese sentido los manuales fueron guías indispensables para apropiarse de comportamientos, maneras, modos y modas que la procedencia social no garantizaba. En una sociedad altamente analfabeta, se entendió naturalmente que los comportamientos deseados debían ser enseñados en la escuela.

Debemos destacar el hecho que la Urbanidad estuvo destinada a la elite y las clases populares, uno muy refinado y complejo para las clases altas, y otro más básico para el resto de la sociedad. En el más refinado, la familia era la principal institución encargada de transmitir las pautas de conducta mediante la imitación y para las elites la enseñanza

${ }^{513}$ GONZALEZ, B., «Modernización y disciplinamiento. La formación del ciudadano...», art. cit., en GONZALEZ, B. (coord.), Esplendores y miserias..., op. cit. p. 439. 
de la Urbanidad tenía como propósito el lucimiento y la distinción, y actuaba como mecanismo de poder y señal de las clases sociales altas. Estos aspectos estaban asociados a la exteriorización de cualidades morales que legitimaban para el ejercicio del poder. Por el contrario, la enseñanza de la Urbanidad dirigida a las clases populares respondía a objetivos de moralización y civilización y se pretendió acomodar las conductas a un código social que permitiese control y disciplina.

La escuela utilizó a la Urbanidad como un componente complementario y transversal en la enseñanza, sin alcanzar un espacio propio en el currículum, sino que más bien acompañando la educación moral y religiosa. Al no existir la asignatura como tal, la escuela fue el espacio donde se desplegaron y materializaron las intenciones del proyecto nacional «en la medida que hacía posible intervenir sobre sujetos claves, como el niño y el joven, que se conciben como futuros y potenciales ciudadanos» ${ }^{514}$ con elementos cívicos, religiosos, personales y sociales que reforzaron el amor a la patria, el culto a los símbolos y los derechos y deberes del ciudadano. En casi todos los manuales de Urbanidad predominó lo religiosos y el énfasis en la familia, la escuela, el matrimonio y las instituciones.

En Chile, para el siglo XIX, hemos logrado identificar once textos estructurados como manuales, compendios, catecismos o libros de consejos sobre Urbanidad que van desde 1847 a 1900, que estuvieron en general dirigidos a niños y jóvenes ${ }^{515}$. Es importante

\footnotetext{
${ }^{514}$ MUÑOZ, Mónica, «El ciudadano en los manuales de historia, instrucción cívica y urbanidad, 19101948», Historia y Sociedad, No 24 (2012), p. 216.

${ }^{515}$ Véase al respecto, STANHOPE, Phillipe, Preceptos de urbanidad y buena crianza o reglas para comportarse con lucimiento en la sociedad. Extracto de las cartas de Lord Chesterfield a su hijo Felipe Stanhope, Valparaíso, Imprenta El Mercurio, 1847; MESTRE i MARZAL, Carlos, Consejos morales a la niñez, seguidos de las reglas de urbanidad ..., op. cit.; Compendio de reglas de urbanidad para el uso de los colegios de la capital, Santiago, Imprenta de Julio Berlín, 1852; ROBLES, Lorenzo, Manual de moral, virtud y urbanidad dispuesto para jóvenes de ambos sexos, Santiago, Imprenta de la Independencia, 1853, Santiago, Imprenta Nacional; CARREÑO, Manuel, Manual de urbanidad y buenas maneras para uso de la juventud de ambos sexos, Caracas, Imprenta y librería Carreño, 1854; CARREÑO, Manuel, Compendio del manual de urbanidad y buenas maneras. Arreglado para el uso de las escuelas de ambos sexos, Valparaíso, Imprenta y librería del Mercurio, 1863; LASTARRIA, José Victorino, El libro de oro de las escuelas, Imprenta nacional, 1862; SUAREZ, José Bernardo, Compendio de moral y urbanidad. Arreglado para uso de las Escuelas primarias, Talca, Imprenta y litografía de los tiempos, 1890; CONSTANCIN, L.A., Manual de urbanidad para el uso de los colegios. Arreglado por un profesor del Seminario de Valparaiso, Escuela litográfica salesiana, 1900; MARTINEZ, P., Manual de urbanidad y Educación, Santiago, Editorial Puga, 1900.
} 
consignar que no tenemos cómo cuantificar el impacto que los textos pudieron tener en el conjunto de la educación impartida en la época, lo que sí sabemos es que algunos de ellos fueron reeditados varias veces, así, por ejemplo, el texto de Lorenzo Robles, en 1853 era la segunda edición del libro, el de José Bernardo Suárez, en 1890, era también la tercera edición, el de Constancin llevaba en 1900 tres ediciones y el Manual de Carreño que ha contado con innumerables ediciones desde la primera vez que apareció en Venezuela en 1853. Es posible sostener que hubo regularidad en la oferta de textos pensados en una forma de normalizar a los niños y jóvenes.

\subsubsection{Los manuales de Urbanidad y la construcción del sujeto ideal}

Los nuevos hábitos y las buenas maneras modernas se enseñaron en la escuela y los autores de los manuales entendieron que el proceso de disciplinamiento también debía desarrollarse en el espacio doméstico. Los textos que analizaremos tuvieron una estructura muy semejante en la forma y los aspectos que tratan. Casi todos tienen una breve introducción en que se presenta una definición de Urbanidad bastante compartida en los textos y los autores. Un texto de 1849 la concebía como una buena forma de vivir en sociedad puesto que «es indispensable observar ciertas reglas, para no ser tenido por rústico y mal criado $(\ldots){ }^{516}$. En este sentido, el planteamiento fue el valor utilitario de las normas de comportamiento. Otro Manual estructurado como catecismo en que la pregunta y la respuesta contenían la finalidad de la urbanidad y referido como sigue: «¿qué entiende usted por urbanidad? Respuesta: Entiendo las maneras, o acciones de comedimiento, atención y buen modo» ${ }^{517}$. La Urbanidad fue concebida como una forma de comportarse en sociedad y como garantía para conseguir hombres y mujeres virtuosos. En 1890 se definía la Urbanidad como una forma de distinguirse y «como la práctica de todas las formalidades que en el trato social ha establecido el uso de las personas cultas» ${ }^{518}$. El fundamento social y utilitario de la Urbanidad enfatizó las dimensiones instrumentales del buen comportamiento social, así como el beneficio

\footnotetext{
${ }^{516}$ MESTRE i MARZAL, C., Consejos morales a la niñez, seguidos de las reglas ..., op. cit., p. 8.

${ }^{517}$ Compendio de Reglas de urbanidad para el uso..., op. cit., p. 3.

518 SUAREZ, J. B., Compendio de moral y urbanidad. Arreglado..., op. cit., p.9.
} 
individual y es por ello que se concibieron los manuales como la manera de formar a los niños y a la juventud.

La Urbanidad fue considerada asimismo como un atributo integral que las personas debían asimilar no reconociendo límite entre lo privado y lo público. De este modo «con la misma caridad cristiana se hermana en mucho la urbanidad social, pues esta, en cuanto a los demás se refiere, nos hace considerarlos semejantes (...) contribuye por su parte a que no hagamos con otros los que con nosotros no quisiéramos que se hiciese» ${ }^{519}$. En este sentido, la Urbanidad tiene un doble propósito, por una parte, fue asociada a la tradición religiosa, por lo que las conductas sociales eran una extensión de la pertenencia cristiana y un deber con los otros. Se enfatizaba la beneficencia social pues «el bien que os hagan, tendréis grabado en el corazón: y os mostraréis generoso, muy humano y bienhechor» ${ }^{520}$ o muy parecido a lo que señalaba otro Manual: «no hagas a otros lo que no quieres que te hagan a ti; y haz a los otros lo que quisieran que te hicieran a ti» ${ }^{521}$. Los principios sociales de los manuales no entran en contradicción con las consideraciones religiosas, más bien se complementan e indudablemente lo cristiano fue la base donde se asentaron y diseñaron las pautas de comportamiento social. En Chile, los manuales tuvieron el mismo fin educativo y moral con acento religioso, pues el hombre verdaderamente religioso fue tenido por modelo de todas las virtudes: padre afectuoso, hijo obediente, esposo fiel y ciudadano útil a su patria.

La sujeción a la autoridad igualmente constituyó un elemento clave en la concepción de la Urbanidad reflejada en la diferencia de trato según el lugar que se ocupa dentro de la sociedad en donde las diferencias de condición social, edad y género fueron consideradas desigualdades genuinas, y varios de los manuales lo expresaban claramente. Sobre la condición social en un Manual de 1847 afirmaba que «no hay cosa más humillante, más provocativa y que menos se perdone, que los esfuerzos declarados para mortificar a alguno dándole a conocer que le somos superiores por el lado del

\footnotetext{
${ }^{519}$ CONSTANCIN, L.A., Manual de urbanidad para el uso de los colegios..., op. cit., pp. 16-17.

${ }^{520}$ Compendio de Reglas de urbanidad para el uso..., op. cit., p. 18.

${ }^{521}$ ROBLES, L., Manual de moral, virtud y urbanidad..., op. cit., p. 5.
} 
saber, de la preeminencia, de la fortuna, etc. ${ }^{522}$. Igual predicamento se planteaba en el de Manuel Carreño que aseveraba que «la urbanidad estima en mucho las categorías establecidas por la naturaleza, la sociedad y el mismo Dios; así es que obliga a dar preferencia a unas personas obre otras (...)»> ${ }^{523}$. Todavía, en 1890, un Manual señalaba cuestiones sobre el orden jerárquico de la sociedad pues «la sociedad ha debido establecer, y ha establecido en efecto, cierta graduación y distinciones que no podemos menos de respetar $(. .$.$) después siguen nuestros iguales y luego nuestros inferiores»» { }^{524}$. De los textos examinados solo el de José Victorino Lastarria manifestó una defensa de la igualdad «por cuanto es una condición de la perfección social que no haya excepciones, ni fueros, ni privilegios que excluyan a los unos de lo que se concede a otros en igualdad de circunstancias $(\ldots) \gg{ }^{525}$. Así los manuales de Urbanidad permitieron que las clases medias adquirieran pautas culturales de la aristocracia colonial y reelaboraron normas de conducta que, a pesar de las proclamas liberales de la equidad social moderna, prolongaron en muchos aspectos las mentalidades de Antiguo Régimen con un discurso y práctica basados en la estratificación social.

Los manuales estaban dirigidos fundamentalmente al padre y a la madre como los intermediarios para educar a los hijos en estos asuntos con una clara intención de consolidar el orden, la jerarquía y el respeto a la autoridad. Esto implicaba que los padres y especialmente las madres, asumieran el proceso de urbanización que garantizase la transmisión de los valores morales y los nuevos hábitos. En las presentaciones de los manuales encontramos comúnmente la idea de simulación de un adulto aconsejando a un niño como se lee a continuación: «no solo debes dar indicio de probidad y hombría de bien cumpliendo exactamente los deberes que te he dado a conocer anteriormente, sino que, estando destinado a vivir en sociedad, te es indispensable observar ciertas reglas $(\ldots){ }^{526}$. En otro texto de 1847 , que es una traducción de un Manual inglés que circuló en Chile, el propio título nos señalaba el

\footnotetext{
${ }^{522}$ STANHOPE, Ph., Preceptos de urbanidad y buena crianza o reglas para comportarse con lucimiento en la sociedad ..., op. cit., p. 51.

${ }_{523}$ Compendio del Manual de urbanidad..., op. cit., p. 35.

${ }^{524}$ SUAREZ, J. B., Compendio de moral y urbanidad. Arreglado..., op. cit., p.17.

${ }^{525}$ El libro de oro de las..., op. cit., p. 112.

${ }^{526}$ MESTRE i MARZAL, C., Consejos morales a la niñez, seguidos de las reglas..., op. cit., p. 8.
} 
vínculo de filiación padre-hijo, parte del título era «reglas para comportarse con lucimiento en la sociedad. Extracto de las cartas de Lord Chesterfield a su hijo Felipe Stanhope ${ }^{527}$. La noción de respeto se fundó en los códigos de las apariencias que comenzaban por el respeto a sí mismo, y reflejadas en todas las normas asociadas a la higiene personal. En un Compendio de 1852, en el tema del aseo personal, se lee: «¿cuál es la primera obligación que nos impone la urbanidad? R. Es la de ser aseados, pues de lo contrario inspiramos mala idea de nosotros mismos y faltamos al respeto debido a los demás» ${ }^{528}$. El célebre Manual de Carreño es enfático cuando afirmaba que «la benevolencia, el decoro, la dignidad personal y nuestra propia conciencia, nos obligan a guardar severamente las leyes del aseo (...)»> ${ }^{529}$.

El siglo XIX es el siglo de la higiene, una preocupación que se manifestó también en las instituciones escolares por medio de los manuales de Urbanidad e incluso incorporado en los contenidos curriculares evidenciando la clara materialización de la preocupación higienista, de disciplinar y regular todas las conductas de la sociedad. Si la escuela fue el espacio para desarrollar los aprendizajes como leer, escribir y contar, también lo fue el aseo personal considerado un acto educativo en sí mismo. El tema del aseo y de la limpieza estuvo presente a todo lo largo del siglo XIX, en 1900 el texto de Constancin se leía: «hay en el aseo (...) algo de honesto y de distinguido que anuncia el respeto de sí mismo y que es símbolo de la pureza del alma» ${ }^{530}$. El aseo personal estuvo concebido esencialmente desde una perspectiva social y moral, de algún modo, más que la limpieza corporal en sí, el niño debía cuidar su aspecto exterior los niños pues «es menester también observar estas otras reglas. Primera: ir siempre decentemente peinados y tener la cabeza limpia de los asquerosos insectos que suelen criarse en ella. Segunda. Cortarnos a menudo las uñas; de modo que en ella no se vea suciedad ${ }^{531}$. En todos los manuales de urbanidad analizados, el aseo fue contemplado como uno de los aspectos básicos del comportamiento social y con sus normas de socialización

\footnotetext{
${ }^{527}$ STANHOPE, Ph., Preceptos de urbanidad y buena crianza o reglas para comportarse con lucimiento en la sociedad ..., op. cit., p. 3.

${ }_{528}$ Compendio de Reglas de urbanidad para el uso..., op. cit., p. 3.

${ }^{529}$ Compendio del Manual de urbanidad..., op. cit., p. 49.

${ }^{530}$ Manual de urbanidad para el uso de los colegios..., op. cit., p. 17.

${ }^{531}$ Compendio de Reglas de urbanidad para el uso..., op. cit., p. 4.
} 
controlaron a los niños hasta en sus funciones biológicas. La concepción higiénica se observó no tan sólo en los manuales de Urbanidad, sino que fundamentalmente en memorias, informes, editoriales de diarios y revistas médicas como promotores de la construcción de una ciudad y sociedad sana. Un primer aspecto para promover la sanidad fue el desarrollo material donde existía una preocupación por la pureza del terreno, del agua y del aire, para disponer de una adecuada evacuación y desinfección de las aguas de la ciudad. Un segundo aspecto pasó por generar un proceso de mejoramiento educativo en las escuelas, en este sentido, surgieron distintas cartillas de promoción higiénica sobre cómo enfrentar la higiene individual y social ${ }^{532}$.

La nación moderna requirió una enseñanza sobre el cuidado del cuerpo, ya en 1847 un texto indicaba que las personas debían «ser prolijamente aseadas (...) es menester que la limpieza de sus manos, dientes y uñas, sea extremada» ${ }^{533}$. La situación de aseo personal constituía un asunto bastante importante tal como lo refiere una publicación en 1854 sobre los estudiantes: «traían mantas, cara, manos, pies mugrientos i uñas largas. Se les mandó entrar peinados, lavados de pies ya que no usaban medias, manos y caras i con las uñas cortadas. Todos los días antes de salir se hace un registro de la ropa, cara, manos, pies i peinado de los alumnos hasta que se acostumbren a este aseo.» ${ }^{534} \mathrm{El}$ desaseo constituía una mirada reprobatoria y la estricta revisión de la apariencia no buscaba exclusivamente evitar la propagación de enfermedades o infecciones, sino que era símbolo manifiesto del desarrollo de la virtud personal.

De este modo se fue estableciendo un sistema moral cuya base fue la educación y los manuales de buenas costumbres asumiendo que «tienden todos a la conservación del orden y de la buena armonía que deben reinar entre los hombres $(\ldots) »^{535}$. Los deberes morales había que enseñarlos, y es así que la educación moral constituyó uno de los

\footnotetext{
${ }^{532}$ Vid. A este respecto, PUGA, F, Cómo se evita el Cólera. Estudio de higiene popular, Santiago, Imprenta Nacional, 1886; Elementos de higiene, Santiago, Imprenta Gutemberg, 1891 y DAVILA, R., Higiene de las Escuelas, Santiago, Imprenta Cervantes, 1884.

${ }^{533}$ STANHOPE, Ph., Preceptos de urbanidad y buena crianza o reglas para comportarse con lucimiento en la sociedad ..., op. cit., p. 40.

534 «Informe del Visitador de escuelas sobre la provincia de Aconcagua», El Monitor de las escuelas primarias, Tomo II, No 7 (1854), p. 17.

${ }_{535}$ CARREÑO, M., Compendio del Manual de urbanidad..., op. cit., p. 22.
} 
objetivos primordiales de la enseñanza pública. El estado nacional puso acento en la educación moral y en la necesidad de transformar las costumbres, porque «la moral y la urbanidad son las bases en que debe estribar la conducta de un niño» ${ }^{536}$. De allí que el compromiso más importante era con los niños y los jóvenes con la firme apuesta de promover la educación como medio para la mejora de la condición del hombre, porque aun cuando el hombre se enajena en sociedad en sus vicios y corrupción, el hombre es capaz de reivindicarse social y moralmente.

El cuerpo, sus energías y pasiones, debían ser dominados y encausados como requisito para el bien común y la productividad económica. Esta idea, en la que cuerpo y comportamiento moral están intrínsecamente ligados a los primeros años de la república cuando se instaló el Instituto Nacional en 1811 con la finalidad de proporcionar «instrucción militar, religión, ejercicios que den actividad, vigor, y salud, y cuanto puede formar el carácter físico y moral del ciudadano» ${ }^{537}$. Desde los primeros años de la república se tuvo la idea que la ciudadanía estaba ligada a las capacidades intelectuales y también al vigor y la salud para la formación del ciudadano virtuoso. La virtud masculina debía ser encausada y dominada en el sentido de la subyugación de las pasiones, por medio del ejercicio, que, en sus manifestaciones externas, da cuenta de una salud física y moral. Con el trascurso del siglo, el discurso sobre el cuerpo se asentó en los proyectos educativos, ahora como parte crítica para la construcción de la nación moderna.

De esta forma, los manuales fueron herramientas indispensables en la creación de hábitos fundamentales en la formación de los individuos, y por ende piezas claves en la formación de los nacionales. El principio fue educar y enseñar contenidos morales desde los niños para formar buenos ciudadanos comprometidos con la nación. La educación se asumió como el principal impulsor de conocimiento costumbres y progreso social. Al respecto, Lastarria señalaba que, dado que «la sociedad no se puede penetrar en el hogar doméstico, y tiene que limitarse a tomar al niño en las puertas de la

\footnotetext{
${ }^{536}$ ROBLES, L., Manual de moral, virtud y urbanidad..., op. cit., p. 5.

${ }^{537}$ LETELIER, V., Sesiones de los cuerpos legislativos de la República de Chile, 1811 a 1845, Tomo I, Santiago, Imprenta Cervantes, p. 213.
} 
escuela, es necesario que desde allí lo conduzca al conocimiento, al amor y a la práctica de lo justo y verdadero» ${ }^{538}$. Las nociones de educación involucraban el respeto y los buenos comportamientos que asumirán la connotación de modernidad.

El proyecto modernizador chileno del siglo XIX intentó abarcar todos los aspectos sociales y culturales de la sociedad, además de las prácticas y hábitos de cada hombre y mujer. Los parámetros culturales del proceso modernizador -como ya se ha dichoestuvieron fundados en las prácticas culturales europeas y la elite nacional conoció e intentó asimilar el estilo de vida propio de la burguesía europea. Uno de los aspectos integrales del proyecto modernizador fue el aspecto de la modelación de hombres y mujeres con el fin que funcionaran convenientemente en este nuevo modo de vida republicano y urbano, ya que se trataba de «la modelación de un tipo de ciudadano que debía habitar las ciudades de esas repúblicas ${ }^{539}$. Tal como había ocurrido desde el periodo colonial, la palabra escrita estaba investida de gran poder y los miembros de la sociedad chilena del siglo XIX aceptaron que lo que estaba escrito era superior y verdadero, ya que escribir en ese siglo respondía a la necesidad de ordenar e instaurar la lógica de la civilización y constituyó uno de los ejercicios claves de la modernización. Es por esto que los periódicos, libros, cartillas, catecismos y manuales adquirieron una relevancia cada vez mayor en la tarea de difundir el ideario liberal a los sectores medios, $\mathrm{y}$, en general, a toda la población. Los manuales de comportamiento manifestaron expresamente una especie de especialización por género, ya que unas normas estaban dirigidas a los hombres y otras a las mujeres.

En los manuales a menudo se describe una jerarquía y división dentro de la casa, en la cual siempre está a la cabeza el padre, le sigue la madre y como dependientes estaban los hijos. Respecto al padre, se estableció claridad en relación a su función y lugar en la sociedad; en prácticamente todos los manuales hubo referencia a unos versos que se repiten a menudo en estos textos en que se conminaba a ser «buen padre, esposo y buen

\footnotetext{
${ }^{538}$ El libro de oro de las..., op. cit., p. 10.

539 GONZALEZ, B., «Modernización y disciplinamiento. La formación del ciudadano...», en GONZALEZ, B. (coord.), Esplendores y miserias..., op. cit. p. 432.
} 
amo, habéis de ser sin flaqueza» ${ }^{540}$. La representación de la masculinidad fue evidente en los manuales al postular una forma correcta de comportarse en sociedad y considerada expresión natural de su género. Uno de los aspectos más recurrentes eran los que hacían alusión a la constitución de la personalidad dominante del hombre.

La cualidad más determinante fue la del carácter, imprescindible para adquirir fisonomía moral y franqueza. En la equivalencia entre carácter y hombría, según el modelo del siglo XIX el hombre debía ser un sujeto que no podía mostrar debilidad ni dobleces, debían ser franco y correcto. En un escrito en verso que fue utilizado en varios de los manuales titulado «Las máximas del hombre de bien o de la sabiduría» y que podíamos leer entre tantos versos el siguiente: «venced siempre los pesares. A que el alma se abandona. Y no hagáis que vuestras penas dañen a alguna persona.» ${ }^{541}$ Además se presentaba al hombre como el género que tiene la cualidad del raciocinio y que la existencia de las pasiones como «el odio, la impaciencia, la soberbia, el orgullo, la envidia, la ambición y la codicia; sentimientos que se llaman odiosos y que son contrarios a la perfección del hombre y de la sociedad, porque todo lo que pensamos y movidos por ellos es un mal o por lo menos es contrario a nuestra razón» ${ }^{542}$. La forma de vencer las pasiones era con trabajo, aspecto coherente con las nuevas exigencias del sistema económico del siglo XIX y que requería forjar un ciudadano con un nuevo tipo de mentalidad donde el cuestionamiento a la recreación y al ocio fueron los principales enemigos de la productividad, puesto que «el amor, el vino, el juego, evitareis cuidadoso: los tres escollos son estos de un naufragio peligroso» ${ }^{543}$. El cuestionamiento al ocio se mantuvo como aspecto siempre presente en los manuales; todavía en 1890 se calificaba al ocio como un vicio pernicioso: «de él nacen infinidad de males tales como el juego, la embriaguez, el hurto (...). Un hombre ocioso es en extremo perjudicial a la sociedad, porque consume el trabajo de los demás (...)» ${ }^{544}$. Los vicios y las debilidades de los hombres fueron atacados por los manuales, especialmente el vicio del alcoholismo, pues todo hombre que quisiese seguir el modelo debía evitar todo acto

\footnotetext{
${ }^{540}$ Compendio de Reglas de urbanidad para el uso..., op. cit., p. 18.

541 Ibidem, p. 20.

${ }^{542}$ LASTARRIA, J. V., El libro de oro de las... op. cit., p. 106.

${ }^{543}$ Compendio de Reglas de urbanidad para el uso..., op. cit., p. 21.

${ }^{544}$ SUAREZ, J. B., Compendio de moral y urbanidad. Arreglado..., op. cit., p.14.
} 
irracional, es por eso que se criticaban los actos en exceso «en el comer y el beber, la sobria moderación. Conservar en toda ocasión la salud sin padecer» ${ }^{545}$ y en el mismo sentido en otro texto se afirmaba que «nunca se debe comer ni beber hasta hartarse porque el exceso en la comida o bebida, destruye la salud y entorpece las facultades intelectuales ${ }^{546}$. La ebriedad se consideraba un perjuicio para el hombre y su familia, y al caer en ella, propiciaba el rechazo y el repudio.

\subsubsection{Los manuales de Urbanidad en cuestiones de género y espacios de sociabilidad}

La modernización de la sociedad chilena en el siglo XIX exigió transformar las ciudades y también incidir en los hábitos y aspecto de sus habitantes. El Estado chileno y sus elites desearon que los chilenos adoptaran las prácticas que habían hecho suyas y que estipulaban como positivas para el progreso material y moral de la nación y de los individuos. Los ideales sobre hombre y mujer formaron parte importante de la forma en que se concibió el funcionamiento de la sociedad. La concepción del hombre se entendió como «buen padre, esposo y buen amo. Habéis de ser sin flaqueza: honrad al padre si es viejo, aún con mayor reverencia» ${ }^{547}$. La forma en que el hombre alcanzaba las virtudes debía ser por medio de la educación, ya que «un hombre que no se halla educado es inepto para la buena compañía y desagradable en ella; y que un hombre mal educado es tan mal educado es tan inhábil para los negocios como para el trato con gente fina ${ }^{548}$. La representación de la masculinidad fue postulada en los manuales como la manera correcta y adecuada de cómo los hombres debían comportarse de acuerdo a su condición de género, sin embargo, en la revisión de los manuales no advertimos una referencia explícita y clara a la situación de la mujer, a excepción del texto de Lorenzo Robles quien en relación al comportamiento público que las mujeres debían tener señala con tono inquisitivo y sancionador particularmente sobre el coqueteo de las mujeres: «las miradas anuncian sin querer lo que pasa en el corazón, las

\footnotetext{
545 Ibidem, p. 37.

${ }^{546}$ Compendio de Reglas de urbanidad para el uso..., op. cit., p. 18.

547 Ibidem, p. 18.

${ }^{548}$ STANHOPE, Ph., Preceptos de urbanidad y buena crianza o reglas para comportarse con lucimiento en la sociedad ..., op. cit., p. 33.
} 
señoras pues deben hacer que en las suyas se vea solo expresión de modestia: una mirada atrevida, en una mujer es una cosa que repugna: sobre todo no se debe buscar de los hombres; esta costumbre procede de la depravación del corazón.»> ${ }^{549}$ De esto inferimos que en los espacios públicos se esperaba de la mujer un comportamiento recatado y prudente.

En lo que fueron enfáticos los autores fue en sostener el orden y la jerarquía dentro del espacio doméstico porque «el conocimiento y la práctica de los deberes morales serán de un grande auxilio para la conservación de la paz en las familias. El respeto de los hijos a sus padres, de los sobrinos a sus tíos, de los hermanos menores a los mayores, y en general, de todos los inferiores a sus superiores, suavizará siempre el trato e unos con otros $(\ldots)\rangle^{550}$. La familia era apreciada como una institución donde cada integrante debía aprender el lugar que ocupaba en el hogar. El orden jerárquico pretendido por la sociedad decimonónica encontraba su asidero en explicaciones asociadas a lo religioso, ya que «aunque ante Dios por las leyes todos seamos iguales, la sociedad ha debido establecer y ha establecido en efecto, cierta graduación y distinciones que no podemos menos de respetar: así, pues, hemos de valorar en primer lugar a los padres, hermanos y parientes (...) después siguen nuestros iguales y luego nuestros inferiores» ${ }^{551}$. La presencia en la escuela de referencias a la urbanidad derivada de principios morales con base religiosa que convivió con nociones más «bien tributarias de una idea secular y racional respecto a la sociedad» ${ }^{552}$. Si bien, estos elementos laicos y religiosos podrían ser vistos como una disputa entre cristianismo y republicanismo, no creemos advertir discordias relevantes, sino más bien una estrategia que pretendió utilizar los soportes existentes para que se lograra asegurar la transmisión de los códigos conductuales esperables por la elite chilena.

La concepción de la Urbanidad fue uno de los soportes desde donde se transmitieron las instrucciones a las que debían atender las niñas para ser las mujeres que deseaba la

\footnotetext{
${ }^{549}$ Manual de moral, virtud y urbanidad..., op. cit., p. 40.

${ }^{550}$ CARREÑO, M., Compendio del Manual de urbanidad..., op. cit., p. 82.

${ }^{551}$ SUAREZ, J. B., Compendio de moral y urbanidad. Arreglado..., op. cit., p. 16.

552 TORO, P., «Dimensiones de la confección de una juventud ...», art. cit., p. 193.
} 
sociedad y los comportamientos que éstas debían seguir para obtenerlo. Para tal cometido las niñas debían tener una buena educación en aspectos físicos y morales, debían evidenciar un cuidado personal, que eran atentas, esbeltas y hermosas, además debían actuar de acuerdo a padrones de virtud para producir honradez a la familia y modelar y remodelar la sociedad, Estas razones inspiraron los modelos de escolarización, ya que la «mujer debe ser atenta y cortés, el mundo juzga severamente este sexo y por esta razón debe siempre caminar como dice el proverbio, con pies de plomo»» ${ }^{553}$. La anterior afirmación expresa la condición de subordinación que tuvieron las mujeres en la sociedad decimonónica, ya que sólo debían atender los deberes el hogar y dejar a los hombres el conocimiento y la política. Era la convicción que «la educación femenina era ante todo un asunto moral y por lo tanto familiar, siendo más importante desde luego la educación que la instrucción» ${ }^{554}$. La educación de las niñas centrada en lo doméstico fue la expresión manifiesta de una sociedad sustentada en las distinciones.

Las mujeres debían limitarse a ser esposas y madres, que era la función de las niñas y debían formarse para aquello desde muy temprano. En 1846 un libro que se distribuyó ampliamente en las escuelas chilenas subrayaba que: «las niñas son tan débiles y delicadas, que no se debe tener mucha prisa en dedicarlas al estudio (...). Una instrucción verdadera acompañada de algunos conocimientos de adorno es una garantía de felicidad doméstica (.....» ${ }^{555}$ El Estado mediante la distribución de los manuales de Urbanidad fue partidario de mantener una instrucción pedagógica de las niñas favorables al statu quo, ya que era cuestión de intereses sociales y económicos. De esta forma, se subraya el interés de los actores sociales por mantener un papel acotado de las mujeres, ya que se trataba de un «modelo de mujer dedicada a las labores de manos en el espacio doméstico, un modelo moral y económico que había condicionado la

\footnotetext{
${ }^{553}$ ROBLES, L., Manual de moral, virtud y urbanidad..., op. cit., p. 5.

${ }^{554}$ GUEREÑA, Jean Louis, «Mujeres autoras de libros. El caso de los manuales de urbanidad en la segunda mitad del siglo XIX y principios del siglo XX», Lectures Genre, No 2 (2008), p. 26.

${ }^{555}$ MINVIELLE, Rafael, El libro de las madres y preceptoras, Santiago, Imprenta de los tribunales, 1846, p. 8.
} 
enseñanza» ${ }^{556}$. Podemos señalar que los manuales de Urbanidad centran su formación de la mujer con unos fines instrumentales en donde imperó la convicción que el papel de la mujer fue limitado.

En el comportamiento en los espacios de sociabilidad destacaremos, el comportamiento en la mesa, ya que esta tuvo una gran importancia en el proceso civilizatorio de occidente y en algunos espacios públicos. El comportamiento en la mesa fue un aspecto recurrente en casi todos los manuales de Urbanidad, ya que «las formas de conducta en la mesa no son algo aislado, sino que forman parte muy característica de la totalidad de los modos de comportamiento transmitidos por la sociedad, cuyo grado de desarrollo se corresponde con una estructura social absolutamente determinada» ${ }^{557}$. Los manuales de Urbanidad ofrecen la posibilidad de escudriñar en las formas de comportamiento que una sociedad esperaba de sus miembros y a la que los individuos intentaban ajustarse.

Estos manuales nos muestran los grados de uso y comportamientos que cada sociedad trataba de acostumbrar a sus miembros en determinadas épocas y en uno de los manuales más difundidos en Chile y América Latina en el siglo XIX se otorgaba importancia capital a la mesa, ya que «es uno de los lugares donde más clara y prontamente se revela el grado de educación y de cultura de una persona, por cuanto son tantas y de naturaleza tan severa, y sobre todo tan fáciles de quebrantarse, las reglas y las prohibiciones a que está sometida» ${ }^{558}$. La mesa a la que se refiere Carreño es la de los hombres y mujeres de sociedad, es decir, aquellos que están invitados a reuniones sociales, bailes en clubes y similares, en donde se juzgaba el comportamiento y las buenas costumbres. Las reglas y conductas que se debían seguir en torno a la mesa iban desde que se llegaba: «(...) cuando a la mesa te llegues, cuida no ser el primero en desliar la servilleta y tomar el plato, siendo político aguardar que den los demás ejemplos» ${ }^{559}$. Una de las funciones principales de los manuales de urbanidad fue

\footnotetext{
${ }^{556}$ SARASÚA, Carmen, «Aprendiendo a ser mujeres: las escuelas de niñas en la España del siglo XIX», Cuadernos de Historia Contemporánea, vol. 24 (2002), p. 296.

${ }^{557}$ ELIAS, Norbert, El proceso de civilización: investigaciones sociogenéticas y psicogéneticas, México, Fondo de Cultura Económica, 1988, p. 114.

${ }_{558}^{55}$ CARREÑO, M., Manual de urbanidad y ..., op. cit., p.114.

${ }^{559}$ MESTRE i MARZAL, C., Consejos morales a la niñez, seguidos de las reglas ..., op. cit., p. 39.
} 
presentar como naturales, eternos y universales los valores fundamentales y las prácticas culturales de la burguesía, ya que estaban investidos del poder del discurso normativo. Los manuales garantizaban que desde la más temprana infancia el futuro ciudadano asimilara la visión de mundo de la burguesía, y este proceso de control empezaba por las costumbres cotidianas en la mesa, así lo afirmaba un texto en el año de 1852: «(...) no debemos ser los primeros en sentarnos, ni en desdoblar la servilleta, ni en poner la mano en los platos y hemos de agradar a que las personas superiores nos den ejemplo $(\ldots) .{ }^{560}$ Estos textos fueron instrumentos eficaces para hacer que los propios ciudadanos asumieran, reprodujeran y reforzaran las costumbres que la nueva república deseaba imponer. Este proceso era más eficaz si se empezaba desde la niñez, ya que de esta manera se inscribía de manera más permanente el sello de la sociedad en modos y costumbres. La construcción de los hábitos en torno a la mesa constituyó un claro ejemplo de un discurso y práctica que se presentaron a sí misma como universales.

Un último aspecto que analizaremos de los manuales de Urbanidad es lo concerniente al orden social y su conservación, tal como fueron pensados estos textos que vinieron a llenar un vacío para las nuevas repúblicas proporcionándole orden y forma a casi todas las relaciones entre los distintos sectores de la sociedad. Estos manuales recogieron acertadamente el concepto de cómo debía estar estructurada la sociedad, definida como de oposición binaria entre superior-inferior, hombre-mujer, barbarie-civilización, etc. y que a pesar de las declaraciones liberales preponderantes en América en el siglo XIX, la gran mayoría de la población siguió creyendo pertenecer a una sociedad donde todos no eran iguales. Así mismo, estos binomios sostuvieron la idea acerca del orden social desde las dualidades y los equilibrios cuya estructura y función fueron resultado de acciones que se debían dar dentro de los límites impuestos por las normas de la sociedad y para que se desarrollen esas normas se debían establecer procesos de socialización.

La aspiración al orden social que concibió la elite chilena en el siglo XIX estuvo desde un principio reglada tanto para los espacios públicos como los privados. El orden social estaba regulado desde la casa donde la mesura y el buen comportamiento fueron

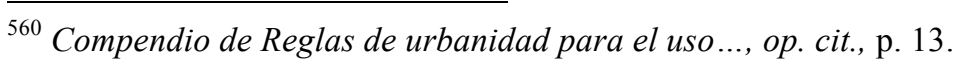


aspectos altamente valorados, reflejados desde la forma en que debías disponerte a la hora de comer donde el mandato era «no disputes en la mesa, antes bien muestra contento, no hables con la boca llena, ni digas cosas que tedio o asco ocasiones, y en todo debes parecer discreto» ${ }^{561}$. El valor del orden constituía uno de los aspectos más preciados por quienes ostentaban el poder que se correspondía con el modelo de sociedad a la que se aspiraba. Las normas prescribían incluso el modo de conversar y así lo estipulaba un texto en 1852: «(...) cuidemos que los asuntos de nuestra conversación sean en lo posible interesantes y agradables; evitando en ellos todas las cosas contrarias a la decencia y a las buenas costumbres (...).» ${ }^{562}$ La disposición de las ideas, los razonamientos, los juicios eran indispensable que se hicieran en orden, exactitud y por, sobre todo, mesura y prudencia.

La preocupación del Estado por moralizar y civilizar a la sociedad chilena del siglo XIX para integrarlos en un orden social encontró en la escuela y en los manuales de urbanidad un aliado perfecto. En la escuela se pusieron en práctica la introducción de nuevas pautas de ordenamiento para el nuevo orden social que se estaba consolidando que consistía en civilizar por medio del disciplinamiento. Las reglamentaciones en las escuelas fueron muy parecidas y coherentes con los manuales de urbanidad, especialmente cuando se establecía que los profesores debían desplegar «el mayor celo porque sus alumnos adquieran hábitos de orden, moralidad y decencia (...)» ${ }^{563}$. La utilización de los manuales en las escuelas diseñados para serializar patrones de conducta que tuvieron la doble intención de ordenar y de diferenciar la sociedad. Como fueron dirigidos a públicos distintos. En primer lugar, aquellos hombres y mujeres educados y virtuosos que fueron los modelos sociales y moderados en sus impulsos y en segundo lugar, los menos favorecidos que mediante la instrucción podían aprenderlas. Igualmente, si una parte de la sociedad aspiró al pulimiento de sus costumbres para alcanzar el éxito, no es menos cierto que los manuales de urbanidad llevaban implícito los límites entre los ciudadanos que debían construir una sociedad civilizada y aquellos que trataban de inmiscuirse en un sociedad regulada y bien portada, cuya unidad se veía

${ }^{561}$ MESTRE i MARZAL, C., Consejos morales a la niñez, seguidos de las reglas ..., op. cit., p. 42.

${ }^{562}$ Compendio de Reglas de urbanidad para el uso..., op. cit., p. 8.

${ }^{563}$ El monitor de las escuelas primarias, Tomo VI, No 9 (1858), p. 283. 
amenazada por la movilidad social del período.

Sostenemos que, efectivamente, los manuales de Urbanidad quisieron ordenar el comportamiento de la vida pública y privada con la aspiración de construir el ciudadano modelo al que había que reglamentarlo para su desempeño social y disciplinarlo en cuerpo y mente para que pudiera desenvolverse en la sociedad moderna y republicana.

Los manuales de Urbanidad constituyeron una pieza clave en el proceso de la construcción de un Chile moderno y racionalizado donde se pretendió controlar los sentimientos, las emociones y los cuerpos. La Urbanidad incluida en la enseñanza fue el referente para idealizar a los hombres y las mujeres con funciones sociales definidas para el óptimo funcionamiento del Estado nacional que se debía construir. La Urbanidad y sus manuales construyeron un individuo que debía tener clara las normas y la capacidad de discernir entre lo beneficioso y lo perjudicial para la sociedad.

Los manuales de Urbanidad fueron expresión del paso de una sociedad religiosa a una sociedad laica, donde se da la transformación de feligreses y súbditos a ciudadanos, también representaron la preocupación por encontrar nuevos modos de vida y de felicidad. Al mismo tiempo fueron códigos de inclusión y exclusión para distinguir la categoría de las personas en el orden social.

\subsubsection{La formación Cívica: el último eslabón de la construcción de la nación}

A finales del siglo XIX, en Chile, se comenzó a dar énfasis a la idea que para tener una nación libre y soberana los ciudadanos debían aprender los hábitos y las costumbres necesarias para convivir en un orden político de libertades y respeto. Para esos fines, la escuela no tan sólo era el lugar donde se aprendían letras, aritmética, ciencias, historia sino que se transformó en una ciudad escolar donde se enseñaban y practicaban valores cívicos por medio de manuales, lecturas, juegos y simulaciones. Fue entonces cuando comenzaron algunas de las ceremonias cívicas que hoy se realizan en la escuela, por 
ejemplo: la conmemoración de la independencia, el saludo a la bandera y la entonación del himno nacional.

Recién a fines del siglo XIX se hicieron los primeros libros de textos de moral Cívica o moral para la patria. Estos libros señalaban una moral republicana tendiente a formar hombres y mujeres necesarios para afianzar y consolidar la nueva república, es por ello, que instruir y educar en lo cívico llegó a significar lo mismo que cuidar la patria. En los primeros años, la instrucción Cívica estuvo muy cerca de la historia nacional, pues se consideraba indispensable conocer los acontecimientos que habían permitido a Chile convertirse en un Estado independiente. Los textos de Historia y Geografía insistieron en las bondades del nuevo Estado, en las razones de su defensa territorial y en la trascendencia de la nación y el hombre para algún día convertirlo en ciudadano. En la historia de Chile la sentencia de Diego Portales sobre la democracia y la ciudadanía explicaba el énfasis por construir la nacionalidad antes que la ciudadanía, pronunciamiento que se transformó en ideario político de la historia política nacional. Portales, en 1822, indicaba que la «república es el sistema que hay que adoptar; ¿pero sabe cómo yo la entiendo para estos países? Un gobierno fuerte, centralizador, cuyos hombres sean verdaderos modelos de virtud y patriotismo, y así enderezar a los ciudadanos por el camino del orden y de las virtudes. Cuando se hayan moralizado, venga el Gobierno completamente liberal, libre y lleno de ideales, donde tengan parte todos los ciudadanos» ${ }^{564}$. La postergación de la formación ciudadana se debió fundamentalmente a que Chile resolvió el dilema que caracterizó a los estados latinoamericanos, es decir, si poner énfasis en la construcción de la nación o en la formación del Estado, dilema que se resolvió en favor de la primera. En otras palabras, desde el proceso de independencia y durante la construcción de la república el acento estuvo puesto en la identidad nacional más que en el ciudadano y las instituciones. En América la construcción de la nación y la ciudadanía fue un proceso complejo como la «construcción misma del estado nacional, porque nominalmente la ciudadanía debía incluir a toda la población, pero en la práctica operó como una categoría excluyente» ${ }^{565}$.

\footnotetext{
${ }^{564}$ Cit. en SILVA, Raúl, Ideas y confesiones de Portales, Santiago, Editorial del Pacífico, 1954, p. 1.

${ }^{565}$ MUÑOZ, M., «El ciudadano en los manuales de historia...», art. cit., p. 221.
} 
En muchos países la ciudadanía universal fue implementada muy avanzado el siglo XX y con períodos de interrupción o restringida para la mayoría de la población por razones, políticas, sociales, económicas, étnicas y de género, lo cual limitó la participación tan sólo a los grupos dirigentes.

La historia nacional fue considerada como uno de los instrumentos fundamentales para construir una conciencia de ser parte de un colectivo que legitimara el Estado nacional y pilar elemental de la posterior construcción de la ciudadanía. En este sentido escribir las historias nacionales fue una tarea difícil, ya que suponía decidir y divulgar cuál pasado elegir, donde establecer el origen y cómo definir las etapas. De allí que para educar a los ciudadanos en las virtudes cívicas se debía reafirmar la historia patria para luego introducir la formación Cívica.

Los textos escolares sobre historia nacional fueron herramientas propicias de la pedagogía Cívica donde encontramos alusiones recurrentes de la conquista española, la independencia, la patria y los héroes. Respecto a estos hechos históricos -como hemos visto anteriormente- en los textos utilizados en las escuelas contenían interpretaciones acerca del pasado, especialmente los de Diego Barros Arana y Miguel de la Barra, en cambio el de Miguel de Amunátegui era de carácter descriptivo. Respecto a la conquista, De la Barra aseveraba que «muy lejos nos hallamos de asentar por esto que el gobierno de las colonias fuera paternal y benéfico: la historia, en sus inexorables páginas, ha fijado un sinnúmero de hechos que revelan lo contrario» ${ }^{566}$. La percepción y juicio sobre el pasado colonial fue presentado de forma negativa con la firme convicción de valorar la independencia y el presente republicano y Barros Arana en ese sentido escribía en su Manual de historia que «los españoles empañaron muchas veces el brillo de estas proezas con actos de crueldad y de perfidia que la moral no pueda disculpar» ${ }^{567}$. Estas referencias fueron mensajes historicistas con un alto contenido patriótico con lo cual se pretendió proporcionar a los chilenos el sentido de pertenencia

\footnotetext{
${ }^{566}$ Compendio de la Historia del coloniaje e independencia ..., op. cit., p. 40.

${ }^{567}$ Compendio de Historia..., op. cit., p. 11.
} 
a un origen oprobioso que justificó la independencia y la construcción de la nación y el Estado.

La aceptación positiva de la independencia explicada en sus causas por la inconformidad justificada por el no acceso de los criollos a la administración política, es decir, al Gobierno ya que «la política suspicaz de España había mantenido a las colonias americanas sin ninguna intervención en sus negocios públicos durante trescientos años, natural era, por consiguiente, que estos se aprovecharan de la primera ocasión que para ello se le presentase» ${ }^{568}$. El descontento criollo por el no acceso a los cargos públicos de mayor connotación se convirtió en una explicación que daba sentido y coherencia a las acciones que llevaron a la separación de España, y con un sentido del desarrollo histórico natural afirmaban la independencia como un hecho esperable dada las arbitrariedades de la Corona pues «de aquí resultaba fácil suponer, una rivalidad constante entre americanos y españoles que contribuyó a preparar la revolución de la independencia» ${ }^{569}$.

La independencia fue una alusión permanente en los textos escolares del siglo decimonónico y casi siempre en alusión a sus héroes considerados como padres de la patria elevados muchos de ellos a niveles sacros venerados en los rituales cívicos tanto en espacios escolares como en manifestaciones públicas, monumentos, panteones y fiestas patrias. En los textos fue recurrente la figura de glorificar a los héroes como prototipos y modelos humanos. Cuando De la Barra se refiere a los precursores de la independencia releva esa idea, pues «los instigadores de los nuevos gobiernos eran por otra parte, hombres liberales, educados casi todos en las escuelas de la filosofía francesa donde habían aprendido las doctrinas que acababan de trastornar la más grande y poderosa de las monarquías, destruyendo la nobleza y la aristocracia y elevando a los pueblos del vasallaje (...)»» ${ }^{570}$. Se intentó fomentar una enseñanza Cívica valiéndose de la independencia para incentivar y motivar en favor del Estado nacional con sentido de lealtad.

${ }^{568}$ BARRA, M. de la, Compendio de la Historia del coloniaje e independencia ..., op. cit., pp. 204-205.

${ }^{569}$ BARROS ARANA, D., Compendio de Historia ..., op. cit., p. 46.

${ }^{570}$ Compendio de la Historia del coloniaje e independencia ..., op. cit., p. 205. 
El patriotismo fue un tema recurrente en los textos escolares con la pretensión de avanzar en la formación ciudadana, ya que la nueva república había llevado a los súbditos de la Corona a la condición de hombres libres y ciudadanos y se buscaba propiciar la difusión de inculcar sentimientos políticos que permitiesen adherir al ideal republicano. Desde muy temprano, la apelación a la patria fue difundida desde los primeros momentos de la independencia: ya en 1808 en un manuscrito señalaba que la «patria, a quien se han sacrificado las almas heroicas, y la que debemos estimar sobre nuestros propios intereses; en una palabra, la acreedora de todos los obsequios posibles cuyo amor han calificado con ejemplos, persuasiones y apotegmas, historiadores, oradores y filósofos, ella es aquel cuerpo político donde, debajo de algún régimen civil y una misma religión, estamos unidos con los vínculos más fuertes de una misma legislación» ${ }^{571}$. La alusión a la patria y al patriotismo fue ideada como uno de los compromisos que debía asumir el ciudadano republicano para con la nación concebida como una virtud que les debía caracterizar, pues para «que los ciudadanos amen la patria, o digamos mejor, para que haya patria y ciudadanos, es preciso que ella sea una madre tierna; que los bienes de que gozan en su país se los haga amable (...)» ${ }^{572}$. De esta forma el patriotismo se vinculó más a una cuestión de carácter afectiva que como virtud Cívica que después consolidaría el Estado republicano. En las últimas dos décadas del siglo XIX la idea de nación se había constituido en una realidad histórica que hubo que resguardar y fortalecer mediante la socialización extensiva del patriotismo, aspecto cuyos más férreos defensores y promotores fueron los pedagogos. A lo largo del siglo se mantuvo la asociación de la patria con lo afectivo, en 1893, el subdirector de la Escuela Normal de Preceptores de Santiago en 1893 señalaba que se debía promover el patriotismo para cohesionar a la sociedad chilena puesto que «el patriotismo es el amor más entrañable, el más desinteresado, el más puro y vivo de los amores terrenales, por medio del cual cuidamos la madre patria, empeñándonos por engrandecerla con el trabajo (...) en un reinado de paz y concordia $(\ldots)^{573}$. Los

\footnotetext{
${ }^{571}$ PINTO, Francisco, «Rasgo patriótico» en DONOSO, Ricardo, (Ed.), El catecismo político cristiano, Santiago, Imprenta Universitaria, 1943, p. 71.

572 HENRÍQUEZ, Camilo, «Del patriotismo o del amor a la patria», La Aurora de Chile, 6 de agosto de 1812, p. 112.

${ }^{573}$ MUÑOZ, José, «El patriotismo en la escuela», Revista de Instrucción primaria, Año VIII, Nº4 (1893), p. 211.
} 
acontecimientos ocurridos en torno a los problemas sociales que experimentó la sociedad chilena, en la llamada «cuestión social» ${ }^{574}$, provocó inquietud «de la comunidad política derivada de los conflictos sociales y la preocupación por formar una moral laica en reemplazo de la religiosa hizo después de la instrucción cívica y del estudio de la historia patria una forma de construir la unidad a través de la educación» ${ }^{575}$. La tarea, entonces, estaba clara para el Estado chileno: había que lograr la identificación de los alumnos con la nación; fue imprescindible replantear la enseñanza de la Historia nacional colocando realce en las hazañas de la patria, en los héroes, en los padres fundadores, aleccionando el respeto por los símbolos patrios y la valoración del paisaje geográfico. El siglo XIX había comenzado con apelaciones emotivas acerca de la patria y a fines de la centuria los conceptos de patria y nación estaban más o menos homologados en el sentido de comunidad político-cultural y la escuela y los pedagogos incentivaron y promovieron su apropiación por parte del alumnado como una forma de cohesionar un país que tenía grados de fractura.

En los textos de Historia y, fundamentalmente, los manuales de Urbanidad reflejaron el interés por sentar las bases de un tipo de ciudadano concurrente con el proyecto político de la república. Es por ello que, por medio de la educación, se modeló la mente y conciencia de los niños con las nuevas pautas de comportamiento. Los textos que sirvieron para el logro del proyecto portaban el discurso principal a saber: un tipo de hombre que se requería. Dentro de los requerimientos exigidos estuvo el reconocimiento de la escritura, el imperio de la ley, el respeto a las autoridades y a las instituciones y los textos escalares y manuales de Urbanidad fueron los primeros instrumentos en la larga carrera de construir el ciudadano. La formación ciudadana que se promovió en estos primeros escritos buscaba relacionar el individuo con los principios modernos de la civilización e intentó generar en los alumnos una serie de obligaciones de cómo comportarse en privado y en público. Especialmente, los

\footnotetext{
${ }^{574}$ El término «cuestión social» fue asociado a los diversos problemas sociales que afectaron a los sectores populares como analfabetismo, prostitución, alcoholismo, hacinamiento, promiscuidad, enfermedades, huelgas, inflación, actividad sindical, lucha de clases, trabajadores y proletarización que se vivieron en Chile entre 1880 y 1920.

${ }^{575}$ SERRANO, Sol; PONCE DE LEON, Macarena, y RENGIFO, Francisca, Historia de la educación en Chile (1810-2010), Tomo II, La educación nacional (1880-1930), Santiago, Taurus, 2012, p. 55.
} 
manuales contenían una serie de normas y obligaciones que promocionaban la autodisciplina y los nuevos códigos sociales. La idea del buen ciudadano como un hombre bien educado que constantemente debía dar muestras de virtudes fue parte importante de los discursos contenidos en esos manuales. En 1847 en un Manual de Urbanidad el consejo del padre a su hijo era «procura que las buenas maneras sean el objeto de tu estudio y de tus acciones. Observa cuidadosamente los modales de aquellos que se distinguen por su buena crianza; imítalos, y aun trata de aventajarlos para llegar a los menos al mismo nivel» ${ }^{576}$. El ideal de ciudadano procuró mostrar la nueva condición del hombre republicano: ordenado, obediente, respetuoso, urbano, civilizado y moderno.

En los manuales de Urbanidad advertimos referencias a los deberes del ciudadano asociados a los comportamientos de carácter moral que debían asumir. Las referencias al respeto a las instituciones y a las autoridades fueron recurrentes en varios de los manuales que hemos analizado en esta investigación. En 1853, el presbítero Lorenzo Robles escribía que «todo ciudadano debe respeto y sumisión a las autoridades constituidas, en cuanto ordenen o manden» ${ }^{577}$. El acatamiento del poder establecido constituyó un principio básico de la república en la convicción que aquello favorecía la construcción de una sociedad civilizada. Por medio de la escuela también se transmitieron elementos claves del sistema republicano, a saber, la naturaleza de sus autoridades. José Victorino Lastarria arguyó en contra de la monarquía que «la democracia representativa esto es, el gobierno que se funda en la soberanía nacional y en el cual los depositarios del poder son elegidos por el pueblo y sin otra consideración que la de su capacidad individual» ${ }^{578}$. El fortalecimiento de la república buscaba el respeto por las autoridades y las instituciones republicanas con la intención de forjar un lazo indestructible de lealtad que le diera legitimidad a la nueva situación. En 1890, uno de estos manuales declaraba que «los magistrados y demás delegados del gobierno son individuos a los cuales se les ha confiado la vigilancia sobre el cumplimiento de las

\footnotetext{
${ }^{576}$ STANHOPE, Ph., Preceptos de urbanidad y buena crianza o reglas para comportarse con lucimiento en la sociedad ..., op. cit., p. 33.

${ }^{577}$ Manual de moral, virtud y urbanidad..., op. cit., p. 28.

${ }^{578}$ El libro de oro de las..., op. cit., p. 96.
} 
leyes, la tranquilidad y el orden público; en una palabra, todo lo que es necesario para que las buenas costumbres no sufran menoscabo alguno, y sean respetados los derechos de cada individuo» ${ }^{579}$.

La Ley de Instrucción Primaria en 1860 estableció que «habrá dos clases de escuelas: elementales y superiores» ${ }^{580}$ De tal forma que la Ley estableció que en «las primeras se enseñará por lo menos lectura e idioma patrio, doctrina y moral cristiana, elementos de aritmética práctica y el sistema legal de pesos y medidas» ${ }^{581}$. En las escuelas superiores «a más de los ramos designados, se dará mayor ensanche a la instrucción religiosa, y se enseñara gramática castellana, aritmética, dibujo lineal, geografía, el compendio de la Historia de Chile y de la Constitución política del Estado (...)» ${ }^{582}$. En términos prácticos la enseñanza de la Formación Cívica estuvo bastante limitada porque «se enfatizaba la memorización, existían pocos manuales, los profesores tenían débil formación en las especialidades $(\ldots)^{583}$. La situación fue diferente en las escuelas secundarias con su marcado elitismo donde la formación como ciudadano político fue más evidente, ya que la enseñanza de la Historia de Chile y Universal y los manuales de Urbanidad fueron mecanismos de formación en los valores cívicos en dichos estudiantes. Al revisar los manuales que se utilizaron en las escuelas nos hemos percatado que la mayor parte de los textos escolares se propusieron describir los acontecimientos relacionados con la conquista y especialmente la independencia con la exacerbación del proceso de formación de la nación y de la república. La reforma curricular de 1872 incorporó la asignatura de Historia desde tercer año de Humanidades y quedó estipulado de la siguiente forma: «en tercer año (...) Historia de América y de Chile (...) Cuarto año (...) Historia antigua, griega y romana (...) Quinto año (...) Historia de la Edad Media (...) Sexto año (...) Historia moderna (...).» ${ }^{584}$ Hubo otros cambios que permitieron a los estudiantes una mayor vinculación con los contenidos de

\footnotetext{
${ }^{579}$ SUAREZ, J. B., Compendio de moral y urbanidad. Arreglado..., op. cit., p. 20.

${ }^{580}$ Ley de Instrucción Primaria, citado en Boletín de las Principales leyes y decretos vigentes redactados..., op. cit., p. 490.

581 Ibidem, p. 490.

582 Ibidem, p. 490.

${ }^{583}$ ROJAS, Jorge, Moral y prácticas cívicas en los niños chilenos, 1880-1950, Santiago, Ariadna Ediciones, 2004, p. 24.

${ }^{584}$ BALLESTEROS, Manuel, Compilación de leyes y decretos vigentes en materia de instrucción pública, Santiago, Imprenta el Independiente, 1871, pp. 91-92.
} 
formación Cívica, ya que, en 1882, se introdujo la asignatura de Historia de Chile en las escuelas primarias elementales y en 1898 se añadió, en dichas escuelas, la Formación Cívica y elementos de economía política.

La formación Cívica -como hemos visto anteriormente- se comenzó a enseñar primeramente en las clases de Historia de Chile, por medio de los manuales de Urbanidad y una pedagogía Cívica expresada en el culto a los símbolos patrios, en los funerales de Estado y en las fiestas cívicas. Si bien, en aspectos generales, el Estado chileno reconoció la necesidad de promover los valores patrios, el sentido de pertenencia al territorio y a una historia común y el respeto a las instituciones no fue hasta fines del siglo XIX concretamente en 1890 cuando surgieron propuestas para añadir educación Cívica en las escuelas hasta que finalmente se incorporó formalmente al currículum en 1898 con la finalidad de poder inculcar en los estudiantes el sentido de pertenencia a un Estado, a su historia, sus instituciones, la autoridad y lograr la identificación con los símbolos que aludían a la patria.

\subsubsection{Los manuales de Formación Cívica en Chile a fines del siglo XIX}

La situación chilena después de la Guerra del Pacífico (1879-1884), los conflictos limítrofes con Argentina y los primeros síntomas de descontento social que experimentó el país propiciaron el surgimiento de una demanda por incorporar oficialmente los contenidos de Formación Cívica en el currículum en un clima de alta sensibilidad frente al tema del patriotismo. La Formación Cívica se incorporó en 1898 de modo bastante descuidado, pero, poco a poco, comenzó a ganarse un estatus y legitimidad en el sistema escolar. Los contenidos comenzaron a ser enseñados desde algunos manuales y por medio de actividades cívicas en desfiles, juramentos y fiestas patriotas.

Los primeros textos que se convirtieron en manuales fueron poco adecuados para los estudiantes de colegios. En 1875, José Bernardo Suarez escribió un texto de divulgación para alumnos de las escuelas primarias que estaba redactado en forma de catecismo con preguntas y respuestas titulado Manual del ciudadano. Este texto tuvo un par de 
ediciones hasta que en 1880 editó Nociones elementales de gobierno republicano obra destinada para el uso de la clase obrera y en las escuelas primarias. En el prólogo de este último libro, Suárez escribía que «en un país republicano y democrático como el nuestro, es indispensable que todos sus hijos, llamados por la Constitución a ser ciudadanos activos con derecho de sufragio, conozcan el mecanismo del gobierno popular que nos rige» ${ }^{585}$. La formación de ciudadanos en Chile fue considerada una tarea preferente para lograr que el país se transformara en una sociedad civilizada y en cuya tarea la educación desempeñó un papel fundamental. El Manual de Suárez estipulaba una serie de contenidos que los ciudadanos debían conocer como: idea del gobierno, ventajas del buen gobierno, moralidad de los gobernantes, los poderes del estado, las elecciones y la constitución política. La idea del Manual era informar y el propio autor lo establecía al sostener que los ciudadanos debían tener conocimiento sobre el funcionamiento de la sociedad política, y Suárez lo aseveraba señalando que «todos debemos estar impuestos de la manera de proceder de nuestro carácter de ciudadanos y de miembros de la sociedad política a que pertenecemos, y ninguno debe ignorar cómo se practican las elecciones, cómo funcionan las cámaras, cómo se administra la justicia, cómo da sus fallos el jurado» ${ }^{586}$. Esto correspondía con la visón que el ciudadano es un sujeto que sabe y que cumple las normas de la convivencia política, pues «las personas que tienen derecho a elegir empleados públicos o ser electos, se llaman ciudadanos» ${ }^{587}$. La correlación entre buen gobierno y buen ciudadano era muy coherente pues «se deduce, que solo habrá buenos gobiernos cuando los ciudadanos sean ilustrados y se preocupen de los negocios públicos (...)» ${ }^{588}$. Al ciudadano chileno en el siglo XIX se le exigieron habilidades de lectura y escritura para contribuir a la idea de la ciudad letrada de modo que la escuela como dispositivo moderno contribuyó a la construcción de las subjetividades producto de la disciplina y la normalización. La concepción de ciudadano fue definida como un conjunto de conocimientos necesarios para todo ciudadano y en este sentido el Manual de Suárez y

\footnotetext{
${ }^{585}$ Nociones elementales de gobierno republicano, extractadas y arregladas para el uso de la clase obrera y de los alumnos de las escuelas primarias de Chile, Santiago, Imprenta El Correo, 1880, p. 5.

586 Ibidem, p. 5.

587 Ibidem, p. 31.

588 Ibidem, p. 38.
} 
el de Ramón Chavarría que ahora examinaremos fueron pensados en las coordenadas del conocimiento necesario que se debía adquirir.

Ramón Chavarría publicó en 1891 un texto denominado Cartilla de derecho chileno para el uso de las escuelas primarias de Chile en cuyas primeras páginas se conoce la intencionalidad puesto que declaraba que «lo hemos escrito especialmente: $1^{\circ}$ para los alumnos de las escuelas primarias; $2^{\circ}$ para los obreros; $3^{\circ}$ para los estudiantes de instrucción primaria. Creemos, sin embargo, que puede prestar una ligera utilidad a toda otra persona que no sea abogado, ya que éstos son en general los únicos que por sus estudios universitarios poseen ideas fijas en estas materias» ${ }^{589}$. Este texto contenía una información legislativa sobre: idea general de la humanidad, nociones de derecho, instituciones políticas, ministerios, aspectos centrales de la Constitución política de Chile, elementos de derecho administrativo, penal, civil y de minería. En rigor era un curso de derecho y leyes para abogados, aunque el autor en la presentación señalaba que la intención había sido un libro que permitiese que «nadie debe carecer de una noción general del derecho: el ciudadano y el que desempeña un cargo público, el marido y la mujer, el padre y el hijo, el comerciante, el minero, el agricultor, etc., todos necesitan conocer, aunque sea elementalmente sus derechos y obligaciones legales» ${ }^{590}$. El texto no poseía ningún tipo de ajuste al tipo de lector que anunciaba como destinatario, aspecto bastante común entre los textos escolares del siglo XIX orientados hacia el aprendizaje memorístico y reproductivo de sus ciudadanos.

Formar ciudadanos en los establecimientos escolares fue transformándose en un asunto primordial para el proyecto republicano. La noción de ciudadano se cimentó en la buena práctica de virtudes ciudadanas basadas fundamentalmente en el cumplimiento de deberes y el ejercicio de derechos. Los textos que fueron usados exclusivamente para la Formación Cívica informaban sobre la organización del Estado y sus instituciones reforzando las ideas de patria y nación, exaltando los símbolos y el respeto a las instituciones. Tanto el texto de Suárez como el de Chavarría eran compendios

\footnotetext{
${ }^{589}$ Cartilla de derecho chileno para el uso de las escuelas primarias de Chile, Leipzig, Imprenta F.A. Brackhaus, 1891, p. V.

${ }^{590}$ Ibidem, p. VIII.
} 
universitarios que pretendieron ser herramientas del soporte escolar para la difusión de la formación cívica.

En 1897 el Gobierno de Chile realizó un concurso público con la finalidad de dotar a las escuelas de un texto para la instrucción Cívica, puesto que dicha asignatura «se encuentra establecida en los planes de estudios de las escuelas públicas» ${ }^{591}$. Malaquías Concha ganó el concurso y el Manual fue publicado en 1905 con evidente retraso. Hemos querido incluir el trabajo de Malaquías Concha porque de alguna manera fue el primer texto de educación Cívica usado en las escuelas chilenas. También lo hemos incorporado porque representa fielmente los temas y concepciones acerca de la Formación Cívica que se tenían a fines del siglo XIX, por lo que no representa un quiebre en el modo de concebirla y además por el mérito de haber incorporado en un mismo texto patria, nación y ciudadanía.

Vincular la nación chilena con el territorio constituye en Malaquías Concha la primera forma de relacionar la ciudadanía con la patria en términos jurídicos y el compromiso afectivo. La patria era «el suelo querido que nos ha visto nacer, la casa donde hemos pasado nuestra infancia; el prado, el bosque, los montes que nos son familiares (...) pero la patria abraza un territorio más vasto, se extiende hasta dónde van los límites geográficos y políticos con los pueblos vecinos» ${ }^{592}$. La Cartilla partía del principio de una ciudadanía territorial en donde amar la patria, participar en los asuntos públicos, respetar y defender las instituciones y el orden eran garantes de la felicidad de la nación. La ciudadanía concebida como deber con la patria sugerida en que «un buen ciudadano lo debe todo a su patria. Se llama patriotismo la virtud del hombre que ama realmente a su país. Los pueblos que carecen de patriotismo son fáciles presa de los enemigos» ${ }^{593}$. Un amor a la patria desinteresado y sin otro fin que no fuera el bienestar de la república.

\footnotetext{
${ }^{591}$ CONCHA, Malaquías, Cartilla de educación civica. Elementos de derecho público y de economía política para el uso de las escuelas superiores y normales de la República, Santiago, Imprenta y litografía Universo, 1905, p. IV.

${ }^{592}$ Ibidem, p. 12.

${ }^{593}$ Ibidem, p. 13.
} 
En la etapa de instalación de la asignatura de Cívica los programas estaban reducidos a la entrega de información sobre la organización del Gobierno, el sistema electoral, la Constitución y muy tenuemente el progreso y bienestar de los ciudadanos. La vinculación de patria y ciudadanía concebida como los deberes fue el punto de partida de la formación ciudadana y Concha lo explicó de la siguiente forma: «hay otros deberes de todos los días que debemos llenar para ella. Debemos interesarnos en los negocios públicos, tomar parte en las elecciones, pagar los impuestos, hacer el aprendizaje de la Guardia Nacional, respetar las leyes y conducirnos bajo todos respectos como buenos y útiles ciudadanos» ${ }^{594}$. A su vez, el Estado debía proporcionar las condiciones a los individuos en pro del bienestar y de la democracia que fue pregonada por los fundadores de la nación se hiciera realidad y por lo tanto «la nación es guardiana de los derechos del individuo, debe proteger al débil contra el fuerte, y tener cuidado de los intereses de aquellos que no pueden valerse por sí mismos» ${ }^{595}$. El bienestar y protección para toda la población estuvo impregnado de la idea liberal de la igualdad entendida como el esfuerzo que debía «asegurar a todos los ciudadanos el derecho a medirse en condiciones idénticas. No es abatiendo las altas cimas como se produce la igualdad sino levantando el nivel inferior por medio del trabajo y la instrucción, hasta igualar a las mayores alturas, a condición de que el derecho sea igual para todos ${ }^{596}$. En el texto de Malaquías Concha las referencias encontradas nos permite asegurar que la finalidad no estaba solo en la instrucción, sino que aspiró a que la formación cívica no se limitara a lo elemental, ya que se requería como mínimo un ciudadano instruido, pues «la educación considerada bajo el punto de vista político, es una tarea primordial del Estado como que es la fuente misma de su existencia luego «cuando exista la instrucción universalizada estará establecido de hecho el sufragio universal» ${ }^{597}$.

La Formación Cívica propiciada en Chile a fines del siglo XIX y principios del XX respondió a dos lógicas, por una parte, proporcionar a los individuos los conocimientos

\footnotetext{
${ }^{594}$ Ibidem, p. 13.

${ }^{595}$ Ibidem, pp. 47-48.

${ }^{596}$ Ibidem, p. 40.

${ }^{597}$ Ibidem, p. 43.
} 
mínimos para manejarse en el ámbito político y, por otro lado, asegurar la cohesión social por medio de la transmisión de los símbolos y la historia de la nación. Un Estado chileno integrador que buscaba el bien general y los principios liberales de fraternidad e igualdad, la primera entendida como «el sentimiento profundo de la solidaridad que debe unir a los hombres entre sí como miembros de una familia» ${ }^{598}$, y la segunda definida en términos de exigencia de los ciudadanos, ya que «lo que debemos reclamar en nombre de la igualdad es que la Nación se esfuerce en facilitar a todos los ciudadanos los medios de corregir, en lo posible, las desigualdades sociales. El más eficaz de estos medios es la educación» ${ }^{599}$. Aun cuando las ideas presentes en el proyecto político y la Formación Cívica enarboló las banderas de la igualdad estas materias al ser impartidas en las escuelas superiores y normales marcó una diferenciación social debido a la procedencia de los estudiantes, la mayor parte de la población cursaba la primaria, sólo los sectores pudientes accedían a la educación secundaria, entonces a uno se les preparaba para ser ciudadanos de primer orden y asumir el aparato estatal, a otros para ser ciudadanos obedientes, civilizados y disciplinados.

La Formación Cívica fue clave en las escuelas secundarias para comunicar las responsabilidades y derechos de los futuros ciudadanos, puesto que «los jóvenes alumnos de hoy llegarán mañana a ser ciudadanos y tendrán derechos que ejercer y deberes que cumplir para con la patria» ${ }^{600}$. La escuela decimonónica centró su atención en favorecer las virtudes cívicas en los estudiantes que acudieron a las escuelas secundarias para que les permitiese actuar en la sociedad republicana, y en ese sentido la escuela se valió de la enseñanza de lo cívico, de textos escolares de Historia, manuales de Urbanidad y finalmente manuales de educación Cívica para instaurar las lealtades republicanas, los elementos de moralidad y los valores cívicos de la república. Como hemos visto anteriormente, en los textos abundaron los temas asociados a los derechos y compromisos de quienes se convertirían posteriormente en actores de la república. Los derechos y deberes estaban fundados en los principios de libertad,

\footnotetext{
598 Ibidem, p. 47.

599 Ibidem, p. 41.

${ }^{600}$ Ibidem, p. 19.
} 
igualdad y fraternidad en términos de proyecto político y en esto se demandó al Estado la función educadora con la finalidad de prosperar en el proceso de formación ciudadana. Si parte importante del siglo XIX había estado centrado en la formación de la nación, a finales de dicha centuria el Estado se entregó a la misión de formar ciudadanos. 


\section{CONCLUSIONES}


En Chile, la nación, los nacionales y la ciudadanía se configuraron en el siglo XIX debido a la importante acción que realizó la elite que fundó el Estado nacional unitario sentando las bases a lo largo de dicha centuria para terminar de consolidarse en el nuevo siglo. Las características de homogeneidad y unidad que definieron al Estado chileno han sido criticadas en las últimas décadas a raíz de los problemas de desigualdad económica y social.

\section{Sobre la conformación del Estado nacional chileno en el siglo XIX: conceptos e historia}

La idea de nación y su concreción en el Chile decimonónico tuvo un genuino carácter civilizador, ya que este fue el medio por el cual se instaló la homogeneidad y la unidad cultural que requería el proceso de identificación entre Estado y nación. Las formaciones de las naciones en América no se pueden explicar sin la presencia del Estado, estas fueron en su proceso de configuración, absolutamente modernas. Modernas porque fueron naciones políticas y desde el siglo XIX constituyeron el armazón material y simbólico de más amplia propagación en las comunidades humanas originando las identidades nacionales. Estas acciones fueron coherentes con las dos preocupaciones de los Estados nacionales: las nociones de prosperidad e identidad nacional.

La identificación con la nación fue una construcción nueva en relación a otras formas de agruparse que existieron antes de siglo XIX. La nación chilena surgió como necesidad de la elite para articular su espacio de dominación, una elite pequeña y altamente cohesionada que fue capaz de crear una nación política, asimilando a la población en general desde la homogeneidad cultural y con muy poca resistencia al proyecto político. En ese papel de configuradores del sentimiento de pertenencia nacional, los intelectuales, los políticos y los pedagogos diseñaron un relato constitutivo de mitos, historias, excepcionalidades, símbolos, ritos de un imaginario nacional que se difundieron a la sociedad por diversos mecanismos. Aun cuando los logros alcanzados en el largo tiempo fueron positivos, la población en edad escolar que acudió a la escuela estuvo por debajo de las expectativas por temas de infraestructura y resistencia de los padres de enviar a sus hijos a los establecimientos educativos generando un absentismo escolar sostenido, pero que al aumentar el número de escuelas y estudiantes permitió ampliar la cobertura escolar en el paso de un siglo a otro. Lo anterior no quita que la deserción no haya sido obstáculo para la implementación de la educación. La concreción de la nacionalización fue posible cuando esos mecanismos se dispusieron para concretar el proyecto y la omnipresencia del Estado fue clave para aumentar la presencia de la escuela en la nación y evidentemente ésta 
se tornó más poderosa cuando se hizo obligatoria, extirpando la diversidad, la heterogeneidad y extendiendo una cultura básica primordial para el funcionamiento del Estado.

Las acciones emprendidas por los sucesivos gobiernos chilenos y los hechos bélicos que debió enfrentar Chile a lo largo del siglo XIX facilitaron la idea de la construcción política y unitaria de un Estado nacional. Desde muy temprano se planteó la idea de nacionalizar las sensibilidades y las costumbres de los chilenos. El unitarismo, la legalidad y la institucionalización del Estado hicieron viable por un largo período edificar las bases de la nación para que se consolidarán en las primeras décadas del siglo XX. La acción del Estado fue imprescindible para la existencia de la nación dada su función básica de integración desarrollada por medio de instituciones, leyes, normas, prácticas comunes y donde la educación debía dotar de organización a sus individuos. El Estado configuró y otorgó identidad a un pueblo tanto en su dimensión espacial como en su despliegue temporal, unificando y reduciendo la diversidad a una unidad política.

La formación del Estado y la nación constituyó un aspecto central del proceso de construcción social en el cual diferentes planos y componentes estructuraron la vida social organizada. Población, territorio, civilización, progreso, historia nacional son algunos de los elementos claves en dicha construcción que fundaron la integración nacional. De tal modo que dicha integración fue el resultado articulador y coherente del Estado configurando la comunidad. Cualquiera sea el origen y tipo de Estado, la unidad no se mantiene cohesionada sólo por un espíritu común de solidaridad, un consentimiento básico, costumbres ancestrales y recientes compartidas por todos o por leyes aceptadas, sino también por el ejercicio monopólico de la coerción. El Estado necesitó un potente dispositivo de fuerza para defender su soberanía y el despliegue de sus instituciones, el imperio de la ley y la integridad territorial, frente a unos eventuales agresores externos o internos, que podrían poner en peligro su continuidad y estabilidad.

La coerción del Estado no sólo es física. Bourdieu agrega una dimensión nueva, que es la coerción ejercida legítimamente por el Estado que no es sólo física, sino que también simbólica ${ }^{601}$. El Estado garantizó la construcción de lo nacional y dispuso de recursos necesarios para imponer significantes. Fueron procesos por los cuales la nación comenzó a reconocerse a sí misma gracias al esfuerzo estatal de reconocimiento de sus miembros. Por ello, aprender a ser nacionales fue un proceso complejo y en dicho aprendizaje el rol de la institución escolar fue

${ }^{601}$ Vid. BORDIEAU, Pierre, Razones prácticas, Barcelona, Ed. Anagrama, 1997. 
clave, ya que debía ser sistemático, integrador y permanente, constituyéndose en uno de los principales mecanismos que el Estado diseñó para contribuir a definir los imaginarios e historias nacionales.

Por lo anterior, el Estado nacional chileno diseñó y ejecutó un plan para la creación de la nación construyendo una república liberal, con instituciones que legitimaron la nueva realidad política. Para la concreción del proyecto utilizó varios mecanismos, entre ellos, la educación, construyendo relatos e historias compartidas y valoradas como gérmenes de la nación. El Estado mediante lo legal y constitucional e institucional proporcionó legitimidad y vínculo a sus habitantes comunicando además símbolos, civismo, urbanidad, territorialidad y los conocimientos básicos requeridos para construir la nación, los nacionales y la ciudadanía.

\section{Papel de la educación en el proyecto de construcción de la nación, los nacionales y la ciudadanía}

Las fuentes utilizadas, los referentes teóricos y conceptuales empleados en esta investigación nos mostraron un discurso extraordinariamente optimista sobre el papel desempeñado por la educación en la construcción del Estado nacional chileno. La visión optimista fue producto del liberalismo que le adjudicó a la instrucción pública una fuente de prosperidad y de medio para la formación de un hombre y sociedad nueva como condiciones mínimas para la felicidad. La misión conferida al Estado para la construcción de la república utilizando la educación fue parte importante de la agenda de la política decimonónica, como asimismo la provisión de recursos financieros y el desarrollo de las obras públicas. Entonces, la educación se configuró como la institución imprescindible para la conformación de la nación, los nacionales y la ciudadanía en el ideario republicano que permitiese el funcionamiento del nuevo estado. Dicho de otra forma, sujetos integrados en una nación moderna fundada en una comunidad de nacionales y ciudadanos.

El sistema escolar se desarrolló en Chile construyendo un sistema centralizado dirigido por el Estado y elevado a la categoría de espacio fundamental para la enseñanza y aprendizaje de lo público donde los valores colectivos, las normas, los rituales, el lenguaje y la historia nacional eran los pretextos ideales para dicha construcción. Los gestores de la República de Chile comprendieron perfecta y tempranamente que la educación era el colaborador idóneo y para las manifestaciones unitarias del nuevo Estado. La implantación del sistema educativo se inició en forma intermitente y con una instalación definitiva a partir de 1840 . 
La educación fue pensada como un mecanismo para fortalecer el Estado y fundar la conciencia nacional; por eso, el interés permanente por estimular su desarrollo. La educación fue pensada como el medio para sacar a la población de la ignorancia y hacerla respetuosa de las normas que debían gobernar a Chile. La educación fue el arma de la razón y por medio de ella los habitantes se convirtieron en chilenos, ciudadanos, hombres disciplinados y ordenados. La educación fue el signo de la lógica de la modernidad decimonónica.

El caso chileno tuvo la particularidad que con el nuevo sistema político tuvo un importante rol no sólo en la organización, sino también en la dotación de educación. Tuvo carácter fundacional, ya que, con su acción, se plasmó la responsabilidad pública de la educación, es decir, un asunto público. La educación tuvo un claro cariz republicano, más que individual y utilitario. Si bien, los resultados cuantitativos pueden ser sometidos a críticas, lo crucial fue la comprensión estatal que la escritura tenía una gran capacidad para transformar a los individuos y a la sociedad, fue el pilar básico del cambio social. Constituyó el requerimiento para ingresar a la nacionalidad, a los preceptos morales, al dominio de las pasiones y del cuerpo, al cumplimiento del deber y a la felicidad del individuo.

La transformación hacia la república se basaba en una comunidad política sustentada en la escritura. La obtención de la escritura se lograba por medio de la instrucción, instruidos debían ser los signos que caracterizaran a los miembros del estado y de la nación, ya que la república era el gobierno de todos y para todos: «todos deben ser instruidos para que todos puedan gobernar.» ${ }^{602}$ Alfabetizar en todas sus dimensiones a la población fue un imperativo estatal y la escuela fue ideada como su principal agente. La Ley de Instrucción Primaria de 1860 constituye no sólo un hito educativo y legislativo ya que fijó una proporción entre número de habitantes y número de escuelas, estableció escuelas gratuitas, generó políticas de financiamiento y que los profesores fuesen empleados públicos. Todo lo anterior, generó un nuevo vínculo entre población y Estado ya no fue el Estado magnánimo, sino que tuvo que hacerse cargo legalmente de su proyecto.

El éxito del proyecto chileno estuvo dado por la existencia de un territorio compacto, con muy poca población indígena al norte del río Biobío, no hubo complicaciones graves ni división de intereses al interior del grupo dominante, hubo muy poca diversidad regional y como señala Collier y Sater «las provincias más remotas al norte y al sur pueden haberse sentido un poco

${ }^{602}$ AMUNATEGUI, M. y AMUNATEGUI, G., De la Instrucción primaria en Chile ..., op. cit., p. 70. 
abandonadas por Santiago, pero no tenían como contrapesar la hegemonía de la capital y de las riquezas de la zona central» ${ }^{603}$. Aunque hubo algunos intentos federalistas y regionalistas como en Concepción y La Serena, el gobierno central terminó por imponerse con poderes y facultades para implementar y conducir el futuro de la nación. Consecuentemente, en el caso chileno hubo un poder central unificado que no tuvo mayores resistencias, en donde estuvieron representados los tres grupos de poder: comerciantes, mineros y hacendados.

La estructuración de una sociedad nacional logró dar importantes pasos en la transmisión de un proyecto nacional en valores y principios republicanos; para ello construyó escuelas, formó preceptores y preceptoras, dictaminó sucesivas normas y leyes, diseñó un sistema educativo en primaria y secundaria y se valió de una diversidad de impresos como los manuales para la difusión de los propósitos nacionales. Desde los primeros años de la República de Chile muchas propuestas se dedicaron, especialmente al fomento de la instrucción pública y a la creación de escuelas. La escuela y especialmente la primaria fueron los principales espacios al cual acudieron progresivamente los futuros nacionales y ciudadanos en los preceptos de la república. En estos espacios se transmitió un discurso sobre el pasado y el presente.

\section{Representaciones e imaginarios republicanos presentes en la elite chilena y en los manuales de Historia, Geografía, Urbanidad y Formación cívica durante el siglo XIX}

El discurso sobre el pasado fue un elemento clave en la configuración de los países latinoamericanos. Sus raíces fueron puestas en el pasado colonial, no como proto-nacionalismo, sino en términos que lo que comenzó a ocurrir después de la independencia fue promovido y construido por la elite que había adoptado los principios liberales y republicanos, por lo tanto, Chile era obra de la república. Esta «nueva elite» proyectó después de la independencia una organización política que permitió la homogeneidad, el control de los mercados internos, la incorporación al mercado internacional y sobre todo la conservación del poder. Los países latinoamericanos construyeron sus relatos nacionales de dos formas: unos, con rasgos y símbolos que provenían de los elementos precoloniales, como México y Perú, y otros, en cambio, como Chile, enfatizaron el carácter occidental de la identidad nacional y se ocultaron los componentes culturales de otro origen. Chile incorporó elementos del pasado colonial de manera discursiva, pero la nación como tal fue una situación nueva que se constituyó con

${ }^{603}$ Historia de Chile ..., op. cit., p. 57. 
posterioridad a la independencia y en donde el componente étnico formador de nacionalidades no se consideró.

En los relatos escolares sobre Chile predominó la idea de la excepcionalidad, ya que en los sectores dirigentes chilenos hubo una temprana idea de forjar la nación y de considerar a Chile como una particularidad en el concierto latinoamericano, incluso el propio Simón Bolívar en la carta de Jamaica refirió que el «(...) reino de Chile está llamado por la naturaleza de su situación, por las costumbres inocentes y virtuosas de sus moradores, por el ejemplo de sus vecinos, los fieros republicanos del Arauco, a gozar de las bendiciones que derraman las justas y dulces leyes de una república. Si alguna permanece largo tiempo en América, me inclino a pensar que será la chilena. Jamás se ha extinguido allí el espíritu de libertad; los vicios de Europa y Asia llegarán tarde o nunca a corromper las costumbres de aquel extremo del universo. Su territorio es limitado; estará siempre fuera del contacto inficionado del resto de los hombres; no alterará sus leyes, usos y prácticas; preservará su uniformidad en opiniones políticas y religiosas; en una palabra, Chile puede ser libre» ${ }^{604}$. En el bautismo republicano de Chile se fraguó a hierro la idea de la peculiaridad chilena como parte esencial de la narrativa, y se construyó y difundió un discurso frecuente de la narrativa histórica nacional. Esta singularidad y aislacionismo son suficientes explicaciones de la nula vocación chilena del panamericanismo y aunque algunos manifestaron deseos del sueño bolivariano, esto no se extendió en la elite.

La conformación de chilenos y ciudadanos pasó inevitablemente por el reconocimiento del poder de la escritura manifestada en la ley, la autoridad, las instituciones republicanas. El Estado mediante la escritura ordena e institucionaliza la nueva realidad política. La escuela y los manuales fueron elementos esenciales en la construcción del ideario republicano homogeneizante donde desempeñaron un papel interesante transmitiendo a los estudiantes la concepción del territorio patrio o nacional. Además, se transformaron en valiosas herramientas para la construcción del imaginario nacional y romper con las viejas concepciones coloniales de tipo tradicional por unas nuevas forjadas en la racionalidad de la escritura.

En la enseñanza de la Historia como hemos podido advertir los historiadores definieron dos asuntos: el pasado que se quería narrar y la función de la historia en la construcción del ideario nacional. Se definió que el pasado se iniciaba con la llegada de los conquistadores, que de los

${ }^{604}$ Ideario Político, Caracas, Ediciones de la Presidencia de la República, 2001, p. 64. 
tiempos coloniales se enfatizaría la valentía y rebeldía de los indios frente al invasor. Por otro lado, estaba la disyuntiva, si el conocimiento histórico debía ser propagado a la sociedad o sólo debía ser conocido por un grupo reducido. Triunfo la narrativa histórica y la enseñanza de Historia se incorporó al currículo escolar en la segunda mitad del siglo XIX.

Los textos escolares utilizados en Chile y que hemos analizado nos reportaron información acerca de las intenciones de sus autores, de la exposición de los contenido y secuencialidad. Los historiadores que en el caso chileno fueron los autores de textos escolares utilizados en las escuelas fueron los profetas de la memoria y los escribas de la patria, ayudaron a crear entidades nacionales y a instalar la idea de los padres fundadores. El plan fue realizar investigaciones produciendo densos trabajos donde compendiaron los resultados de esas indagatorias y hacerlos circular por medio de la escuela pública y la labor de los preceptores.

Estos manuales recogían el conocimiento de la historia nacional por medio de relatos heroicos, pero en el siglo XIX su acceso y cobertura fue limitada. Ese guion lo aportó la historia para la celebración y teatralización de los acontecimientos del pasado. La escuela fue le lugar predilecto en que el Estado se hacía presente en los discursos de autoridades políticas y académicas, en la exhibición y devoción por lo símbolos patrios. La escuela fue $-\mathrm{y}$ sigue siendo- el espacio de la lealtad simbólica a la patria gracias a gestos, cantos y signos. La escuela generó en Chile una suerte de «estadocentrismo» donde la historia escrita y la historia festejada fueron la expresión más evidente del amor a la patria y el respeto al Estado.

La difusión y cobertura de los manuales no fue la deseada, pero tuvieron los contenidos esenciales del discurso acerca de la historia nacional con el hito fundacional de la independencia nacional. Los relatos en los manuales fueron muy conciliadores, no se ensalzó a determinados personajes como en el resto de los países latinoamericanos. En estos textos la biografía prolija, detallada y extensa no existe, son relatos de la elite en su conjunto y faltos de una crónica castrense como constructores de la nación privilegiando el relato histórico de carácter colectivo.

Los manuales escolares fueron un instrumento aventajado para la definición de identidades y políticas de la memoria. Sus contenidos fueron regulados a fin de transmitir la versión oficial de la historia e imponer valores y conductas en los educandos. Se buscaba formar un ciudadano obediente que no alterara la estabilidad política ni la paz social e integrar a todos los habitantes en un sentimiento y certidumbre común. 
La educación cumplió una función de reproducción y conservación cultural que influyó sobre la sociedad en su conjunto. Las políticas educativas definieron los planes de estudio y diseñaron los contenidos de los programas de las asignaturas. La escuela desempeño un rol fundamental en la preparación, transferencia e inculcación de los contenidos y referentes pretéritos configuradores de las comunidades imaginadas que comenzaron en ese siglo a llamarse naciones. Los ritos de adhesión a la patria plasmada en las efemérides y los manuales escolares constituyeron los mecanismos eficaces para la concreción de del proyecto político de la elite. Tanto el sistema, como los textos, estuvieron al servicio de un proyecto que requirió cumplir con tres objetivos: sentar las bases del orden liberal, construir un sistema de representación política unificado y organizar el Estado. La formación de la nación implicó una fundación por la palabra escrita que supuso la creación de un relato discursivo legitimador y cohesionador con el establecimiento de una liturgia cívica.

Los estados modernos del siglo XIX que fueron herederos de las tradiciones revolucionarias del siglo XVIII involucró la consolidación de sistemas políticos, administrativos, jurídicos y educativos que contribuyeron paulatinamente a la gobernabilidad territorial. De esta forma, desde mediados del diecinueve el Estado chileno comenzó a gobernar una sociedad definida territorialmente lo hizo en calidad de nacional.

En la misión de obtener la unidad nacional, la educación desempeñó un papel importante, tarea que la realizó entre otras, por medio de los textos escolares y manuales que promovieron los imaginarios para la construcción de la nación tales como el territorio, asumido como el espacio en que se desenvuelve la nación; la ley y la constitución, como las fuentes de la gobernabilidad y el orden; el catolicismo, entre otros. Se construyeron referentes que articularon y dieron sentido a la nación naturalizando y legitimando las instituciones como formas genuinas de organización social. Los textos alentaron la cohesión entre territorio y nación a partir de las relaciones simbólicas provistas por el lenguaje y el Gobierno.

El Estado nacional chileno fue comprendido como una transformación natural de la sociedad y que bajo su amparo ofreció un futuro positivo, y en los textos se definía la patria como base nuclear de la nación donde se advirtió que la existencia de la misma debía ser enseñada pues «la tarea de la escuela primaria queda claramente determinada: la historia de Chile tiene que formar el punto de mira para el cultivo dela mor patrio: ella debe presentar vivamente al discípulo la vida, los hechos y destinos del país. El corazón del niño debe filtrarse, por decirlo así, mediante 
el conocimiento de la historia nacional, de esas cualidades especiales que le cautivan y llenan de interés: el heroísmo, la abnegación, el sacrificio, grandezas morales que resplandecen de un modo especial en el suelo patrio, como astros de primera magnitud ${ }^{605}$. Así podemos aseverar que la idea de nación estuvo vinculada a la acción de unos hombres -valientes e ilustres- que sacrificaron su vida por la patria, por lo tanto, la organización política resultantes fue por la acción heroica y noble de unos notables. La forma en que se incorporó a la sociedad fue con la promoción de la idea abstracta de la nación centrando el recuerdo en una historia política de héroes nacionales donde la historia no solo es fuente del pasado, sino que es la forma en que se pensó la construcción de la nueva nación, idea que adjudicó a los héroes la formación de la nación lo que redundó en que los hechos fundacionales fueran las campañas militares.

Los manuales de Geografía apoyaron el discurso e interpretación del pasado y el presente situado en una representación positiva y compartida del territorio, de la forma como ha sido ocupado, las características de sus habitantes. Los textos de Historia y Geografía apoyaron las ideas de legitimación, homogeneización e instalación de una cultura común que exigía la nueva comunidad política. Estos manuales incluían la apología del territorio con una descripción parcial y sesgada y la utilización de mapas que incitaban a la conformación de una imagen del nuevo suelo. La geografía política contribuyó a identificar el centralismo santiaguino con la modernidad y que en ello radicaba el éxito del Estado nacional.

Los textos escolares geográficos simplificaron la realidad nacionalizando el paisaje proyectando una imagen optimista del país para despertar entre los niños y jóvenes la admiración por su patria. La imagen elogiosa estaba relatada alrededor de la idea que los chilenos gozan del mejor de los espacios posibles con bellísimos paisajes, clima benigno, suelos fértiles, ríos caudalosos, recursos minerales abundantes, población caucásica y nada de salvajismo. Los inconvenientes no eran presentados, y que, de haberlos, estaban en vías de inminente solución. Se insistía hasta la saciedad de la condición geográfica excepcional y por eso Chile era una nación distinta.

La función de la enseñanza de la Urbanidad y de los preceptos morales fue en consecuencia enseñar las normas que debían regir tanto en los espacios privados como públicos transmitiendo los aspectos básicos que rigen las relaciones sociales y fue un vehículo para comunicar los valores que la elite quería transferir a las demás clases sociales. Los manuales de Urbanidad

${ }^{605}$ OROZ, Ruperto, El amor patrio. Formación y desarrollo en la escuela, Valparaíso, Imprenta y Litografía Excelsior, 1900, p. 29. 
proporcionaron a los niños y jóvenes decimonónicos los principios del buen comportamiento y las buenas maneras que se consideraban indispensables para formar parte de la sociedad liberal, acomodada y moderna. Fueron textos utilizados también en las escuelas que se mantuvieron sin grandes modificaciones a lo largo de toda la historia republicana de Chile.

Los textos de Urbanidad utilizados tuvieron gran impacto en la educación informal y formal, en escuelas, parroquias y en los hogares. Los manuales fueron instrumentos y evidencia del rasgo de una sociedad colonial y religiosa a una republicana y laica cambiando feligreses por nacionales y ciudadanos que se fueron secularizando en el tiempo. El estudio de estos manuales constituye más una exploración de los ideales y normas que la elite y el Estado deseaban conformar que una historia de la forma en que se dio en la práctica. La existencia de más de diez manuales de Urbanidad -citados en esta investigación- fueron un signo de la preocupación por modificar modos de vida tanto en los espacios privados como públicos en pro de la felicidad republicana y fueron herramientas indispensables para la creación de hábitos indispensables para los requerimientos de la república.

Los manuales de Formación Cívica que circularon en Chile a fines del siglo XIX y principios del XX constituyeron un instrumento que trasmitió las responsabilidades y derechos de los futuros ciudadanos, aunque como hemos visto, estos contenidos antes de la aparición de dichos manuales estuvieron implícitos en las clases y manuales de Historia donde se enseñó cómo se había formado el Estado, nociones de las instituciones republicanas, y por sobre todo el amor a la patria. En el programa que se aprobó para la enseñanza de la educación Cívica en 1901, ésta se debía impartir en Cuarto año de Humanidades y debía centrarse en la noción de patria y su historia, los derechos y deberes ciudadanos y la organización del Estado. Se enfatizó en las obligaciones y el fomento del sentimiento patrio. Con la incorporación de la Formación Ciudadana la escuela ya no fue sólo el lugar donde se aprendía y enseñaba religión, letras, aritmética, historia, ciencias, sino que se fue transformando en una simulación de la república, pues los valores cívicos se enseñaron por medio de textos y por la imitación de las formas republicanas, especialmente por medio de las ceremonias cívicas como: conmemoración de la independencia, saludo a la bandera, entonación del himno nacional y los aniversarios de los hechos históricos más relevantes. Lo anterior, se debió a la concepción de formar hombres en una moral republicana liberal y se entendió que los niños y los jóvenes eran los cimientos del nuevo proyecto de nación y que salvaguardar su educación era cuidar sus costumbres que era lo mismo que defender la patria. 
Todos estos manuales analizados en esta investigación impulsaron también formas de rendir culto y lealtad a la nación, que más allá de los contenidos curriculares que se enseñaron permitieron el desarrollo de una pedagogía cívica reflejada en fiestas cívicas, bandera, escudo, himno, funerales de Estado y, por cierto, el buen uso de la lengua castellana.

Las fiestas cívicas actuaron como formas de fijar actitudes y comportamientos morales y patrióticos. Y hubo que pasar de la fiesta colonial a la fiesta republicana con una estructura muy parecida a las que se realizaron bajo el Imperio español, pero teñidas simbólicamente de un nuevo pensamiento y estética. La nueva fiesta republicana fue capaz de educar y lugar privilegiado para transmitir las virtudes y valores republicanos en la comprensión del poder de la representación simbólica del Estado nacional. La fiesta fue la mezcla de elementos intelectuales y emocionales que se dispusieron para el adoctrinamiento.

La bandera nacional constituyó también una interesante mezcla de colores y emociones. Los colores terminaron por asociarse a la nación donde se simbolizaron los atributos geográficos, de sus antiguos habitantes y de los ideales republicanos. Es por ello que el rojo simboliza la sangre derramada por el pueblo araucano, la franja azul representa la pureza de nuestro cielo, el blanco la majestuosidad de nuestra cordillera de los Andes y la estrella solitaria representa la calidad de República libre y unitaria. El escudo nacional utilizó los mismos colores y con sus elementos gráficos construyó un relato abstracto y poderoso representado en dos animales a los cuales se les proporcionó atributos de chilenidad republicana: grandiosidad del cóndor y singularidad del huemul.

El himno nacional en el proyecto cultural simbólico del Estado chileno logró crear afectos hacia la patria y sentimientos de pertenencia a una unidad colectiva constituyendo una forma efectiva de fomentar la lealtad y cohesión ajustadas a los intereses de la elite que controlaba el poder. La letra y música fueron capaces de configurar un intenso sentimiento de unión entre pueblo y nación. El himno fue particularmente exitoso e importante, ya que fue capaz de representar a los chilenos una imagen y narrativa aceptable e estimulante.

Los funerales de Estado fueron los momentos solemnes en que se rindió homenaje a aquellas figuras que merecían el culto laico pues encarnaron la nación en la cabeza y corazón de la población y constituyeron ejemplos a seguir. La elite modeló y proporcionó al imaginario un discurso ideológicamente motivante. De esta forma, los personajes históricos se insertaron en 
los anales de la historia de Chile, los funerales formaron parte de un proceso de invención y reproducción del simbolismo nacional.

La lengua castellana fue un referente que contribuyó a la construcción de la nación, ya que fue un factor determinante en la apropiación de los saberes sociales y, sobre todo, que al potenciarse su uso en forma escrita permitió la implementación del proyecto político. El castellano asumido como lengua oficial fue instalado y comunicado desde la escuela y permitió la unidad y la homogeneidad.

En todo lo anterior, la escuela y los manuales promovieron los mitos e historias de la nación privilegiando territorio, ley, héroes, hechos históricos, sustentos de la república independiente. El siglo XIX nos proporciona evidencia histórica de la ardua labor de hombres interesados en la construcción de una nación imaginada. Se buscó por parte de intelectuales, políticos, maestros, militares, entre otros grupos sociales, transformar un país tan desigual en su origen, sin embargo, el avance del siglo con sus duras sacudidas transformó sus ideas, pragmáticas y racionales en un país que enfrentó los desafíos de la modernidad que pretendió ser moderna, pero que en el siglo XX no fue capaz de mantener la cohesión. Los problemas de la incipiente nación no fueron limitantes para construir un proyecto educativo; el desánimo no era parte del siglo, muestra de ello es la cantidad de documentación escrita a lo largo de estos años: leyes, decretos, constituciones, reglamentos, manuales, libros, y mucho más. El objetivo era claro: se requería de la educación para construir y dar sentido a la nación.

A lo largo de las páginas de esta investigación hemos pretendido dar cuenta de los esfuerzos y logros del papel educador e ideológico del Estado nacional chileno para garantizar el orden, la estabilidad y la institucionalidad política. El proceso de construcción y de modernización de la nación y del Estado requirió ocuparse adecuadamente del liderazgo para configurar en la población un imaginario común. Por consiguiente, el proceso de consolidación necesitó de la educación como un espacio que legitimó y dotó de solidez institucional el Estado nacional chileno.

La educación chilena tuvo la capacidad de vincular el pasado colonial con el presente republicano promoviendo los cambios sociales, culturales y políticos que permitieron sentar las bases para un país que deseaba ser moderno. En virtud del proyecto nacional la elite depositó en la educación la tarea de construir la nación, los nacionales y la ciudadanía chilena. 
FUENTES Y BIBLIOGRAFÍA 


\section{1) Fuentes Primarias}

\section{a) Archivos}

Archivo Nacional de Chile, Fondo Ministerio de Educación.

Archivo Nacional de Chile, Fondo Ministerio de Justicia.

\section{2) Fuentes secundarias}

\section{a) Fuentes oficiales}

Anuarios Estadísticos de la República de Chile, 1845-1900.

Boletín de leyes y decretos del Gobierno de Chile, Imprenta nacional, Santiago, 1891.

Censo General de la República de Chile levantado en abril de 1854, Santiago, Imprenta del Ferrocarril, 1858.

Constitución provisoria para el Estado de Chile de 1818, en Archivo O’Higgins (AOH), vol. 11 .

Constitución política del Estado de Chile, Santiago, Imprenta del Estado, 1822.

Constitución política de la República de Chile, Santiago, Imprenta de R. Rengifo, 1828.

Elementos de higiene, Santiago, Imprenta Gutemberg, 1891.

El monitor de las escuelas primarias, Tomo VI, № 9 (1858).

«Ley de Instrucción Primaria» en LARRAIN, J. Ignacio y LARRAIN, J. Joaquín, Boletín de las principales leyes y decretos vigentes dictados desde enero 1 de 1870 hasta enero 1 de 1871 y recopilación por orden de materias, Valparaíso, Imprenta El Mercurio, 1871.

Memoria del Ministerio de Justicia, Culto e Instrucción Pública, Santiago, Imprenta Nacional, 14 de agosto de 1865 .

Ministerio de Educación, Análisis de indicadores educativos de Chile y la OCDE en el contexto de la reforma Educacional, Santiago, Ed. Ministerio de Educación,2015.

Oración fúnebre pronunciada por el presbitero Rafael $V$. Valdivieso en las exequias que se celebraron en la santa Iglesia de la Catedral por el alma del finado señor ministro de la guerra don Diego Portales, Santiago, Imprenta La independencia, 1837

OFICINA CENTRAL DE ESTADISTICA, Cuarto Censo de la Población de Chile, 1865, Santiago, Imprenta Nacional, 1866

OFICINA CENTRAL DE ESTADISTICA, Quinto Censo de la Población de Chile, 1875, Valparaíso, Imprenta El Mercurio, 1878.

OFICINA CENTRAL DE ESTADISTICA, Sexto Censo de la Población de Chile, 1885, Valparaíso, Imprenta de la Patria, 1890. 
OfICINA Central De ESTADISTICA, Séptimo Censo de la Población de Chile, 1895, Valparaíso; Imprenta Universo, 1900.

«Ordenanzas del Instituto Nacional, Literario, económico, civil y Eclesiástico del Estado», Sesiones de Cuerpos Legislativos, Santiago, Imprenta Cervantes, 1886-1908.

Reglamento constitucional provisorio del pueblo de Chile, subscripto por el de la capital, presentado a las provincias, sancionado y jurado por las autoridades constituidas, Santiago, Imprenta del Gobierno, 1812.

Sesiones de los Cuerpos Legislativos de la República de Chile 1811 a 1845, Santiago, Imprenta Cervantes, 1889.

Sesiones del Congreso Nacional, Valparaíso, Imprenta Progreso, 1865.

Sesiones de Cuerpos Legislativos de la República de Chile, 1842, Santiago de Chile, Editorial Progreso, 1900.

\section{b) Fuentes impresas}

ALFONSO, José, Colección de Documentos relativos a la Sociedad de Instrucción Primaria de Santiago, Santiago, SIP, 1857.

«Algunas ideas acerca de la libertad», Revista Católica, № 208 (1850), pp. 300-356.

AMOR DE LA PATRIA, Catecismo Político Cristiano, Santiago de Chile, Editorial del Pacifico, 1975.

AMUNATEGUI, Domingo, Formación de la nacionalidad chilena, Santiago, Ediciones de la Universidad de Chile, 1943.

AMUNATEGUI, Miguel y AMUNATEGUI, Gregorio. De la Instrucción Primaria en Chile, lo que es y lo que debiera ser, Santiago, Imprenta El Ferrocarril, 1856.

AMUNATEGUI, Miguel Luis, «Discurso de recepción de Don Miguel Luis Amunátegui en la Facultad de Filosofía y Humanidades de la Universidad de Chile», Anales de la Universidad de Chile, (1852), pp. 457-466.

AMUNATEGUI, Miguel Luis, Compendio de la Historia política y eclesiástica de Chile, Valparaíso, Imprenta El Universo, 1856.

ANGUITA, Ricardo, Leyes promulgadas en Chile. Desde 1810 hasta el $1^{\circ}$ de junio de 1913, Santiago, Imprenta, Litografía y Encuadernación Barcelona, 1913.

BALLESTEROS, Manuel, Compilación de leyes y decretos vigentes en materia de instrucción pública, Santiago, Imprenta el Independiente, 1871. 
BARRA, Miguel de la, Compendio de la Historia del coloniaje e independencia de América. Obrita aprobada por el Consejo de la Universidad para texto de estudio en los colegios de la República, Valparaíso, Imprenta y Librería europea, 1869.

BARROS ARANA, Diego, Compendio de Historia de América, Santiago, Imprenta del Ferrocarril, 1865.

BARROS ARANA, Diego, Compendio elemental de historia de América, Santiago, Imprenta el Ferrocarril, 1865.

BARROS ARANA, Diego, Don Claudio Gay, su vida y sus obras. Estudio biográfico y crítico, Santiago, Imprenta Nacional, 1876.

BARROS ARANA, Diego, Historia General de Chile I, Santiago, Ed. Rafael Jover, 1884.

BARROS ARANA, Diego, Historia General de Chile II, Santiago, Ed. Rafael Jover, 1886.

BARROS ARANA, Diego, Elementos de Geografia física, Santiago, Imprenta Central de Mariano Servat, 1888.

BARROS ARANA, Diego, Miguel L. Amunátegui 1828-1888, Paris. A. Lahure, 1890

BARROS ARANA, Diego, Obras Completas, Tomo XI, Estudios históricos-biográficos, Santiago, Imprenta Cervantes, 1911.

BARROS ARANA, Diego, Historia General de Chile, Santiago, Editorial Nascimiento, 1930.

BELLO, Andrés, Principio de derechos de jentes, Santiago, Imprenta de la Opinión, 1832.

BELLO, Andrés, «Discurso Inaugural de la Universidad de Chile, 17 de septiembre de 1843», Revista Anales de la Universidad de Chile, Santiago, Universidad de Chile, 1843.

BELLO, Andrés, Cosmografia o descripción del universo conforme a los últimos descubrimientos, Santiago, Imprenta La Opinión, 1848.

BELLO, Andrés, «Memoria correspondiente al curso de la Instrucción pública en el quinquenio 1849-1853» Revista Anales de la Universidad de Chile, IX, 1854.

BELLO, Andrés, «Memoria presentada al Consejo de la Universidad por el Rector de la misma», Anales de Universidad de Chile, Santiago, Imprenta Chilena, 1854.

BELlO, Andrés, Obras Completas, Vol. VII. Opúsculos literarios y Críticos II, Santiago, Impreso por Pedro Ramírez, 1884

BELLO, Andrés, «Modo de escribir la Historia» en BELLO, Andrés, Obras Completas Temas Educacionales, Caracas, Fundación La Casa de Bello, 1982.

BELLO, Andrés, «Sobre los fines de la educación y los medios para difundirla», en BELLO, Andrés, Obras Completas. Temas Educacionales, Caracas, Fundación La Casa de Bello, 1982. 
«Bibliografía. Compendio de la Historia de América por Don Diego Barros Arana. Noticia de esta obra», Anales de la Universidad de Chile, 1865, Tomo 26, enero-junio, pp. 8-21.

BOLIVAR, Simón, Ideario Político, Caracas, Ediciones de la Presidencia de la República, 2001.

CARNICER, Ramón y LILLO, Eusebio, Himno Patrio de la República de Chile, Imprenta del Gobierno, 1910.

CARREÑO, Manuel, Manual de urbanidad y buenas maneras para uso de la juventud de ambos sexos, Caracas, Imprenta y librería Carreño, 1854.

CARREÑO, Manuel, Compendio del manual de urbanidad y buenas maneras. Arreglado para el uso de las escuelas de ambos sexos, Valparaíso, Imprenta y librería del Mercurio, 1863.

«Catecismo de los Patriotas», El Monitor Araucano, núms. 99-100, 27 al 30 de noviembre de 1813.

CHAVARRÏA, Ramón, Cartilla de derecho chileno para el uso de las escuelas primarias de Chile, Leipzig, Imprenta F.A. Brackhaus, 1891.

CHACON, Jacinto, Discurso redactado con motivo de la oposición a las cátedras de historia y literatura del Instituto Nacional, Siglo, Santiago, 1846.

«Cómo entienden algunos la libertad y el progreso», Revista Católica, № 460 (1856), pp. 1.6501.670 .

Compendio de reglas de urbanidad para el uso de los colegios de la capital, Santiago, Imprenta de Julio Berlín, 1852.

CONCHA, Malaquías, Cartilla de educación cívica. Elementos de derecho público y de economía política para el uso de las escuelas superiores y normales de la República, Santiago, Imprenta y litografía Universo, 1905.

CONCHA, Malaquías, Cartilla de educación cívica. Elementos de derecho público y de economía politica para el uso de las escuelas superiores y normales de la República, Santiago, Imprenta y litografía Universo, 1924.

CONSTANCIN, L.A., Manual de urbanidad para el uso de los colegios. Arreglado por un profesor del Seminario de Valparaíso, Escuela litográfica salesiana, 1900.

Constitución Política de la Monarquía española, promulgada en Cádiz a 19 de Marzo de 1812, Cádiz, Librerías L, 2011.

«Constitución Política de la República de Chile» en Recopilación de todas las leyes, decretos, y demás disposiciones de interés general, Santiago, Imprenta Nacional, 1897.

DAVILA, Ricardo, Higiene de las Escuelas, Santiago, Imprenta Cervantes, 1884.

DOMEYKO, Ignacio, Memoria sobre el modo más conveniente de reformar la instrucción pública en Chile, Santiago, Ed. Semanario de Santiago, 1842. 
DOMEYKO, Ignacio, «La fiesta del Aniversario de la Independencia de Chile», Mapocho, $\mathrm{N}^{\circ} 1$, (1963)

DONOSO, Ricardo, Barros Arana, educador, historiador y hombre público, Santiago, Editorial Universidad de Chile, 1931.

EGAÑA, Juan, El chileno consolado en los presidios o filosofia de la religión, Londres, Imprenta de M. Calero, 1826.

EGAÑA, Juan, «Discurso sobre el amor de la patria y la confianza y buena opinión que deben tomar los ciudadanos de sus gobiernos principalmente en los tiempos peligrosos», en SILVA, Raúl, (ed.) Antología, Santiago, Editorial Andrés Bello, 1969.

ENCINA, Francisco, Nuestra inferioridad económica, sus causas, sus consecuencias, Santiago, Imprenta Universitaria, 1912.

«Enseñanza de niñas», La Aurora de Chile (21 de agosto de 1812) Número 29, jueves 27 de agosto de 1812.

«Enseñanza de las primeras letras», La Aurora de Chile (30 de diciembre de 1812), Número 1. jueves, 7 de enero de 1813 .

ERCILLA, Alonso de, La Araucana, Santiago, Imprenta Cervantes, 1888.

ERRAZURIZ, Crescente, Historia de Chile sin gobernador 1154-1557, Santiago, Imp. Universitaria, 1912.

ESPEJO, Juan y BARCELO, Juan, Álbum del Instituto Nacional, 1813-1913. Publicado con motivo de su primer centenario, Santiago, 1916.

GUZMAN, José Javier, El Chileno instruido en la historia topográfica, civil y política de su pais, Santiago, Imprenta nacional, 1834.

La corona del héroe: recopilación de datos y documentos para perpetuar la memoria del General Don Bernardo O'Higgins, mandada a publicar por el ex - ministro de Guerra don Francisco Echaurren, Santiago, Imprenta Nacional, 1872.

«La Iglesia y sus enemigos», Revista Católica, № 462 (1856)

JOVELLANOS, Gaspar, «Apuntamientos para el plan de estudios o discurso al Rey», en JOVELlANOS; Gaspar, Obras Completas. XII Escritos Pedagógicos, Ed. Sans y Torres, Madrid, 2010.

LASTARRIA, José Victorino Lastarria, Investigaciones sobre la influencia social de la conquista y del sistema colonial de los españoles en Chile, Santiago, Imprenta del Siglo, 1844.

LASTARRIA, José Victorino, Lecciones de Geografia moderna escritas para la enseñanza de la juventud americana, Valparaíso, Imprenta del Mercurio, 1846. 
LASTARRIA, José Victorino, Bosquejo Histórico de la Constitución del Gobierno de Chile durante el primer periodo de la revolución desde 1810 hasta 1814, Santiago, Imprenta Chilena, 1847.

LASTARRIA, José Victorino, El libro de oro de las escuelas, Imprenta nacional, 1862.

LASTARRIA, José Victorino, «Moción sobre arreglo de la Instrucción primaria presentada a la cámara de Diputados en sesión de 18 de agosto de 1843», en Proyectos de Ley y discursos parlamentarios. Primera serie, Santiago, Imprenta y Encuadernación Barcelona, 1907.

LENIN, Vladimir, «La revolución socialista y el derecho de las naciones a la autodeterminación» en Obras Escogidas, Moscú, Editorial Progreso, 1946.

LETELIER, Valentín, La Gran Convención de 1831-1833. Recopilación de las actas, sesiones, discursos, proyectos y artículos de diarios relativos a la Constitución de 1833, Santiago, Imprenta Cervantes, 1901.

LETELIER, Valentín, Sesiones de los cuerpos legislativos de la República de Chile, 1811 a 1845, Tomo I, Santiago, Imprenta Cervantes, 1912.

LETELIER, Valentín, Filosofia de la Educación, Santiago, Imprenta Cervantes, 1912.

LIRA, José Bernardo, La Independencia de la América ifue un hecho necesario o accidental?, Santiago, Imprenta del Correo, 1859.

LOPEZ, Vicente Fidel, Manual de Historia de Chile, Santiago, Imprenta El Progreso, 1846.

LOPEZ, Vicente Fidel, Historia de la República Argentina, su origen, su evolución y su desarrollo político hasta 1852, Buenos Aires, Imprenta y Librería de Mayo, 1881

LOPEZ, Vicente Fidel, La Revolución argentina. Su origen, sus guerras y su desarrollo político hasta 1830, Buenos Aires, Imprenta y Librería de Mayo, 1881.

MARIATEGUI, José Carlos, 7 Ensayos de Interpretación de la realidad peruana, Lima, Amauta, 1928.

MARTINEZ, P., Manual de urbanidad y Educación, Santiago, Editorial Puga, 1900.

MARX Karl y ENGELS, Friedrich, Manifiesto del Partido Comunista, Santiago, Ediciones Olimpo, 2001.

MESTRE i MARZAL, Carlo, Consejos morales a la niñez, seguidos de las reglas de urbanidad. Puesta en verso, Santiago, Imprenta chilena, 1849.

MINVIELLE, Rafael, El libro de las madres y preceptoras, Santiago, Imprenta de los tribunales, 1846.

MOESTA, Carlos, Observaciones astronómicas hechas en el Observatorio Nacional de Santiago de Chile en los años 1853, 1854 y 1855, Santiago, Imprenta El Ferrocarril, 1859. 
MONTT, Manuel, Moción presentada al Congreso Nacional por el señor diputado D. Manuel Montt sobre la Instrucción primaria, Santiago, Imprenta el Progreso. Sesiones de Cuerpos Legislativos, 18 de junio de 1849.

MONTT, Luis, Discursos, papeles y correspondencia de Manuel Montt, Santiago, Imprenta Cervantes, Tomo II, 1905.

MUÑOZ, José, «El patriotismo en la escuela», Revista de Instrucción primaria, Año VIII, Nº (1893), pp. 66-82.

MORLA, Carlos, Don Miguel Amunátegui, 1828-1888, Paris, Imprenta Lahure, 1890.

OROZ, Ruperto, El amor patrio. Formación y desarrollo en la escuela, Valparaíso, Imprenta y Litografía Excelsior, 1900.

ORREGO, Augusto, Amunátegui, Santiago, Imprenta de la Época, 1887.

ORREGO, Luis, Chile contemporáneo, Santiago, Imprenta Cervantes, 1904.

PALACIOS, Nicolás, Raza Chilena. Libro escrito por un chileno y para los chilenos, Santiago, Editorial chilena, 1918.

PINOCHET, Tancredo, La Conquista de Chile en el siglo XX, Santiago, Imprenta La Ilustración, 1909.

PINTO, Francisco, «Rasgo patriótico» en DONOSO, Ricardo, El catecismo político cristiano, Santiago, Imprenta Universitaria, 1943.

Proyecto de Constitución para el Estado de Chile, Santiago, Imprenta del Gobierno, 1813.

PUGA, Federico, Cómo se evita el Cólera. Estudio de higiene popular, Santiago, Imprenta Nacional, 1886.

«Reglamento para la enseñanza y Régimen de las Escuelas Elementales», en PONCE, Manuel Antonio, Prontuario de Legislación escolar. Recopilación de leyes, decretos, circulares y resoluciones sobre instrucción Primaria, Santiago, Imprenta Ercilla, 1890.

RENAN, Ernest, ¿Qué es una nación?, Buenos Aires, Editorial Elevación, 1947.

ROBLES, Lorenzo, Manual de moral, virtud y urbanidad dispuesto para jóvenes de ambos sexos, Santiago, Imprenta de la Independencia, 1853.

ROJAS, Ricardo, Historia de la Literatura americana y argentina, Buenos Aires, Librería de la Facultad, 1929.

SALAS, Manuel de, Argumentos para la creación del Instituto Nacional, en Sesiones de Cuerpos Legislativos, Santiago, Imprenta Cervantes, 1886-1908, Tomo I.

SARMIENTO, Domingo Faustino, «Los Maestros de la Escuela», Monitor de las Escuelas Primarias, 15 de octubre de 1852. 
STALIN, Joseph, El marxismo y la cuestión nacional, Barcelona, Anagrama, 1977

STANHOPE, Phillipe, Preceptos de urbanidad y buena crianza o reglas para comportarse con lucimiento en la sociedad. Extracto de las cartas de Lord Chesterfield a su hijo Felipe Stanhope, Valparaíso, Imprenta El Mercurio, 1847

SUAREZ, José Bernardo, Compendio de moral y urbanidad. Arreglado para uso de las Escuelas primarias, Talca, Imprenta y litografía de los tiempos, 1890.

SUAREZ, José, Nociones elementales de gobierno republicano, extractadas y arregladas para el uso de la clase obrera y de los alumnos de las escuelas primarias de Chile, Santiago, Imprenta El Correo, 1880.

VERA, Bernardo y ROBLES, Manuel, «Canción nacional chilena», en Revista las Bellas Artes $\mathrm{N}^{\mathrm{o}} 1,(1869), \mathrm{pp} .4-5$.

VICUÑA MACKENNA, Benjamín, La inauguración de la estatua ecuestre del Capitán Don Bernardo O'Higgins en mayo de 1872, Santiago, Imprenta Nacional, 1872.

\section{c.- Fuentes hemerográficas}

Aurora de Chile, 13 de febrero de 1812.

Aurora de Chile, 9 de abril de 1812.

Aurora de Chile, 9 de abril de 1812.

Aurora de Chile: Camilo Henríquez, «De las diversas formas de gobierno», 28 de mayo de 1812 ,

Aurora de Chile: Camilo Henríquez, «Del patriotismo o del amor a la patria», 6 de agosto de 1812.

Aurora de Chile: Camilo Henríquez, «Los hombres se habitúan a la esclavitud", 3 de septiembre de 1812.

Aurora de Chile, 29 de octubre de 1812.

El Araucano, 30 de junio de 1837

El Araucano, 30 de junio de 1837.

El Araucano, 9 de septiembre de 1853.

El Araucano, 17 de septiembre de 1830.

El Araucano, 9 de abril de 1841.

El Araucano, 9 de abril de 1841. 
El Ferrocarril, 2 de mayo de 1860.

El Minero del año 34, 24 de septiembre de 1834.

El Monitor Araucano, 8 de abril de 1813.

El Progreso, 14 de febrero de 1843.

\section{d.- Fuentes de internet}

GUEREÑA, Jean Louis, «Mujeres autoras de libros. El caso de los manuales de urbanidad en la segunda mitad del siglo XIX y principios del siglo XX», Lectures Genre, N² (2008), http://www.lecturesdugenre.fr/Lectures_du_genre_2/Guerena_files/GUERENA.pdf

LENIN, Vladimir, «Tesis y adiciones sobre los problemas nacional y colonial» en Los Cuatro primeros Congresos de la Internacional Comunista, http://grupgerminal.org 2008.

Papel encontrado entre las pertenencias personales de Bernardo de Vera y Pintado durante el proceso iniciado en su contra en 1810. Su autoría se atribuye a Francisco Antonio Pinto. http://www.bicentenariochile.cl/index.php?option $=$ com_content\&view $=$ article\&id $=82:$ rasgopatriotico\&catid=10:independencia-de-chile\&Itemid $=\overline{9}$

REYES, Leonor, «¿Olvidar para contruir nación? Elaboración de los planes y programas de estudio de Historia y Ciencias Sociales en el período post-autoritario», Ciberhumanitas, $\mathrm{N}^{\circ} 23$ (2002)

http://web.uchile.cl/vignette/cyberhumanitatis/CDA/texto_simple2/0,1255,SCID\%253D3541\% 2526ISID\%253D258,00.html

\section{3) Bibliografía}

ACTON, John, «Nationality», en Essays in the History of Liberty. Selected Writings, Tomo 1, Liberty Classics, Indianapolis, (1986), pp. 409-433.

AFANADOR, Ma. Isabel y BAEZ, Juan, «Manuales de urbanidad en la Colombia del siglo XIX: modernidad, pedagogía y cuerpo», Historia y Memoria, Nº11 (2015), pp. 57-82.

AGUILAR, Enrique, Nación y Estado en el pensamiento de Ortega y Gasset, Buenos Aires, Ed. Ciudad Argentina, 1998.

ANDERSON, Benedict, Comunidades imaginadas. Reflexiones sobre el origen y la difusión del nacionalismo, Buenos Aires, Fondo de Cultura Económica, 1993.

APPELBAUM, Nancy; MACPHERSON, Anne y ROSEMBLAT, Karin, Race and Nation in Modern Latin America, North Carolina, The University of North Carolina Press, 2003. 
ARELLANO, Juan Carlos, «La invención del mito de Diego Portales: la muerte y el rito fúnebre en la tradición republicana chilena», Atenea, No 503 (2011), pp. 147-163.

BALIBAR, Etienne, «La forma nación: historia e ideología» en BALIBAR, Etienne y WALERSTEIN, Immanuel (eds.), Raza, nación y clase, Madrid, IEPALA, 1998, pp. 135-168.

BENGOA, José, Historia del Pueblo mapuche: Siglo XIX y XX, Santiago, LOM, 2008.

BERTONI, Lilia Ana, Patriotas, cosmopolitas y nacionalistas. La construcción de la nacionalidad argentina a fines del siglo XIX, Buenos Aires, Fondo de Cultura Económica, 2001.

BHABHA, Homi K., El lugar de la cultura, Buenos Aires, Manantial, 2002.

BHABHA, Homi, Nación y narración. Entre la ilusión de una identidad y las diferencias culturales, Buenos Aires, Editorial Siglo XXI, 2010.

BLADTH, Carlos, La República de Chile 1821-1828, Santiago, Imprenta Universitaria, 1951.

BORDIEAU, Pierre, Razones prácticas, Barcelona, Ed. Anagrama, 1997.

BRADFORD, Burns, «Ideology in Nineteenth Latin American Historiography», Hispanic American Historical Review, vol. 58, No 3 (1978) pp. 409-431.

BRADING, David, Los orígenes del nacionalismo mexicano, México, Erac, 1980.

BRAUN, Juan, BRAUN, Matías, BRIONES, Ignacio, y DIAZ, José, LÜDERS, Rolf y WAGNER, Gert, Economía chilena 1810-1995. Estadísticas históricas, Santiago, Instituto de Economía Universidad Católica de Chile, 2000.

BREUILLY, John, Nacionalismo y estado, Barcelona, Pomares-Corredor, 1990.

BREUILLY, John, Nationalism and the State, Manchester, Manchester University Press, 1982.

BURUCÚA José Emilio y CAMPAGNE, Fabián, «Mitos y simbologías nacionales en los países del Cono Sur», en ANNINO, Antonio y GUERRA, François-Xavier (eds.), Inventando la nación: Iberoamérica Siglo XIX, México, Fondo de Cultura Económica, 2003, pp. 433-474.

CALDERON, María Teresa, «Los términos del debate contemporáneo en torno a la nación», Revista de Estudios Sociales, №12 (2002), pp. 83-91.

CAMPOS, Fernando, Desarrollo educacional 1810-1960, Santiago, Editorial Andrés Bello, 1960.

CASANOVA, Holednis, «Entre la ideología y la realidad: la inclusión de los mapuches en la nación chilena (1810-1830)», Revista de Historia Indígena, N²4 (2000), pp. 9-48.

CAVIERES, Eduardo, «Educación y sociedad en los inicios de la modernización de Chile, 1840-1880», Dimensión Histórica de Chile, № 6-7 (1989-1990), pp. 33-49. 
CAVIERES, Eduardo, «Modernización, transformaciones sociales y educación. Experiencias del pasado, consideraciones sobre el presente», Cuadernos de Historia, $\mathrm{N}^{\circ}$ 17, 1997.

CHARTIER, Roger, El mundo como representación. Estudios sobre historia cultural, Barcelona, Gedisa, 1996.

CHATTERJEE, P., Nationalist Thought and the colonial world, Minneapolis, University of Minessota Press, 1986.

CHATTERJEE, Partha, La nación en tiempo heterogéneo y otros estudios subalternos, Buenos Aires, Siglo XXI, 2008.

CHIARAMONTE, José Carlos, «La Formación de los Estados Nacionales en Iberoamérica», Boletín del Instituto de Historia Argentina y Americana Dr. Emilio Ravignan, vol. 15 (1997), pp. 143-165.

CHIARAMONTE, José Carlos, Ciudades, provincias, Estados: orígenes de la nación argentina, 1800-1846, Buenos Aires, Ariel, 1997.

CHOPIN, Alain «Pasado y Presente en los manuales escolares», Revista de Educación y Pedagogía, vol. XIII, No 29-30 (2001), pp. 209-229.

CID, Gabriel, «Nacionalizando la "segunda independencia” chilena. Fiestas y discursos cívicosreligiosos en torno a la Guerra contra la Confederación, 1836-1851», Revista de Historia de Chile y América, vol. 7, №2, (2008), pp. 5-33.

CID, Gabriel, «Un ícono funcional: la invención del roto como símbolo nacional, 1870-1888», en CID, Gabriel y SAN FRANCISCO, Alejandro (eds.), Nación y Nacionalismo en Chile, Siglo $X I X$, Santiago, Centro de Estudios Bicentenario, vol. 1, 2009, pp. 221-254.

CID, Gabriel, «La nación bajo examen», Polis, N³2 (2012), pp. 2-15.

CID, Gabriel y TORRES, Isabel, «Conceptualizar la identidad: patria y nación en el vocabulario chileno del siglo XIX» en CID, Gabriel y SAN FRANCISCO, Alejandro (eds.), Nación y Nacionalismo en Chile. Siglo XIX, Santiago, Centro de Estudios Bicentenario, 2009, vol. 1, pp. 23-51.

CID, Gabriel y VERGARA, Jacinta, «Representando la "copia feliz del Edén" Rugendas: paisaje e identidad nacional en Chile, siglo XIX» Revista de Historia Social y de las Mentalidades, vol. 15, №2 (2011), pp. 109-135.

COCCA, Ximena y ROBINOVICH, Paola, Juristas chilenos del siglo XIX. Miguel Luis Amunategui Aldunate, Santiago, Universidad de Chile, 1993.

COLLIER, Simon, Ideas y politica de la Independencia chilena, 1808-1833, Santiago, Ed. Andrés Bello, 1977.

COLLIER, Simon y SATER, William, Historia de Chile 1808-1994, Madrid, Ed. Cambridge, 1998. 
COLLIER, Simon, La construcción de la República, 1830-1865. Política e ideas, Santiago, Ediciones Universidad Católica de Chile, 2005.

CONNOR, Walker, Etnonacionalismo, Madrid, Editorial Trama, 1998.

CONTADOR, Ana María, Los Pincheira: un caso de bandidaje social, Chile 1817-1832, Santiago, Ed. Bravo y Allende, 1998.

CRUZ, Isabel, La fiesta: metamorfosis de lo cotidiano, Santiago, Ediciones Universidad Católica de Chile, 1995.

CRUZ, Isabel, «Lo sagrado como raíz de la Fiesta», Revista Humanitas, №2 (1996), pp. 258269.

DAGER, Joseph, «El debate en torno al método historiográfico en el Chile del siglo XIX», Revista Complutense de Historia de América, vol. 28 (2002), pp. 97-138.

DE VOS, G. Y ROMANUCCI-ROSS, L., Ethnicity: Vessel of Meaning and Emblem of Contrast, Chicago, The University of Chicago Press, 1982.

DONOSO, Andrés, Educación y nación al sur de la frontera. Organizaciones mapuches en el umbral de nuestra contemporaneidad, 1880-1930, Santiago, Editorial Pehuen, 2008.

EGAÑA, Loreto, «La cobertura de la Educación Primaria Popular en Chile; 1890-1920», Boletín de Investigación Educativa, No 10 (1995), pp. 308-319.

EGAÑA, María Loreto, La educación primaria popular en el siglo XIX en Chile: una práctica de política estatal, Santiago, Ed. DIBAM, 2000.

EGAÑA, María Loreto; NUÑEZ, Iván y SALINAS, Cecilia, La educación primaria en Chile: 1860-1930. Una aventura de niñas y maestras, Santiago, LOM, 2003.

ELIAS, Norbert, El proceso de civilización: investigaciones sociogenéticas y psicogéneticas, México, Fondo de Cultura Económica, 1988.

EYZAGUIRRE, Jaime, Fisonomía histórica de Chile, Santiago, Editorial Universitaria, 1976.

FELIU, Guillermo, El pensamiento político de O'Higgins. Estudio histórico, Santiago, Imprenta Universitaria, 1955.

FERMANDOIS, Joaquín, Mundo y fin de mundo. Chile en la política mundial 1900-2004, Ediciones Universidad Católica de Chile, Santiago, 2005.

FERMANDOIS, Joaquín, Historia, ideas y política. El fin del viaje y otros ensayos estudios, Instituto Respublica, Santiago, 2016.

FERNANDEZ, Álvaro, La invención de la nación. Lecturas de la identidad de Herder a Homi Bhabha, Buenos Aires, Manantial, 2002.

FONTANA, Josep, «¿Qué historia para el siglo XXI?», Analecta, Revista de Humanidades, N¹ (2006), pp. 1-12. 
FICHTE, Johann, Discursos a la nación alemana, Buenos Aires, ORBIS, 1984.

FLORESCANO, Enrique, Estado, etnia y nación, México, Ed. Taurus, 2001.

GAYOL, Sandra, «La celebración de los grandes hombres: funerales gloriosos y carreras post mortem en Argentina», Quinto Sol, vol. 16, No2 (2012), pp. 1-29.

GAZMURI, Cristián, El 48 chileno. Igualitarios, reformistas, radicales, masones y bomberos, Santiago, Editorial Universitaria, 1998.

GIDDENS, Anthony, The Nation-State and Violence, California, University of California Press, 1985.

GODOY, Oscar, «Funciones de Integración del Estado», Revista de Ciencia Política, volumen XXII, No 2 (2002), pp. 105-119.

GONGORA, Mario, Ensayo histórico sobre la noción de Estado en Chile en los siglos XIX y XX, Santiago, Editores La Ciudad, 1981.

GONZALEZ, Beatriz, La historiografia literaria del liberalismo hispanoamericano del siglo XIX, Madrid, Ed. Casa de las Américas, 1987.

GONZALEZ, Beatriz, «Modernización y disciplinamiento. La formación del ciudadano: del espacio público y privado», en GONZALEZ, Beatriz (coord.), Esplendores y miserias del siglo XIX. Cultura y sociedad en América Latina, Caracas, Equinoccio Ediciones de la Universidad Simon Bolívar, 1995, pp. 431-456.

GONZALEZ, Sergio, Chilenizando a Tunupa. La escuela pública en el Tarapacá andino, 18801990, Santiago, LOM, 2002.

GREENFELD, Liah, «Nationalism and Agression», en Theory and Society, $\mathrm{N}^{\circ} 23$ (1994), pp. $79-130$.

GROSS, Héctor, «El constitucionalismo latinoamericano y la codificación en el siglo XIX», Anuario iberoamericano de justicia constitucional, $\mathrm{N}^{\mathrm{o}} 6$ (2002), pp. 143-176.

GUERRA, François-Xavier, Modernidad e Independencias. Ensayo sobre las revoluciones hispánicas, Madrid, Editorial MAPFRE, 1992.

GUERRA, François Xavier, México del Antiguo Régimen a la revolución, México, Fondo de Cultura Económica, 1995.

GUERRA, François-Xavier, «La ruptura originaria: mutaciones, debates y mitos de la Independencia», en ALVAREZ, Izakun y SANCHEZ, Julio (eds), Visiones y revisiones de la independencia americana, Salamanca, Ediciones Universidad de Salamanca, 2003, pp. 89-110.

GUERRA, François-Xavier y QUIJADA, Mónica (coords.), Cuadernos de Historia Latinoamericana. Imaginar la Nación, Hamburgo, Lit. Verlag, 1994. 
HARWICH, Nikita, «La Historia Patria», en ANNINO, Antonio y GUERRA, François-Xavier, (coords.), Iberoamérica siglo XIX, 2003, pp. 533-549.

HAUPT, George y LÜWY, Michael, Los marxistas y la cuestión nacional, Barcelona, Ed. Fontamara, 1980.

HAYES, Carlton, El nacionalismo: una religión, México, U.T.E.H.A., 1986.

HEISE, Julio, Años de formación y aprendizaje políticos 1810-1833, Santiago, Ed. Universitaria, 1978.

HERDER, J.G, Ideas para una filosofia de la Historia de la Humanidad, Buenos Aires, Ed. Losada, 1959.

HOBSBAWM, Eric, Naciones y Nacionalismo desde 1780, Barcelona, Editorial Crítica, 1998

HOBSBAWM, Eric, La era del imperio, 1875-1914, Buenos Aires, Crítica, 1998.

HOBSBAWM, Eric, «Introducción: La invención de la tradición», en HOBSBAWM, Eric y RANGER, Terence (eds.), La invención de la tradición, Barcelona, Crítica, 2002, pp. 7-21.

HUALDE, Margarita, «Vicente Fidel López, político e historiador (1815-1903)», Revista del Instituto de Historia, vol. 11 (1966-67), pp. 23-44.

ILLANES, María Angélica, «Azote, salario y ley. Disciplinamiento de la mano de obra en la minería de Atacama (1817-1850)», Proposiciones, N¹9, (1990), pp. 90-122.

JAFFRELOT, Cristopher «Los modelos explicativos del origen de las naciones y del nacionalismo. Revisión Crítica», en DELANNOI, G. y TAGUIEFF, Pierre (comps.), Teoría del Nacionalismo, Barcelona, Paidos, 1993, pp. 201-211.

JENKINS; Keith, Repensar la Historia, Madrid, Editorial Siglo XXI, 2009.

JOCELYN-HOLT, Alfredo, La Independencia de Chile, Madrid, Editorial MAPFRE, 1992.

JOCELYN-HOLT, Alfredo, El peso de la noche. Nuestra frágil fortaleza histórica, Santiago, Ed. Planeta, 1998.

JOCELYN-HOLT, Alfredo «El liberalismo moderado chileno siglo XIX», Estudios Públicos, No 69 (1998), pp. 440-485.

JOCELYN-HOLT, Alfredo, «¿Un proyecto nacional exitoso? La supuesta excepcionalidad chilena.» en COLOM, Francisco (eds.), Relatos de la nación. La construcción de las identidades nacionales en el mundo hispánico, Madrid, Vervuert, (2005), pp. 417-438.

KAPLAN, Marcos, Estado y Sociedad, México, Universidad Nacional Autónoma de México, 1980.

KNIGHT, Alain, «El Estado en América Latina desde la Independencia», Revista Economía y Política, $\mathrm{N}^{\mathrm{o}} 1$ (2013), pp. 7-30. 
KÖNIG, Joachim, «Símbolos nacionales y retórica política», en BUISSON, Inge, (ed.), Problemas de la formación del Estado y la nación en Hispanoamérica, Bonn, Inter Nations, 1984, pp. 389-405.

KÖNING, Hans-Joachim, En el camino hacia la nación. Nacionalismo en el proceso de formación del Estado y de la nación de la Nueva Granada, Bogotá, Banco de la República, 1994.

KÖNING, Hams-Joachim, «Discursos de identidad, Estado-nación y ciudadanía en América Latina: viejos problemas-nuevos enfoques y dimensiones», Historia y Sociedad, Nº11 (2011), pp. 9-31.

KYMILCKA, Will, «Derechos individuales y derechos de grupo en la democracia liberal», ISEGORIA, $\mathrm{N}^{\circ} 14$ (1996), pp. 5-36.

KYMILCKA, Will, Estados, naciones y culturas, Córdoba, Ediciones Almuzara, 2004.

LEON, Leonardo, «Reclutas forzados y desertores de la Patria: el bajo pueblo chileno en la guerra de la independencia, 1810-1814», Historia, N53, (2002), pp. 251-297.

LETTIERI, Alberto, Vicente Fidel López: la construcción histórico-político de un liberalismo conservador, Buenos Aires, Editorial Biblos, 1995.

LIONETTI, Lucía, «La función republicana de la escuela pública: la formación del ciudadano en Argentina a fines del siglo XIX», Revista Mexicana de Investigación Educativa, vol. X, No 27 (2005), pp. 1225-1255.

LOYOLA, Manuel, y GREZ, Sergio, Los proyectos nacionales en el pensamiento político y social chileno del s. XIX, Santiago; Ediciones UCSH, 2002.

MADERO, Roberto, La Historiografía entre la República y la Nación. El caso de Vicente Fidel López, Buenos Aires, Catálogos, 2005.

MARQUEZ, Martha, «Perspectivas teóricas para abordar la nación y el nacionalismo», Papel Político, Vol. 16, No 2 (2011), pp. 567-595.

Mc EVOY, Carmen, «El funeral de Estado y la invención de la tradición republicana en América del Sur», en Mc EVOY, Carmen (ed.), Funerales Republicanos en América del Sur. Tradición, Ritual y Nación, 1832-1896, Santiago, Centro de Estudios Bicentenario, 2006, pp. XI-XXXIII.

MELlAFE, Rolando; REBOLlEDO, Antonia y CARDENAS, Mario, Historia de la Universidad de Chile, Santiago, Ediciones de la Universidad de Chile, 1992.

MENARD, André, «La escritura y su resto (el suplemento mapuche)», Historia Indígena, $\mathrm{N}^{\circ} 8$ (2004), pp. 57-88.

MEZA, Néstor, La conciencia política chilena durante la monarquía, Santiago, Ed. Universidad de Chile, 1958. 
MILLER, Nicola, «Historiography of nationalism and national identy in Latin America», Nation and nationalism, vol. 12, $\mathrm{N}^{\mathrm{o}} 2$ (2006), pp. 201-221.

MIRANDA, Pedro, «Los manuales de buenas costumbres. Los principios de la urbanidad en la ciudad de Mérida durante el siglo XIX», Takwá, N. 11-12 (2007), pp. 131-157.

MONSALVE, Mario, Fuentes para la historia de la República, Vol. IX. Documento para la historia de la Instrucción Primaria, 1840-1920, Santiago, Editorial Centro de Investigaciones Barros Arana, 1998.

MUÑOZ, Mónica, «El ciudadano en los manuales de historia, instrucción cívica y urbanidad, 1910-1948», Historia y Sociedad, № 24 (2012), p. 216.

MURILO DE CARVALHO, José, A formação das almas: O imaginário da República no Brasil, São Paulo, Companhia das letras, 1995.

NARVAJA de ARNOUX, Elvira, «Discurso pedagógico y discurso político en la construcción del objeto Nación Chilena. El Manual de Historia de Chile de Vicente Fidel López», Cuadernos de Recienvenido, $\mathrm{N}^{\mathrm{o}} 22$ (2000), pp. 5-67.

NEIRA NAVARRO, Marcelo y BENTHAM, Jeremy, «El Liberalismo en Chile durante la primera mitad del siglo XIX», Boletín de la Academia Chilena de la Historia, N ${ }^{\circ} 113$ (2004), pp. 285-313.

ORTEGA, Luis, «De la Construcción del Estado-nación y la política económica. Chile 18171890» en CID, Gabriel. y SAN FRANCISCO, Alejandro. (eds.) Nación y Nacionalismo en Chile. Siglo XIX, Santiago, Centro de Estudios Bicentenario, vol. 2, 2009, pp. 145-166.

OSSENBACH, Gabriela, «Educación en América Latina a partir de su independencia. Siglos XIX y XX», Revista Iberoamericana de Educación, N 1 (1993), pp. 56-62.

OYARZUN, Luis, El Pensamiento de Lastarria, Valparaíso, Editorial Jurídica de Chile, 1953.

PERALTA, Paulina, ;Chile tiene fiesta! El origen del 18 de septiembre (1810-1837), Santiago, LOM, 2007.

PEREZ GARZON, Juan, «¿Por qué enseñamos Geografía e Historia? ¿Es tarea educativa la construcción de identidades?», Revista de la Educación: Revista Interuniversitaria, $\mathrm{N}^{\mathrm{o}} 27$ (2008), pp. 37-55.

PEREZ, Federico, «Will Kymilcka: La defensa del nacionalismo minoritario» en Astrolabio. Revista Internacional de Filosofia, № 4 (2007), pp. 61-77.

PICCIRILLI, Ricardo, Los López. Una dinastía intelectual. Ensayo histórico literario.18101852, Buenos Aires, EUDEBA, 1972.

PINTO, Julio, La formación del Estado y la nación, y el pueblo mapuche. De la inclusión a la exclusión, Santiago, Centro de Investigaciones Diego Barros Arana, 2003.

PINTO, Julio y VALDIVIA, Verónica, ¿Chilenos todos? La construcción social de la Nación, 1810-1840, Santiago, LOM, 2009. 
POBLETE, María, «Prácticas Educativas misionales franciscanas, creación de las escuelas en territorio mapuche y significado de la educación para los mapuches-huilliche del siglo XVIII y XIX», Espacio Regional, vol. 2, Nº6 (2009), pp.23-33

PONCE DE LEON, Macarena, «La llegada de la escuela y la llegada a la escuela. La extensión de la educación primaria en Chile, 1840-1907», Historia, Nº43, vol. II (2010), pp. 449-486.

PURCELL, Fernando, Diversiones y juegos populares. Formas de sociabilidad y crítica social. Colchagua, 1850-1880, Santiago LOM, 2000.

QUIJADA, Mónica, «La caja de Pandora. El sujeto político indígena en la construcción del orden liberal», Historia Contemporánea, No 33 (2006), pp. 605-638.

RAMOS, Johana, «Catecismos y manuales de urbanidad como recurso de acción y práctica política en Venezuela, 1830-1855», Boletín americanista, vol. 66 (2013), pp. 161-179.

REYES, Leonor, «¿Olvidar para construir nación? Elaboración de los planes y programas de estudio de Historia y Ciencias Sociales en el período post-autoritario», Ciberhumanitas, $\mathrm{N}^{\circ} 23$ (2002)

ROCKWELL, Elsie, Hacer escuela, hacer Estado. La educación posrevolucionaria vista desde Tlaxcala, México, Colegio de Michoacán, Centro de Investigaciones y Estudios Superiores en Antropología Social -CIESAS- y Centro de Investigación y de Estudios Avanzados, 2007.

ROJAS, Jorge, Moral y prácticas cívicas en los niños chilenos, 1880-1950, Santiago, Ariadna Ediciones, 2004.

ROMERO, Esteban, El discurso de la Patria: la historia de Chile en la sala de clase (18431880), Tesis para optar al grado de Licenciado en Historia, Santiago, Pontificia Universidad Católica de Chile, 1994.

ROSALES, José María, «Patriotismo constitucional: sobre el significado de la lealtad política republicana, ISEGORIA, No 20 (1999), pp. 139-149.

ROSANVALLON, Pierre, Le moment Guizot, Paris, Ed. Gallimard, 1985.

ROSS, H., A History of Modern Poland, London, Ed. Alfred Knopf, 1966.

SABATO, Hilda, (Coord.), Ciudadanía política y formación de las naciones. Perspectivas históricas desde América Latina, México, FCE - El Colegio de México, 1999.

SAGREDO, Rafael, «Chile: de fines terrae imperial a "copia feliz del Edén" autoritario», en CHIARAMONTE, José; MARICHAL, Carlos y GRANADOS, Aimer, (comp.), Crear la nación. Los nombres de los países de América Latina, Buenos Aires, Sudamericana, 2008, pp. 41-67.

SAGREDO, Rafael, «Geografía y nación. Claudio Gay y la primera representación cartográfica de Chile», Estudios Geográficos, vol. LXX (2009), pp. 231-267. 
SAGREDO, Rafael y SERRANO, Sol, «Un espejo cambiante: la visión de la Historia de Chile en los textos escolares, INTERAMER, Nº 29 (1994), pp. 6-12.

SALAZAR, Augusto, ¿Existe una filosofía de nuestra América?, México, Editorial siglo XXI, 1969.

SALAZAR, Gabriel, Construcción de Estado en Chile (1800-1837). Democracia de los "pueblos". Militarismo ciudadano. Golpismo oligárquico, Santiago: Editorial Sudamericana, 2005.

SALINAS, Maximiliano, «Tú no eres nada/Tú no eres mapuche ni español. La descolonización del conocimiento histórico en América del Sur: el caso de Chile», Docencia, No 47 (2012), pp. 43-52.

SAN FRANCISCO, Alejandro, «La excepción honrosa de paz y estabilidad, de orden y libertad. La autoimagen política de Chile en el siglo XIX» en CID, Gabriel y SAN FRANCISCO, Alejandro (eds.), Nación y Nacionalismo en Chile. Siglo XIX, Santiago, Centro de Estudios Bicentenario, vol. 1, 2009, pp. 55-84.

SANDERS, Karen, Nación y Tradición. Cinco discursos en torno a la nación peruana, $1885-$ 1930, Lima, Fondo de Cultura Económica, 1997.

SANHUEZA, Carlos, Chilenos en Alemania y alemanes en Chile. Viaje y nación en el siglo XIX, Santiago, DIBAM/LOM, 2006.

SANUCCI, Lía, «Vicente Fidel López: filiación de sus ideas», Trabajos y comunicaciones, $\mathrm{N}^{\circ}$ 19 (1969), pp. 177-203.

SARASÚA, Carmen, «Aprendiendo a ser mujeres: las escuelas de niñas en la España del siglo XIX» en Cuadernos de Historia Contemporánea, vol. 24 (2002), pp. 281-297.

SCHURDEVIN-BLAISE, Chloé, «Los manuales escolares como fuente de la Historia Chilena (1850-1860)», Boletín Americanista, Año LVII, Nº 57 (2007), pp. 257-272.

SEPULVEDA, Alberto, «La formación del estado nacional en Chile», Revismar, №3 (2010), pp. 240-251.

SERRANO, Sol, Universidad y nación. Chile en el siglo XIX, Santiago, Editorial Universitaria, 1994.

SERRANO, Sol, «La ciudadanía examinada: el control estatal de la educación en Chile (18101870)», en ANNINO, Antonio y GUERRA, François-Xavier, (coords.), Inventando la nación. Iberoamérica siglo XIX, México, Fondo de Cultura Económica, 2003, pp. 550-564.

SERRANO, Sol, «Enseñanza de la Historia e identidad nacional: un vínculo a historizar desde la experiencia chilena», Encounters, vol. No 15 (2014), pp. 209-222.

SERRANO, Sol; PONCE DE LEON, Macarena y RENGIFO, Historia de la educación en Chile (1810-2010). Tomo I. Aprender a leer y escribir (1810-1880). Santiago, Editorial Taurus, 2012. 
SERRANO, Sol; PONCE DE LEON, Macarena y RENGIFO (eds), Historia de la educación en Chile (1810-2010). Tomo II. La educación nacional (1880-1930), Santiago, Editorial Taurus, 2012.

SETON-WATSON, Hugh, Nations and States, Londres, Methuen, 1982.

SILVA, Bárbara, «Símbolos y discursos en torno a la nación. Patria Vieja y Centenario»en Tesis Bicentenario 2004, Santiago, Colección Tesis Bicentenario/Centro de Investigaciones Barros Arana, 2006.

SMITH, A. D., The ethnic revival, Cambridge, Cambridge University Press, 1981.

SMITH, Anthony, The Ethnic Origins of Nations, Oxford, Blacwell, 1986.

SMITH, Anthony, «Culture, Community and Territory. The Politics of Ethnicity and Nationalty», International Affairs, vol. 72, No 3 (Julio 1996), pp. 445-458.

SMITH, Anthony, La identidad Nacional, Madrid, Trama, 1997.

SMITH, Anthony, Nacionalismo y modernidad, Madrid, Istmo, 2000.

STUVEN Ana María, «La generación de 1842 y la conciencia nacional chilena», Revista de Ciencia Politica, vol. IX, № 1 (1987), pp. 61-80.

STUVEN, Ana María, La seducción de un orden: las elites y la construcción de Chile en las polémicas culturales y políticas del siglo XIX, Santiago, Ediciones Universidad Católica de Chile, 2000.

STUVEN, Ana María, «La palabra en armas: patria y nación en la prensa de la guerra entre Chile y la Confederación Perú-boliviana, 1835-1839», en Mc. EVOY, Carmen y STUVEN, Ana María (eds.), La República peregrina: hombres de armas y letras en América del Sur, 18001884, Lima, IFEA/IEP, 2007, pp. 407-441.

SUBERCASEUX, Bernardo, «Caminos interferidos. De lo político a lo cultural», Estudios Públicos, $\mathrm{N}^{\circ} 73$ (1999), pp. 149-164.

SUBERCASEUX, Bernardo, «Raza y nación: el caso de Chile», A contra corriente, vol. $5 \mathrm{~N}^{\circ} 1$ (2007), pp.29-63.

SUBERCASEUX, Bernardo, Historia de las ideas y de la Cultura en Chile. Tomo IV. Nacionalismo y cultura, Santiago, Ed. Universitaria, 2007.

SUBERCASEUX, Bernardo, Historia del libro en Chile. Desde la colonia hasta el bicentenario, Santiago, LOM, 2010, p. 73.

TAPIA, Luis, «La producción teórica para pensar América Latina», en AGUILUZ, Maya y RIOS, Norma de los (coords.), René Zavaleta Mercado. Ensayos, testimonios y re-visiones, Argentina, Miño y Dávila Editores, 2006, pp. 213-223.

TENORIO, Manuel, Artilugio de la nación moderna. México en las exposiciones universales, 1880-1930, México, Fondo de Cultura Económica, 1998. 
TILLY, Charles, Coercion, Capital and European States 990-1990, Oxford, Blackwell, 1990.

TORO, Pablo, «Dimensiones de la confección de una juventud virtuosa: manuales de urbanidad en Chile (c.1840-c.1900)» Universum, $\mathrm{N}^{\mathrm{o}} 27$ (2012), 191-205.

TURNER, V, Dramas, Fields, and metaphors, Symbolic action in Human Society, London, Cornell University Press, 1974.

VERGARA, Jacinta, «Desde el bastidor al imaginario nacional: Rugendas y la representación de la identidad chilena», en CID, Gabriel y SAN FRANCISCO, Alejandro (eds.), Nación y Nacionalismo en Chile. Siglo XIX, Santiago, Centro de Estudios Bicentenario, Vol. 1, 2009, pp. 137-175.

VERGARA, Sergio, «Iglesia y Estado en Chile, 1750-1850», Revista Historia, No 20 (1985), pp. 319-362.

VILLALOBOS, Sergio, Tradición y reforma en 1810, Santiago, RIL, 1961.

VILlalobOS, Sergio, Historia del Pueblo chileno, Tomo I, Santiago, Instituto de Estudios Humanísticos, 1980.

VILLALOBOS, Sergio, Chile y su historia, Santiago, Ed. Universitaria, 2003.

WALLERSTEIN, Immannuel, «La construcción de los pueblos: racismo, nacionalismo y etnicidad», en BALIBAR, Etienne y WALLERSTEIN, Inmannuel, (eds.) Raza, Nación y Clase, Madrid, IEAPALA, 1988, pp. 111-134.

WEINBERG, Gregorio, Modelos Educativos en la Historia de América Latina, Buenos Aires, Kapelusz, 1984.

WOLL, Allen, A functional past: the uses of history in nineteenth-century Chile, Lousiana, Louisiana State University Press, 1982.

ZALDIVAR, Trinidad y SANCHEZ, Macarena, «Símbolos, emblemas y ritos en la construcción de la nación. La fiesta cívica republicana: Chile 1810-1830», en CID, G. y SAN FRANCISCO, A. (eds.) Nación y Nacionalismo en Chile. Siglo XIX, Santiago, Centro de Estudios Bicentenario, Volumen 2, 2009, pp. 73-115.

ZEA, Leopoldo, El pensamiento latinoamericano, Barcelona, 1976

ZERMEÑO, Sergio, «Las fracturas del Estado en América Latina», en LECHNER, Norbert, (ed.), Estado y Política en América Latina, México, Siglo XXI, 1983, pp. 60-86. 
